\title{
Coordination Chemistry of Phosphinocarbonyls with Platinum
}

\author{
by \\ David J. Koedyk
}

\begin{abstract}
A thesis
submitted to the Victoria University of Wellington in partial fulfilment of the degree of

Master of Science

in Chemistry
\end{abstract}

Victoria University of Wellington

2012 


\section{Abstract}

This thesis reports the coordination chemistry of phosphinocarbonyl ligands with platinum and describes the influence of phosphine substituents on the mechanism of chelation and the coordination mode of the carbonyl moiety.

The ligands synthesised were 2-diphenylphosphinobenzaldehyde

2-diphenylphosphinoacetophenone (2), 2-bis(pentafluorophenyl)phosphinobenzaldehyde (3), and 2-di-tert-butylphosphinobenzaldehyde (4). Compounds 1, 3, and 4 were selected on the basis of their steric bulk and extent to which they donate electron density to the metal. Compound 2 contained the same phosphine substituents to 1, but is the methyl ketone analogue and therefore does not contain the $\mathrm{CHO}$ moiety. The cone angle and electronic parameter of compounds 1-4 were compared to the reported values of $\mathrm{PPh}_{3}, \mathrm{PPh}\left(\mathrm{C}_{6} \mathrm{~F}_{5}\right)_{2}$, and $\mathrm{PPh}^{t} \mathrm{Bu}_{2}$. Compounds 3 and 4 were similarly bulky, and had larger cone angles than 1 . The electron donating capacity of compound 4 was greater than that of 1 , and compound 3 was the least electron donating. A new synthetic method for the preparation of 4 is also reported.

The coordination chemistry of ligands 1-4 was investigated with platinum(II) and platinum(0) starting materials to assess the influence of the steric and electronic parameters of the phosphine on the chelation of the ligand through the carbonyl to platinum. Coordination of the ligand went through the initial coordination of the phosphine and, depending on the identity of that phosphine, may be followed by chelation of the carbonyl moiety to form a $P, C$ chelate. However, the site of the platinum-carbon bond in the $P, C$ metallacycle depends on the ligand employed. Coordination of the phosphinoaldehyde ligands 1, 3, and 4 produced $\mathrm{Pt}-\mathrm{C}$ bonds via the $\mathrm{C}-\mathrm{H}$ activation of the aldehyde $\mathrm{CHO}$ group whereas for ketophosphine $2, \mathrm{C}-\mathrm{H}$ activation occurred at the $\alpha$-methyl group. The rate at which $\mathrm{C}-\mathrm{H}$ activation occurred increased with increasing electron donation from the phosphorus to platinum. Compound 4 chelates to platinum more rapidly than compound $\mathbf{1}$, while 3 did not undergo chelation at room temperature.

Although chelation was only observed to occur via $\mathrm{C}-\mathrm{H}$ activation, the final products of the coordination reactions of 1-4 with platinum starting materials differed depending on the identity of the ligand. The $\mathrm{C}-\mathrm{H}$ activation of two molecules of 1 with platinum(II) or 
platinum(0) produced a platina- $\beta$-diketone, cis- $\left[\mathrm{Pt}\left(P, C-2-\mathrm{PPh}_{2} \mathrm{C}_{6} \mathrm{H}_{4} \mathrm{CO}\right)_{2}\right](21)$, which is capable of coordinating to $\mathrm{H}^{+}, \mathrm{Li}^{+}, \mathrm{BF}_{2}^{+}$, and $[\mathrm{Rh}(1,5 \text {-cyclooctadiene })]^{+}$between the mutually cis carbonyl groups. One carbonyl moiety of 21 can also undergo condensation with primary amines and ammonia to produce platina- $\beta$-ketoimine complexes.

The ketone moiety of ligand 2 reacted with platinum(II) starting materials through $\mathrm{C}-\mathrm{H}$ activation of the terminal methyl group to form the six-membered bis-chelate complex analogous to complex 21. The reaction of 2 with platinum(0) starting materials resulted in the formation of a platinum hydride intermediate which mediated chelation through the partial reduction of the ketone group of one ligand, to form the product, $\left[\mathrm{Pt}\left(P, C-2-\mathrm{PPh}_{2} \mathrm{C}_{6} \mathrm{H}_{4} \mathrm{COCH}_{2}\right)\left(P, C-2-\mathrm{PPh}_{2} \mathrm{C}_{6} \mathrm{H}_{4} \mathrm{C}(\mathrm{OH}) \mathrm{CH}_{3}\right)\right](48)$.

The reaction of 3 with [ $\mathrm{PtMe}_{2}(1,5$-hexadiene)] at elevated temperatures resulted in the formation of $\left[\mathrm{Pt}\left(P, C-2-\mathrm{PPh}_{2} \mathrm{C}_{6} \mathrm{H}_{4}\right)\left(P, C-2-\mathrm{PPh}_{2} \mathrm{C}_{6} \mathrm{H}_{4} \mathrm{CO}\right)\right](54)$ - a decarbonylated and ortho-metallated complex containing a four-membered metallacycle. The platinum-phosphorus bond in the four-membered ring of 54 has a bond distance of 2.385(2) $\AA$ - the longest Pt-P bond reported to date.

Ligand 4 reacted rapidly with platinum(II) starting materials and produced numerous chelation products. Complexes of ligand 4 were only observed to contain mutually trans phosphines, likely due to the steric bulk of the tert-butyl substituents.

Comparison of the coordination chemistry of ligands 1-4 suggests that the propensity toward $\mathrm{C}-\mathrm{H}$ activation of the ligands is predominantly determined by the electronic character of the phosphine (although steric effects cannot be disregarded), and the more electron-rich the phosphine, the more rapidly chelation occurs. 


\section{Acknowledgements}

Thank you to my supervisor, Professor John L. Spencer, for guidance and motivation throughout every stage of this research project.

I would like to thank Victoria University of Wellington for funding through the Victoria Graduate Award and the Curtis-Gordon Scholarship.

I would also like to thank Drs Horst Puschmann and Jan Wikaira for the collection of single-crystal X-ray diffraction data. Dr Puschmann also solved the structures of the platinum complexes, 30 and 53. Thanks also to Ian Vorster and Dr John Ryan for help with low-temperature NMR and two-dimensional NMR experiments.

Thank you to the Organometallic research group, Kathryn Allan, Bradley Anderson, Sarah Hoyte, Chris Munro, Melanie Nelson, Teresa Vaughan, and Almas Zayya for all their assistance with my labwork, the preparation of starting materials, and for making the lab a fun place to work. Special thanks also to Kathryn, Brad, and Sarah for proofreading this thesis.

Finally, thank you to my parents, Eleanor and Wayne, and my partner, Stacey, for the love and support through my Master's degree. 


\section{Table of Contents}

1 Introduction 2

1.1 Phosphorus coordination to late transition metals 4

1.2 Ligands in this project 8

1.3 Coordination chemistry of phosphinocarbonyls 8

2 Ligand Synthesis 13

2.1 2-Diphenylphosphinobenzaldehyde (1) 13

2.2 2-Diphenylphosphinoacetophenone (2) 13

$2.3 \quad$ 2-Bis(pentafluorophenyl)phosphinobenzaldehyde (3) 14

2.4 2-Di-tert-butylphosphinobenzaldehyde (4) 15

3 Coordination Chemistry 21

3.1 Coordination chemistry of 2-diphenylphosphinobenzaldehyde 21

3.2 Coordination chemistry of 2-diphenylphosphinoacetophenone 51

3.3 Coordination chemistry of 2-bis(pentafluorophenyl)phosphinobenzaldehyde 57

3.4 Coordination chemistry of 2-di-tert-butylphosphinobenzaldehyde with platinum(II) 66

3.5 Evaluation of coordination chemistry and ligand reactivity 70

4 Conclusion $\quad 75$

5 Experimental 78

$\begin{array}{lll}5.1 & \text { General procedures } & 78\end{array}$

$\begin{array}{lll}5.2 & \text { Crystallography } & 78\end{array}$

$\begin{array}{lll}5.3 & \text { Ligand synthesis } & 79\end{array}$

5.4 Platinum complexes of 2-diphenylphosphinobenzaldehyde 84

5.5 Platina- $\beta$-diketones 88

5.6 Platinum complexes of 2-diphenylphosphinoacetophenone 93

5.7 Platinum complexes of 2-bis(pentafluorophenyl)phosphinobenzaldehyde 96

5.8 Platinum complexes of 2-di-tert-butylphosphinobenzaldehyde 98

6 References 102 


\section{Glossary}

\begin{tabular}{|c|c|}
\hline Ar-C & Aryl carbon \\
\hline Ar-F & Aryl fluoride \\
\hline $\mathrm{Ar}-\mathrm{H}$ & Aryl proton \\
\hline $\mathrm{ArF}-\mathrm{C}$ & Pentafluorophenyl carbon \\
\hline bipy & 2,2'-bipyridine \\
\hline COSY & Correlation spectroscopy \\
\hline $\mathrm{HMBC}$ & Heteronuclear multiple-bond correlation spectroscopy \\
\hline HR-ESIMS & High resolution electrospray ionisation mass spectrometry \\
\hline HSQC & Heteronuclear single-quantum correlation spectroscopy \\
\hline$m / z$ & Mass to charge ratio \\
\hline $\mathrm{nb}$ & Norbornene (bicyclo[2.2.1]heptene) \\
\hline nbd & Norbornadiene (bicyclo[2.2.1]hepta-2,5-diene) \\
\hline NMR & Nuclear magnetic resonance \\
\hline$p^{-\mathrm{TsOH}}$ & para-Toluenesulfonic acid \\
\hline TEP & Tolman electronic parameter \\
\hline $\mathrm{THF}$ & Tetrahydrofuran \\
\hline
\end{tabular}




\section{Introduction}

Ligands that contain both phosphine and carbonyl groups have an interesting and wideranging coordination chemistry. This is primarily due to the varied reactivity of the carbonyl moiety with respect to transition metals. This class of ligands, termed in this thesis as phosphinocarbonyls, has the ability to coordinate to a metal centre through both the phosphorus and the carbonyl moieties and are thus potentially bidentate, chelating ligands. With aldehyde functionality, phosphinocarbonyls have four different possible modes of coordination: as a monodentate ligand through phosphorus, as a bidentate ligand through phosphorus and oxygen, through phosphorus and carbon via $\mathrm{C}-\mathrm{H}$ activation, or, rarely, through phosphorus and the $\mathrm{C}=\mathrm{O} \pi$-system. The coordination chemistry of phosphinocarbonyls has been investigated in some detail for a number of transition metals, however, the investigation of platinum with phosphinocarbonyls has been relatively unexplored. ${ }^{1}$ Meanwhile, phosphinocarbonyl coordination chemistry with other late transition metals has shown some novel and interesting results.

This thesis documents the research carried out into the coordination chemistry of phosphinocarbonyl ligands with platinum. The focus of the research was to investigate the mechanism of chelation of the prototypical phosphinocarbonyl ligand, 2-diphenylphosphinobenzaldehyde. The extent to which steric and electronic factors modify the coordinative reactivity of this phosphinocarbonyl ligand was investigated through the synthesis and coordination of three other phosphinoaldehyde or ketophosphine analogues.

The compound, 2-diphenylphosphinobenzaldehyde (1) is a simple, structurally rigid phosphinoaldehyde, the reactivity of which has precedent across a large number of transition metals. ${ }^{2}$ Depending on the metal and its coordination environment, 1 has been observed to coordinate in all four possible bonding modes.

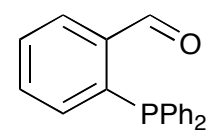

1

Ligands that contain a phosphorus donor atom have a dominant role in the coordination chemistry of late transition metals. ${ }^{3}$ Indeed, the reactivity of $\mathbf{1}$ is so varied due, in part, to the 
strong and inert bond formed between phosphorus and a metal, which keeps the aldehyde group in close proximity to the metal centre. The popularity of phosphorus ligands in coordination chemistry is not only due to the stability of a metal-phosphorus bond but also to the way the steric and electronic properties of the ligand can be tuned by the manipulation of the substituents bonded to phosphorus, which determine the bulk and electronic character of the ligand overall. The control of the coordination environment of a metal through the properties of the phosphine substituents has therefore become a simple and popular method for the optimisation of complexes involved in homogeneous catalysis.

Different bonding modes have been observed for ligand 1 on different metals, but it remains unclear what the influence of the steric and electronic properties of the phosphorus group have on the rate of chelation and the coordination mode of the carbonyl. The aim of this research was to perform a systematic study into the influence of steric and electronic factors on the coordination of phosphinocarbonyls to platinum. This was accomplished through the comparison of the coordination chemistry of platinum(0) and platinum(II) with the ligands, 2-diphenylphosphinobenzaldehyde (1), 2-diphenylphosphinoacetophenone (2), 2-bis(pentafluorophenyl)phosphinobenzaldehyde and 2-di-tert-butylphosphinobenzaldehyde (4). Each ligand except for 2 was chosen because of the different steric and electronic profile of the phosphine substituents. The ligand, 2, was included in the study to assess the coordination chemistry of the carbonyl for ketophosphines as compared to phosphinoaldehydes. Whereas the coordination chemistry of 1 has been relatively extensively explored, the chemistry of the related ligands, 2,3 , and 4 , has not.<smiles>O=Cc1ccccc1P(=O)(O)c1ccccc1</smiles>

1<smiles>CC(=O)c1ccccc1P</smiles>

2<smiles>CC(C)(C)[Pb]c1ccccc1C=O</smiles>

3<smiles>CCCCCc1ccccc1C=O</smiles>

4

The phosphinoaldehyde compound, $\mathbf{1}$ is a common precursor to the development of bidentate, phosphorus/nitrogen $(P, N)$ ligands, which have come to prominence in the past two decades by virtue of their potential to act as tethered, weakly coordinating $\mathrm{N}$-donors. ${ }^{2}$ The relative ease of displacement of the nitrogen group (as compared to phosphorus groups) by other potential ligands means $P, N$ ligands have potential in homogeneous catalysis. 
Compound 1 can be converted to an imine or amine through condensation with a primary amine (Scheme 1 ) or reductive amination, respectively. ${ }^{2}$

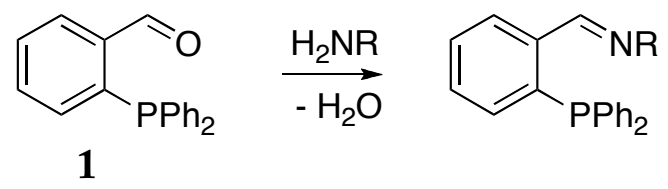

Scheme 1: A phosphinoaldehyde undergoes condensation with a primary amine to produce an iminophosphine.

In contrast to iminophosphines, phosphinocarbonyl ligands typically coordinate to late transition metals through phosphorus and the carbon atom of the carbonyl, via the scission of or insertion into a carbon-hydrogen bond by a metal centre. ${ }^{2}$ This mechanism, known as $\mathrm{C}-\mathrm{H}$ activation, results in the formation of strong bonds between the metal and both the phosphorus and the carbonyl moieties. The product is a metal complex that includes a metal hydride and the $P, C$ chelated phosphinocarbonyl (Scheme 2). The formation and analysis of metal hydrides from the $\mathrm{C}-\mathrm{H}$ activation reaction means such complexes are valuable investigative models because acylhydride metal complexes are intermediates in catalytic decarbonylation and hydroacylation reactions. ${ }^{4}$ In this vein, the chemistry of phosphinoaldehydes has recently been extensively explored with the late transition metals rhodium and iridium. ${ }^{2,4-14}$ However, very little exploration of the corresponding coordination chemistry with platinum has been made since the early 1980 s.<smiles>O=Cc1ccccc1P(=O)(c1ccccc1)c1ccccc1</smiles>

1<smiles>[Mg][Mg]</smiles><smiles>O=Cc1ccccc1P(#[W])c1ccccc1</smiles>

Scheme 2

\subsection{Phosphorus coordination to late transition metals}

The electronic and steric influences of phosphine ligands on a metal's coordination environment has been systematically detailed, first by Tolman and by numerous others later. ${ }^{15}$ Tolman's seminal report of the steric and electronic influences of substituents on phosphorus-based ligands helped foster the field of rational ligand design, leading to greater control of coordination chemistry and even proving useful in the optimisation of catalytic processes in industry. ${ }^{15-19}$ 
Despite an in-depth investigation of phosphinocarbonyl coordination chemistry with a wide variety of metals, the effect of the phosphorus donor on the reactivity of the carbonyl moiety has been somewhat marginalised. There is no doubt that the identity of the phosphine of a phosphinocarbonyl ligand in coordination with a metal ought to have a strong effect on the chelation of the carbonyl group due to its steric profile and its ability to donate and withdraw charge from a metal centre.

\subsubsection{The steric influence of phosphines}

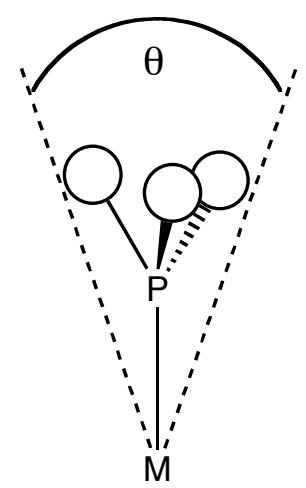

Figure 1: Tolman's cone angle, $\theta$.

The bulk, or steric parameter, of a phosphine ligand is typically determined through measurement of the 'cone angle' $(\theta)$ of the ligand; an effective measurement of the amount of space around a metal the ligand occupies (Figure 1). ${ }^{19}$ The cone angle of a phosphine ligand is defined as "the apex angle of a cylindrical cone, centred $2.28 \AA$ from the centre of the $\mathrm{P}$ atom, which just touches the van der Waals radii of the outermost atoms", and has become the de facto unit of measurement for the steric bulk of all phosphine ligands. ${ }^{15}$

Very bulky substituents on phosphorus ligands can stabilise unusual coordination modes and can form unusual reaction products. ${ }^{15}$ tert-Butyl, ortho-tolyl, and mesityl groups are commonly used bulky substituents for phosphines..$^{20,21}$ These ligands are known to form linear, two-coordinate, 14-electron complexes with palladium and platinum. These complexes, which deviate from the 16- or 18-electron rule, are stabilised by the steric hindrance of the phosphines excluding the coordination of other potential ligands.

Since Tolman's definition of the cone angle, there have been numerous attempts to optimise the calculated $\theta$ values. More prominent advances to the cone angle concept are those proposed by Ferguson ${ }^{22}$ and by Immirzi, ${ }^{23}$ both of whom acknowledge that phosphines are 
less cone-like and more 'cog-like' in shape, and report more intricate calculations to arrive at a more exact value. Despite Tolman's famously rudimentary techniques for calculating phosphine cone angles, the reported values agree well with $\mathrm{X}$-ray crystal structures and other mathematical methods and serve as a simple and useful concept in the analysis of the research in this thesis. ${ }^{15}$

\subsubsection{The electronic influence of phosphines}

The substituents on a phosphine affect its properties as a $\pi$-acceptor and $\sigma$-donor. Phosphorus coordination to metals involves the donation of electron density to a metal through a $\sigma$-bond. Some phosphine species can also withdraw electron density into the $\mathrm{P}-\mathrm{C}$ $\sigma^{*}$-orbitals from the metal's $d$-orbitals through $\pi$-back bonding, although the extent of this orbital interaction depends on the metal centre and the nature of the substituents. ${ }^{19,24,25}$ The amount of electron density donated to the metal depends on how electron-rich the phosphorus atom is, which is dependent on the electron donating or withdrawing characteristics of the phosphine substituents. ${ }^{24}$ Alkyl groups are electron donating, aryl groups less so, and halogen groups are electron withdrawing. ${ }^{26}$

The effect of different substituents on the $\sigma$-donation to the metal by phosphorus was studied by Tolman using infrared spectroscopy to measure the stretching frequency of the $A_{1}$ mode of the $\mathrm{C} \equiv \mathrm{O}$ bond in $\left[\mathrm{NiPR}_{3}(\mathrm{CO})_{3}\right]$ (where $\mathrm{R}$ is any phosphine substituent) (Figure 2). Strongly electron donating phosphines cause more electron density to shift into the $\pi^{*}$ antibonding orbitals of $\mathrm{CO}$ ligands, thereby weakening the $\mathrm{C} \equiv \mathrm{O}$ bond and decreasing the stretching frequency. The wavenumber, $v$, of the $\mathrm{C} \equiv \mathrm{O}$ stretching frequency is known as the Tolman electronic parameter (TEP). ${ }^{27}$

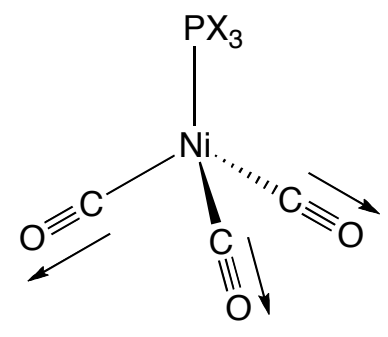

Figure 2: The $A_{1}$ stretching mode used to measure the Tolman electronic parameter.

The Tolman electronic parameter provides quantitative data for the electronic influence of phosphine ligands and enables a systematic analysis of the role of substituents in 
metal-phosphine complexes. However, a disadvantage of this method of measurement is that there must be a coordinated carbonyl in the complex to measure the electronic influence this way. Advances in NMR technology and the use of spin- $1 / 2$ metals such as ${ }^{195} \mathrm{Pt}$ and ${ }^{103} \mathrm{Rh}$ have enabled the employment of ${ }^{31} \mathrm{P}$ NMR spectroscopy to probe the electronic influence of phosphine ligands through their chemical shifts and coupling constant values. Although ${ }^{31} \mathrm{P}$ NMR does not probe the same phenomenon as the TEP, it is a measurement of the electronic interaction between a phosphorus ligand and metal and can be used to compare metal-phosphorus interactions in similar complexes. ${ }^{28}$

Platinum-phosphorus ${ }^{1} \mathrm{Jt}_{\mathrm{Pt}-\mathrm{P}}$ coupling constants are very sensitive to changes in electronic influences, and are a useful tool in the investigation of the bonding between metal and ligand. The exact determinants of the magnitude of coupling between nuclei, as measured by NMR spectroscopy, are complex and difficult to define, yet a sufficient explanation is that coupling between nuclei involves an interaction between the electrons and nuclei of two spin-active atoms." This requires a degree of $s$-character to the electrons involved, as it is only s-orbitals for which there is a finite probability of an electron at the nucleus. As such, ${ }^{1} J_{\mathrm{Pt}-\mathrm{P}}$ coupling is a measurement of the $s$-character of the metal-ligand bond and is therefore a valuable tool in the analysis of electronic influence. ${ }^{28,29}$

There have been a number of investigations that report correlations between the bond distance of phosphorus-metal bonds and the ${ }^{31} \mathrm{P}$ NMR chemical shifts and coupling constants of the complexes..$^{17,18,30-33}$ Notably, in 1999, Nolan and others undertook to correlate the electronic, structural and enthalpic data of simple phosphines in platinum complexes of the type cis- $\left[\mathrm{PtMe}_{2}\left(\mathrm{PX}_{3}\right)_{2}\right]$ using calorimetry, NMR, and single-crystal XRD analysis. ${ }^{18}$ The research showed that while the magnitude of the ${ }^{1} \mathrm{Jt}_{\mathrm{Pt}-\mathrm{P}}$ spin coupling constants do not give a representation of the strength of the $\mathrm{Pt}-\mathrm{P}$ bond, they were closely correlated to the TEP of the phosphine ligand: as a phosphine ligand became more electron deficient (i.e. the TEP increased), ${ }^{1} J_{\mathrm{Pt}-\mathrm{P}}$ coupling increased.

\footnotetext{
* For a more detailed discussion, see Section 3.3.1.1.
} 


\subsection{Ligands in this thesis}

This research project examined the effect of the electronic and steric influence of different phosphine substituents through the reaction pathway and products of the coordination reaction of ligands $1-4$ with platinum. For the purposes of comparison of the relative steric and electronic parameters of the ligands 1-4, the parameters of the related monodentate phosphine compounds are set out in Table 1. Ligands $\mathrm{PPh}^{t} \mathrm{Bu}_{2}$ and $\mathrm{PPh}\left(\mathrm{C}_{6} \mathrm{~F}_{5}\right)_{2}$ have similar cone angles of $170^{\circ}$ and $171^{\circ}$, respectively, and both are much bulkier than $\mathrm{PPh}_{3}\left(145^{\circ}\right)$. In terms of electronic parameters, $\mathrm{PPh}^{t} \mathrm{Bu}_{2}$ is the most electron-rich and $\mathrm{PPh}\left(\mathrm{C}_{6} \mathrm{~F}_{5}\right)_{2}$ is the least, although the latter has been found to have negligible $\pi$-acidity, so back-donation of electron density is not a consideration. ${ }^{16}$

Table 1: Cone angle and electronic parameter of phosphine ligands.

\begin{tabular}{lcc}
\hline & Cone angle, $\theta /^{\circ}$ & TEP, $v / \mathrm{cm}^{-1}$ \\
\hline $\mathrm{PPh}\left({ }^{t} \mathrm{Bu}\right)_{2}$ & 170 & 2060.4 \\
$\mathrm{PPh}\left(\mathrm{C}_{6} \mathrm{~F}_{5}\right)_{2}$ & 171 & 2082.8 \\
$\mathrm{PPh}_{3}$ & 145 & 2069.0 \\
\hline
\end{tabular}

\subsection{Coordination chemistry of phosphinocarbonyls}
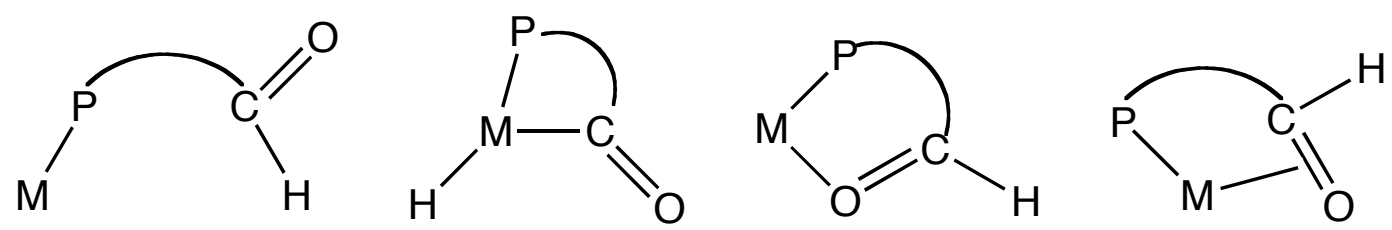

Figure 3: From left to right - monodentate $P$ coordination, $\mathrm{C}-\mathrm{H}$ activation, $P, O$ coordination, $P, \pi$ coordination.

The capability of a bidentate ligand to form a chelate with a metal is entropically stabilising, and therefore chelation is usually more favoured than monodentate coordination. For example, benzaldehyde does not coordinate to late transition metals, yet aldehyde ligands containing another donor atom such as phosphorus or nitrogen coordinate rapidly. ${ }^{5,34}$

This section describes relevant selections of the reported coordination chemistry of 1 . In all cases, the phosphine moiety coordinates first, followed by the coordination of the aldehyde 
group (Figure 3). ${ }^{2}$ The mode of carbonyl coordination has an impact on the overall chemistry of a metal complex as each mode has a different degree of electron donation and contribution to steric strain. ${ }^{2}$ The way in which the carbonyl coordinates to a metal depends on the identity of the metal centre, the oxidation state, the formal charge of the complex, and the steric requirements of the ancillary ligands. ${ }^{2}$

\subsubsection{Monodentate Coordination}

In certain instances, phosphinocarbonyls only coordinate through phosphorus, and behave as a monodentate ligand. ${ }^{2,35}$ This can be due to the inability of the complex to increase its coordination number and/or the inertness of the bonds between the metal and coordinated ligands. Compound 1 behaves as a monodentate ligand in some platinum and palladium complexes such as $\left[\mathrm{MCl}_{2}\left(2-\mathrm{PPh}_{2} \mathrm{C}_{6} \mathrm{H}_{4} \mathrm{CHO}\right)_{2}\right]$ (where $\mathrm{M}$ is $\mathrm{Pt}$ or $\left.\mathrm{Pd}\right){ }^{2}$

\subsection{2 $P, C(O)$ coordination via $\mathrm{C}-\mathrm{H}$ activation}

Aldehydes do not tend to undergo spontaneous intermolecular $\mathrm{C}-\mathrm{H}$ activation with late transition metals, the coordination of formaldehyde to the highly nucleophilic iridium phosphine complex, $\left[\operatorname{Ir}\left(\mathrm{PMe}_{3}\right)_{4}\right] \mathrm{PF}_{6}$, being a notable exception. ${ }^{1,36}$ However, when an aldehyde forms part of a bidentate ligand, C-H activation becomes a favoured chelation pathway in the reaction with late transition metals.

The $\mathrm{C}-\mathrm{H}$ activation reaction to form a $P, C(O)$ chelate ring is the chelation mode observed for 1 with almost all late transition metals., ${ }^{2,4}$ In all cases, coordination of phosphorus occurs first, followed by insertion of the metal into the $\mathrm{C}-\mathrm{H}$ bond. This produces an acylhydride complex, which can either exist as an unstable intermediate or a stable final product. The oxidative addition reaction to form an acylhydride complex is an important step in catalytic reactions involving aldehydes, such as decarbonylation and hydroacylation. ${ }^{4}$ For this reason, $\mathrm{C}-\mathrm{H}$ activation is the coordination reaction that has received the most attention.

Stable acylhydride complexes have been isolated from the reaction of 1 with platinum, ${ }^{1,34,37}$ iridium, ${ }^{5,7}$ rhodium, ${ }^{6,9,13}$ and cobalt. ${ }^{38}$ Acylhydride complexes tend to be relatively unstable, and frequently undergo reductive elimination to regenerate starting materials. Chelation of the coordinated acyl group in $\mathbf{1}$ stabilises the acylhydride complex, and disfavours the reductive elimination of the aldehyde. For example, Scheme 3 depicts $\mathrm{C}-\mathrm{H}$ activation of 1 
with platinum to form a platinum acylhydride complex, 5. Acylhydrides are not typically stable complexes, even when the acyl is chelated, and in this case a decarbonylation reaction took place, converting complex 5 to $6 .^{1}$

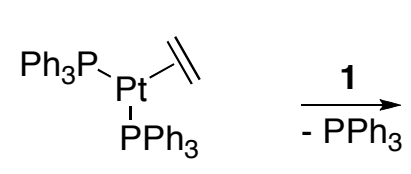<smiles>O=c1[pH]c2ccccc2p(-c2ccccc2)c1=O</smiles>

5

$$
\underset{-\mathrm{CO}}{\stackrel{\mathrm{PPh}_{3}}{\longrightarrow}} \quad\left[\mathrm{Pt}\left(\mathrm{PPh}_{3}\right)_{3}\right]
$$

\section{6}

Scheme 3: C-H activation followed by decarbonylation of 1 by platinum( 0$)$.

Although, by definition, $\mathrm{C}-\mathrm{H}$ activation of aldehydes form acylhydride complexes, often the metal hydride is an unstable intermediate and not isolable. For example, the coordination reaction of two equivalents of 1 with potassium tetrachloroplatinate at high temperature results in the formation of the final product, 7 , a complex containing one chelated and one monodentate ligand. ${ }^{34}$ Scheme 4 shows a typical coordination mechanism for phosphinocarbonyls with late transition metals: phosphorus coordination followed by $\mathrm{C}-\mathrm{H}$ activation. ${ }^{34}$ It has been proposed that formation of the product, 7 , is via an unstable 18electron, six-coordinate intermediate, followed by reductive elimination of $\mathrm{HCl}$, accounting for the isomerisation of the complex. ${ }^{5,34}$

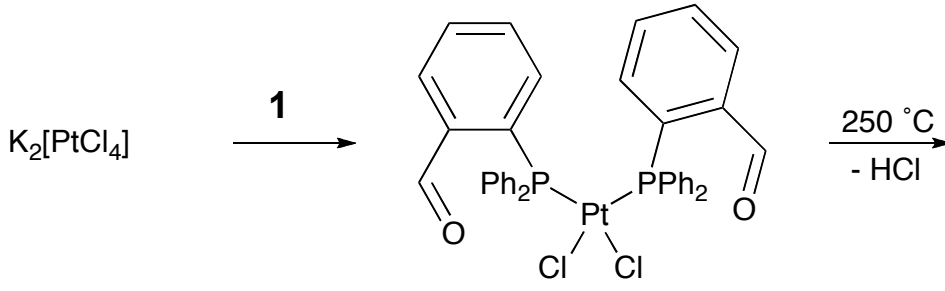

Scheme 4<smiles>O=Cc1ccccc1P[P+]1(Cl)C(=O)c2ccccc2[PH]1=O</smiles>

7

\subsubsection{Decarbonylation}

Catalytic decarbonylation of aldehydes is of great importance to organometallic and organic synthesis, and is dependent on the $\mathrm{C}-\mathrm{H}$ activation reaction between aldehydes and metals. ${ }^{38,39}$ The insertion of a metal into the $\mathrm{C}-\mathrm{H}$ bond of aldehydes produces metal acylhydrides, which are susceptible to decarbonylation, as illustrated in Schemes 3 and 5. 
However, decarbonylation of aldehyde ligands is usually hindered by chelation. For example, the reaction between 1 and $\left[\mathrm{CoMe}\left(\mathrm{PMe}_{3}\right)_{4}\right]$ results in the formation of a stable $P, C(O)$ chelate. ${ }^{38}$ Conversely, aldehydes without a chelating phosphine have been shown to undergo decarbonylation when reacted with the same cobalt complex (Scheme 5). ${ }^{39}$

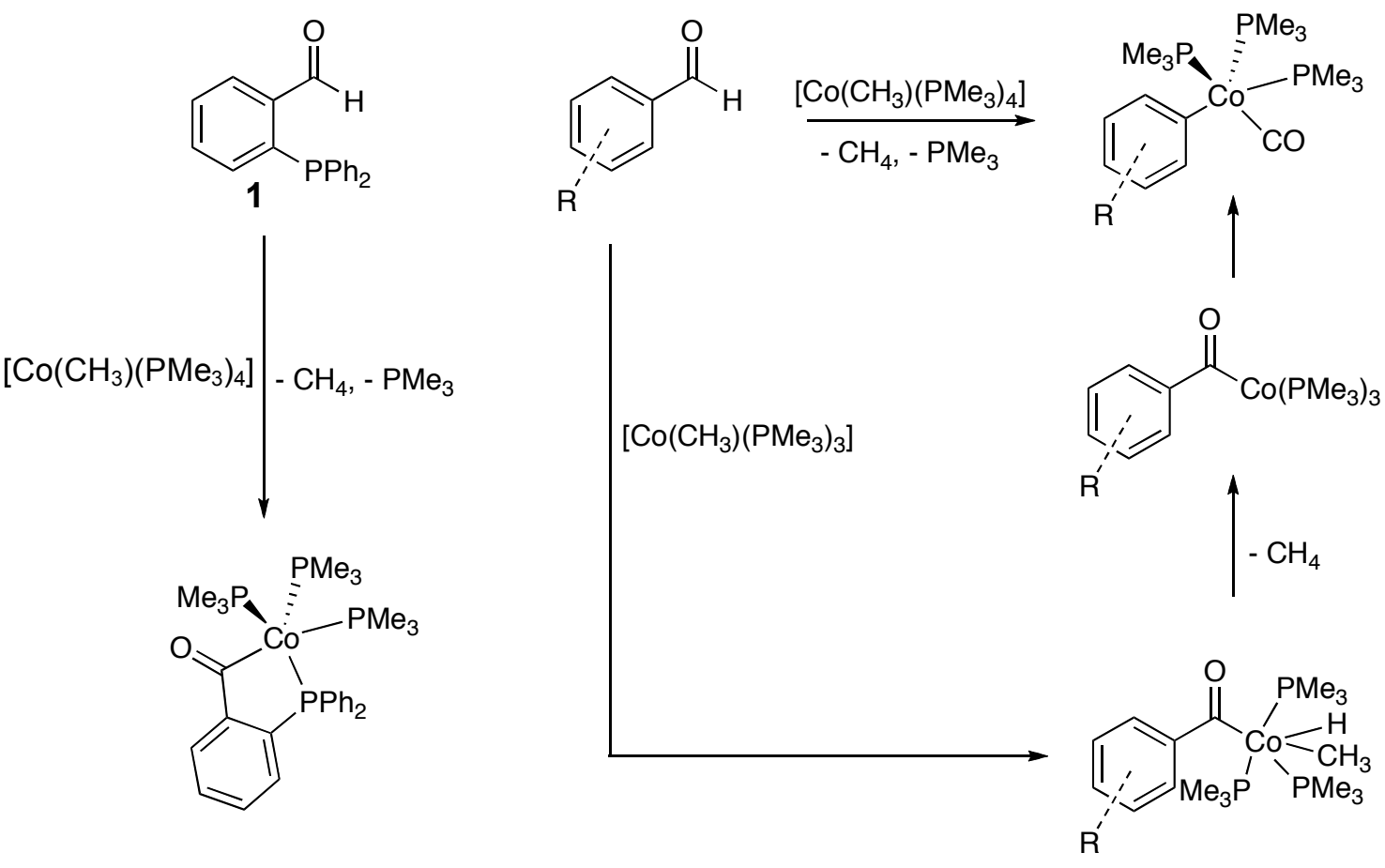

Scheme 5: $\mathrm{R}=\mathrm{H}, \mathrm{Me}, \mathrm{Et}, \mathrm{NH}_{2}$, or $\mathrm{CF}_{3}$.

\subsection{4 $P, O$ coordination}

Experiments with rhenium, ${ }^{40}$ tungsten, ${ }^{41}$ and rhodium ${ }^{2,27,42}$ show coordination can occur between a metal and the carbonyl oxygen of 1 through an $\mathrm{M}-\mathrm{O} \sigma$-interaction. Late transition metals, which display soft Lewis acidity, may form weak and labile bonds due to the poor orbital interaction between ligand and metal. ${ }^{27,42}$ Such interactions appear to be more stable when the ligand is a ketone; phosphinoaldehydes readily undergo oxidative addition of the aldehyde $\mathrm{C}-\mathrm{H}$ bond whereas ketophosphines tend to chelate through phosphorus and $\sigma$-bonded oxygen.

In late transition metal complexes with bidentate ligands that comprise both hard and soft donor atoms, the hard donor atom may engage in fluxional dissociation and association with the soft metal centre in a process known as hemilability. ${ }^{42}$ The rate of the dynamic exchange process is rapid for such ligands compared to monodentate ligands because the dissociated 
moiety of the ligand is tethered by a strong ligand-metal bond, and is therefore always in proximity to a coordination site. This premise forms part of the motivation for research into these types of ligands for catalytic applications: hemilability facilitates catalytic processes through the exchange of the tethered, placeholder ligand for another substrate. The tethered ligand can rapidly re-coordinate after dissociation of the substrate, improving the rate of reaction and stabilising the resting state of the complex in a catalytic cycle.

\subsection{5 $P, \pi(C=O)$ coordination}

Interactions between metals and the $\pi$-system of the carbonyl in phosphinocarbonyl ligands have been observed in tungsten ${ }^{41}$ and cobalt ${ }^{43}$ complexes. An examination of bidentate, carbonyl-containing ligands in coordination with a cobalt(I) complex was undertaken by Brookhart et al. in 1999. ${ }^{43}$ The research compared the bonding modes of the aldehyde functionality of 1, 2-formylstyrene, and phthalaldehyde with a $\left[\mathrm{CoCp}^{*}\right]$ organometallic complex $\left(\mathrm{Cp}^{*}=\right.$ pentamethylcyclopentadienyl $)$, forming complexes 8,9 , and 10 , respectively. In each case, the ligands interacted with the metal through both a $\sigma$-bond and a $\pi$-bond.

The coordination of cobalt to the $\pi$-system of the aldehyde is driven by increased electron density at the metal, which is caused by donation of electron density from the M-O or M-P $\sigma$-bond. Coordination of the carbonyl through the $\mathrm{C}=\mathrm{O} \pi$-bond enables the back donation of electron density into the $\pi^{*}$-antibonding orbitals, which reduces electron density on the metal and stabilises the complex. In another study, the coordination of 1 with a tungsten carbonyl complex, $\left[\mathrm{W}(\mathrm{CO})_{3}\left(\eta^{3}-\left(\mathrm{MeNCH}_{2}\right)_{3}\right)\right]$, has also been found to form a $P, \pi(C=O)$ chelate complex, $\mathbf{1 1} .^{41}$

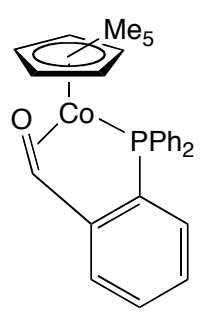

8

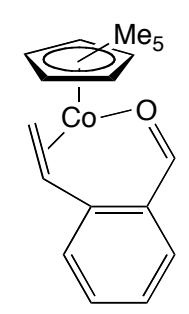

9

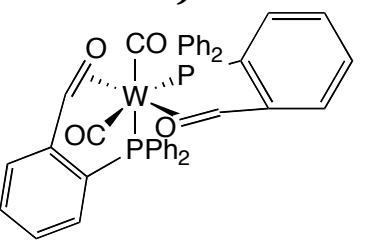

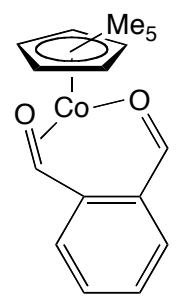

10 


\section{Ligand Synthesis}

There are numerous methods for preparing phosphinocarbonyl compounds, four of which were attempted in various synthetic strategies to produce the target compounds for this project. Common synthetic procedures include the nucleophilic attack on a halodiphenylphosphine by an activated aryl group, either as a lithiated species or Grignard reagent. For such preparations, acyl groups must be protected, commonly as acetals. A more novel method of synthesis has been developed to circumvent the requirement of protecting groups for such moieties and involves the reaction of potassium phosphide nucleophiles with fluoroaryls.

\subsection{2-Diphenylphosphinobenzaldehyde (1)}

2-Diphenylphosphinobenzaldehyde was synthesised according to the method reported by Hoots et al. ${ }^{44}$ 2-Bromobenzaldehyde diethyl acetal was reacted with magnesium to form the Grignard reagent, 2- $\mathrm{BrMgC}_{6} \mathrm{H}_{4} \mathrm{CH}(\mathrm{OEt})_{2}$, to which was added chlorodiphenylphosphine. Deprotection afforded the final product, 1, in good yield (Scheme 6). Compound 1 crystallised as a yellow solid that was air-stable, but it slowly oxidised in solution if exposed to air.

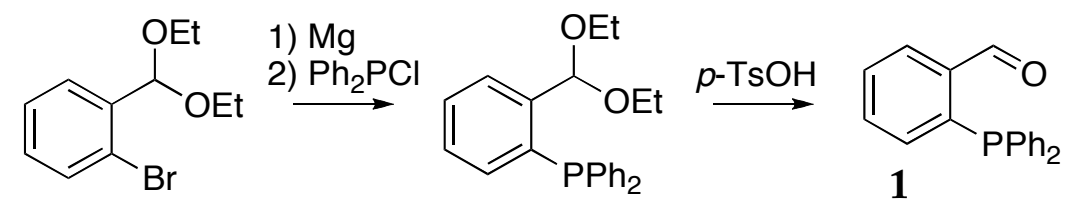

Scheme 6: For complete reaction conditions see Section 5.3.1.

\subsection{2-Diphenylphosphinoacetophenone (2)}

The ketophosphine, 2, was prepared according to the method reported by Coote et al., which was based on the nucleophilic substitution reaction between an aryl fluoride and potassium diphenylphosphide to produce the arylphosphine. ${ }^{45}$ This one-pot reaction required no protecting groups, and resulted in high yields. It can be applied to aryl fluorides with a 
variety of substitutents that are sensitive to conventional Grignard or organolithium reagents, such as aldehydes or nitriles.

Diphenylphosphine was reacted with potassium metal to form the potassium diphenylphosphide nucleophile, ${ }^{46}$ which was then reacted at reflux with the aryl fluoride, 2-fluoroacetophenone (Scheme 7). An alternative preparation of potassium diphenylphosphide is through the reaction of potassium metal with triphenylphosphine, which yields potassium diphenylphosphide and phenylpotassium. ${ }^{47}$ This preparation requires the selective quenching of $\mathrm{KPh}$, and the method using $\mathrm{Ph}_{2} \mathrm{PH}$ and potassium was favoured due its greater product yield and simplicity.

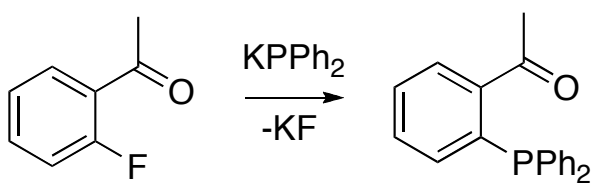

2

Scheme 7: For complete reaction conditions see Section 5.3.2.

\subsection{2-Bis(pentafluorophenyl)phosphinobenzaldehyde (3)}

Compound 3 was prepared according to the Hoots et al. method, ${ }^{44}$ modified by Barber, ${ }^{48}$ and involved the use of the bromobis(pentafluorophenyl)phosphine as the phosphine reagent (Scheme 8).

The electron withdrawing and sterically bulky pentafluorophenyl groups confer a large degree of air-stability to the phosphine. In solution, ${ }^{31} \mathrm{P}$ NMR showed that 3 resisted oxidation more strongly than 1 or triphenylphosphine.<smiles>CCOC(OCC)c1ccccc1Br</smiles><smiles>CCOC(OCC)c1ccccc1P(O)(F)(F)F</smiles>

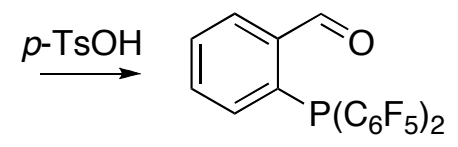

3

Scheme 8: For complete reaction conditions see Section 5.3.3.

Phosphine species that contain pentafluorophenyl substituents have been investigated for their potential as ligands in homogeneous catalysis due to their stability in air and water, as well as their solubility in fluorous phases and supercritical $\mathrm{CO}_{2 \cdot}{ }^{49,50}$ As they are very poor electron donors, pentafluorophenylphosphines have similar $\sigma$-donation properties to 
phosphite ligands $\left(\mathrm{P}(\mathrm{OR})_{3}\right.$ ligands), which have been incorporated successfully into a number of catalytic complexes, especially in Wilkinson-type rhodium hydroformylation catalysts. ${ }^{50}$ Pentafluorophenylphosphines have been proposed as replacements for phosphites, which contain water-sensitive $\mathrm{P}-\mathrm{O}$ bonds. ${ }^{50}$ However, their role in catalysis has met with little success thus far.

\subsection{2-Di-tert-butylphosphinobenzaldehyde (4)}

\subsubsection{Attempted synthesis of 4 with a potassium phosphide nucleophile}

Previous attempts at the synthesis of 4 within the research group showed that a synthetic pathway using conventional methodologies such as through a lithiated aryl or aryl Grignard were unsuccessful and an alternative methodology was sought. ${ }^{51}$ The high yield and simple synthesis of 2-diphenylphosphinoacetophenone (2) using a potassium diphenylphosphide nucleophile was therefore an attractive synthetic strategy on which to base the preparation of 4.

It was found that the method reported by Ashby, ${ }^{46}$ wherein diphenylphosphine was deprotonated with potassium metal to produce the potassium diphenylphosphide nucleophile, failed to produce the di-tert-butylphosphide anion from di-tert-butylphosphine. There are two published examples of the successful synthesis and use of $\mathrm{KP}^{t} \mathrm{Bu}_{2}{ }^{52,53} \mathrm{One}$, published by Haenel, involved the substitution of the fluoro groups of 1,8-difluoroanthracene with di-tert-butylphosphine groups. ${ }^{52}$ The other instance, published in 2005 by Schultz, ${ }^{53}$ reported the reaction of $\mathrm{KP}^{t} \mathrm{Bu}_{2}$ with potassium 2-fluorobenzoate to produce potassium 2-di-tert-butylphosphinobenzoate. Schultz reported that although potassium tert-butoxide was capable of deprotonating di-tert-butylphosphine, the subsequent nucleophilic substitution of an aryl fluoride was ineffective. The preparation of $\mathrm{KP}^{t} \mathrm{Bu}_{2}$ and successful substitution of the fluoride was achieved only through the use of the strong reducing agent, potassium graphite, $\mathrm{KC}_{8}{ }^{53}$ As the starting materials and reported product were closely related to the target compound, the method reported by Schultz was adapted.

Potassium graphite, $\mathrm{KC}_{8}$, is a bronze-coloured, pyrophoric powder that comprises a lamellar structure wherein potassium ions are intercalated between each layer of the graphite lattice. ${ }^{54}$ Preparation of $\mathrm{KC}_{8}$ was relatively simple, and involved melting the metal over graphite at 
elevated temperatures. The synthesis has been reported in a number of publications, however the temperature at which the reaction was performed varied from $70{ }^{\circ} \mathrm{C}$ to $275{ }^{\circ} \mathrm{C} .{ }^{54-56}$ The preparation was carried out at various temperatures under a nitrogen atmosphere using flame-dried glassware, dried graphite, and potassium metal washed with hexane. Various temperatures were used for the synthesis although it was found that performing the reaction in an oil bath at $220{ }^{\circ} \mathrm{C}$ or higher resulted in rather unnerving flashes and sparks upon addition of potassium. A smoother reaction was achieved at temperatures closer to $170{ }^{\circ} \mathrm{C}$.

The reaction of ${ }^{t} \mathrm{Bu}_{2} \mathrm{PH}$ and $\mathrm{KC}_{8}$ in $\mathrm{THF}$ produced a green-yellow filtrate presumed to contain $\mathrm{KP}^{t} \mathrm{Bu}_{2}$. The addition of 2 -fluorobenzaldehyde followed by reflux resulted in a single product, 5, which resonated as a doublet in the ${ }^{31} \mathrm{P}$ NMR spectrum with a chemical shift of $57.2 \mathrm{ppm}$ and a coupling constant of $47 \mathrm{~Hz}$ (Figure 4). The ${ }^{19} \mathrm{~F}$ spectrum showed one resonance as a doublet of quartets at $-112.4 \mathrm{ppm}$ with a doublet coupling constant of $47 \mathrm{~Hz}$, ascribed to ${ }^{31} \mathrm{P}_{-}{ }^{19} \mathrm{~F}$ coupling. The magnitude of the $J_{\mathrm{P}-\mathrm{F}}$ coupling suggests that the coupling is through three bonds, and that the phosphine group is in the ortho position relative to fluorine, and meta to the aldehyde group (Scheme 9).

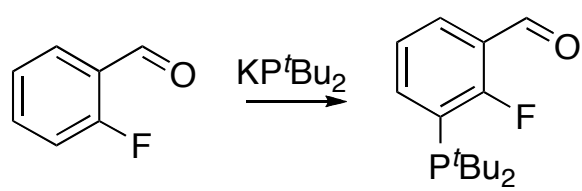

Scheme $9 \quad 5$

A study of ortho-, meta-, and para-substituted 2-fluoro-3-dimethylphosphinobenzene compounds showed that P-F coupling was only observed when the substituents were in an ortho relationship. ${ }^{57}$ The compound, 1-dimethylphosphino-2-fluorobenzene (12), has a ${ }^{3} \mathrm{P}-\mathrm{F}$ coupling of $34 \mathrm{~Hz}$, which is comparable to the ${ }^{3} J_{\mathrm{P}-\mathrm{F}}$ observed in the product of the present reaction of $\mathrm{KP}^{t} \mathrm{Bu}_{2}$ with 2-fluorobenzaldehyde.

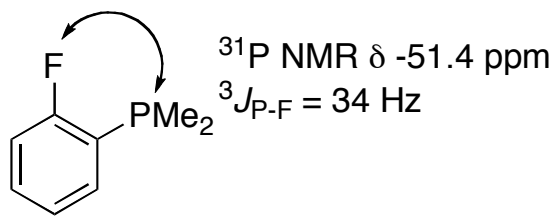

12

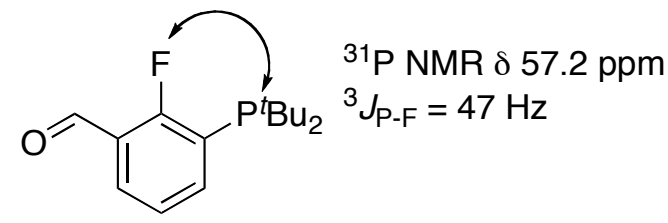

5

Figure 4: Similar ${ }^{3} J_{\mathrm{P}-\mathrm{F}}$ coupling between 5 and 12 supports the assigned structure of 5. 


\subsubsection{Attempted synthesis of potassium 2-di-tert-butylphosphinobenzoate}

It was proposed that the success of the reported synthesis of ${ }^{-}{ }^{-} \mathrm{Bu}_{2} \mathrm{PC}_{6} \mathrm{H}_{4} \mathrm{COO}^{-}$(14) by Schultz may have been dependent upon the formation of a phosphoranone, 13, wherein the pentavalent phosphorus is bound to the carboxylate oxygen and also to a proton (the origin of which was never specified) (Scheme 10). ${ }^{53}$<smiles>COC(=O)c1ccccc1F</smiles>

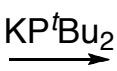<smiles>CC(C)(C)P1(Br)(Br)OC(=O)c2ccccc21</smiles>

13

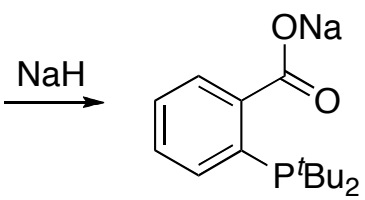

14

Scheme 10

A new synthetic strategy was devised where a phosphinocarboxylate would be produced, and subsequently reduced to the aldehyde. This method was found to result in the formation of a number of unknown products. At this point, the methodology using $\mathrm{KP}^{t} \mathrm{Bu}_{2}$ was stopped in favour of testing the more conventional approach to the synthesis of arylphosphines using organolithium reagents.

\subsubsection{Synthesis of 4 using butyllithium reagents}

The synthesis of di-tert-butylphosphinoaryl derivatives via the lithiation of aryl halide substrates is a very common methodology and there are many successful reports of its use. ${ }^{56}$ It was therefore determined that revisiting this methodology was required for the synthesis of 4.

A similar compound to 4 has been prepared by Bei and co-workers using butyllithium reagents. The researchers produced 2-dicyclohexylphosphinobenzaldehyde from the reaction of chlorodicyclohexylphosphine with 2-lithio-benzaldehyde dimethyl acetal, where lithiation was achieved with $n^{-}$or tert-butyllithium. Hydrolysis of the acetal protecting groups produced the product, 2-dicyclohexylphosphinobenzaldehyde..$^{58,59}$ This method was adapted for the synthesis of 4 .

2-Bromobenzaldehyde diethyl acetal was lithiated with $n$-butyllithium, followed by its reaction with chloro-di-tert-butylphosphine. The reaction was monitored by ${ }^{31} \mathrm{P}$ NMR spectroscopy, which showed a conversion of ${ }^{t} \mathrm{Bu}_{2} \mathrm{PCl}$ to the product (15) of roughly $25 \%$ 
after two days, by which point the reaction had ceased. Analysis of the reaction products by ${ }^{1} \mathrm{H}$ NMR showed the limited conversion to the target compound was due to a side-reaction between $n$-bromobutane and 2-lithiobenzaldehyde diethyl acetal, which produced 2-butylbenzaldehyde diethyl acetal, 16 (Scheme 11). The competition between halobutanes and halophosphines for nucleophilic attack of a lithiated carbon is a common problem encountered in ligand syntheses, especially where the desired reaction is sterically encumbered and thus proceeds at a sluggish rate. ${ }^{56}$

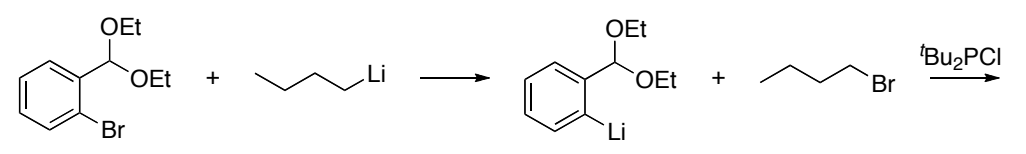

Scheme 11

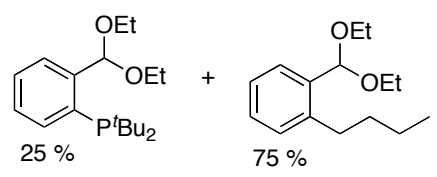

15

16

Formation of the byproduct 16 was avoided by using tert-butyllithium instead of n-butyllithium. The abstraction of the bromide from 2-bromobenzaldehyde diethyl acetal by tert-butyllithium results in the formation of 2-halomethylpropane, which is itself attacked by another molecule of tert-butyllithium to form methylpropane and methylpropene (Scheme 12). Two equivalents of tert-butyllithium were thus required for a lithium-halide exchange reaction. The absence of a competing haloalkane allowed the slow reaction between 2lithiobenzaldehyde diethyl acetal and ${ }^{t} \mathrm{Bu}_{2} \mathrm{PCl}$ to go further towards completion.

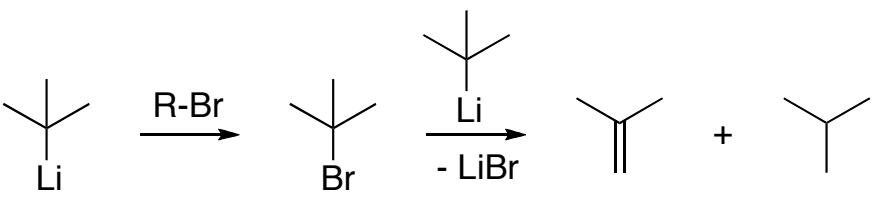

Scheme 12

After ten days at room temperature, the tert-butyllithium facilitated methodology produced compound 15 with a yield of $80 \%$ relative to 2-bromobenzaldehyde diethyl acetal, based on the integration of the $\mathrm{CH}(\mathrm{OEt})_{2}$ methyne signals in ${ }^{1} \mathrm{H} \mathrm{NMR}$ spectra. It was found that better yields were obtained if an excess of ${ }^{t} \mathrm{Bu}_{2} \mathrm{PCl}$ was used and then removed under vacuum after the reaction workup. A reaction duration of ten days was considerably longer than many reported reactions between tert-butylphosphines and aryllithium species. For example, the tert-butyllithium-facilitated reaction of bromobenzaldehyde dimethyl acetal and chlorodicyclohexylphosphine was complete within eighteen hours to a yield of $91 \% .{ }^{58}$ The 
byproduct, benzaldehyde diethyl acetal (17), was produced as a result of the quenching of remaining lithiated materials in the aqueous work up.

The separation of compound 15 from the byproduct 17 and the separation of the deprotected compound 4 from benzaldehyde were attempted via column chromatography. The air-sensitivity of both 4 and 15 required columns to be loaded and eluted under inert atmosphere using either silica gel or Florisil ${ }^{\circledR}$ packing material." Both the protected and deprotected target compounds, 15 and 4, fluoresce under ultraviolet light $(365 \mathrm{~nm})$, and their movement through the stationary phase could be followed. Although separation was achieved, all attempts resulted in unsatisfactorily low yields of the target product. The fluorescence of the column under UV light showed that the phosphine had adhered to the packing material. Furthermore, chromatographic purification was poor due to the only slight difference in $R_{\mathrm{f}}$ values even at 19:1 hexane/diethyl ether, and the difficulty in detecting the point at which compounds eluted from the column. The protected product, 15, was therefore used without further purification.

Deprotection of compound 15 was achieved through an acid-catalysed hydrolysis of the diethyl acetal group (Scheme 13). Owing to the air-sensitivity of the phosphine, higher temperature conditions were used for shorter durations than typical deprotection methods in order to afford a lower incidence of oxidation. ${ }^{58} \mathrm{~A}$ pressure tube was employed to enable a closed-system deprotection reaction in $1: 2 \mathrm{H}_{2} \mathrm{O} / \mathrm{THF}$ at $80^{\circ} \mathrm{C}$ for two hours, which provided higher yields of 4 than the same reaction at $55{ }^{\circ} \mathrm{C}$ for 20 hours. ${ }^{58}$ Compound 4 was not isolated from the workup as a pure material, but as a mixture of $80 \% 4$ and $20 \%$ benzaldehyde. Heating the crude product to $35^{\circ} \mathrm{C}$ under vacuum for four hours removed the benzaldehyde, and left the product in $95 \%$ purity (assessed by ${ }^{1} \mathrm{H}$ and ${ }^{31} \mathrm{P} \mathrm{NMR}$ data).

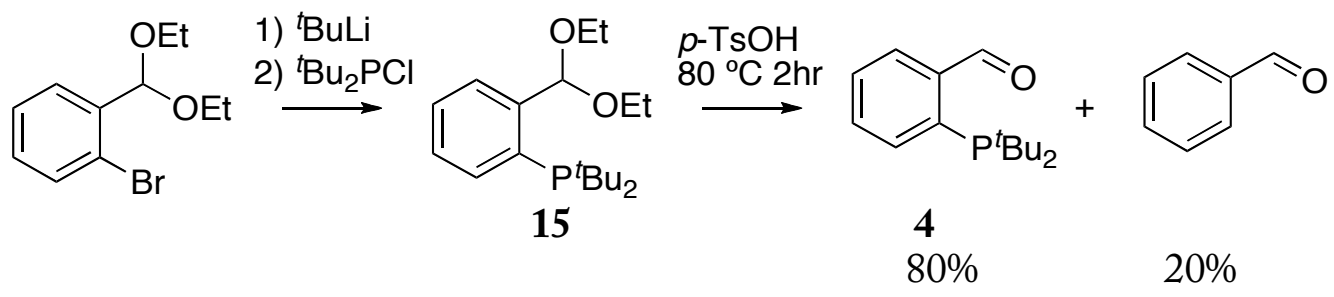

Scheme 13: For complete reaction conditions see Sections 5.3.4 and 5.3.5.

${ }^{*}$ Florisil ${ }^{\circledR}$ is activated magnesium silicate with the empirical formula $\mathrm{MgSiO}_{3}$. 
The slow rate of reaction was thought to be due to not only the bulk of the phosphine, but also due to the bulk of the diethyl acetal group at the ortho position to the lithiated site. An alternative substrate, 2-bromobenzaldehyde ethylene acetal, was used in reactions with both $n$-butyllithium and tert-butyllithium, followed by addition of ${ }^{t} \mathrm{Bu}_{2} \mathrm{PCl}$. The reaction with $n$-butyllithium produced no measurable change to the rate of reaction compared to the diethyl acetal protecting group; the maximum yield observed after nine days of reaction was $25 \%$. When the experiment was carried out using tert-butyllithium, the reaction underwent a colour change to dark yellow, and only $17 \%$ of the target phosphine product was observed in the ${ }^{31} \mathrm{P}$ NMR spectrum of the sample (Scheme 14). The ethylene acetal protected substrate was obviously more reactive to the strongly basic butyllithium reagents. This is a possible reason why, in the synthesis of their dicyclohexylphosphinoaryl ligands, Bei and co-workers reported the use of $n$-butyllithium with 2-bromobenzaldehyde ethylene acetal, and used tert-butyllithium for 2-bromobenzaldehyde dimethyl acetal. ${ }^{58,59}$

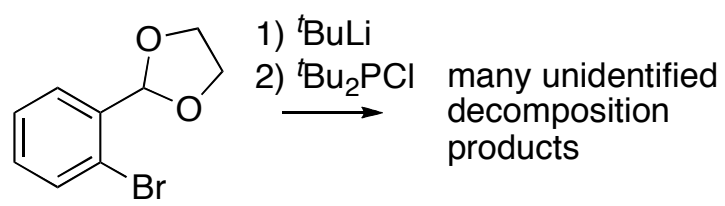

Scheme 14 


\section{Coordination Chemistry}

\subsection{Coordination chemistry of 2-diphenylphosphinobenzaldehyde}

The coordination chemistry of 2-diphenylphosphinobenzaldehyde (1) with platinum(0) and platinum(II) starting materials has been previously investigated by Koh, Rauchfuss, and Ghilardi. ${ }^{1,34,37}$ As with other late transition metals such as iridium and rhodium, the reaction pathway involved the initial coordination of phosphorus followed by the oxidative addition of the aldehyde group. The chemistry of 1 with rhodium and iridium has been the subject of intense research by Garralda in recent years, from which a number of novel materials have been prepared. ${ }^{2,412}$ A thorough investigation into the coordination chemistry of 1 with platinum(0) and platinum(II) was undertaken as a starting point for the comparison of the rate and reactivity of $\mathrm{C}-\mathrm{H}$ activation of phosphinocarbonyls.

\subsubsection{Coordination chemistry of 1 with platinum(II)}

Reactions between dimethylplatinum(1,5-hexadiene) ([PtMe 2 (1,5-hexadiene)]) and 1 in 1:1 and 2:1 ligand/metal ratios were carried out to establish the extent of $\mathrm{C}-\mathrm{H}$ activation, and the rate at which it occurred. The reaction of 1 with $\left[\mathrm{PtMe}_{2}(1,5\right.$-hexadiene)] in either ratio resulted in the rapid substitution of coordinated hexadiene for the phosphine moieties of two molecules of 1 to form the complex cis- $\left[\mathrm{PtMe}_{2}\left(2-\mathrm{PPh}_{2} \mathrm{C}_{6} \mathrm{H}_{4} \mathrm{CHO}\right)_{2}\right]$ (18). The ${ }^{31} \mathrm{P} \mathrm{NMR}$ chemical shift of the phosphine moved to $23.7 \mathrm{ppm}$ upon coordination, from $-10.9 \mathrm{ppm}$ as a free ligand. The relatively low ${ }^{1} J_{\mathrm{Pt}-\mathrm{P}}$ coupling constant of $1831 \mathrm{~Hz}$ was consistent for a structure that contained mutually cis phosphine groups, each trans to a methyl ligand. ${ }^{18}{ }^{1} \mathrm{H}$ NMR signals of the methyl ligands in the complex became distinctly second order with an $\mathrm{AA}^{\prime} \mathrm{X}_{3} \mathrm{X}_{3}{ }^{\prime}$ spin system, and this was further evidence for the assignment of a mutually cis configuration. ${ }^{60-62}$

Over a few hours at room temperature, one monodentate ligand underwent oxidative addition to form a $P, C$-platinacycle, cis- $\left[\mathrm{PtMe}\left(P, C-2-\mathrm{PPh}_{2} \mathrm{C}_{6} \mathrm{H}_{4} \mathrm{CO}\right)\left(2-\mathrm{PPh}_{2} \mathrm{C}_{6} \mathrm{H}_{4} \mathrm{CHO}\right)\right]$ (19), via the reductive elimination of methane (Scheme 15). Complete conversion to 19 occurred after one day at room temperature. The complex was isolated from benzene as 
orange crystals, and was air-stable at room temperature as a solid. The molecular composition of the complex was confirmed by elemental analysis and high-resolution electrospray mass spectrometry (HR-ESIMS). Integration of the ${ }^{1} \mathrm{H}$ NMR spectral data showed the presence of one aldehyde proton and three methyl protons per complex. Upon the chelation of 1 to form the $P, C(O)$ chelate, the ${ }^{31} \mathrm{P}$ NMR chemical shift of that phosphine moved downfield to $51.4 \mathrm{ppm}$, while the ${ }^{31} \mathrm{P}$ NMR chemical shift of the monodentate ligand remained similar to the ${ }^{31} \mathrm{P}$ NMR resonance of 18 at $18.8 \mathrm{ppm}$. Such a dramatic change in chemical shift for a phosphorus signal is diagnostic for its involvement in a five-membered ring. ${ }^{63,64}$ The low ${ }^{3} J_{\mathrm{P}-\mathrm{P}}$ coupling of $11 \mathrm{~Hz}$ indicated a cis relationship between the two phosphorus atoms.

Complex 19 was analogous to the product reported by Rauchfuss, where the reaction of 1 with $\mathrm{K}_{2}\left[\mathrm{PtCl}_{4}\right]$ resulted in the formation of the chloro analogue, $\left[\mathrm{PtCl}\left(P, C-2-\mathrm{PPh}_{2} \mathrm{C}_{6} \mathrm{H}_{4} \mathrm{CO}\right)\left(2-\mathrm{PPh}_{2} \mathrm{C}_{6} \mathrm{H}_{4} \mathrm{CHO}\right)\right](7) .{ }^{34}$ However, 19 was formed at room temperature, compared to the forcing conditions of vacuum thermolysis at $250{ }^{\circ} \mathrm{C}$ required for 7 .

\subsubsection{Mechanism of coordination}

Low temperature ${ }^{1} \mathrm{H}$ and ${ }^{31} \mathrm{P}$ NMR experiments were carried out to analyse the formation of a short-lived platinum acylhydride complex (20), that was observed early in the coordination reaction (Scheme 15). The presence of a hydride ligand was readily distinguishable by the presence of a signal in the ${ }^{1} \mathrm{H}$ NMR spectrum with a chemical shift below zero ppm. After five minutes of the reaction between $\left[\mathrm{PtMe}_{2}\left(1,5\right.\right.$-hexadiene)] and 1 performed at $-15{ }^{\circ} \mathrm{C}$, a hydride resonance was clearly visible in the ${ }^{1} \mathrm{H}$ NMR spectrum at $-2.76 \mathrm{ppm}$ as a doublet of doublets, with ${ }^{2} J_{\mathrm{P}-\mathrm{H}}$ coupling of 18.6 and $14.8 \mathrm{~Hz}$ and ${ }^{1} J_{\mathrm{Pt}-\mathrm{H}}$ of $761 \mathrm{~Hz}$, indicating that the platinum was also coordinated to two phosphines in a cis and trans relationship relative to the hydride.

The presence of a hydride in the very early stages of the reaction meant that $\mathrm{C}-\mathrm{H}$ activation of one ligand had occurred, but reductive elimination of methane had not. Both methyl groups were therefore expected to be coordinated to the platinum intermediate. A second-order signal with ${ }^{2} \mathrm{Jt}_{\mathrm{Pt}-\mathrm{H}}$ coupling of $41 \mathrm{~Hz}$ resonated at $-0.30 \mathrm{ppm}$ and integrated 3:1 to the hydride. It was assigned as one of the methyl groups on the intermediate platinum 
hydride complex. The other methyl group could not be observed and it is likely the signal coincided with methyl groups of complexes 18 and 19, which were extant in much higher populations. The aldehyde proton signal of the monodentate ligand in 20 resonated at 9.27 ppm - substantially upfield compared to both 18 and 19 (10.69 and 10.47 ppm, respectively).

The ${ }^{31} \mathrm{P}$ NMR experiment at low temperature showed the resonances of complexes 18 and 19, as well as two signals relating to the intermediate complex 20 at $-4.2\left({ }^{1} J_{\mathrm{Pt}-\mathrm{P}}=1004 \mathrm{~Hz}\right)$ and $29.0 \mathrm{ppm}\left({ }^{1} J_{\mathrm{Pt}-\mathrm{P}}=1421 \mathrm{~Hz}\right)$. The phosphorus resonances appeared as slightly broadened singlets, and their identical peak integration was good evidence for them being on the same molecule.

In order to account for the phosphine, aldehyde, and hydride resonances observed by NMR, the acylhydride intermediate 20 was determined to be a six-coordinate, $\mathrm{Pt}(\mathrm{IV})$ intermediate which rapidly undergoes reductive elimination of methane to form the square planar complex, 19. The NMR evidence was therefore consistent with metallation occurring through an acylhydride intermediate.

[PtMe 2 (1,5-hexadiene) $]$

$\frac{1}{-\mathrm{C}_{6} \mathrm{H}_{10}}$

9<smiles>C=C</smiles>

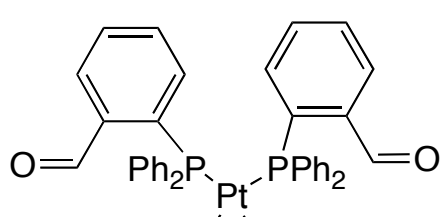

Mé 'Me

18 $\left[\mathrm{PtHMe}_{2}\left(P, \mathrm{C}-2-\mathrm{PPh}_{2} \mathrm{C}_{6} \mathrm{H}_{4} \mathrm{CO}\right)\left(2-\mathrm{PPh}_{2} \mathrm{C}_{6} \mathrm{H}_{4} \mathrm{CHO}\right)\right]$ 20

Scheme 15

\subsubsection{Formation of a bimetallated complex}

The elucidation of the mechanism of chelation suggested that metallation of the second aldehyde group should also occur. It was determined that there was probably a large energy barrier between a single metallated and a doubly metallated complex. The chelation of the 
pendant aldehyde was not observed in solution at temperatures up to $60{ }^{\circ} \mathrm{C}$, so a sample of complex 19 was dissolved in toluene and heated to reflux. This resulted in the formation of the doubly metallated complex, $\left[\mathrm{Pt}\left(P, C-2-\mathrm{PPh}_{2} \mathrm{C}_{6} \mathrm{H}_{4} \mathrm{CO}\right)_{2}\right]$ (21) (Scheme 16). After eight hours at reflux, all of the starting material had reacted to form the cis and trans isomers of 21 . Red microcrystals (which were identified as the cis isomer) precipitated from refluxing toluene and a more soluble green powder was isolated and identified as the trans isomer.

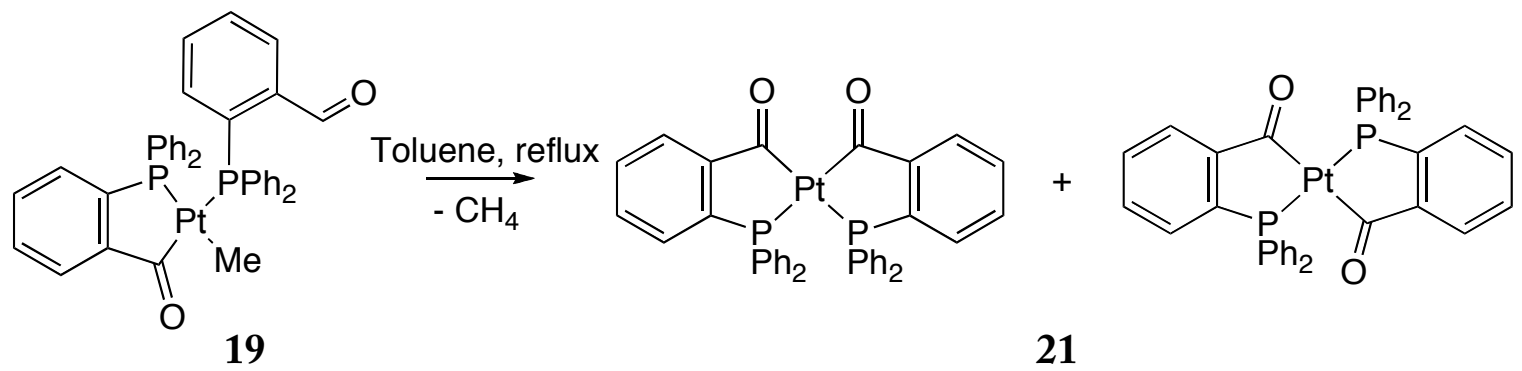

Scheme 16

${ }^{1} \mathrm{H}$ NMR data of both isomers of 21 confirmed the absence of aldehyde protons and platinum-methyl groups. ${ }^{31} \mathrm{P}$ NMR spectroscopy of the red, cis isomer showed a singlet with a chemical shift of $47.8 \mathrm{ppm}$ and a ${ }^{1} J_{\mathrm{Pt}-\mathrm{P}}$ coupling of $1843 \mathrm{~Hz}$. The observation of a single peak at lower field suggested this complex was symmetrical where both phosphine groups existed in five-membered rings. The platinum-phosphorus coupling constant showed that the phosphorus atoms were trans to the carbonyl groups, and therefore the structure was in a mutually cis geometry regarding the carbonyl and phosphine groups. Similarly, the green compound contained one singlet in the ${ }^{31} \mathrm{P} \mathrm{NMR}$ spectrum at $51.0 \mathrm{ppm}$, with a ${ }^{1} J_{\mathrm{Pt}-\mathrm{P}}$ coupling constant of $3362 \mathrm{~Hz}$, showing that, again, a symmetrical, bimetallated complex was formed, and in this case the phosphine groups were trans to each other. Both cis and trans isomers have a very low solubility in common laboratory solvents, for example, chloroform, dichloromethane, benzene, toluene, acetone, $\mathrm{D}_{2} \mathrm{O}$, and dimethylsulfoxide. As such, a ${ }^{13} \mathrm{C}$ NMR spectrum could not be acquired.

Although both cis and trans isomers of 21 were produced, the cis isomer was formed in higher quantities (74\%). Isolation of the cis isomer for the purpose of further reactions was based on its lower solubility compared to that of the trans isomer (see Sections 3.1.4 and 3.1.5). Purification of each isomer was achieved via silica column chromatography, and through this method, the isomers were not only purified, they crystallised almost immediately from the eluting solvent. Each isomer is highly stable in solution, resisting 
degradation for over a week, and ${ }^{31} \mathrm{P}$ NMR of each isomer showed interconversion between cis and trans complexes does not occur.

\subsubsection{Comparison of reactivity of methyl-platinum and chloro-platinum complexes}

When the coordination reaction was performed using 1 and $\left[\mathrm{PtCl}_{2}(1,5\right.$-hexadiene)], the same reactivity was observed to that performed by Rauchfuss with $\mathrm{K}_{2}\left[\mathrm{PtCl}_{4}\right]$ (Scheme 17). ${ }^{34}$ The reactants were stirred in toluene at room temperature for two hours, which produced a precipitate of $\left[\mathrm{PtCl}_{2}\left(2-\mathrm{PPh}_{2} \mathrm{C}_{6} \mathrm{H}_{4} \mathrm{CHO}\right)_{2}\right]$, 22. No further reaction was observed after heating the solid in refluxing toluene overnight; 22 is insoluble in toluene even at reflux. Dissolving the complex in chloroform and heating to $60{ }^{\circ} \mathrm{C}$ yielded the complex 7 .

The reactivity pattern of the $2: 1$ reaction of 1 and [ $\mathrm{PtMe}_{2}(1,5$-hexadiene)] was similar to that of the 2:1 reaction between 1 and $\left[\mathrm{PtCl}_{2}(1,5\right.$-hexadiene)], however, the differences therein are illustrative of the effect of leaving groups in a platinum starting material on the identity of the final product. Rauchfuss produced the trans isomer of 7 through $\mathrm{C}-\mathrm{H}$ activation of 22 , whereas the methyl derivative, 18, reacts to form the cis isomer of 19 . Furthermore, the conditions required for $\mathrm{C}-\mathrm{H}$ activation of the chloro-coordinated phosphinocarbonyl complex (from 22 to 7) were much more forcing. Rauchfuss reported facile substitution of two chloride ions to produce 22 , however, $\mathrm{C}-\mathrm{H}$ activation was only observed when the complex was subjected to vacuum thermolysis at $250{ }^{\circ} \mathrm{C}$, and the $\mathrm{C}-\mathrm{H}$ activation of the second pendant aldehyde was not observed. It could be concluded that phosphorus rapidly substituted chloride ligands, but the energy barrier of either the oxidative addition of the aldehyde to form the acylhydride $\mathrm{Pt}(\mathrm{IV})$ intermediate or the reductive elimination of $\mathrm{HCl}$ was much higher than the analogous reaction with platinum-methyl complexes.

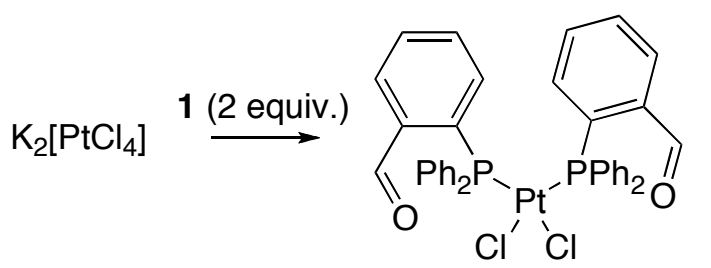

22

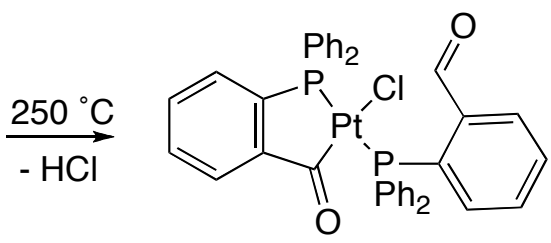

7

Scheme 17 


\subsubsection{Coordination chemistry of 1 with platinum(0)}

Oxidative addition reactions such as $\mathrm{C}-\mathrm{H}$ activation necessitate an increase in the oxidation state of the metal centre. It was therefore instructive to analyse the reaction of 1 with platinum(0) starting materials to ascertain whether the reactivity resembled that with platinum(II). Tris(norbornene)platinum (norbornene = bicyclo[2.2.1]hept-2-ene) was chosen as the platinum(0) starting material due to the facile displacement of norbornene, its solubility in a variety of organic solvents, air-stability, and its relative ease of synthesis.

The final products of a reaction between tris(norbornene)platinum and 1 in a 1:2 ratio were both the cis and the trans isomer of the bimetallated complex, 21 - the same final product as the reaction between 1 and $\left[\mathrm{PtMe}_{2}(1,5\right.$-hexadiene)]. This complex formed over a period of days at room temperature, after moving through a number of intermediate products, some of which were fully or partially characterised using ${ }^{1} \mathrm{H},{ }^{13} \mathrm{C}$, and ${ }^{31} \mathrm{P}$ NMR spectroscopy.

\subsubsection{2-Norbornyl intermediate}

The reactants, $\left[\mathrm{Pt}(\mathrm{nb})_{3}\right](\mathrm{nb}=$ norbornene) and 1 (two equivalents), were combined and dissolved in toluene. $\mathrm{C}-\mathrm{H}$ activation of one aldehyde group occurred within minutes of the reaction to form cis and trans isomers of a platinum-2-norbornyl complex, $\left[\mathrm{Pt}\left(\mathrm{C}_{7} \mathrm{H}_{11}\right)\left(P, C-2-\mathrm{PPh}_{2} \mathrm{C}_{6} \mathrm{H}_{4} \mathrm{CO}\right)\left(2-\mathrm{PPh}_{2} \mathrm{C}_{6} \mathrm{H}_{4} \mathrm{CHO}\right)\right]$ (23). The trans isomer of complex 23 $\left({ }^{2} J_{\mathrm{P}-\mathrm{P}}=410 \mathrm{~Hz}\right)$ completely isomerised to the cis configuration over 20 hours, leaving a virtually pure solution of cis-23. This complex was isolated from toluene as yellow crystals. HR-ESIMS was consistent with an $[\mathrm{M}+\mathrm{H}]^{+}$molecular ion accounting for $\left[\mathrm{C}_{45} \mathrm{H}_{41} \mathrm{O}_{2} \mathrm{P}_{2} \mathrm{Pt}\right]^{+}$. Carbon and hydrogen elemental analysis provided further proof of the molecular formula.

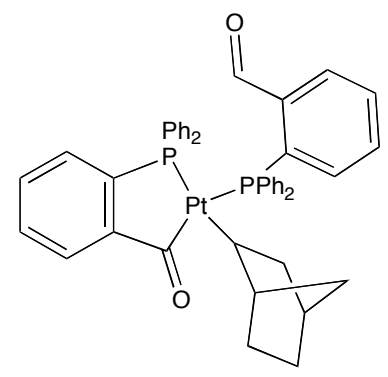

cis-23 
Complex 23 was air-stable as a solid at room temperature for at least two days, for example, it could be safely stored in the air while it awaited elemental analysis. However, it was quite unstable in solution at room temperature. NMR experiments that required long acquisition times for high-resolution spectra such as ${ }^{13} \mathrm{C}$ NMR and the two-dimensional analyses, HSQC and HMBC, were therefore performed at low temperature $\left(-20{ }^{\circ} \mathrm{C}\right)$ on an NMR spectrometer operating at $600 \mathrm{MHz}$ for ${ }^{1} \mathrm{H}$ and $150 \mathrm{MHz}$ for ${ }^{13} \mathrm{C}$ NMR to allow for rapid accumulation of data. The majority of proton resonances overlapped, although the combined integration of the peaks due to the norbornyl ligand accounted for the eleven protons of the Pt- $\mathrm{C}_{7} \mathrm{H}_{11}$ unit. A broad multiplet at $2.85 \mathrm{ppm}$ with ${ }^{3} \mathrm{~J}_{\mathrm{Pt}-\mathrm{H}}$ of $103 \mathrm{~Hz}$ was determined to be the proton at the 1-position of the norbornyl ligand. Many of the ${ }^{1} \mathrm{H}$ NMR resonances were broad and highly coupled, and tended to overlap between 2.12 and $-0.05 \mathrm{ppm}$.

The two-dimensional NMR sequences, COSY and HMBC, were useful in the characterisation of the 2-norbornyl ligand. However, precise assignment using these pulse sequences was elusive due to extensive long-range four- and five-bond coupling. Longerrange coupling is often observed in rigid, strained bicyclic ring systems where there are multiple coupling pathways. ${ }^{65}$ The bridged, bicyclic structure of the 2-norbornyl ligand allowed for extensive four-bond coupling between hydrogen atoms. ${ }^{65}$ Coupled ${ }^{1} \mathrm{H}-{ }^{13} \mathrm{C}$ HSQC spectra were found to be much more helpful in the characterisation of the structure, as the carbon with the largest $J_{\mathrm{Pt}-\mathrm{C}}$ value, a doublet of doublets at $39.5 \mathrm{ppm}$ with ${ }^{1} J_{\mathrm{Pt}-\mathrm{C}}=751 \mathrm{~Hz}$, was taken to be that directly coordinated to platinum. This provided a reference point from which ${ }^{1} \mathrm{H}$ and ${ }^{13} \mathrm{C}$ NMR resonances could be assigned to the rest of the ligand.

Aside from the 2-norbornyl intermediate, which was fully characterised, a very small signal in the ${ }^{1} \mathrm{H}$ NMR was observed at -0.60 ppm only in the first fifteen minutes of reaction. This complex could be the platinum-hydride resonance of the intermediate that would ultimately form the 2-norbornyl complex, 23. The signal appeared as a doublet of doublets, with ${ }^{1} J_{\mathrm{Pt}-\mathrm{H}}$ of $780 \mathrm{~Hz}$ and ${ }^{2} J_{\mathrm{P}-\mathrm{H}}$ of 173.1 and $31.9 \mathrm{~Hz}$, indicating its coordination to platinum along with two phosphines in a trans and cis relationship. 
3.1.2.2 Norbornyl ligands in late transition metal complexes

Hydrogenation of norbornadiene ligands has been reported to occur from the $\mathrm{C}-\mathrm{H}$ activation of $\mathbf{1}$ on rhodium. ${ }^{13,65-68} \mathrm{El}$ Mail and co-workers reported that the addition of $\mathbf{1}$ to [RhCl(bipy)(nbd)] $(\mathrm{nbd}=$ norbornadiene $=$ bicyclo[2.2.1] hepta-2,5-diene, bipy $=2,2$-bipyridine) resulted in the $\mathrm{C}-\mathrm{H}$ activation of 1 and migration of the resulting metal hydride to the norbornadiene ligand to form a 2-norbornenyl ligand, 25 (Scheme 18). ${ }^{67}$ The mechanism of hydrogen migration was observed to be dependent on the solvent. In benzene, the coordination and chelation of 1 to $[\mathrm{RhCl}($ bipy)(nbd)] resulted in hydrogen transfer to the norbornadiene ligand to form complex 24 containing a nortricycle group. The same reaction performed in methanol, however, formed the rhodium 2-norbornenyl complex, 25 (Scheme 18). ${ }^{67}$ The different products were rationalised through the proposition of different mechanistic pathways. In the polar methanol solution, the dissociation of the chloride ligand formed the cationic complex, $[\mathrm{Rh}($ bipy $)(\mathrm{nbd})] \mathrm{Cl}$, allowing for the chelation and oxidative addition of 1 via the opening of the norbornadiene chelate to afford a monoolefin complex, 26. Subsequent hydrogen migration to the norbornadiene and coordination of the chloride anion produced the neutral complex, 25. The reaction performed in non-polar benzene disfavoured a cationic intermediate, and instead it was proposed that the bidentate bipy ligand dissociated the rhodium centre. This produced a rhodium hydride intermediate that contained a chelated norbornadiene ligand (27), positioned to allow for hydrogen migration as well as a double bond shift to form the nortricycle complex, 24.

[RhCl(bipy)(nbd)]

$1 \downarrow \mathrm{C}_{6} \mathrm{H}_{6}$

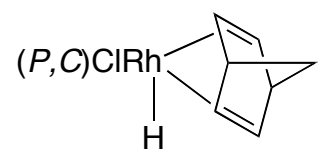

$\stackrel{\text { bipy }}{\longrightarrow}$

27

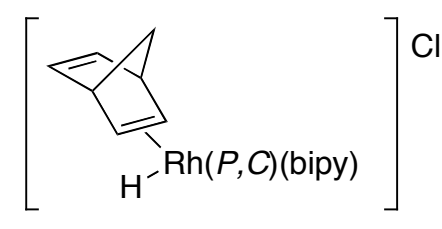

26

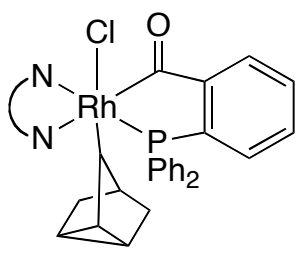

24

Scheme 18 
The above-mentioned work was useful in the elucidation of the mechanism of the formation of the platinum-2-norbornyl complex, 23. However, as the coordinated olefin in this case is norbornene instead of norbornadiene, a double bond shift was not accessible. It is therefore probable that the small signal at $-0.60 \mathrm{ppm}$ observed in the early stages of the reaction between 1 and $\left[\mathrm{Pt}(\mathrm{nb})_{3}\right]$ relates to an unstable, 18-electron acylhydride platinum complex formed upon chelation/C-H activation of one phosphinocarbonyl ligand. The doublet of doublets coupling pattern of the hydride signal is indicative of the coordination of two phosphines, one of which must be chelated to account for the hydride, and one norbornene ligand must be coordinated as an $\eta^{2}$-olefin in order to enable hydrogen migration. Therefore, it is probable that the hydride signal accounts for the complex, $[\mathrm{PtH}(P, C) P(\mathrm{nb})],(P$ is the monodentate ligand of 1 and $P, C$ is the chelated ligand of 1) and represents a low and dynamic population of the intermediate that quickly reacts to form the more stable complex, 23.

\subsubsection{Formation of the bimetallated complex}

In solution at room temperature, the monodentate phosphinoaldehyde ligand of complex 23 underwent $\mathrm{C}-\mathrm{H}$ activation of the aldehyde to form the cis and trans isomers of the bimetallated complex, 21 (Scheme 19). No reaction intermediates were observed in the second chelation reaction as it was a slow process relative to the first chelation, and therefore there was never a large enough concentration of any reaction intermediate to observe with NMR spectroscopy. However, no norbornane was observed to be produced, only norbornene. In addition, a sharp peak at $4.47 \mathrm{ppm}\left(\right.$ in $\mathrm{C}_{6} \mathrm{D}_{6}$ ) in the ${ }^{1} \mathrm{H}$ NMR spectrum indicated the presence of molecular hydrogen. This suggested that the 2-norbornyl ligand was eliminated via $\beta$-hydrogen elimination along with molecular hydrogen following the $\mathrm{C}-\mathrm{H}$ activation of the second pendant aldehyde group. The final product, cis-21 and trans-21, crystallised slowly from toluene or benzene as red and green crystals, respectively. 


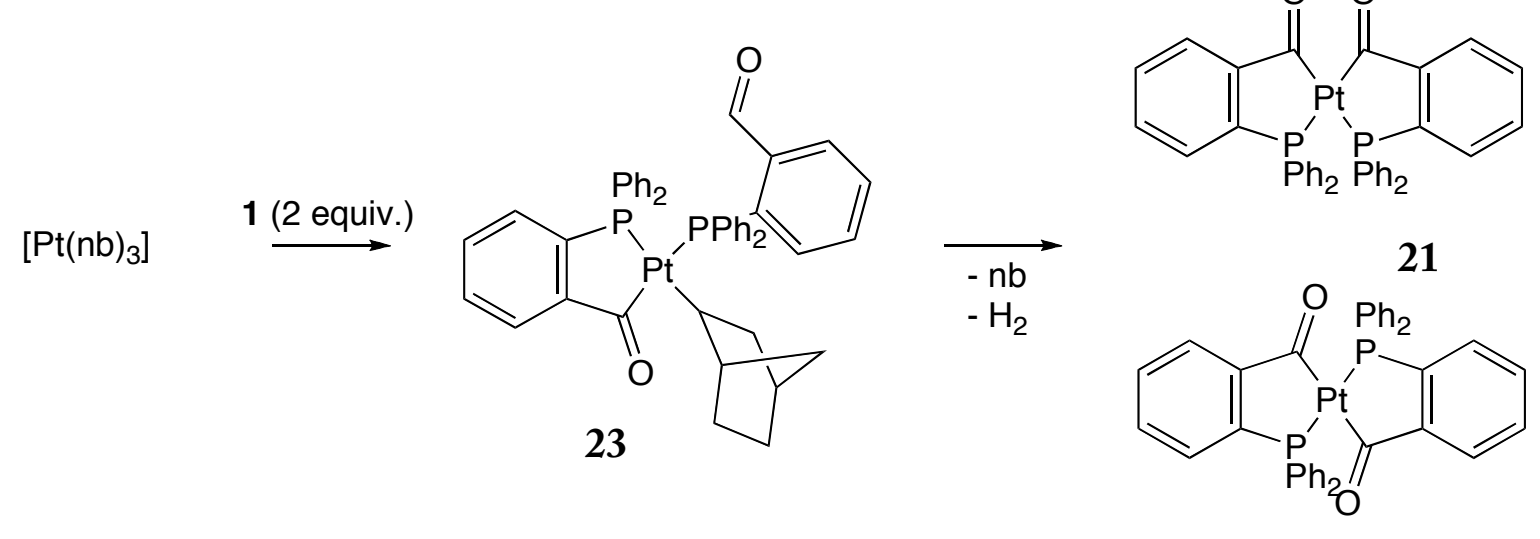

Scheme 19: The reactivity of 1 with tris(norbornene)platinum.

\subsubsection{X-ray crystal structure of cis-21}

The preparation of cis-21 from the reaction of 1 with $\left[\mathrm{Pt}(\mathrm{nb})_{3}\right]$ produced red/orange crystals occupying the $C 2 / c$ space group and the crystals were suitable for X-ray crystallographic analysis. The asymmetric unit included a benzene solvate molecule and the platinum metal centre lay on the $C_{2}$ axis (Figure 5). The bis-platinacycle core and aryl backbones of the complex were substantially coplanar. The occupancy of the carbonyl oxygens across O1a and O1b was $47 \%$ and 53\%, indicating that the diketone moiety existed in two geometric configurations wherein one carbonyl oxygen lay relatively close to the plane and the other was displaced from the plane by $0.64 \AA$. The out-of-plane configuration could be due to electrostatic repulsion caused by the relatively short in-plane $\mathrm{O} \cdots \mathrm{O}$ separation of $2.61 \AA$ compared to the combined van der Waal radii of $3.04 \AA$ (the out-of-plane O $\cdots$ O distance is $2.82 \AA$ A). Selected bond lengths and bond angles are contained in Table 2. 


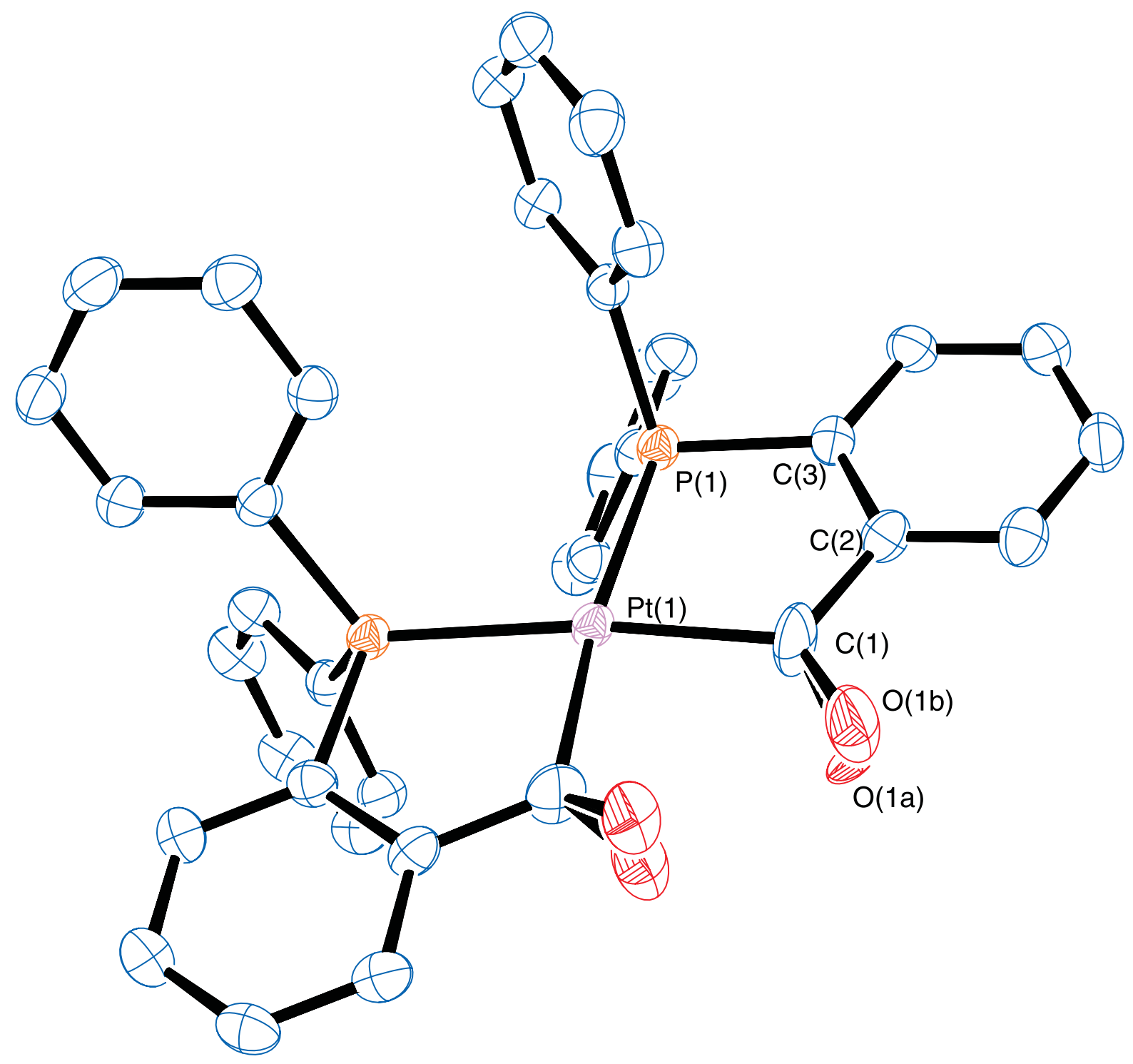

Figure 5: ORTEP-3 diagram of $c i s-[21] \cdot \mathrm{C}_{6} \mathrm{H}_{6}$ showing $50 \%$ probability thermal ellipsoids. $\mathrm{H}$-atoms and the benzene solvate molecule have been omitted for clarity. 
Table 2: Selected bond distances ( $(\AA)$ and bond angles $\left(^{\circ}\right)$ for complex 21.

\begin{tabular}{lrlr}
\hline \multicolumn{5}{c}{ Distance / } & Angle $^{\circ}$ \\
\hline $\mathrm{Pt}(1)-\mathrm{P}(1)$ & $2.3096(12)$ & $\mathrm{C}(1)-\mathrm{Pt}(1)-\mathrm{C}(1)$ & $89.3(3)$ \\
$\mathrm{Pt}(1)-\mathrm{C}(1)$ & $2.073(5)$ & $\mathrm{C}(1)-\mathrm{Pt}(1)-\mathrm{P}(1)$ & $83.16(17)$ \\
$\mathrm{P}(1)-\mathrm{C}(3)$ & $1.820(5)$ & $\mathrm{P}(1)-\mathrm{Pt}(1)-\mathrm{P}(1)$ & $104.45(6)$ \\
$\mathrm{C}(1)-\mathrm{C}(2)$ & $1.495(8)$ & $\mathrm{C}(1)-\mathrm{Pt}(1)-\mathrm{C}(1)$ & $89.3(3)$ \\
$\mathrm{C}(1)-\mathrm{O}(1 \mathrm{~A})$ & $1.333(15)$ & $\mathrm{C}(1)-\mathrm{Pt}(1)-\mathrm{P}(1)$ & $83.16(17)$ \\
$\mathrm{C}(1)-\mathrm{O}(1 \mathrm{~B})$ & $1.209(17)$ & $\mathrm{P}(1)-\mathrm{Pt}(1)-\mathrm{P}(1)$ & $104.45(6)$ \\
$\mathrm{O}(1 \mathrm{~B}) \cdots \mathrm{O}(1 \mathrm{~B})$ & 2.61 & & \\
\hline
\end{tabular}

Table 3: Crystallographic data for platinum complex cis-21 ${ }^{\mathrm{C}_{6}} \mathrm{H}_{6}$

\begin{tabular}{|c|c|}
\hline Empirical formula & $\mathrm{C}_{23} \mathrm{H}_{18} \mathrm{O}_{2} \mathrm{PtP}$ \\
\hline Formula weight & 851.74 \\
\hline Temperature / K & 120 \\
\hline Crystal system & Monoclinic \\
\hline Space group & $C 2 / c$ \\
\hline$a / \AA$ & $13.6485(11)$ \\
\hline$b / \AA$ & $18.4002(13)$ \\
\hline$c / \AA$ & $14.5882(11)$ \\
\hline$\alpha /^{\circ}$ & 90.00 \\
\hline$\beta /^{\circ}$ & $112.622(4)$ \\
\hline$\gamma /{ }^{\circ}$ & 90 \\
\hline Volume / $\AA^{3}$ & $3381.7(4)$ \\
\hline Z & 4 \\
\hline$d / \mathrm{g} \mathrm{cm}^{-3}$ & 1.673 \\
\hline$\mu / \mathrm{mm}^{-1}$ & 4.283 \\
\hline $\mathrm{F}(000)$ & 1688 \\
\hline$\theta$ range $/^{\circ}$ & $1.96 \rightarrow 34.37^{\circ}$ \\
\hline Index range $b$ & $-20 \rightarrow 20$ \\
\hline Index range $k$ & $-26 \rightarrow 28$ \\
\hline Index range $l$ & $-20 \rightarrow 22$ \\
\hline Reflections collected & 44399 \\
\hline Independent reflections & 6456 \\
\hline Data/restraints/parameters & $6456 / 0 / 233$ \\
\hline Goodness of fit & 1.004 \\
\hline$R_{1}[\mathrm{I}>2 \sigma(\mathrm{I})]$ & 0.045 \\
\hline$w R_{2}[\mathrm{I}>2 \sigma(\mathrm{I})]$ & 0.12 \\
\hline$R_{1}$ [all data] & 0.074 \\
\hline$w R_{2}$ [all data] & 0.14 \\
\hline
\end{tabular}




\subsection{4 $\left[\mathrm{Pt}\left(P, C-2-\mathrm{PPh}_{2} \mathrm{C}_{6} \mathrm{H}_{4} \mathrm{CO}\right)_{2}\right]$, a platina- $\beta$-diketone}

The configuration of the carbonyl groups about the platinum core of 21 is reminiscent of $\beta$-diketones well known to organic chemists. Accordingly, 21 is a part of the metalla- $\beta$-diketone class of organometallic compounds (Figure 6). These complexes contain two directly bonded acyl groups in a cis configuration, wherein the intervening methyne is substituted with an transition metal. ${ }^{69}$ The first complex of this class was reported by Lukehart in 1975 (28), ${ }^{70}$ and from there the chemistry was explored in detail over a decade. ${ }^{69}$ The reactivity of metalla- $\beta$-diketones is based on the protonation of the diketone group, and is conceptually similar to the reactive enol tautomer of organic $\beta$-diketonates. This enables the complexes to undergo condensation reactions, for example, with primary amines to form Schiff bases. In addition, the carbonyl oxygen atoms have the potential to coordinate to an electrophilic centre and behave as a ligand, potentially in the same way as the ubiquitous acetylacetonate anion.<smiles>CC1=C(C)C(=[N+]([O-])[O-])OPO1</smiles>

28

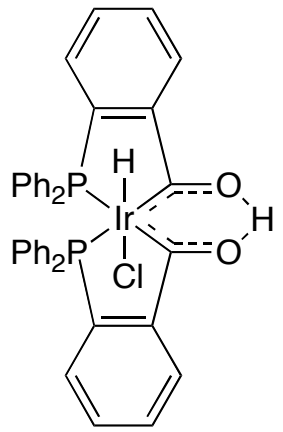

29

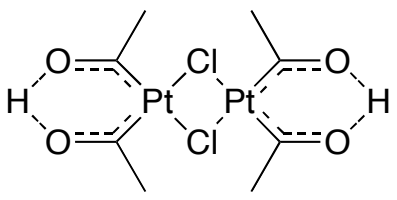

30

Figure 6: Metalla- $\beta$-diketonate complexes produced by (from left to right) Lukehart, Garralda, and Steinborn.

The formation of $\mathbf{2 1}$ was recognised as an important addition to the class of metalla- $\beta$-diketones and their derivatives, especially in light of the extensive work presently carried out by Garralda on iridium analogues (such as complex 29). ${ }^{7}$ Therefore, research was undertaken to explore the reactivity of 21 compared to that of other, previously studied metalla- $\beta$-diketones.

\subsubsection{Protonation of diketone 21}

The addition of an acid to cis-21 resulted in the immediate protonation of the diketone to form the cationic complex 31, wherein the proton was coordinated to the two carbonyl 
oxygen atoms via hydrogen bonding (Scheme 20). Reaction of 21 with the acids, $\mathrm{CH}_{2}\left(\mathrm{SO}_{2} \mathrm{CF}_{3}\right)_{2}, \mathrm{CHPh}\left(\mathrm{SO}_{2} \mathrm{CF}_{3}\right)_{2},{ }^{71}$ or $\mathrm{HBF}_{4}$ in dichloromethane all resulted in an immediate colour change to yellow was observed along with the complete dissolution of solid starting material. The product was formed quantitatively and identified as the cationic, protonated adduct, 31 . Addition of these acids to trans-21 did not result in any reaction.<smiles>O=C1c2ccccc2PP1(=P)P</smiles>

21

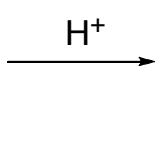

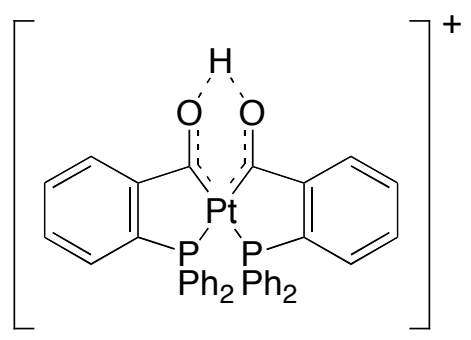

31

The success of the protonation reaction of cis-21 could be easily discerned both by the physical changes exhibited and the presence of distinctive chemical shifts in the ${ }^{1} \mathrm{H}$ and ${ }^{13} \mathrm{C}$ NMR spectra. A ${ }^{1} \mathrm{H}$ NMR signal at $22.05 \mathrm{ppm}$ with ${ }^{3} \mathrm{Pt}_{\mathrm{t}-\mathrm{H}}$ of $104 \mathrm{~Hz}$ was diagnostic of the presence of a proton bonded to the diketone through strong hydrogen bonds (Figure 7).69,72 The enol hydroxylic proton of the organic $\beta$-diketone, acetylacetone (2,4-pentadione), contains a true $\mathrm{O}-\mathrm{H}$ covalent bond and resonated at approximately $16 \mathrm{ppm} .{ }^{73}$ Comparison of the two $\mathrm{OH}$ resonances therefore suggested a decreased covalent character for 31 relative to organic $\beta$-diketones and instead a bond more akin to a hydrogen bond (see Section 3.1.4.6).

The ${ }^{31} \mathrm{P}$ NMR chemical shift changed from 47.8 to $45.2 \mathrm{ppm}$, and the ${ }^{1} \mathrm{Jt}_{\mathrm{Pt}-\mathrm{P}}$ coupling increased from 1843 to $2114 \mathrm{~Hz}$. The ${ }^{13} \mathrm{C}$ NMR chemical shift of the diketonate carbonyl resonated at $250.5 \mathrm{ppm}$ and had a ${ }^{1} \mathrm{Jt}_{\mathrm{Pt}-\mathrm{C}}$ coupling constant of $991 \mathrm{~Hz}$. The dramatic downfield chemical shift of the acyl carbon atom was indicative of the partial delocalisation of charge about the $\mathrm{Pt}-\mathrm{C}=\mathrm{O} \cdots \mathrm{H} \cdots \mathrm{O}=\mathrm{C}$ ring, and a $\mathrm{Pt}-\mathrm{C}$ bond with a degree of carbene character. $^{74,75}$ 

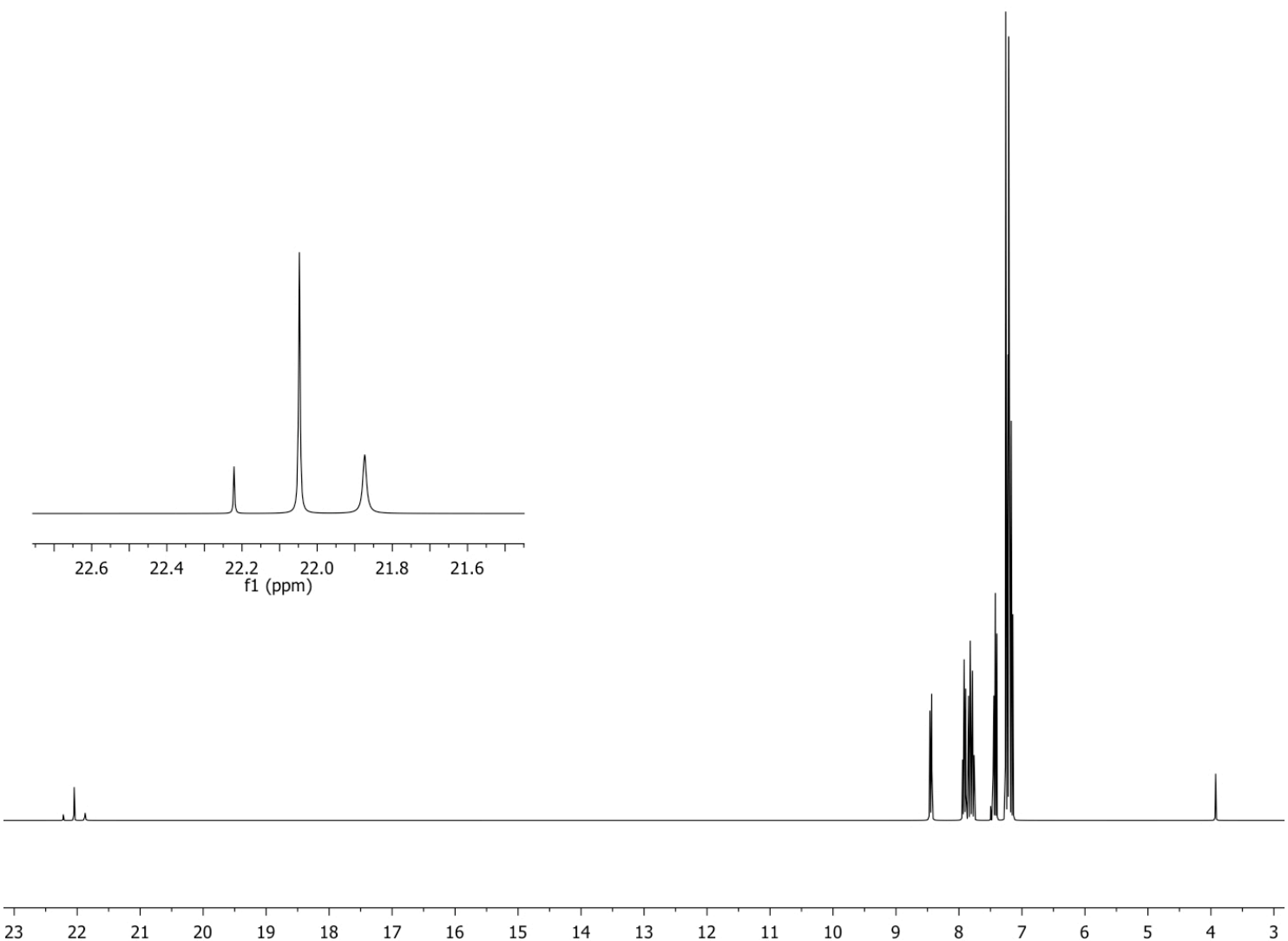

Figure 7: ${ }^{1} \mathrm{H}$ NMR spectrum at $500 \mathrm{MHz}$ of complex 31 . The proton resonance at $22.05 \mathrm{ppm}$ indicates a hydrogen bonded $\mathrm{O} \cdots \mathrm{H} \cdots \mathrm{O}$.

In contrast to 21 , which has a very low solubility in all solvents, 31 was quite soluble in chlorinated solvents and acetone. Complex 31 could be crystallised via a number of crystallisation methods, including slow evaporation of solvent or inwards diffusion of diethyl ether or pentane into a dichloromethane solution. The complex formed yellow crystals that varied in shape depending on the anion present. The $\mathrm{CH}\left(\mathrm{SO}_{2} \mathrm{CF}_{3}\right)_{2}^{-}$and $\mathrm{CPh}\left(\mathrm{SO}_{2} \mathrm{CF}_{3}\right)_{2}^{-}$ salts of 31 formed needle-like crystals, while the $\mathrm{BF}_{4}^{-}$salt yielded prismatic crystals. A crystalline sample of $[31] \mathrm{BF}_{4}$ was submitted for single-crystal X-ray diffraction analysis at The Chemical Crystallography Laboratory at Durham University, United Kingdom (Figure 8). Data acquisition and structural refinement of 31 were performed by Dr Horst Puschmann of Durham University. The computer program, Olex2 was used for structure solution and refinement; ${ }^{76}$ the structure was solved with olex2.solve ${ }^{77}$ using Charge Flipping, and refined with olex2.refine ${ }^{78}$ using Gauss-Newton minimisation. The $\mathrm{BF}_{4}{ }^{-}$counter ion is disordered over two positions in the ratio 85:15 and was refined with heavy restraints to keep the geometry chemically sensible. 


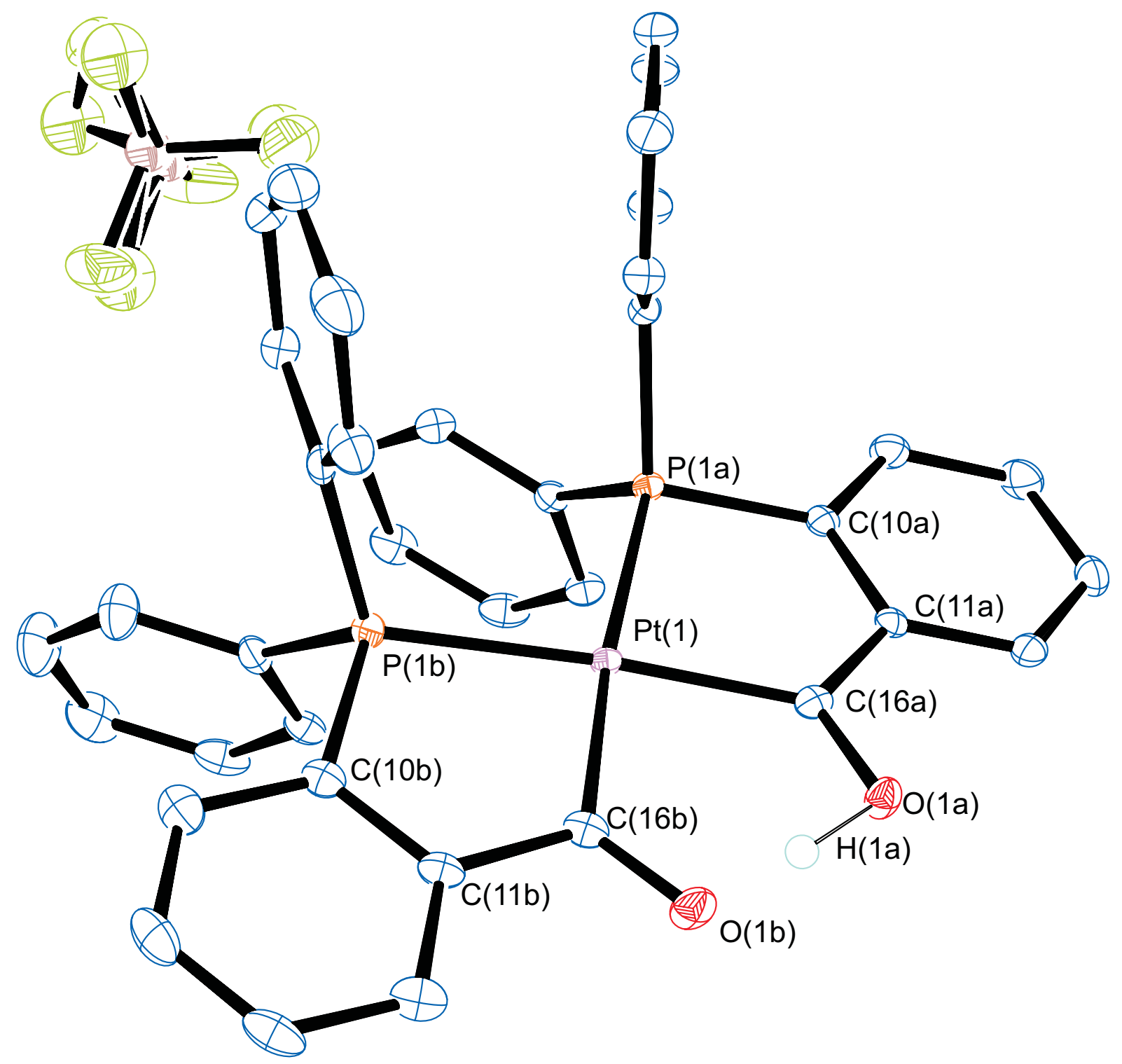

Figure 8: ORTEP-3 diagram of platinum complex [31] $\mathrm{BF}_{4} \cdot \mathrm{CH}_{2} \mathrm{Cl}_{2}$. $\mathrm{H}$ atoms other than $\mathrm{H}(1 \mathrm{a})$ and the $\mathrm{CH}_{2} \mathrm{Cl}_{2}$ solvent of crystallisation have been omitted for clarity. 


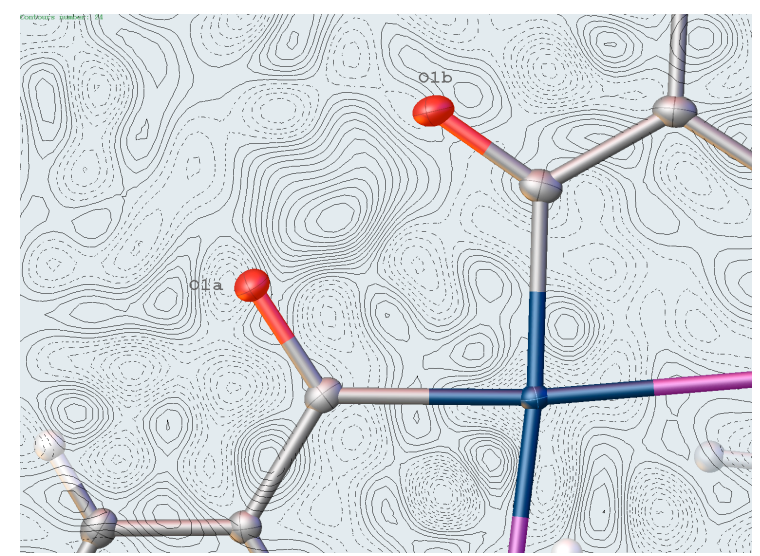

Figure 9: Residual electron density map of $[31] \mathrm{BF}_{4}$ viewed along the plane normal: $0.748,-0.663,-0.030$. At the position of the $\mathrm{O} \cdots \mathrm{H} \cdots \mathrm{O}$ proton the electron density is approximately one electron per $\AA^{3}$.

Table 4: Crystallographic data of protonated platinum complex, [31] $\mathrm{BF}_{4} \cdot \mathrm{CH}_{2} \mathrm{Cl}_{2}$

\begin{tabular}{lr}
\hline Empirical formula & $\mathrm{C}_{39} \mathrm{H}_{31} \mathrm{~B}_{2} \mathrm{~F}_{8} \mathrm{P}_{2} \mathrm{PtCl}_{2} \mathrm{O}_{2}$ \\
\hline Formula weight & 946.43 \\
Temperature / K & 120 \\
Crystal system & Triclinic \\
Space group & $P 1$ \\
$a / \AA$ & $9.3641(5)$ \\
$b / \AA$ & $13.1706(5)$ \\
$c / \AA$ & $15.0365(6)$ \\
$\alpha /{ }^{\circ}$ & $94.411(3)$ \\
$\beta /{ }^{\circ}$ & $91.574(4)$ \\
$\gamma /{ }^{\circ}$ & $106.220(4)$ \\
Volume / ${ }^{3}$ & $1773.05(14)$ \\
$Z$ & 2.7726 \\
$d /$ g cm & \\
$\mu /$ mm & -1
\end{tabular}


Comparison of the crystal structures of 21 and 31 gave an insight into the effect of protonation. Like the neutral complex, 21, complex 31 contains a planar bicyclic core. Protonation of 21 causes a shortening of the $\mathrm{Pt}-\mathrm{C}$ bond from 2.073(5) to 2.029(3) $\AA$ with a concomitant lengthening of the C-O bond from 1.209(17) to 1.263(3) A, illustrative of the conversion of the formally separate ketone groups on 21 to a system that contains a degree of hydroxycarbene character. ${ }^{7}$ The remarkable shortening of the $\mathrm{O} \cdots \mathrm{O}$ separation from $2.64 \AA$ in 21 to $2.419 \AA$ in 31 is also a likely result of both electron delocalisation and hydrogen bonding of the intervening proton with the carbonyl oxygen atoms. The position of the hydrogen-bonded proton was assigned based on the residual energy density present between the two carbonyl oxygen atoms (Figure 9). Table 5 contains selected bond lengths and angles of complex 31.

Table 5: Selected bond distances $(\AA ̊)$ and bond angles $\left({ }^{\circ}\right)$ for $[31] \mathrm{BF}_{4} \cdot \mathrm{CH}_{2} \mathrm{Cl}_{2}$.

\begin{tabular}{lrlr}
\hline & Distance $/ \AA$ & Angle $^{\circ}$ \\
\hline Pt-C(16a) & $2.029(3)$ & $\mathrm{P}(1 \mathrm{a})-\mathrm{Pt}-\mathrm{C}(16 \mathrm{a})$ & 83.85 \\
$\mathrm{Pt}-\mathrm{P}(1 \mathrm{a})$ & $2.3155(7)$ & $\mathrm{P}(1 \mathrm{a})-\mathrm{Pt}-\mathrm{P}(1 \mathrm{~b})$ & 101.47 \\
$\mathrm{C}(16 \mathrm{a})-\mathrm{O}(1 \mathrm{a})$ & $1.263(3)$ & $\mathrm{C}(16 \mathrm{a})-\mathrm{Pt}-\mathrm{C}(16 \mathrm{~b})$ & 91.07 \\
$\mathrm{O}(1 \mathrm{a}) \cdots \mathrm{O}(1 \mathrm{~b})$ & 2.419 & $\mathrm{O}(1 \mathrm{~b})-\mathrm{C}(16 \mathrm{~b})-\mathrm{Pt}-\mathrm{C}(16 \mathrm{a})$ & 3.92 \\
$\mathrm{O}(1 \mathrm{a})-\mathrm{H}(1 \mathrm{a})$ & $1.15(4)$ & & \\
\hline
\end{tabular}

\subsubsection{Lithiation of diketone 21}

Complex 21 also reacted with lithium ions to form the lithiated adduct, 32, a similar complex to 31 wherein the diketone group is coordinated to a lithium ion. The complex was formed from the reaction of a suspension of 21 with one equivalent of $\mathrm{LiCH}\left(\mathrm{SO}_{2} \mathrm{CF}_{3}\right)_{2}$, which was prepared in situ from the stoichiometric reaction of lithium carbonate with $\mathrm{CH}_{2}\left(\mathrm{SO}_{2} \mathrm{CF}_{3}\right)_{2}$. Complex 32 was purified by crystallisation via the diffusion of pentane into dichloromethane solution and isolated as orange crystals.

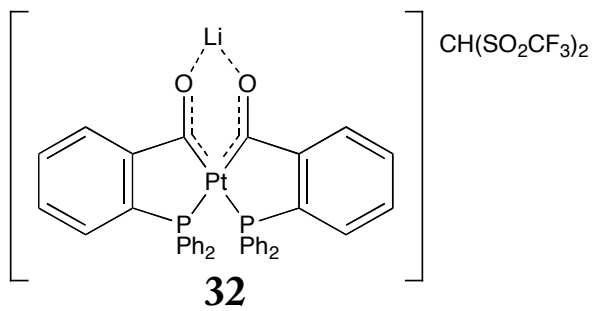


Like complex 31, complex 32 is soluble in chlorinated solvents and acetone, thereby enabling ${ }^{13} \mathrm{C}$ NMR analysis. The NMR spectra of 32 showed many similarities to that of the protonated complex, 21, notably the upfield shift of the acyl carbon to $244.1 \mathrm{ppm}$ in the ${ }^{13} \mathrm{C}$ NMR spectrum. The lithium cation was probably stabilised through an interaction with the counter ion, $\left[\mathrm{CH}\left(\mathrm{SO}_{2} \mathrm{CF}_{3}\right)_{2}\right]^{-}$, which was evident from the differences in the ${ }^{1} \mathrm{H}$ and ${ }^{13} \mathrm{C}$ NMR chemical shifts of the counter ion. In $\mathrm{CDCl}_{3}$, the proton of the counter ion in 32 had a ${ }^{1} \mathrm{H}$ chemical shift of $4.07 \mathrm{ppm}$, whereas for the non-coordinated counter ion the ${ }^{1} \mathrm{H}$ chemical shift was found to be $3.93 \mathrm{ppm}$.

\subsubsection{Lukehart metalla- $\beta$-diketones}

Lukehart recognised the potential for complexes containing two mutually cis acyl moieties to act as bidentate ligands in the same way as organic $\beta$-diketone compounds. An extensive investigation into the reactivity of a family of 18-electron complexes with the general formula $\left[(\mathrm{CO})_{\mathrm{x}} \mathrm{M}(\mathrm{COR})\left(\mathrm{COR}^{\prime}\right)\right]^{-}$was carried out. ${ }^{69}$ The synthesis of these compounds involved the alkylation (usually methylation using methyllithium) of a carbonyl ligand on $\left[(\mathrm{CO})_{\mathrm{x}+1} \mathrm{M}(\mathrm{COR})\right]^{-}$to form an anionic diketonate complex (e.g. Scheme 21$) .^{70}$

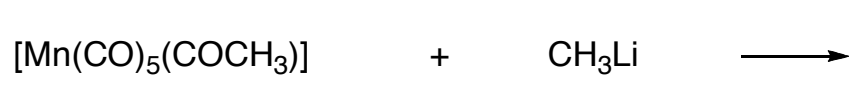

Scheme 21

From their origin, Lukehart enlarged the family of metalla- $\beta$-diketones/ates: complexes of this type have been synthesised for rhenium and iron, all almost exclusively from within the Lukehart research group. ${ }^{69}$ The coordinating potential of the diketone moiety has also been extensively investigated, and cyclic $\mathrm{M}-\mathrm{C}=\mathrm{O}-\mathrm{X}-\mathrm{O}=\mathrm{C}$ fragments have been produced where $\mathrm{X}$ is a Lewis acid such as $\mathrm{H}^{+}, \mathrm{Li}^{+}, \mathrm{Al}^{3+}$, trivalent boron compounds, and a plethora of transition metals. $^{70,79-81}$

\subsubsection{Garralda irida- $\beta$-diketones}

In 2003, Garralda reported the first synthesis of an irida- $\beta$-diketone complex, $\left[\mathrm{IrClH}\left\{\left(P, C-2-\mathrm{PPh}_{2} \mathrm{C}_{6} \mathrm{H}_{4} \mathrm{CO}\right)_{2} \mathrm{H}\right\}\right](29)$, consisting of an $\mathrm{Ir}-\mathrm{C}=\mathrm{O} \cdots \mathrm{H} \cdots \mathrm{O}=\mathrm{C}$ iridacycle 
formed from the $\mathrm{C}-\mathrm{H}$ activation of two units of $1 .^{7}$ The delocalisation of electronic charge about the diketonate ring is characteristic of metalla- $\beta$-diketones and distinguishable by the low-field ${ }^{13} \mathrm{C}$ NMR chemical shift of the carbonyl group for 29 (258.3 ppm). 8-Quinoline-carbaldehyde has been used in conjunction with 1 as a chelating $N, C(O)$ aldehyde to form a $\mathrm{Ir}-\mathrm{C}=\mathrm{O}-\mathrm{H}-\mathrm{O}=\mathrm{C}$ iridacycle (33) similar to that in 29 (Scheme 22). ${ }^{11}$ Complex 29 has almost identical structural parameters to the platina- $\beta$-diketone, 31 ; the $\mathrm{M}-\mathrm{C}$ bond length, $\mathrm{C}-\mathrm{O}$ bond length, and $\mathrm{O} \cdots \mathrm{O}$ separation are all within $0.02 \AA$ of each other (Table 6).
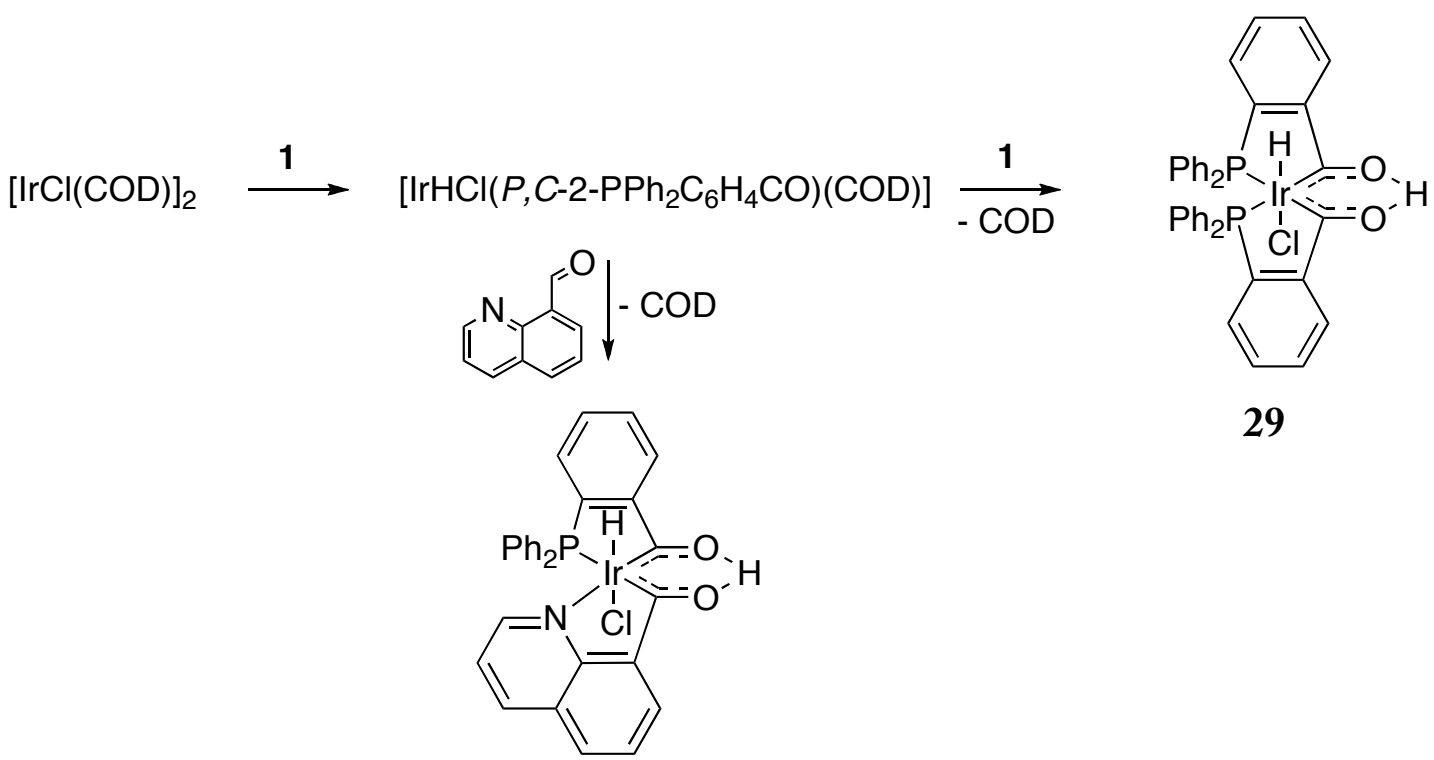

29

33

Scheme 22: Preparation of irida- $\beta$-diketone complexes 29 and 33 via the $\mathrm{C}-\mathrm{H}$ activation of tethered aldehydes, 8-quinoline-carbaldehyde and 1.

\subsubsection{Steinborn platina- $\beta$-diketones}

Platina- $\beta$-diketones have previously been prepared by Steinborn in an altogether different way compared to other reported methods. The reaction of hexachloroplatinic acid with $n$-butanol and bis(trimethylsilyl)acetylene produced the air-sensitive dimer, $\left[\mathrm{Pt}_{2}(\mu-\mathrm{Cl})_{2}\left\{(\mathrm{COMe})_{2} \mathrm{H}\right\}_{2}\right], 30$, (Scheme 23). ${ }^{82}$ The diketonate structure of 30 was more reminiscent of Lukehart's metalla- $\beta$-diketones like 28 rather than that of 31 or Garralda's irida- $\beta$-diketone, 29 . In both 29 and 31 the diketone moiety was stabilised by the structural rigidity and entropic favourability of a chelate ring. 
$\left[\mathrm{H}_{2} \mathrm{PtCl}_{6}\right] \cdot 6 \mathrm{H}_{2} \mathrm{O}+\mathrm{TMS}=\mathrm{TMS} \stackrel{\mathrm{BuOH}}{\longrightarrow}$

30

Scheme 23: Preparation of a Steinborn platina- $\beta$-diketone.

When the diphosphine ligand, 1,2-bis(diphenylphosphino)ethane was added to a solution of 30, the monomeric diphosphine platina- $\beta$-diketonate complex (34) was produced. This complex was unstable at room temperature, and protonation of the diketone moiety has not been reported (Scheme 24). ${ }^{83}$

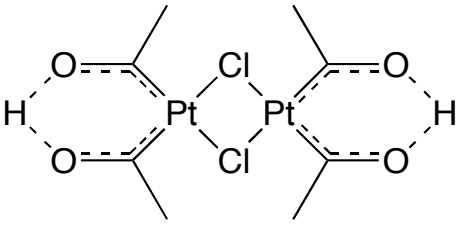

30
1) dppe (2 equiv.)

2) $\mathrm{NaOMe}$<smiles>CC(=O)P(C(C)=O)P1CCPC1</smiles>

34

Scheme 24

The $\mu$-dichloro- $\mu$-bis(platina- $\beta$-diketonate) complex, 30 , has similar structural parameters to 31, but the ${ }^{13} \mathrm{C}$ and ${ }^{1} \mathrm{H}$ NMR illustrate quite different electronic characteristics between the two complexes (Table 6). The carbonyl carbon of 30 resonated at $228 \mathrm{ppm}$ with an anomalously large ${ }^{1} \mathrm{Jt}_{\mathrm{Pt}-\mathrm{C}}$ of $1457 \mathrm{~Hz}$. This chemical shift is $22 \mathrm{ppm}$ further upfield than that of platinacycle 31 or iridacycle 29 , and the ${ }^{1} \mathrm{Jt}_{\mathrm{Pt}-\mathrm{C}}$ is 300 to $500 \mathrm{~Hz}$ larger than that measured in previously reported platinum-carbonyl or even some platinum-carbene complexes. ${ }^{75,82}$ The $\mathrm{OHO}$ proton in 30 also appeared as a broad singlet at $16 \mathrm{ppm}$, roughly 6 ppm upfield from the resonances of the OHO protons in 31 and 29. Indeed, Steinborn's platina- $\beta$-diketones exhibit spectroscopic characteristics that are much more similar to the organic $\beta$-diketones. ${ }^{73}$ 
Table 6: Comparison of NMR and structural parameters of selected metalla- $\beta$-diketones. NMR chemical shifts measured in ppm, coupling constants measured in $\mathrm{Hz}$.

\begin{tabular}{lllll}
\hline & \multicolumn{1}{c}{31} & \multicolumn{1}{c}{$29^{7}$} & \multicolumn{1}{c}{$30^{82}$} & \multicolumn{1}{c}{ cis-21 } \\
\hline$\delta_{\mathrm{C}} \mathrm{CO}\left({ }^{1} J_{\mathrm{Pt}-\mathrm{C}}\right)$ & $250.5(991.2 \mathrm{~Hz})$ & 258.3 & $228.1(1457 \mathrm{~Hz})$ & $*$ \\
$\delta_{\mathrm{H}} \mathrm{O}-\mathrm{H}-\mathrm{O}\left({ }^{3} J_{\mathrm{Pt}-\mathrm{H}}\right)$ & $22.05(104.2 \mathrm{~Hz})$ & 22.61 & $c a .16(\mathrm{br} \mathrm{s})$ & - \\
$\delta_{\mathrm{P}}\left({ }^{1} \mathrm{Pt}_{\mathrm{Pt}-\mathrm{P}}\right)$ & $45.8(2056 \mathrm{~Hz})$ & 23.7 & - & $47.8(1843 \mathrm{~Hz})$ \\
$v(\mathrm{C}=\mathrm{O}) / \mathrm{cm}^{-1}$ & 1524 & 1624 & 1548 & 1632 \\
$\mathrm{M}-\mathrm{C}$ bond length / & 2.03 & $2.00,2.01$ & 1.95 & 2.07 \\
$\mathrm{C}-\mathrm{O}$ bond length / & 1.26 & 1.27 & $1.26,1.23$ & $1.21($ co-planar $)$ \\
O $\cdots$ O separation / $\AA$ & 2.42 & 2.41 & 2.37 & 2.64
\end{tabular}

${ }^{*}{ }^{13} \mathrm{C}$ NMR data for 21 was not obtained due to its low solubility in all tested solvents (see Section 3.1.1.2).

\subsubsection{Hydrogen bonding in metalla- $\beta$-diketones}

In 2007, Steinborn carried out a computational investigation into the strength of hydrogen bonding in metalla- $\beta$-diketones of the type observed in complexes 28 and 30 compared to the intramolecular hydrogen bonding present in acetylacetone. ${ }^{72}$ It was reported that the "resonance-assisted hydrogen bonding" present in metalla- $\beta$-diketones was much stronger the hydrogen bonds in acetylacetone, and could be related to the $\mathrm{O} \cdots \mathrm{O}$ distance in the diketone moiety: the shorter the $\mathrm{O} \cdots \mathrm{O}$ separation, the stronger the bond. Where the separation of acetylacetone oxygen atoms is $2.543 \AA$, the $\mathrm{O} \cdots \mathrm{O}$ separations of 31,29 and 30 are 2.42, 2.41 and $2.37 \AA$, respectively (Table 6).

\subsubsection{Chemistry of $\left[\mathrm{Pt}\left\{\left(P, C-2-\mathrm{PPh}_{2} \mathrm{C}_{6} \mathrm{H}_{4} \mathrm{CO}\right)_{2} \mathrm{H}\right\}\right]^{+}$}

\subsubsection{Metalla- $\beta$-diketones as ligands}

Lukehart's metalla- $\beta$-diketones were found to have very similar chelating properties to organic $\beta$-diketones, and a series of coordination complexes of metalla- $\beta$-diketonates with metals were prepared. The motivation for this research lay in the potential to easily produce polymetallic, non-cluster complexes, wherein the metals within the complex were in a degree of electronic contact through the unsaturated $\mathrm{C}-\mathrm{O}$ bonds of the diketonate system. Complexes of this type have been formed with a wide variety of metals such as aluminium(III), gallium(III), iron(III), zinc(II) and chromium(III). ${ }^{70,80}$ The first reported metalla- $\beta$-diketonate-metal complex was of 
tris(cis-diacetyltetracarbonylmanganate)aluminium, 35, (Scheme 25). ${ }^{70}$ Similar complexes have been produced with rhena- $\beta$-diketones. ${ }^{79}$

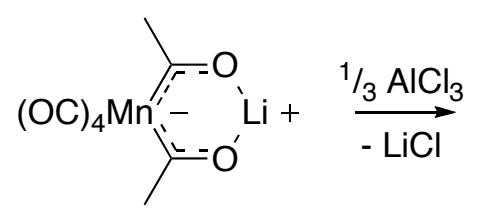

Scheme 25<smiles>CC1=C(C)[N+](C=O)=C(C)C(C)([Te])O1</smiles>

35

Garralda's irida- $\beta$-diketone complexes have also been found to form dinuclear complexes. ${ }^{10}$ The reaction of 29 with $[\mathrm{Rh}(\mathrm{OMe})(\mathrm{COD})]_{2}(\mathrm{COD}=1,5$-cyclooctadiene $)$ produced an irida- $\beta$-diketonatorhodium(I) complex (36) with the elimination of methanol. In contrast to the Lukehart chelate complexes, however, Garralda's binuclear complexes were not stable in this configuration and reacted in refluxing methanol to form the thermodynamically stable complex wherein rhodium was coordinated to iridium via one acyl and one bridging hydride (37) (Scheme 26).

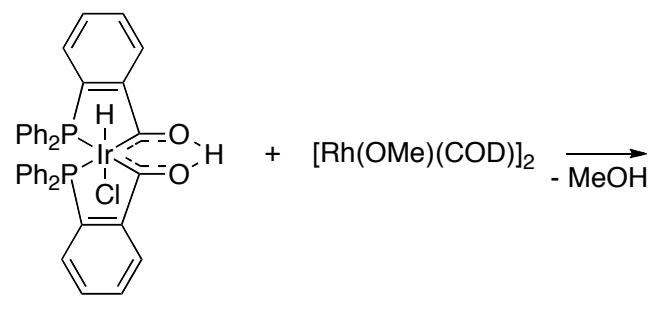

29

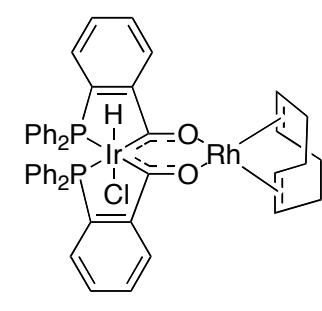

36

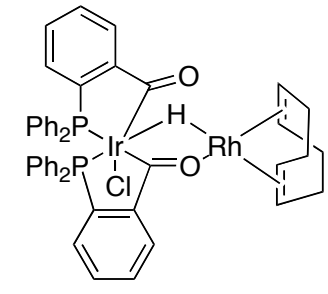

37

Scheme 26

The reaction of complex 31 with $[\mathrm{Rh}(\mathrm{OMe}) \mathrm{COD})]_{2}$ produced similar results to those reported by Garralda. It was proposed that the delocalisation of charge about the diketonate system observed in complex 31 would enable some metal-metal coupling if 31 were employed as a chelating ligand to another transition metal.

Upon addition of $[\mathrm{Rh}(\mathrm{OMe})(\mathrm{COD})]_{2}$ to a solution of 31 there was an immediate colour change to blood red, which was identified by NMR analysis as due to the $[21(\mathrm{COD})]^{+}$ adduct, 38 (Scheme 27). The ${ }^{13} \mathrm{C} \mathrm{NMR}$ shift of the carbonyl to $257.5 \mathrm{ppm}$ is further downfield from 31 by roughly $7 \mathrm{ppm}$, and the ${ }^{31} \mathrm{P}$ NMR signal changed from 45.2 to $38.6 \mathrm{ppm}$. Electron delocalisation is evident from the changes in the NMR spectra and suggests that there may be some interaction between the platinum and rhodium metal 
centres via the carbonyl framework, although the ${ }^{13} \mathrm{C}$ NMR signal of the carbonyl carbons does not show any ${ }^{2} J_{\mathrm{Rh}-\mathrm{C}}$ coupling. The NMR evidence suggested the formation of a cationic complex with symmetry in two planes; there were three peaks in the ${ }^{1} \mathrm{H}$ NMR spectrum and two peaks in the ${ }^{13} \mathrm{C}$ NMR spectrum relating to the coordinated COD on rhodium, and the ${ }^{31} \mathrm{P}$ NMR resonance remained a singlet. When the reaction was performed in deuterated chloroform, ${ }^{1} \mathrm{H}$ NMR data of the reaction showed the immediate loss of the proton resonance at $22.05 \mathrm{ppm}$ and quantitative formation of methanol, indicative of an acid-base reaction between the methoxide anions of $[\mathrm{Rh}(\mathrm{OMe})(\mathrm{COD})]_{2}$ and the $\mathrm{OHO}$ proton of $31 .^{84}$

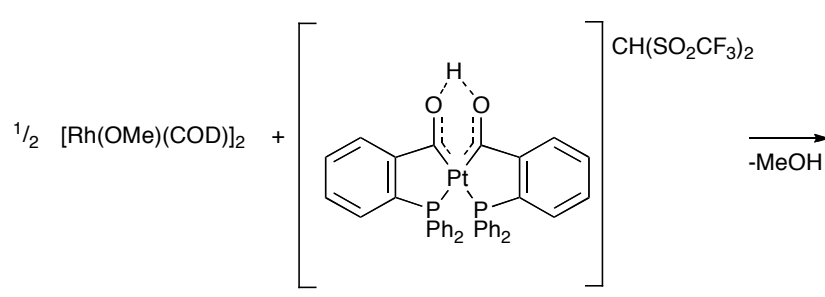

31

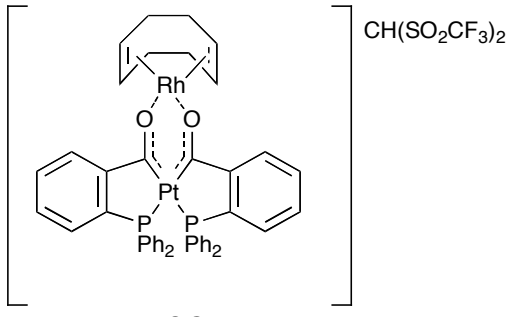

38

Scheme 27

\subsubsection{Schiff-base synthesis}

Both Lukehart and Garralda report facile syntheses of Schiff-base products from their metalla- $\beta$-diketonate complexes by reaction with primary amines or ammonia. ${ }^{12,85}$ The straight-forward synthesis of metalla- $\beta$-diketones and their subsequent reaction with amines may provide a simple route for the incorporation of the metal complexes into biological systems. Lukehart has incorporated metalla- $\beta$-diketonates into peptide sequences through condensation reactions between the carbonyl moiety with amino acids. ${ }^{85}$

Imines can be synthesised through the condensation of a carbonyl (usually an aldehyde) and a primary amine. Nucleophilic attack by the amine at the carbonyl carbon forms a hemiaminal intermediate, which eliminates water to form the $\mathrm{C}=\mathrm{N}$ double bond of an imine. ${ }^{86}$ Complete conversion to an imine often requires dehydration of the reaction mixture, which can be achieved with molecular sieves.

The conversion of 31 from a diketone to a ketoimine was first explored using benzylamine. Benzylamine was chosen for two reasons: firstly, the chemical shift of benzyl protons are easily tracked by ${ }^{1} \mathrm{H}$ NMR data as they resonate in a typically empty area of the spectrum (around $3.8 \mathrm{ppm}$ ), and secondly benzylamine was successfully used by Lukehart to produce 
the metalla- $\beta$-ketoimine in high yield. ${ }^{85}$ Addition of a slight excess of benzylamine to a stirred solution of 31 in dichloromethane resulted in an initial colour change from yellow to pink, which slowly returned to yellow. Conversion to the ketoimine was complete after four hours. Analysis of the reaction by NMR showed that the initial colour change is due to the (at least partial) deprotonation of 31 and protonation of the amine to $\mathrm{BnNH}_{3}{ }^{+}$.

The product, $\left[\mathrm{Pt}\left(P, C-2-\mathrm{PPh}_{2} \mathrm{C}_{6} \mathrm{H}_{4} \mathrm{CO}\right)\left(P, C-2-\mathrm{PPh}_{2} \mathrm{C}_{6} \mathrm{H}_{4} \mathrm{CNHBn}\right)\right] \mathrm{CH}\left(\mathrm{SO}_{2} \mathrm{CF}_{3}\right)_{2}$ (39), was isolated as a yellow oil from the reaction mixture after the solvent and excess benzylamine were removed in vacuo. ${ }^{1} \mathrm{H}$ and ${ }^{31} \mathrm{P} \mathrm{NMR}$ of the product indicated the presence of syn and anti isomers, 39a and 39b, which are possible due to the lack of rotation about the $\mathrm{C}=\mathrm{N}$ bond (Scheme 28). Complex 39a contains an internal hydrogen bond from the $\mathrm{NH}$ to the carbonyl oxygen, while $39 \mathrm{~b}$ contains no such stabilising interaction. The formation of a diimine was not observed, even in the presence of a large excess of amine starting material. Diimine complexes are also not observed in the analogous reactions with Lukehart metalla- $\beta$-diketones, or in reactions with the hydridoirida- $\beta$-diketone, 29.

The NMR characterisation of the two isomers 39a and 39b from the NMR spectra was not immediately obvious. Table 7 contains chemical shifts relevant to the characterisation of the two isomers. The NH proton of the isomer that was present in higher concentrations, comprising $84 \%$ of the product, resonated at $13.11 \mathrm{ppm}$ and had a ${ }^{3} J_{\mathrm{Pt}-\mathrm{H}}$ of $83 \mathrm{~Hz}$. This product showed the $P, C(N)$ ligand in the ${ }^{31} \mathrm{P}$ NMR spectrum at $33.1 \mathrm{ppm}\left({ }^{1} \mathrm{Jt}_{\mathrm{Pt}-\mathrm{P}}=1736 \mathrm{~Hz}\right)$ and the $P, C(O)$ ligand at $49.1 \mathrm{ppm}\left({ }^{1} J_{\mathrm{Pt}-\mathrm{P}}=2532 \mathrm{~Hz}\right)$. The difference in chemical shift and coupling constant of the two phosphine environments is primarily due to the difference in trans influence of $\mathrm{C}=\mathrm{N}$ and $\mathrm{C}=\mathrm{O}$ groups, as imine groups have a lower trans influence than acyls. ${ }^{87}$ 


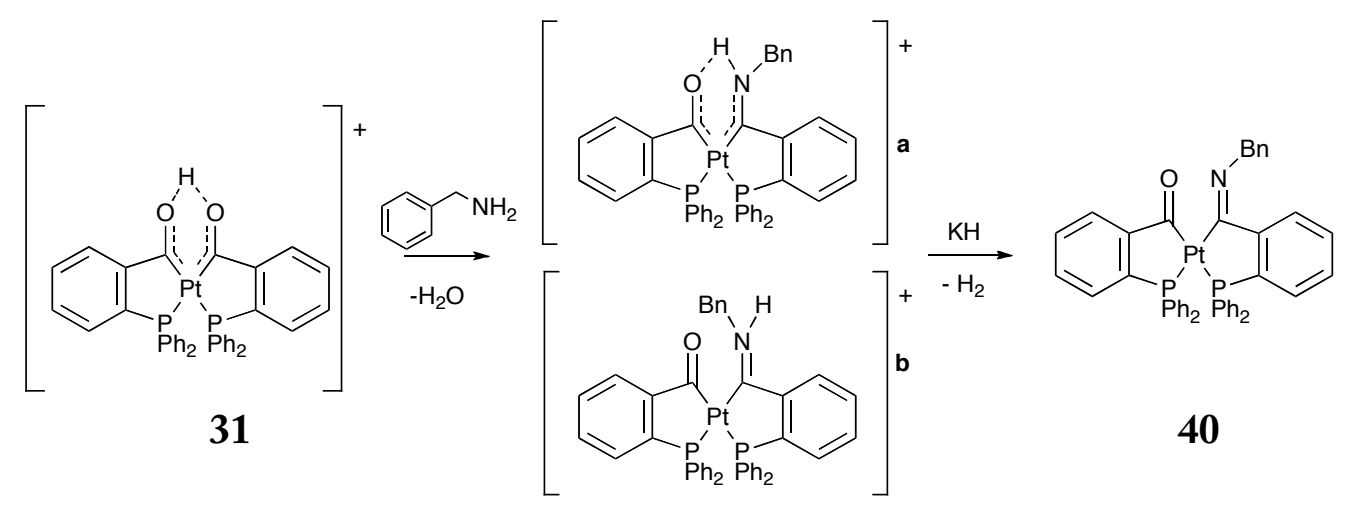

39

Scheme 28

Table 7: ${ }^{1} \mathrm{H}$ and ${ }^{31} \mathrm{P}$ NMR data for platina- $\beta$-ketoimine complexes, $39 \mathrm{a}, 39 \mathrm{~b}$, and 40 . NMR chemical shifts measured in ppm, coupling constants measured in $\mathrm{Hz}$.

\begin{tabular}{ccccc}
\hline Compound & $\delta_{\mathrm{P}}(\mathrm{P} \cap \mathrm{CO})\left({ }^{1} J_{\mathrm{Pt}-\mathrm{P}}\right)$ & $\delta_{\mathrm{P}}(\mathrm{P} \cap \mathrm{CN})\left({ }^{1} J_{\mathrm{Pt}-\mathrm{P}}\right)$ & $\delta_{\mathrm{H}}(\mathrm{NH})\left({ }^{1} J_{\mathrm{Pt}-\mathrm{H}}\right)$ & $\delta_{\mathrm{H}}(\mathrm{Bn})$ \\
\hline 39a (major) & $49.1(2532.0)$ & $33.1(1736.2)$ & $13.11(84.1)$ & 5.24 \\
39b (minor) & $47.9(2623.4)$ & $28.5(1453.5)$ & $10.89($ ca. 100$)$ & 5.15 \\
40 & $47.1(2117.0)$ & $38.7(1687.0)$ & - & 4.84
\end{tabular}

The NH proton signals of $39 \mathrm{a}$ and $39 \mathrm{~b}$ have higher field resonances than platina- $\beta$-diketonate, 31. This suggests the bond between the proton and nitrogen is covalent in character, as opposed to a strong hydrogen bond observed in 31, and hydrogen bonding between the $\mathrm{NH}$ and the carbonyl oxygen is present when the hydrogen occupies the necessary syn geometry.

Like 39a and 39b, the Lukehart metalla- $\beta$-ketoimine, cis- $\left[\mathrm{Re}\left(\mathrm{CH}_{3} \mathrm{CO}\right)\left(\mathrm{CH}_{3} \mathrm{CNHBn}\right)(\mathrm{CO})_{4}\right](41)$ was isolated as both syn and anti geometric isomers. The anti isomer (where $\mathrm{H}$ cannot coordinate to the carbonyl oxygen) was characterised based on XRD structure and related to the chemical shift of the NH proton. The ${ }^{1} \mathrm{H}$ NMR chemical shift of the hydrogen bonded $\mathrm{NH} \cdots \mathrm{O}$ proton is further downfield than that of the ketoimine wherein the $\mathrm{NH}$ is in the anti position relative to the carbonyl oxygen. ${ }^{85}$ Applying Lukehart's reasoning to the characterisation of $39 \mathrm{a}$ and $39 \mathrm{~b}$, the assignment of the ${ }^{1} \mathrm{H}$ NMR chemical shift of $13.11 \mathrm{ppm}$ to the syn isomer is consistent with internal hydrogen bonding of the proton. This characterisation is also consistent with the 
presumption that, as the major product, 39a would be expected to be the isomer with the reduced steric crowding and the favoured $\mathrm{NH}$... O interaction.

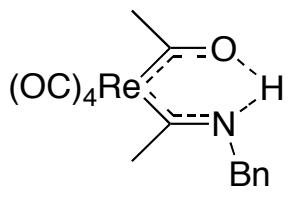

syn
$\mathrm{Bn}$

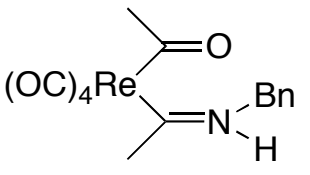

anti

Deprotonation of 39 is readily achieved using potassium hydride to produce the neutral platinum complex, $\left[\mathrm{Pt}\left(P, C-2-\mathrm{Ph}_{2} \mathrm{PC}_{6} \mathrm{H}_{4} \mathrm{CO}\right)\left(P, C-2-\mathrm{PPh}_{2} \mathrm{C}_{6} \mathrm{H}_{4} \mathrm{CNBn}\right)\right]$ (40) (Scheme 28). $\mathrm{KH}$ was an obvious choice for the base as it is insoluble in organic solvents and the byproducts of deprotonation are simply hydrogen gas and an insoluble potassium salt. Addition of $\mathrm{KH}$ followed by filtration and recrystallisation yielded the neutral product as pink-orange crystals in good yield.

Complex 39 acts as a bidentate ligand in a similar way to the diketone, 31. Reaction of 39 with $[\mathrm{Rh}(\mathrm{OMe})(\mathrm{COD})]_{2}$ results in the immediate formation of $[39\{\mathrm{Rh}(\mathrm{COD})\}]^{+}(42)$, as a deep red solution (Scheme 29). Although the reaction was superficially similar to the preparation of the diketone 38 , the NMR resonances of the COD hydrogen and carbon nuclei were substantially broadened, and the ${ }^{1} \mathrm{H}$ and ${ }^{13} \mathrm{C}$ resonances of the $\mathrm{CH}\left(\mathrm{SO}_{2} \mathrm{CF}_{3}\right)_{2}{ }^{-}$counter ion had moved from the typical chemical shifts of a free anion. The ${ }^{13} \mathrm{C}$ NMR chemical shift of the central $\mathrm{CH}\left(\mathrm{SO}_{2} \mathrm{CF}_{3}\right)_{2}{ }^{-}$carbon was also split by coupling to rhodium and platinum $\left(J_{\mathrm{Rh}-\mathrm{C}}=8.2 \mathrm{~Hz}, J_{\mathrm{Pt}-\mathrm{C}}=72.6 \mathrm{~Hz}\right)$. The broadening of the COD resonances and the chemical shift of the counter ion indicates an interaction between $\mathrm{CH}\left(\mathrm{SO}_{2} \mathrm{CF}_{3}\right)_{2}^{-}$and the metal complex. Coordination of $\mathrm{CH}\left(\mathrm{SO}_{2} \mathrm{CF}_{3}\right)_{2}^{-}$to platinum has been previously reported, but the ${ }^{1} J_{\mathrm{Pt}-\mathrm{C}}$ values are much higher than were observed in 42 , and in this case it is proposed that the anion interacts with rhodium dynamically, resulting in a five-coordinate rhodium centre. ${ }^{88,89}$ This interaction would therefore be responsible for the broadening of the COD ${ }^{1} \mathrm{H}$ and ${ }^{13} \mathrm{C}$ NMR signals. 


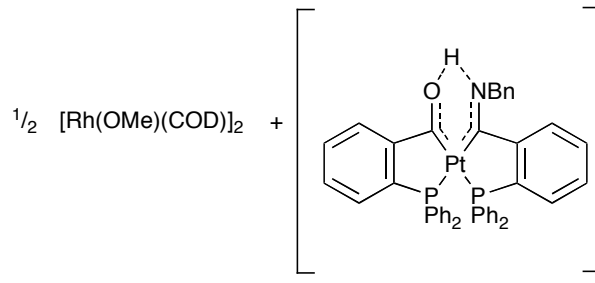

39

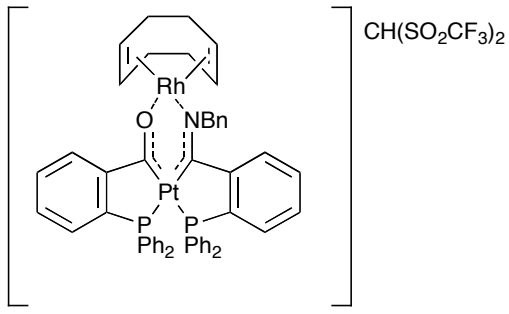

42

Scheme 29: Preparation of the asymmetric metalla- $\beta$-ketoimine rhodium complex, 42 .

A primary ketoimine was also formed from the reaction of 31 with ammonia, producing the platina- $\beta$-ketoimine, $\quad\left[\mathrm{Pt}\left(P, C-2-\mathrm{PPh}_{2} \mathrm{C}_{6} \mathrm{H}_{4} \mathrm{CO}\right)\left(P, C-2-\mathrm{PPh}_{2} \mathrm{C}_{6} \mathrm{H}_{4} \mathrm{CNH}_{2}\right)\right] \mathrm{CH}\left(\mathrm{SO}_{2} \mathrm{CF}_{3}\right)_{2}$ (43). A disadvantage to using ammonia gas was that the addition of a stoichiometric amount of reagent was impractical, and the solubility of ammonia in most organic solvents is such that a massive excess of ammonia is present after a matter of seconds. ${ }^{90}$ While the $\mathrm{p} K_{a}$ of ammonia and benzylamine are similar (both are 9.4 in water), the excess of ammonia resulted in the complete deprotonation of 31 to 21 , which quickly precipitated from solution. It was therefore necessary to add extra $\mathrm{CH}_{2}\left(\mathrm{SO}_{2} \mathrm{CF}_{3}\right)_{2}$ to reprotonate 21 to its soluble salt and reduce the $\mathrm{pH}$ to a level sufficient to facilitate the reaction. Performing the reaction in this way resulted in the formation of $\mathbf{4 3}$ over four hours.

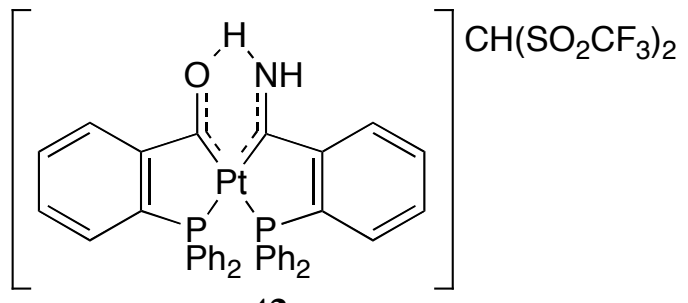

43

An acidic solution is necessary for this reaction to proceed; benzylamine does not react with 21, but when an equivalent of $\mathrm{CH}_{2}\left(\mathrm{SO}_{2} \mathrm{CF}_{3}\right)_{2}$ is added to the mixture, complete conversion is effected within a day at room temperature. All imine condensation reactions are $\mathrm{pH}$ dependent, and typically require a slightly acidic environment due to the mechanism involving the protonation of a carbonyl, but also require enough free amine to engage in nucleophilic attack. ${ }^{86}$ The $\mathrm{pH}$ is also important for this reaction as $\mathbf{2 1}$ is virtually insoluble in dichloromethane, whereas 31 is soluble.

The chemistry of complex 31 therefore makes it an excellent starting material for the preparation of many ketoimines. Furthermore, the stability of 31 and the inertness of the platinum-ligand bonds therein would likely enable it to undergo reactions in fairly harsh 
environments. Reactions between imine derivatives of 1 such as 2- $\mathrm{PPh}_{2} \mathrm{C}_{6} \mathrm{H}_{4} \mathrm{CHNR}$ and platinum starting materials do not produce the analogous metalla- $\beta$-diimines. Instead, the reaction between platinum(II) and phosphinoimines of this type produce singly metallated platinum hydride complexes which are stable even in refluxing toluene. ${ }^{51}$ Therefore the only way to produce platina- $\beta$-ketoimines of the $\mathbf{2 1}$ family is, at present, through the diketone.

\subsubsection{Synthesis of a boron difluoride adduct}

The formation of stable, cationic platina- $\beta$-diketone adducts, 31 and 32 highlighted the potential of diketone $\mathbf{2 1}$ to coordinate to other Lewis acids, such as trigonal boron compounds. Lukehart's metalla- $\beta$-diketones formed stable compounds with these materials through their carbonyl groups. The reaction of $\left[\operatorname{Re}\left\{\left(\mathrm{CH}_{3} \mathrm{CO}\right)_{2} \mathrm{H}\right\}(\mathrm{CO})_{4}\right]$ with two equivalents of a boron trihalide produced the neutral and stable boron dihalide adduct (Scheme 30). ${ }^{91,92}$ It was predicted that similarly stable compounds could be formed with the platina- $\beta$-diketone, 21.

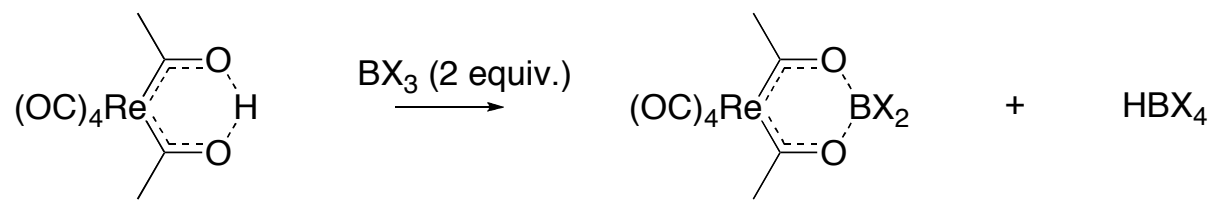

Scheme 30

The addition of two equivalents of boron trifluoride diethyl etherate to a stirred suspension of 21 resulted in the immediate formation of a symmetric complex, $\left[21 . \mathrm{BF}_{2}\right] \mathrm{BF}_{4}(44)$ complex wherein the $\mathrm{BF}_{2}{ }^{+}$was bonded to the two carbonyl oxygens (Scheme 31). Complex 44 was characterised by ${ }^{1} \mathrm{H},{ }^{13} \mathrm{C},{ }^{19} \mathrm{~F}$, and ${ }^{31} \mathrm{P} \mathrm{NMR}$. Notably, the carbonyl groups in this complex have a ${ }^{13} \mathrm{C}$ NMR chemical shift of $260.4 \mathrm{ppm}$ and a ${ }^{1} \mathrm{Jt}_{\mathrm{Pt}-\mathrm{C}}$ coupling of $1019 \mathrm{~Hz}$, the furthest downfield chemical shift and largest platinum-carbon coupling observed of all the [21-Lewis acid] derivatives. This is probably due to the $\mathrm{BF}_{2}{ }^{+}$group withdrawing more electron density from the carbonyl than is resupplied by back donation from the platinum core. 
<smiles>O=C1c2ccccc2P2P(c3ccccc3)C(=O)C12P</smiles>

21

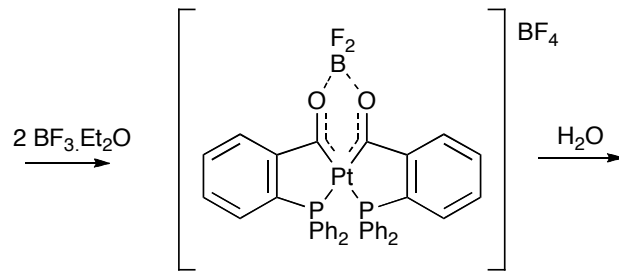

44

Scheme 31

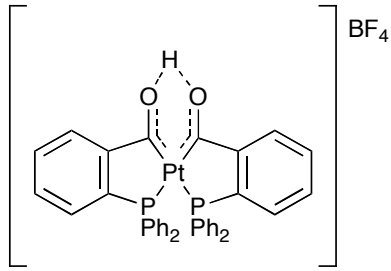

31

In contrast to the highly stable Lukehart derivatives, 44 rapidly reacts to form the protonated diketonate complex 31 with a tetrafluoroborate anion. Complex 44 is highly unstable, even in the solid state, and a pure sample could not be isolated for elemental analysis or HR-ESIMS. Even when the adduct is prepared in a dichloromethane suspension of calcium hydride, filtered and transferred to a flame-dried NMR tube, 31 is the major product, evident from the diagnostic presence of the low-field ${ }^{1} \mathrm{H}$ NMR chemical shift of the OHO proton. The best yields of 44 (as determined from the integration of ${ }^{31} \mathrm{P}$ NMR chemical shifts) were obtained through its in situ synthesis in an NMR tube immediately prior to spectroscopic analysis, presumably due to the complex's reduced exposure to potentially reactive protons. 


\subsection{Coordination chemistry of 2-diphenylphosphinoacetophenone}

The previous sections have shown that the coordination chemistry of phosphinoaldehydes with late transition metals has been relatively heavily investigated. However, similar emphasis has not been placed on the coordination chemistry of the related ketophosphine, 2-diphenylphosphinoacetophenone (2), the methyl ketone relative of $1 .^{93}$ The lack of a $\mathrm{C}-\mathrm{H}$ bond at the carbonyl prevents the favoured reaction route between 1 and platinum, meaning that for chelation to occur a different reaction pathway would be expected. Comparing the key mechanistic steps and intermediates formed upon $\mathrm{C}-\mathrm{H}$ activation of related phosphinocarbonyl ligands enables a deeper understanding as to how the reactivity of platinum and other late transition metals is affected by different carbonyl functional groups.

Bonds between platinum(0) and platinum(II) and oxygen are relatively unfavourable compared to the interaction with carbon. ${ }^{94}$ Carbon forms more stable $\sigma$-bonds with platinum as the energy of the bonding orbitals are closer together - they form a 'soft'/soft' bonding interaction, as opposed to a mismatched 'hard'/'soft' interaction between oxygen and platinum. It was therefore expected that the terminal methyl group, being a conventionally highly reactive site in organic chemistry, would also be the site of reactivity with platinum.

\subsubsection{Coordination chemistry of 2 with platinum(II)}

The reaction between $\left[\mathrm{PtMe}_{2}(1,5\right.$-hexadiene)] and 2 followed the same initial reaction pathway as the reaction with 1 . The reaction occurred in a 2:1 ligand/metal ratio regardless of the stoichiometry of the starting materials. The initial displacement of 1,5-hexadiene by two phosphine groups occurred rapidly - within five minutes at room temperature - and formed the complex $\left[\mathrm{PtMe}_{2}\left(2-\mathrm{PPh}_{2} \mathrm{C}_{6} \mathrm{H}_{4} \mathrm{COCH}_{3}\right)_{2}\right]$ (45). Complex 45 was observed in ${ }^{31} \mathrm{P} \mathrm{NMR}$ as a singlet at $33.1 \mathrm{ppm}$ with ${ }^{1} J_{\mathrm{Pt}-\mathrm{P}}=2067 \mathrm{~Hz}$.

$\mathrm{C}-\mathrm{H}$ activation of the terminal methyl group of 2 resulted in the formation of a sixmembered chelate ring and the elimination of methane. The reaction was complete after one day at room temperature in chloroform or dichloromethane. The reaction formed both cis and trans isomers of $\left[\mathrm{PtMe}\left(P, C-2-\mathrm{PPh}_{2} \mathrm{C}_{6} \mathrm{H}_{4} \mathrm{COCH}_{2}\right)\left(2-\mathrm{PPh}_{2} \mathrm{C}_{6} \mathrm{H}_{4} \mathrm{COCH}_{3}\right)\right]$ (46), with the trans isomer formed in higher yields. Both complexes had two signals in the ${ }^{31} \mathrm{P}$ NMR 
spectrum, and each signal was assigned on the basis of its chemical shift and ${ }^{2} J_{\mathrm{P}-\mathrm{P}}$ coupling. One phosphine group of each complex was shifted about ten ppm upfield from the chemical shift of the monodentate complex, 45, indicative of the formation of a six-membered ring. ${ }^{63,64}$ The ${ }^{2} J_{\mathrm{P}-\mathrm{P}}$ coupling was 476 and $11 \mathrm{~Hz}$ for the trans and cis isomers, respectively (Scheme 32).

Heating 46 in refluxing chloroform resulted in the $\mathrm{C}-\mathrm{H}$ activation of the pendant ketone group to form the cis isomer of the bimetallated complex, $\left[\mathrm{Pt}\left(P, C-2-\mathrm{PPh}_{2} \mathrm{C}_{6} \mathrm{H}_{4} \mathrm{COCH}_{2}\right)_{2}\right]$ (47), which recrystallised as white needle-like crystals. The ${ }^{1} \mathrm{H}$ NMR chemical shift for the methylene in the complex was $3.38 \mathrm{ppm}\left({ }^{1} J_{\mathrm{Pt}-\mathrm{P}}=93 \mathrm{~Hz}\right)$.

$\left[\mathrm{PtMe}_{2}\left(\mathrm{C}_{6} \mathrm{H}_{10}\right)\right] \underset{-\mathrm{C}_{6} \mathrm{H}_{10}}{\stackrel{2(2 \text { equiv. })}{\longrightarrow}}\left[\mathrm{PtMe}_{2}\left(2-\mathrm{PPh}_{2} \mathrm{C}_{6} \mathrm{H}_{4} \mathrm{COCH}_{3}\right)_{2}\right]$

45
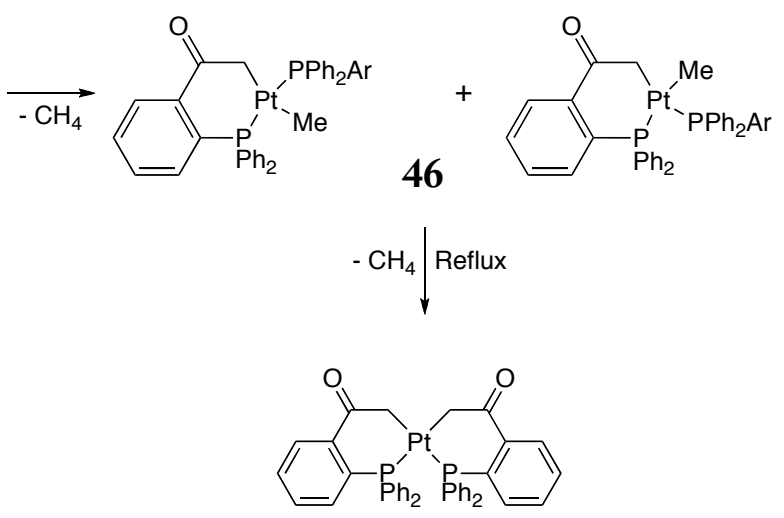

47

Scheme 32

The chelation reactions to form 46 and the second chelation to form the bimetallated complex 47 proceeded at a comparable rate to the analogous chelation reactions with 1 and [PtMe 2 (1,5-hexadiene)] to form 19 and 21. However, the synthesis of 47 could be carried out in refluxing chloroform $\left(61^{\circ} \mathrm{C}\right)$, whereas the formation of 21 could only be effected in refluxing toluene $\left(111^{\circ} \mathrm{C}\right)$. This could possibly be due to the greater acidity of the $\alpha$-protons on the terminal methyl group which resulted in a more facile $\mathrm{C}-\mathrm{H}$ activation reaction, reduced steric repulsion between the carbonyl moieties, or a lower ring strain from the formation of a six-membered ring. 


\subsubsection{Stability of 47}

Unlike the platina- $\beta$-diketone, 21 , the carbonyl groups of cis-47 were unreactive towards activation with acids such as $\mathrm{CH}_{2}\left(\mathrm{SO}_{2} \mathrm{CF}_{3}\right)_{2}$. This was not entirely unexpected, as the presence of the intervening $\mathrm{sp}^{3}$ methylene units would disrupt any electron delocalisation and the outward-facing orientation of the carbonyls would make the $\mathrm{O} \cdots \mathrm{O}$ separation too great for them to act as a bidentate and chelating unit.

To enable a condensation reaction, protonation of 21 to 31 was required to activate the diketone moiety. Thus, the lack of reactivity toward protonation rendered cis-47 quite inert and it was unsurprising that the complex did not react with benzylamine to form an imine.

\subsubsection{The reaction of platinum(0) with 2}

The reaction of tris(norbornene)platinum with two equivalents of 2 resulted in the virtually immediate coordination of to platinum. In the same reaction as was observed between $\operatorname{Pt}(0)$ and 1, the phosphinocarbonyl initially coordinated as a monodentate ligand to platinum. The complexes, $\left[\mathrm{Pt} P(\mathrm{nb})_{2}\right] \quad\left(\delta_{\mathrm{P}} 50.3 \mathrm{ppm},{ }^{1} J_{\mathrm{Pt}-\mathrm{P}}=4905 \mathrm{~Hz}\right)$, and $\left[\operatorname{Pt} P_{2}(\mathrm{nb})\right] \quad\left(\delta_{\mathrm{P}} 38.4\right.$, $\left.{ }^{1} J_{\mathrm{Pt}-\mathrm{P}}=3851 \mathrm{~Hz}\right)\left(P=2-\mathrm{PPh}_{2} \mathrm{C}_{6} \mathrm{H}_{4} \mathrm{COCH}_{3}\right)$ were successively observed, with the monosubstituted $\left[\mathrm{Pt} P(\mathrm{nb})_{2}\right]$ complex disappearing within the first hour of reaction. ${ }^{95}$

The final product of this reaction, complex 48, was quite different to the products of the reaction of 2 with $\left[\mathrm{PtMe}_{2}(1,5\right.$-hexadiene)]. The sole product was a bimetallated complex, 48 , containing a six-membered, $P, C$ metallacycle bound to platinum through the terminal carbon, and a five-membered $P, C$ metallacycle wherein the carbonyl moiety had been reduced to a hydroxyl.

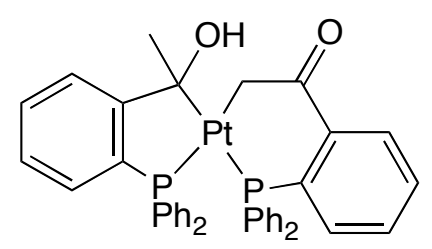

48

After one day, the reaction had quantitatively produced complex 48 through the $\mathrm{C}-\mathrm{H}$ activation of the methyl group of one ligand and the apparent reduction of the ketone moiety 
of the other to form a platinum-carbon bond at the $\mathrm{C}(\mathrm{OH})$ group. The complex had two ${ }^{31} \mathrm{P}$ NMR chemical shifts at 19.2 and $41.0 \mathrm{ppm}$, and a ${ }^{2} J_{\mathrm{P}-\mathrm{P}}$ coupling constant of $8 \mathrm{~Hz}$, which is consistent with a complex comprising both six- and five-membered rings wherein the phosphine groups are in a cis relationship. The ${ }^{1} \mathrm{H}$ spectrum of 48 showed the hydroxyl proton as a broad singlet with platinum satellites at $6.06 \mathrm{ppm}\left({ }^{3} \mathrm{Pt}_{\mathrm{t}-\mathrm{H}}=30 \mathrm{~Hz}\right)$. Assignment of this signal to the hydroxyl was confirmed when a drop of $\mathrm{D}_{2} \mathrm{O}$ was added to an NMR sample and the signal at $6.06 \mathrm{ppm}$ disappeared due to rapid H-D exchange. The metallated methylene protons resonate separately in the ${ }^{1} \mathrm{H}$ NMR spectrum at 4.16 and $3.68 \mathrm{ppm}$, each integrating for one proton. The difference in chemical shift of these protons can be ascribed to the relative proximity of each proton to the hydroxyl and methyl group of the $\mathrm{Pt}-\mathrm{C}(\mathrm{OH})\left(\mathrm{CH}_{3}\right)$ unit. This could not be confirmed through structural characterisation, as attempts at obtaining suitable crystals for single-crystal X-ray crystallography were unsuccessful.

\subsubsection{Mechanism of formation of 48}

The initial $\mathrm{C}-\mathrm{H}$ activation of the methyl group of one phosphine ligand formed an intermediate complex, 49, comprising a six-membered $P, C$ metallacycle, a second monodentate phosphine, and a hydride ligand. The hydride signal appeared as small peaks in the ${ }^{1} \mathrm{H}$ and ${ }^{31} \mathrm{P}$ NMR spectra, and remained visible for the first four hours of reaction. Greater proportions of $\mathbf{4 9}$ were present within the first few minutes of the reaction, and were more visible when $\left[\mathrm{Pt}(\mathrm{COD})_{2}\right]$ was used as the starting material. In the ${ }^{1} \mathrm{H}$ NMR spectrum, the metallated methylene of 49 was observed at $3.71 \mathrm{ppm} \quad\left(\mathrm{t}, \quad{ }^{2} J_{\mathrm{P}-\mathrm{H}}=10.2 \mathrm{~Hz}\right.$, ${ }^{1} J_{\mathrm{Pt}-\mathrm{H}}=95.0 \mathrm{~Hz}$ ), the signal for the non-metallated methyl group was a singlet at $2.33 \mathrm{ppm}$ and the hydride was observed at $-4.68\left(\mathrm{dd},{ }^{2} \mathrm{~J}_{\mathrm{P}-\mathrm{H}}=195.6,28.8 \mathrm{~Hz},{ }^{1} J_{\mathrm{Pt}-\mathrm{H}}=1086 \mathrm{~Hz}\right)$. The ${ }^{31} \mathrm{P}$ NMR spectrum showed two doublets, one at $29.6 \mathrm{ppm}\left(\mathrm{d},{ }^{2} \mathrm{~J}_{\mathrm{P}-\mathrm{P}}=11 \mathrm{~Hz},{ }^{1} J_{\mathrm{Pt}-\mathrm{P}}=2853 \mathrm{~Hz}\right.$, trans to $\mathrm{CH}_{2}$ ), and the other at $17.1\left(\mathrm{~d},{ }^{2} J_{\mathrm{P}-\mathrm{P}}=11 \mathrm{~Hz},{ }^{1} J_{\mathrm{Pt}-\mathrm{P}}=1898 \mathrm{~Hz}\right.$ trans to hydride). Once formed, the hydride intermediate rapidly mediates the formation of a bond between platinum and the carbonyl carbon of the second phosphine ligand to produce the fivemembered ring (Scheme 33). Comparison of the ${ }^{31} \mathrm{P}$ NMR resonances of the intermediate hydride complex, 49, with the unmetallated complex, 45 (33.1 ppm), illustrates the upfield shift of both phosphorus signals, especially that of the chelated phosphine which is consistent with the mechanism comprising the initial formation of the six-membered ring. ${ }^{63}$ 


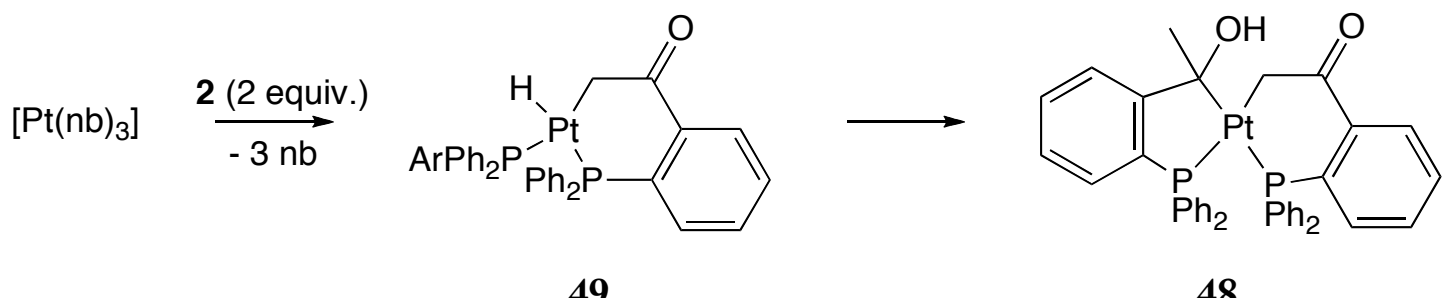

Scheme 33. $\mathrm{Ar}=2-\mathrm{C}_{6} \mathrm{H}_{4} \mathrm{C}(\mathrm{O}) \mathrm{CH}_{3}$

Complex 48 exists as an air-stable yellow solid, but is oxygen-sensitive in solution, reacting to form both the cis and trans isomers of $\mathbf{4 7}$. The decomposition of $\mathbf{4 8}$ into $\mathbf{4 7}$ was observed to occur gradually by NMR with the loss of molecular hydrogen (observed as a sharp peak in the NMR at $4.47 \mathrm{ppm}$ in $\left.\mathrm{C}_{6} \mathrm{D}_{6}\right){ }^{84}$ The presence of water in a reaction under inert atmosphere was found to have no effect on degradation. It was found that degradation was facilitated by exposure to air, and that when sealed under nitrogen, 48 was quite stable. However, 48 was found to decompose to the bis-chelate 47 within 24 hours if a solution was exposed to air. Metal-hydroxyl complexes similar to 48 have also been reported to convert to metal carbonyls over time (e.g. complex 51 in Section 3.2.2.2).

\subsubsection{Hydroxyalkyl complexes}

The formation of hydroxyalkyl complexes similar to complex 48 have been reported by Vaughn (Scheme 34) and Garralda (Scheme 35), wherein the insertion of an aldehyde into a metal-hydride bond was observed. ${ }^{6,9697}$ In these investigations, it was proposed that the character of the hydride ligand was relatively acidic, which enabled its addition to the carbonyl. ${ }^{96,97}$

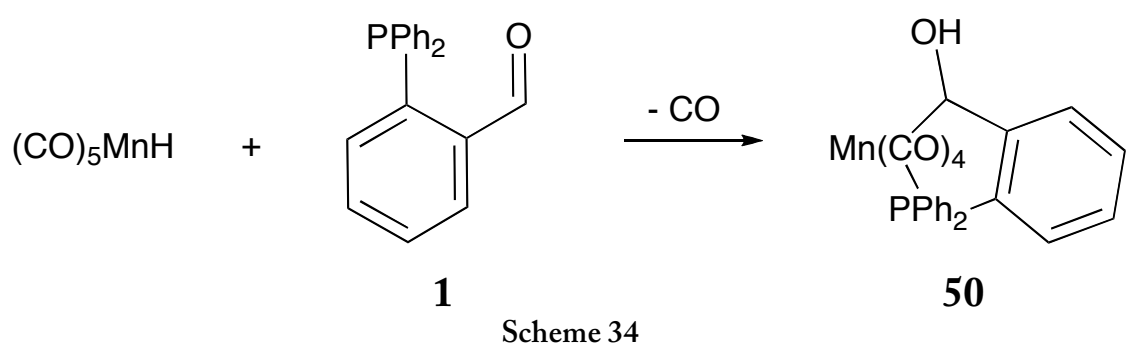

The reaction of $[\mathrm{Rh}(\mathrm{COD})(\mathrm{bdh}) \mathrm{Cl}]$ (bdh = biacetyldihydrazone) with two equivalents of 1 resulted in the $\mathrm{C}-\mathrm{H}$ activation of the aldehyde and formation of an acylhydridorhodium complex intermediate. ${ }^{6}$ The insertion of the pendant aldehyde into the $\mathrm{Rh}-\mathrm{H}$ bond formed 
via the $\mathrm{C}-\mathrm{H}$ activation of the first aldehyde produced the hydroxyalkyl complex 51 (Scheme 35). Like complex 48 , the rhodium alkoxy complexes degrade over time. ${ }^{9}$

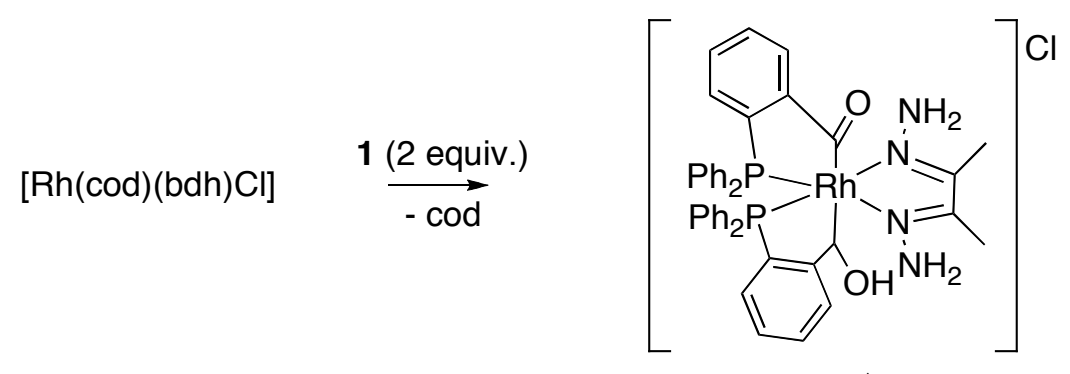

Scheme 35

In contrast to the reaction to form 48 , the insertion of a carbonyl group into the $\mathrm{Pt}-\mathrm{H}$ bond did not occur in the reaction between 1 and $\mathrm{Pt}(0)$. As described in Section 3.1, the reaction of 1 with $\left[\mathrm{Pt}(\mathrm{nb})_{3}\right]$ resulted in the formation of an acylhydride complex, but this rapidly reacted to form the relatively stable 2-norbornyl intermediate, 23. The divergence in reactivity between the coordination chemistry of $\mathbf{1}$ and 2 with platinum in identical conditions is interesting because the intermediate complexes that form are likely to have a role in the determination of the final products. 


\subsection{Coordination chemistry of 2-bis(pentafluorophenyl)phosphinobenzaldehyde}

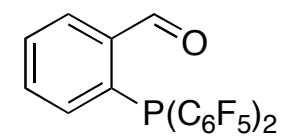

3

Pentafluorophenyl substituents endow phosphines with greater bulk and reduced $\sigma$-bonding character than the ubiquitous phenyl groups. ${ }^{15}$ These phosphines are electron-poor compared to phenylphosphines; $\mathrm{PPh}\left(\mathrm{C}_{6} \mathrm{~F}_{5}\right)_{2}$ has a Tolman electronic parameter of $2082.8 \mathrm{~cm}^{-1}$, compared to $2069.0 \mathrm{~cm}^{-1}$ for $\mathrm{PPh}_{3}$, and $2060.4 \mathrm{~cm}^{-1}$ for $\mathrm{PPh}^{t} \mathrm{Bu}_{2 .}{ }^{15,16}$ Although pentafluorophenylphosphines are electron-poor, a computational analysis of ligand effects developed by Giering et al. has found that, despite being strongly electron withdrawing moieties, pentafluorophenyl groups do not stimulate any $\pi$-acidity in the phosphine. ${ }^{16}$ The incorporation of pentafluorophenyl substituents into a phosphine ligand only reduces the amount of electron density donated to platinum through the metal-phosphorus $\sigma$-bond. This chapter describes the different coordination chemistry that results from these groups.

Due to time constraints, the coordination chemistry of 3 was only investigated with the platinum(II) starting material, [ $\mathrm{PtMe}_{2}(1,5$-hexadiene $\left.)\right]$.

\subsubsection{Coordination chemistry of 3 with platinum(II)}

The reaction of 3 with $\left[\mathrm{PtMe}_{2}(1,5\right.$-hexadiene $\left.)\right]$ at room temperature resulted in the substitution of 1,5-hexadiene by two phosphine ligands, regardless of the stoichiometry employed. In contrast to the analogous reaction between 1 or 2 and [ $\mathrm{PtMe}_{2}(1,5$-hexadiene)], for which monodentate coordination is virtually immediate, this reaction was much slower, taking several hours to produce $\left[\mathrm{PtMe}_{2}\left\{2-\mathrm{P}\left(\mathrm{C}_{6} \mathrm{~F}_{5}\right)_{2} \mathrm{C}_{6} \mathrm{H}_{4} \mathrm{CHO}\right\}_{2}\right]$ (52). No chelation was observed at room temperature, and the product was air-stable in solution for weeks. The ${ }^{31} \mathrm{P}$ NMR spectrum showed a singlet at $17.5 \mathrm{ppm}$ with ${ }^{1} J_{\mathrm{Pt}-\mathrm{P}}=2091.4 \mathrm{~Hz}$. The chemical shift was six ppm upfield compared to the related platinum complex of 1, (18) and the coupling constant was roughly $200 \mathrm{~Hz}$ greater. Previously reported platinum complexes containing two coordinated tris(pentafluorophenyl)phosphine groups on platinum all comprise mutually trans phosphine ligands..$^{50,98-102}$ These complexes have negative chemical shift values in their 
${ }^{31} \mathrm{P} \quad \mathrm{NMR}$ spectra and ${ }^{1} J_{\mathrm{Pt}-\mathrm{P}}$ coupling constants of between $1929 \mathrm{~Hz}$ (for

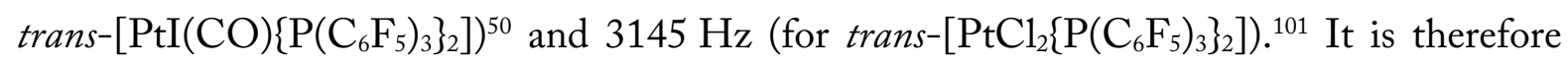
unclear by NMR whether 52 exists in cis or trans geometry: the large cone angle of 4 suggests 52 should be more stable in a mutually trans configuration, while the presence of the methyl groups in the complex means that a cis configuration would be more electronically stable.

In an attempt to induce $\mathrm{C}-\mathrm{H}$ activation, the reaction of 3 with $\left[\mathrm{PtMe}_{2}(1,5\right.$-hexadiene)] was also performed in refluxing toluene. Within four hours, 52 had entirely reacted to form two different complexes. The absence of aldehyde proton resonances in the ${ }^{1} \mathrm{H}$ NMR spectrum of the reaction products suggested complete $\mathrm{C}-\mathrm{H}$ activation of both of the aldehyde groups of complex 52. The two complexes were characterised as trans $-\left[\mathrm{Pt}\left(P, C-2-\mathrm{P}\left(\mathrm{C}_{6} \mathrm{~F}_{5}\right)_{2} \mathrm{C}_{6} \mathrm{H}_{4} \mathrm{CO}\right)_{2}\right]$ (53), the pentafluorophenyl analogue of trans-21, and a decarbonylated, ortho-metallated product, $\left[\mathrm{Pt}\left\{P, C-2-\mathrm{P}\left(\mathrm{C}_{6} \mathrm{~F}_{5}\right)_{2} \mathrm{C}_{6} \mathrm{H}_{4}\right\}\left\{P, C-2-\mathrm{P}\left(\mathrm{C}_{6} \mathrm{~F}_{5}\right)_{2} \mathrm{C}_{6} \mathrm{H}_{4} \mathrm{CO}\right\}\right]$ (54) (Scheme 36). The complexes were separated via column chromatography using 19:1 hexane/ethyl acetate to yield green, rhombohedral crystals of 53, and yellow, needle-like crystals of 54.

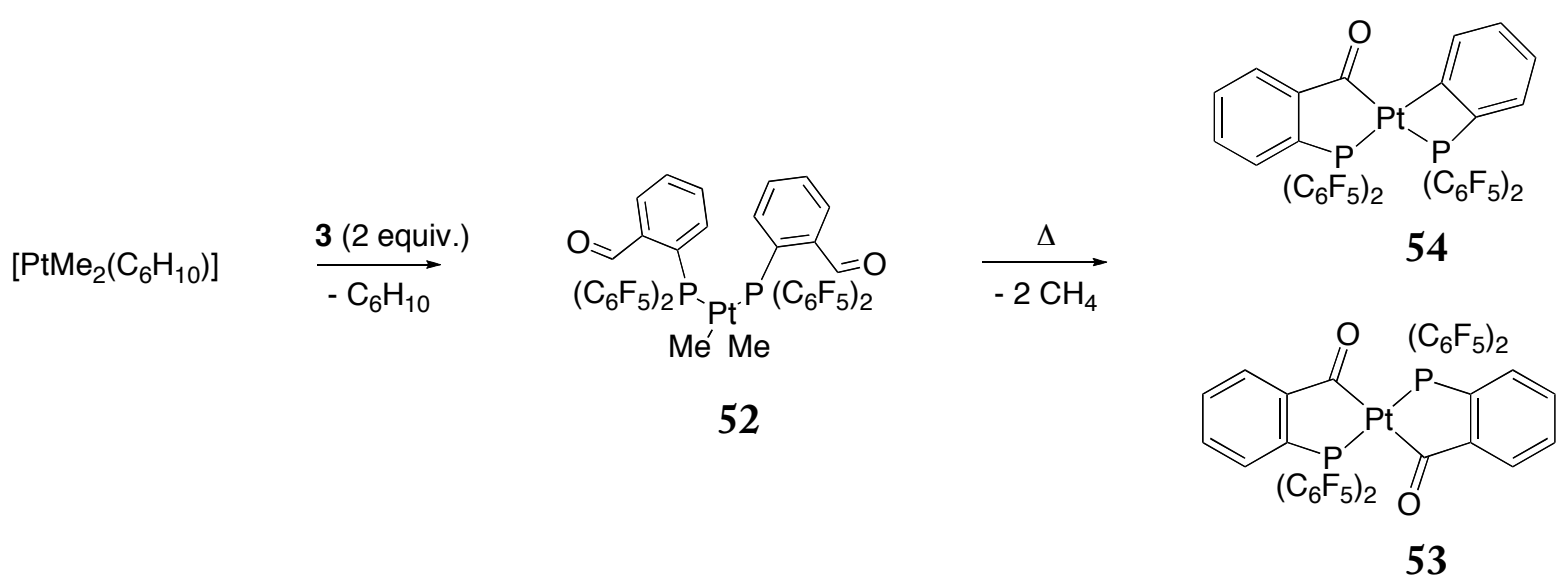

Scheme 36

Complex 53 appeared as a singlet in the ${ }^{31} \mathrm{P}$ NMR spectrum at $19.9 \mathrm{ppm}$ with a ${ }^{1} J_{\mathrm{Pt}-\mathrm{P}}$ of $3917 \mathrm{~Hz}$. Interestingly, formation of a five-membered ring in this instance did not result in a significant downfield shift as was observed when the phosphine had phenyl substitutents such as in ligands 1 and $2 .{ }^{63}$ Furthermore, the platinum-phosphorus coupling constant of 53 was large for two phosphine groups trans to one another. ${ }^{19} \mathrm{~F}$ NMR confirmed a symmetrical structure as the spectrum contained three signals, accounting for one chemical environment for each ortho, meta, and para fluorine position. 
In the ${ }^{1} \mathrm{H}$ NMR spectrum of 54, an apparent quartet at $9.37 \mathrm{ppm}$ with ${ }^{3} \mathrm{P}_{\mathrm{Pt}-\mathrm{H}}$ of $53 \mathrm{~Hz}$ denoted the presence of an aryl-platinum bond and suggested that a ligand had undergone ortho-metallation. HR-ESIMS of the complex indicated that this proceeded through decarbonylation, as the $\mathrm{m} / \mathrm{z}$ ratio accounted for the loss of $\mathrm{CO}$ in the $[\mathrm{M}+\mathrm{H}]^{+}$molecular ion. Decarbonylation was confirmed by gas-phase IR spectroscopy, which showed the presence of carbon monoxide in the headspace of a sealed reaction vessel. Complex 54 had two ${ }^{31} \mathrm{P}$ NMR chemical shifts, one at $16.1 \mathrm{ppm}\left({ }^{1} \mathrm{~J}_{\mathrm{Pt}-\mathrm{P}}=2299 \mathrm{~Hz}\right)$ and the other at $-96.8 \mathrm{ppm}$ $\left({ }^{1} J_{\mathrm{Pt}-\mathrm{P}}=522 \mathrm{~Hz}\right)$. Dramatic upfield shifts of ${ }^{31} \mathrm{P} \mathrm{NMR}$ signals are often indicative of the involvement of phosphorus in four-membered rings, and a structure was proposed for complex 54 that contained one five-membered and one four-membered metallacycle (Scheme 36). However, the magnitude of the upfield shift and decrease in ${ }^{1} J_{\mathrm{Pt}-\mathrm{P}}$ coupling constant of the phosphorus signal, although consistent with the ring-size dependence of phosphorus chemical shifts, ${ }^{63}$ could not be justified by ring-strain alone. Platinum-phosphorus coupling constants of closely related, ortho-metallated platinum complexes of triphenylphosphine are considerably larger (see Table 10). ${ }^{29,103-106}$

Many attempts at obtaining a crystalline sample of $\mathbf{5 4}$ suitable for $\mathrm{X}$-ray diffraction were made, and even the best quality crystals were very fine in at least one spatial dimension. However, crystallographic data were successfully collected, solved, and refined by Dr Horst Puschmann at Durham University, United Kingdom (Figure 10). The molecular structure confirmed the NMR-based characterisation of complex 54; one of the ligands had chelated to platinum through $\mathrm{C}-\mathrm{H}$ activation of the aldehyde, and the other ligand had coordinated through phosphorus and eliminated $\mathrm{CO}$ to form a bidentate, ortho-metallated metallacycle comprising a platinum-carbon bond to the aryl group. 


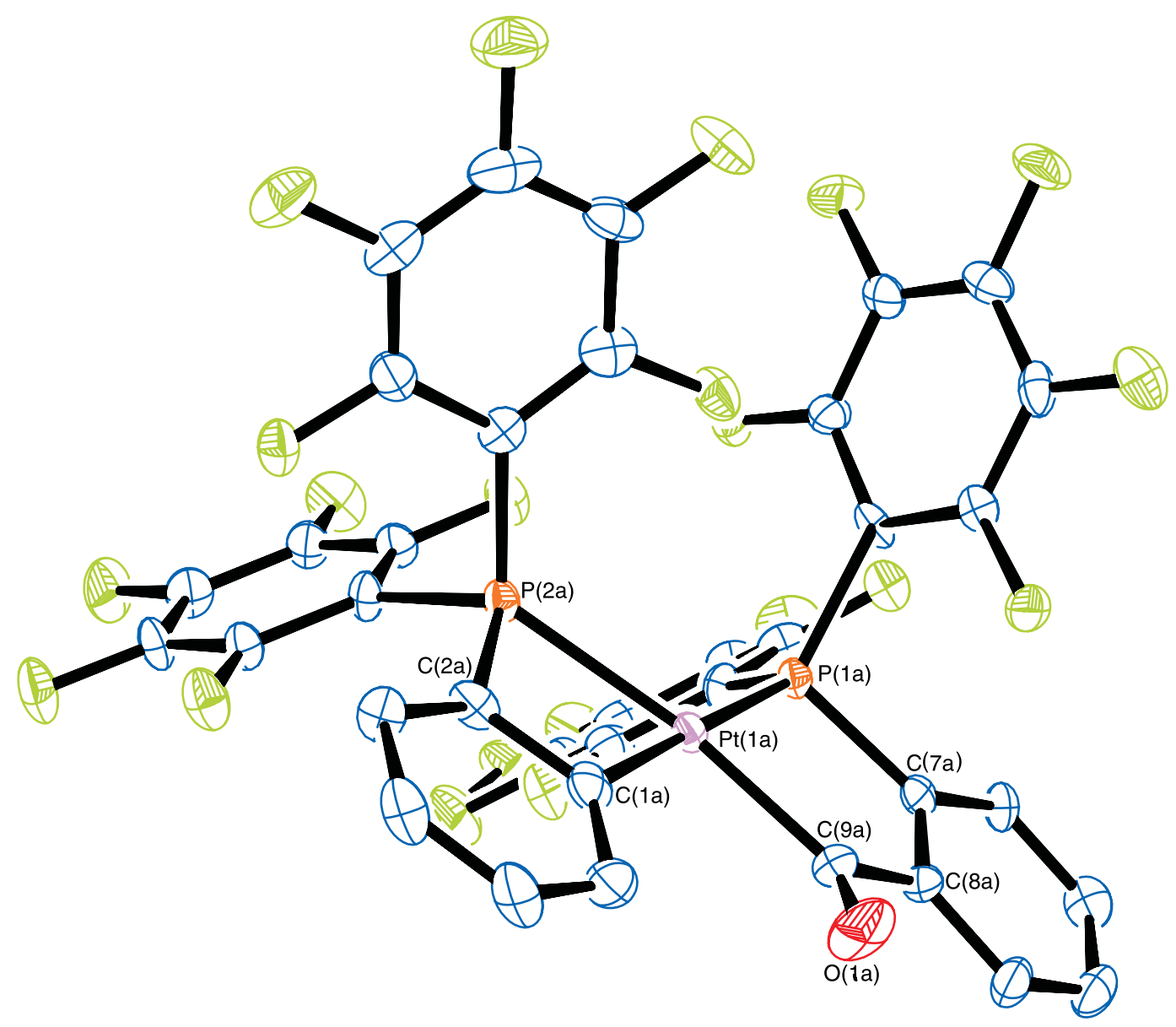

Figure 10: ORTEP-3 diagram of 54 showing 50\% probability ellipsoids. $\mathrm{H}$ atoms omitted for clarity. One complex within the asymmetric unit is pictured.

Table 8: Selected bond distances $(\AA)$ and bond angles $\left(^{\circ}\right)$ for 54 . Bond distances and angles for each complex in the asymmetric unit are given.

\begin{tabular}{lllr}
\hline \multicolumn{3}{c}{ Distance / } \\
\hline $\mathrm{Pt}(1)-\mathrm{C}(1)$ & $2.063(7), 2.055(9)$ & $\mathrm{P}(2)-\mathrm{Pt}(1)-\mathrm{C}(1)$ & Angle ${ }^{\circ}$ \\
$\mathrm{Pt}(1)-\mathrm{P}(2)$ & $2.379(2), 2.385(2)$ & $\mathrm{P}(2)-\mathrm{Pt}(1)-\mathrm{P}(1)$ & $113.60(7), 113.23(7), 67.3(2)$ \\
$\mathrm{Pt}(1)-\mathrm{P}(1)$ & $2.270(2), 2.272(2)$ & $\mathrm{P}(1)-\mathrm{Pt}(1)-\mathrm{C}(9)$ & $83.0(3), 83.8(3)$ \\
$\mathrm{Pt}(1)-\mathrm{C}(9)$ & $2.034(8), 2.041(9)$ & $\mathrm{O}(1)-\mathrm{C}(9)-\mathrm{Pt}(1)-\mathrm{C}(1)$ & 18.97 \\
$\mathrm{P}(2)-\mathrm{C}(2)$ & $1.804(9), 1.814(4)$ & $\mathrm{C}(7)-\mathrm{C}(8)-\mathrm{C}(9)-\mathrm{Pt}(1)$ & 11.73 \\
$\mathrm{P}(1)-\mathrm{C}(7)$ & $1.824(8), 1.825(8)$ & & \\
\hline
\end{tabular}


Table 9: Crystallographic data of platinum complex 54.

\begin{tabular}{|c|c|}
\hline Empirical Formula & $\mathrm{C}_{74} \mathrm{H}_{16} \mathrm{O}_{2} \mathrm{Pt}_{2} \mathrm{P}_{4} \mathrm{~F}_{40}$ \\
\hline Molecular weight & 2210.94 \\
\hline Crystal system & Monoclinic \\
\hline Space group & $P 1$ \\
\hline$a / \AA$ & $11.7466(3)$ \\
\hline$b / \AA$ & $21.8301(4)$ \\
\hline$c / \AA$ & $15.8771(3)$ \\
\hline$\alpha /^{\circ}$ & 90 \\
\hline$\beta /^{\circ}$ & $111.438(3)$ \\
\hline$\gamma /{ }^{\circ}$ & 90 \\
\hline$V / \AA^{3}$ & $3789.68(15)$ \\
\hline Z & 2 \\
\hline$T / \mathrm{K}$ & 120 \\
\hline $\mathrm{L} / \AA$ & 0.71703 \\
\hline$d_{\text {calcd }}, \mathrm{g} \mathrm{cm}^{-3}$ & 1.9374 \\
\hline $\mathrm{F}(000)$ & 2100.225 \\
\hline$\mu, \mathrm{cm}^{-1}$ & 3.916 \\
\hline Reflections collected & 28101 \\
\hline Index range $h$ & $-15 \rightarrow 16$ \\
\hline Index range $\mathrm{k}$ & $-29 \rightarrow 28$ \\
\hline Index range 1 & $-21 \rightarrow 21$ \\
\hline Theta range $/^{\circ}$ & $2.64 \rightarrow 29.30^{\circ}$ \\
\hline Independent reflections & 15408 \\
\hline Data/restraints/parameters & $15408 / 0 / 1026$ \\
\hline Goodness of fit & 1.017 \\
\hline$R_{1}(I>2 \sigma(I)]$ & 0.034 \\
\hline$w R_{1}(\mathrm{I}>2 \sigma(\mathrm{I})]$ & $\mathrm{N}$ \\
\hline$R_{1}($ all data $)$ & 0.037 \\
\hline$w R_{2}(\text { all data })^{a}$ & 0.10 \\
\hline
\end{tabular}

The complex crystallised in the $P 1$ space group, and the asymmetric unit contained two separate but virtually identical complexes (each complex contained very similar bond distances). The presence of two separate complexes within the asymmetric unit was useful in confirming structural parameters as the two units could be compared. The metal and surrounding inner core of the complex is predominantly co-planar, except for the fivemembered ring which has a slight envelope geometry with the carbonyl carbon bent out of the plane $\left(\mathrm{C}(7 \mathrm{a})-\mathrm{C}(8 \mathrm{a})-\mathrm{C}(9 \mathrm{a})-\mathrm{Pt}(1 \mathrm{a})\right.$ torsional angle of $\left.11.73^{\circ}\right)$. The distances of the Pt-P bonds in the four-membered platinacycles were very similar for the two complexes in the asymmetric unit, at 2.385(2) (for $\mathrm{Pt}(1 \mathrm{a})-\mathrm{P}(2 \mathrm{a})$ ) and 2.379(2) $\AA$ (for $\mathrm{Pt}(1)-\mathrm{P}(2))$ (Table 8). 
This Pt-P bond distance was significantly longer than monodentate tris(pentafluorophenyl)phosphine-platinum bonds. For example, the Pt-P bond distance of $\left[\mathrm{PtCl}_{2}\left\{\mathrm{P}\left(\mathrm{C}_{6} \mathrm{~F}_{5}\right)_{3}\right\}_{2}\right]$ is $2.280 \AA{ }^{107}$ The bond distance is also much greater than other ortho-platinated complexes of triphenylphosphine. ${ }^{29,103-106}$ According to a recent Cambridge Crystallographic Data Centre Mogul database search, at 2.379(2) Å, the Pt-P bond distance of 54 is longer than any reported platinum-phosphorus bond, whether as part of a metallacycle or as a monodentate ligand. ${ }^{108}$

\subsubsection{Relationship between ${ }^{1} J_{\mathrm{Pt}-\mathrm{P}}$ and $\mathrm{Pt}-\mathrm{P}$ bond length}

The s-orbitals alone have finite density at the nucleus, and therefore it is assumed that it is the electrons that occupy these orbitals which interact with nuclear spin. ${ }^{28}$ The coupling between phosphorus and platinum is therefore given by the proportionality

$$
J_{P t-P} \propto \gamma_{P t} \gamma_{P}(\Delta E)^{-1} \alpha_{P t}^{2} \alpha_{P}^{2}\left|\Psi_{P t(0)}\right|^{2}\left|\Psi_{P(0)}\right|^{2} \quad \text { Equation } 1
$$

The variables, $\gamma_{P t}$ and $\gamma_{P}$ are the gyromagnetic ratios for the spin $1 / 2$ nuclei, platinum and phosphorus, $\Delta E$ is the mean singlet-triplet excitation energy, $\alpha_{P t}^{2}$ and $\alpha_{P}^{2}$ represent the $s$-characters of the hybrid orbitals used by the platinum and phosphorus in the Pt-P bond, and $\left|\Psi_{P t(0)}\right|^{2}$ and $\left|\Psi_{P(0)}\right|^{2}$ are the squares of the magnitudes of the valence-state $s$-orbitals at the nucleus. ${ }^{29}$ However, the usual determinant of ${ }^{1} J_{\mathrm{Pt}-\mathrm{P}}$ is $\alpha_{P t}^{2}$, meaning that changes to the observed coupling constant are due to changes in the $s$-character of the Pt-P bond. ${ }^{109,110}$

The complexity of the variables in Equation 1 has meant that reported correlations between bond length and ${ }^{1} J_{\mathrm{Pt}-\mathrm{P}}$ have been based mostly on empirical evidence; the platinum-phosphorus bond length is inversely proportional to the coupling constant and the correspondence between the parameters is not exact. ${ }^{29} \mathrm{~A}$ number of attempts at establishing a correlation between the parameters have been made, although in all instances the authors have acknowledged the simplistic methodology. ${ }^{109}$ A series of ortho-metallated platinum complexes based on cis- $\left[\mathrm{Pt}\left(P, C-2-\mathrm{PPh}_{2} \mathrm{C}_{6} \mathrm{H}_{4}\right)_{2}\right]$ (55) and its ring-opened derivatives have been investigated by Bennett et al. in an attempt to establish a correlation (Scheme 37)..$^{29,103,105}$ 

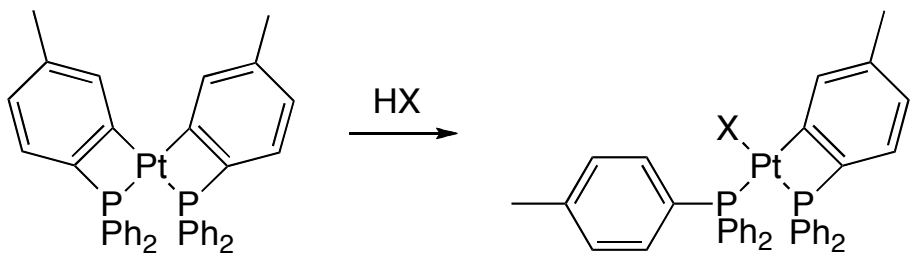

55

Scheme 37: Reaction by Bennett et al. to compare platinum-phosphorus coupling with bond length. Where $\mathrm{X}$ is a neutral ligand, the complex is associated with a $\mathrm{BF}_{4}^{-}$counter ion.

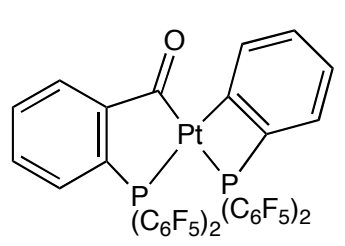

54

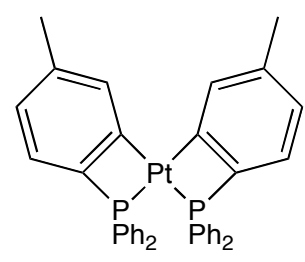

55

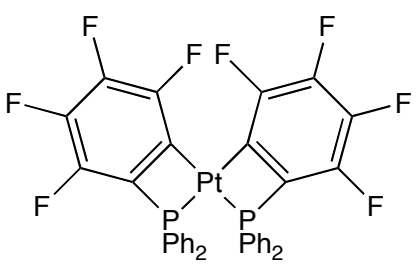

56

Table 10

\begin{tabular}{cccccc}
\hline Complex & $\delta_{\mathrm{P}}\left({ }^{1} J_{\mathrm{Pt}-\mathrm{P}}\right)$ & $\delta_{\mathrm{P}}\left({ }^{1} J_{\mathrm{Pt}-\mathrm{P}}\right)^{\ddagger}$ & $d(\mathrm{Pt}-\mathrm{P}) / \AA^{\ddagger}$ & $d(\mathrm{Pt}-\mathrm{C}) / \AA \AA^{\ddagger}$ & $\mathrm{P}-\mathrm{Pt}-\mathrm{C} /{ }^{\circ} \neq$ \\
\hline $\mathbf{5 4}$ & $16.1(2299)$ & $-96.8(522)$ & $2.385(2)$ & $2.055(9)$ & 67.3 \\
$\mathbf{5 5 ^ { 2 9 }}$ & $-52.2(1352)$ & $-52.2(1352)$ & $2.306(1)$ & 2.060 & 68.9 \\
$\mathbf{5 6 ^ { 1 0 6 }}$ & $-64.2(1697)$ & $-64.2(1697)$ & $2.2754(9)$ & 2.110 & 69.4 \\
$\mathbf{5 7}^{29}$ & $18.5(1990)$ & $-72.8(3392)$ & $2.3350(8)$ & 2.056 & 68.79 \\
$\mathbf{5 8 ^ { 2 9 }}$ & $21.6(2123)$ & $-50.7(1122)$ & $2.3324(7)$ & 2.069 & 68.95 \\
\hline
\end{tabular}

${ }^{\ddagger}$ Denotes the nucleus or bond is part of a four-membered ring.

Waddell has also recently reported a study of the correlation between the ${ }^{1} J_{\mathrm{Pt}-\mathrm{P}}$ and platinum-phosphorus bond distance, and provided an equation based on empirical evidence to predict one parameter from the other (Equation 2)..$^{33}$

$$
l_{P t-P}=2.422-\frac{J}{21827} \quad \text { Equation } 2
$$

Applying the ${ }^{1} \mathrm{Pt}_{\mathrm{Pt}} \mathrm{P}$ coupling constant of the strained phosphorus atom in 54 of $522 \mathrm{~Hz}$ to Equation 2 provides a predicted bond length of $2.40 \AA$. This is quite close to the measured value of 2.385(2) $\AA$, although such linear equations are unlikely to be particularly accurate at predicting Pt-P distances at the outer edges of the range. The magnitude of coupling is a 
better measure of $s$-orbital overlap than bond length, and does not vary linearly with distance. $^{28}$ It is apparent that the Pt-P bond length and ${ }^{1} \mathrm{~J}_{\mathrm{Pt}-\mathrm{P}}$ of complex 54 differs to Bennett's series, which may be attributed to different steric and electronic properties of the $\mathrm{C}_{6} \mathrm{~F}_{5}$ substituents compared to phenyl substituents.

The P-Pt-P bond angle of 54 is $113.29^{\circ}$, and therefore a significant deviation from the preferred $90^{\circ}$ in square planar configurations. However, when compared to the $\mathrm{P}-\mathrm{Pt}-\mathrm{P}$ bond angle of other ortho-metallated complexes, the deviation from $90^{\circ}$ per se does not present a

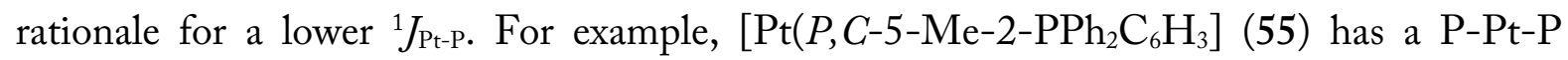
bond angle of $117.4^{\circ}$ yet it has a ${ }^{1} J_{\mathrm{Pt}-\mathrm{P}}$ coupling constant of $1352 \mathrm{~Hz}$ (Table 10). ${ }^{105}$ Bond length is more instructive in the present case.

A possibility arose that, in solution, 54 may not actually contain a true bond between platinum and phosphorus in the decarbonylated ligand, and the platinum-phosphorus coupling observed was from a ${ }^{3} \mathrm{~J}_{\mathrm{Pt}-\mathrm{P}}$ coupling through the platinum-aryl bond. Complexes of ortho-metallated arylphosphines wherein the phosphine is dissociated tend to have a ${ }^{3} \mathrm{Pt}_{\mathrm{t}-\mathrm{P}}$ value of between 184 and $227 \mathrm{~Hz}$, roughly half the coupling constant of the strained phosphorus in 54. ${ }^{29}$ In order to prove the presence of a conventional, non-labile platinum-phosphorus bond, 54 was reacted with acetonitrile, trimethylacetonitrile, and triphenylphosphine - all are potential ligands known to coordinate to platinum. Analysis of the ${ }^{31} \mathrm{P}$ and ${ }^{1} \mathrm{H}$ NMR spectra of these reactions showed the complex was unaffected by the presence of acetonitrile or trimethylacetonitrile. However, triphenylphosphine rapidly displaced the strained phosphine to produce the new platinum complex, 59 (Scheme 38).

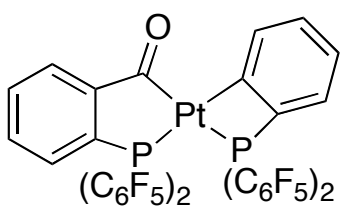

54

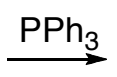

Scheme 38

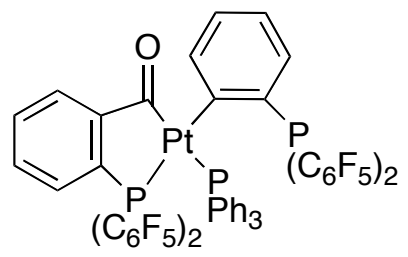

59

Complex 59 was analysed using 1- and 2-dimensional NMR techniques. The presence of an aryl signal with ${ }^{3} J_{\mathrm{Pt}-\mathrm{H}}$ coupling of $62 \mathrm{~Hz}$ in the ${ }^{1} \mathrm{H}$ NMR showed the aryl remained coordinated to platinum. The ${ }^{31} \mathrm{P}$ NMR showed a broad singlet at $-61.4 \mathrm{ppm}$, which was assigned to the displaced phosphine of the decarbonylated ligand. The signal showed no platinum coupling, and its resonance downfield from $\mathbf{5 4}$ was consistent with the relaxation of 
ring strain. ${ }^{63}$ Two signals were also observed at 16.0 and $16.3 \mathrm{ppm}$, with ${ }^{1} \mathrm{JPt}_{\mathrm{Pt}}$ constants of 1989 and $1605 \mathrm{~Hz}$, respectively. They were assigned on the basis that aryl ligands have a greater trans influence than carbonyl ligands. ${ }^{29}$ Thus the signal at $16.0 \mathrm{ppm}$ was assigned to triphenylphosphine (trans to the coordinated carbonyl), and the signal at $16.3 \mathrm{ppm}$ was assigned as the chelated phosphinoaldehyde (trans to the coordinated aryl).

The experiment supported the postulate that 54 contained a true platinum-phosphorus bond and a four-membered $P, C$ metallacycle existed both in solution as well as in the solid state.

\subsubsection{Decarbonylation and the mechanism of formation of $\mathbf{5 4}$}

The divergence of the coordination chemistry between 3 and $\mathbf{1}$ is interesting because, of the two complexes that were formed in this reaction, 53 followed what could be predicted from the results of the reaction of $\left[\mathrm{PtMe}_{2}(1,5\right.$-hexadiene] with $\mathbf{1}$, while $54 \mathrm{did}$ not. The chelation reaction of 52 to form 53 and 54 occurs only at elevated temperatures, so observing shortlived intermediates of the reaction by NMR was infeasible. However, the presence of 53 and 54 in similar amounts suggests an initial mechanism related to the formation of the cis and trans isomers of $\mathbf{2 1}$, that is, through stepwise $\mathrm{C}-\mathrm{H}$ activation of the pendant aldehyde groups, each step followed by reductive elimination of methane. A proposed mechanism for the formation of $\mathbf{5 4}$ is therefore the initial formation and subsequent decarbonylation of an isomer of 53 that comprises mutually cis phosphines (55), wherein the decarbonylation is facilitated by either the electronic or steric influence of the phosphine groups (Scheme 39).

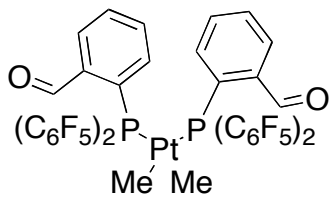

52

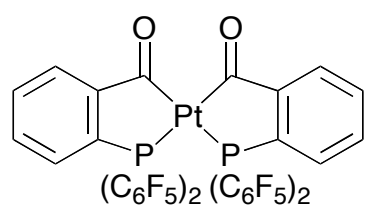

$54 a$

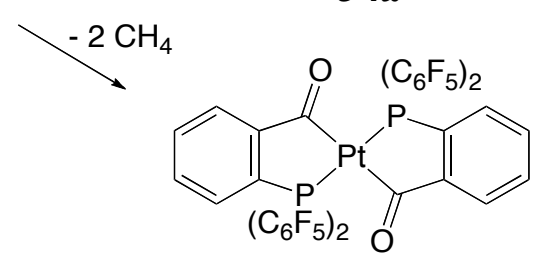

53
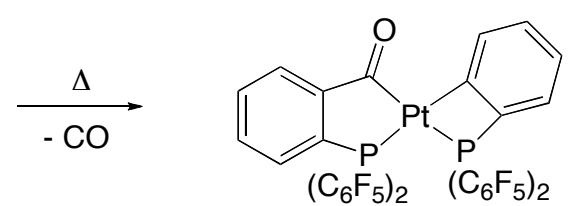

54 


\subsection{Coordination chemistry of 2-di-tert-butylphosphinobenzaldehyde with platinum(II)}

The synthesis of the ligand, 2-di-tert-butylphosphinobenzaldehyde (4), required more time than was originally anticipated, and as a result the investigation into its coordination chemistry with platinum was not as extensive as with compounds 1-3. However, a method for the preparation of 4 opens up the potential for derivatisation to imines through reactions with primary amines to afford an addition to the class of iminophosphines. Investigation into these variants fell outside the ambit of this research project, and was not explored. The coordination chemistry of 4 with platinum(II) was investigated.

Although compounds 3 and 4 have comparable cone angles, $\left(171^{\circ}\right.$ and $170^{\circ}$ for $\mathrm{PPh}\left(\mathrm{C}_{6} \mathrm{~F}_{5}\right)_{2}$ and $\mathrm{PPh}^{t} \mathrm{Bu}_{2}$, respectively), 4 was expected to have a larger steric profile than $3 .{ }^{16,23}$ The planar character of pentafluorophenyl groups allows them to interleave with other planar moieties, whereas tert-butyl groups do not have this feature. ${ }^{94}$ It was therefore anticipated that the coordination chemistry of $\mathbf{4}$ with platinum would involve mutually trans phosphine moieties to the exclusion of $c$ is isomers. The formation of platinum complexes with mutually cis di-tert-butylphenylphosphine ligands has, however, been reported by Immirzi et al., albeit in highly distorted complexes. ${ }^{111}$

Compound 4 and [ $\mathrm{PtMe}_{2}\left(1,5\right.$-hexadiene)] were combined in NMR tubes in $\mathrm{C}_{6} \mathrm{D}_{6}$ in $1: 1$ and 1:2 metal/ligand ratios order to observe the reaction pathway. Many resonances were observed both upfield of zero ppm and downfield of ten ppm in the ${ }^{1} \mathrm{H}$ NMR spectrum, indicating the presence of numerous different compounds containing platinum hydride and aldehyde groups. However, it was immediately apparent that the reaction involved the same stoichiometry as the reactions between $\mathbf{1}, 2$, or 3 with $\left[\mathrm{PtMe}_{2}(1,5\right.$-hexadiene)]; two molecules of 4 reacted with one platinum complex. Chelation of 4 occurred very rapidly, and the complex $\left[\mathrm{PtMe}\left(P, C-2-\mathrm{P}^{t} \mathrm{Bu}_{2} \mathrm{C}_{6} \mathrm{H}_{4} \mathrm{CO}\right)\left(2-\mathrm{P}^{t} \mathrm{Bu}_{2} \mathrm{C}_{6} \mathrm{H}_{4} \mathrm{CHO}\right)\right](60)$ was observed to be the major product after two minutes of reaction (Scheme 39). A tall, sharp peak at $0.16 \mathrm{ppm}$ in the ${ }^{1} \mathrm{H}$ NMR spectrum showed that methane had been eliminated from the complex. The ${ }^{31} \mathrm{P}$ NMR spectrum of 60 showed two sets of doublets at 78.7 and $43.0 \mathrm{ppm}$ (with ${ }^{1} J_{\mathrm{Pt}-\mathrm{P}}$ of 3458 and $2913 \mathrm{~Hz}$, respectively). The monodentate phosphine ligand of the complex appeared as a broadened doublet, although the peaks were sharp enough to enable the 
determination of ${ }^{3} J_{\mathrm{P}-\mathrm{P}}$ and ${ }^{1} J_{\mathrm{Pt}-\mathrm{P}}$ parameters. The chelated ligand had a ${ }^{31} \mathrm{P} \mathrm{NMR}$ chemical shift roughly $35 \mathrm{ppm}$ downfield from that of the monodentate ligand, and confirmed that chelation of one ligand had taken place to form a five-membered metallacycle as observed with the singly-metallated complexes 19 and 46. The phosphine moieties displayed ${ }^{3}$ P-P coupling of $369 \mathrm{~Hz}$ and confirmed that they occupied mutually trans coordination sites. In contrast to complexes 19 and 46, only the trans isomer was formed. The ${ }^{1} \mathrm{H}$ NMR showed a signal at $12.35 \mathrm{ppm}$, which integrated for one proton per complex and represented the pendant aldehyde. The chemical shift of the aldehyde was downfield from the free ligand, whereas for the platinum complexes of 1 and 3 that contain pendant aldehydes, the $\mathrm{CHO}$ resonance moves upfield upon coordination. Time constraints prohibited the separation and characterisation of many complexes, most of which were air-sensitive, and as such only the major products of reactions were characterised.

The pendant aldehyde in complex 60 reacted to form the bimetallated complex, $\left[\mathrm{Pt}\left(P, C-2-\mathrm{P}^{t} \mathrm{Bu}_{2} \mathrm{C}_{6} \mathrm{H}_{4} \mathrm{CO}\right)_{2}\right]$ (61) gradually at room temperature (Scheme 40). Complex 61 had a relatively low solubility in benzene, and slowly crystallised from solution as pale yellow prismatic crystals. The complex showed no aldehyde $\mathrm{CHO}$ proton resonance in the ${ }^{1} \mathrm{H}$ NMR spectrum, and had a ${ }^{31} \mathrm{P}$ NMR chemical shift of $82.0 \mathrm{ppm}$. As the chemical shift was a singlet and roughly $39 \mathrm{ppm}$ downfield of any monodentate phosphine ligands it was clear that the complex was symmetrical, bimetallated and comprised of five-membered rings. ${ }^{63}$ The ${ }^{1} \mathrm{Jt}_{\mathrm{Pt}-\mathrm{P}}$ value of $3307 \mathrm{~Hz}$ meant that the phosphine atoms were mutually trans, which was expected due to the large steric bulk of the phosphine substituents. ${ }^{18}$

$\left[\mathrm{PtMe}_{2}(1,5\right.$-hexadiene) $]$
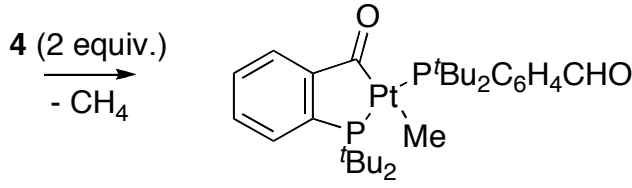

60

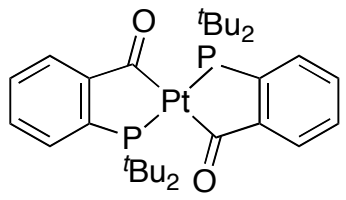

61

\section{Scheme 40}

The rapidity of the chelation of one ligand to form 60 is interesting in that an expected intermediate complex, $\left[\mathrm{PtMe}_{2}\left(2-\mathrm{P}^{t} \mathrm{Bu}_{2} \mathrm{C}_{6} \mathrm{H}_{4} \mathrm{CHO}\right)_{2}\right]$, was not observed. In order to characterise the reaction in greater detail, low-temperature ${ }^{1} \mathrm{H}$ and ${ }^{31} \mathrm{P}$ NMR experiments were carried out during the initial stages of the reaction. The reactants were separately dissolved in $d_{8}$-toluene, cooled to $-78{ }^{\circ} \mathrm{C}$, and then combined in an NMR tube. The mixture 
was kept at $-78{ }^{\circ} \mathrm{C}$ until it was analysed with $\mathrm{NMR}$ at -30 and $-15^{\circ} \mathrm{C}$. No reaction was observed at $-30{ }^{\circ} \mathrm{C}$ at a rate that could be observed with NMR, but when the reaction was warmed to $-15{ }^{\circ} \mathrm{C},{ }^{31} \mathrm{P}$ NMR showed the formation of complex 60 without showing any signal that could be assigned to a fully monodentate intermediate complex. This experiment illustrated a much greater propensity toward chelation for ligand 4 than for any other ligand studied in this research project. The reaction of 3 with $\left[\mathrm{PtMe}_{2}(1,5\right.$-hexadiene)] was only observed to produce a monodentate complex (chelation requires elevated temperatures), and the reaction of 1 with $\left[\mathrm{PtMe}_{2}(1,5\right.$-hexadiene)] produced a singly chelated complex at room temperature (22), but that reaction went through an observable monodentate complex. Considering the similar steric bulk of 3 and 4 , it is likely that the susceptibility to chelation of 4 with platinum(II) is based on electronic, rather than steric, factors.

A similar reaction pathway to that observed with dimethylplatinum(1,5-hexadiene) was also observed when $[\mathrm{PtClMe}(1,5$-hexadiene $)]$ was used as the starting material. [PtClMe(1,5-hexadiene)] was used in order to reduce the reactivity of the platinum centre, and therefore to increase selectivity towards one product, namely the singly metallated complex. The 2:1 reaction of 4 with [PtClMe(1,5-hexadiene)] resulted in the formation of the chloro analogue of $60,\left[\mathrm{PtCl}\left(P, C-2-\mathrm{P}^{t} \mathrm{Bu}_{2} \mathrm{C}_{6} \mathrm{H}_{4} \mathrm{CO}\right)\left(2-\mathrm{P}^{t} \mathrm{Bu}_{2} \mathrm{C}_{6} \mathrm{H}_{4} \mathrm{CHO}\right)\right]$ (62) (Scheme 41). Complex 62 showed very similar NMR parameters to 60: the complex contained mutually trans phosphine groups $\left({ }^{3} J_{\mathrm{P}-\mathrm{P}}=341 \mathrm{~Hz}\right)$ with chemical shifts of 78.3 and $44.7 \mathrm{ppm}$. The ${ }^{1} J_{\mathrm{Pt}-\mathrm{P}}$ values, at 3617 and $3473 \mathrm{~Hz}$ for the chelated and monodentate ligands, respectively, were larger than those for complex 59. In contrast to the reaction of 1 with [PtMe 2 (1,5-hexadiene)], which formed complex 19 gradually over the course of one day at room temperature, the formation of 62 was very rapid, and no monodentate intermediate complex was observed (Scheme 41). ${ }^{34}$

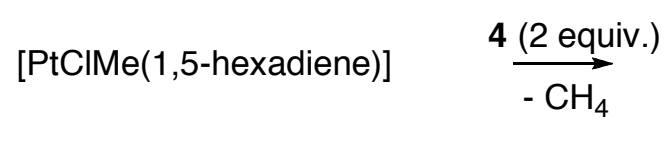

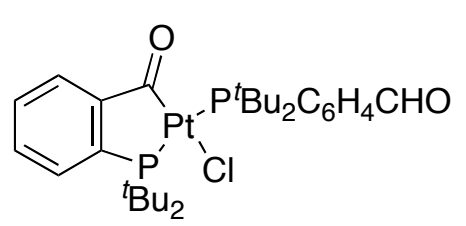

62

Scheme 41

Many reaction products of $\left[\mathrm{PtMe}_{2}(1,5\right.$-hexadiene $\left.)\right]$ with 4 were air-sensitive, and in the presence of air the aldehyde group of one ligand converted to a carboxylate, forming a sixmembered ring through a platinum-oxygen bond. This complex had a very low solubility in 
benzene or toluene, and crystallised from solution as purple rhombohedral crystals. HR-ESIMS, and NMR and infrared (IR) spectroscopy were used to characterise the complex as $\left[\mathrm{Pt}\left(P, C-2-\mathrm{P}^{t} \mathrm{Bu}_{2} \mathrm{C}_{6} \mathrm{H}_{4} \mathrm{CO}\right)\left(P, O-2-\mathrm{P}^{t} \mathrm{Bu}_{2} \mathrm{C}_{6} \mathrm{H}_{4} \mathrm{COO}\right)\right]$ (63). ${ }^{31} \mathrm{P}$ NMR data showed the complex contained mutually trans phosphine moieties $\left(3_{\mathrm{P}-\mathrm{P}}=324.5 \mathrm{~Hz}\right)$, wherein the phosphine in the five-membered metallacycle resonated at $78.8 \mathrm{ppm}$ with a ${ }^{1} J_{\mathrm{Pt}-\mathrm{P}}$ of $3673.9 \mathrm{~Hz}$ while the phosphine of the six-membered, carboxylate-containing metallacycle resonated at $42.2 \mathrm{ppm}$ with a ${ }^{1} \mathrm{Jt}_{\mathrm{Pt}-\mathrm{P}}$ of $3134 \mathrm{~Hz} .{ }^{13} \mathrm{C}$ NMR spectroscopy showed both the metallated aldehyde and carboxylate carbonyl groups at 200.6 and $174.3 \mathrm{ppm}$, respectively. The IR spectrum clearly showed two different $\mathrm{C}=\mathrm{O}$ stretches at 1638 and $1612 \mathrm{~cm}^{-1}$, and the $\mathrm{m} / \mathrm{z}$ ratio showed confirmed this was due to the formation of a carboxylate.

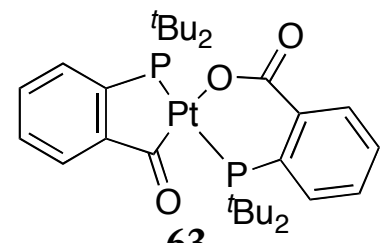

63 


\subsection{Evaluation of coordination chemistry and ligand reactivity}

\subsubsection{Comparison of the coordination chemistry of phosphinoaldehyde ligands 1,3 , and 4}

One of the primary aims of this thesis was to investigate the mechanism of chelation of the phosphinoaldehyde, 2-diphenylphosphinobenzaldehyde (1), and to assess the extent to which the manipulation of its steric and electronic parameters could modify its coordinative reactivity. Ligands 2, 3 and 4 were used to qualitatively assess this objective.

Ligands 3 and $\mathbf{4}$ have similar Tolman cone angles, and are very bulky compared to ligand $\mathbf{1}$. The cone angle for $\mathrm{PPh}_{3}$ is $145^{\circ}$, while for $\mathrm{PPh}\left(\mathrm{C}_{6} \mathrm{~F}_{5}\right)_{2}$ and $\mathrm{PPh}^{t} \mathrm{Bu}_{2}$ the cone angles are $171^{\circ}$ and $170^{\circ}$, respectively. The influence of the electronic parameter in chelation was also assessed through the analysis of the coordination chemistry of 3 and 4 ; ligand 3 is much less electron donating than $\mathbf{1}$ while ligand $\mathbf{4}$ is much more donating.

Scheme 42 shows the marked difference in coordination chemistry between ligands 1,3 , and 4. The reaction between two equivalents of 1 and [ $\mathrm{PtMe}_{2}(1,5$-hexadiene)] initially formed the monodentate phosphine platinum complex, 18, and over one day formed complex 19. Formation of the bimetallated complex, 21, required reflux in toluene.

The reaction between $\left[\mathrm{PtMe}_{2}(1,5\right.$-hexadiene)] with 3 was much slower than with 1 . The reaction to form the monodentate phosphine complex, 52, took over one day and no chelation products formed at room temperature. Chelation required heating, which produced two complexes: a trans bimetallated complex, 53, and a decarbonylated complex, 54 .

In contrast to the slow reaction between $\left[\mathrm{PtMe}_{2}(1,5\right.$-hexadiene)] and ligand 3 at room temperature, the major initial products of the reaction of 4 with $\left[\mathrm{PtMe}_{2}(1,5\right.$-hexadiene)] or [PtClMe(1,5-hexadiene)] were the singly metallated complexes, 60 or $\mathbf{6 2}$. No monodentate complexes were observed, even when the initial stages of the reaction were monitored by NMR at low temperature. The bimetallated complex, 61 , was also observed to form at room temperature. Furthermore, while the reactions of 1 and 3 with [ $\mathrm{PtMe}_{2}(1,5$-hexadiene)] produced a sequence of relatively specific products, the same reaction with 4 resulted in a large number of products being produced very rapidly. 
The rate of reaction and the conditions required for the $\mathrm{C}-\mathrm{H}$ activation and concomitant chelation - from monodentate phosphine platinum complexes to singly metallated complexes to doubly metallated complexes - appear to be determined by the electronic nature of the phosphine. Although 3 and 4 have similar steric profiles, chelation of 4 is very rapid and proceeds at room temperature whereas ligand 3 requires elevated temperatures to chelate at all. Compound 1 has a rate of chelation that lies in between ligands 3 and 4 , suggesting that the trend in reactivity is related to the decreasing TEP of the ligands. However, the differences in coordination chemistry between 1,3 , and 4 cannot be definitively ascribed to either steric or electronic effects, and the two influences are likely to operate in tandem. Steric influences are likely to play a part in the coordination chemistry of the reactants; for example, complexes of 4 contained phosphines that were all in mutually trans positions. However, the metallated complexes of 3 (53 and 54) comprised trans and cis geometries, which may be due to the interleaving potential of the planar pentafluorophenyl rings. The steric crowding in intermediate complexes of 3 where the phosphines were mutually cis may have contributed toward the decarbonylation of one of the ligands. 


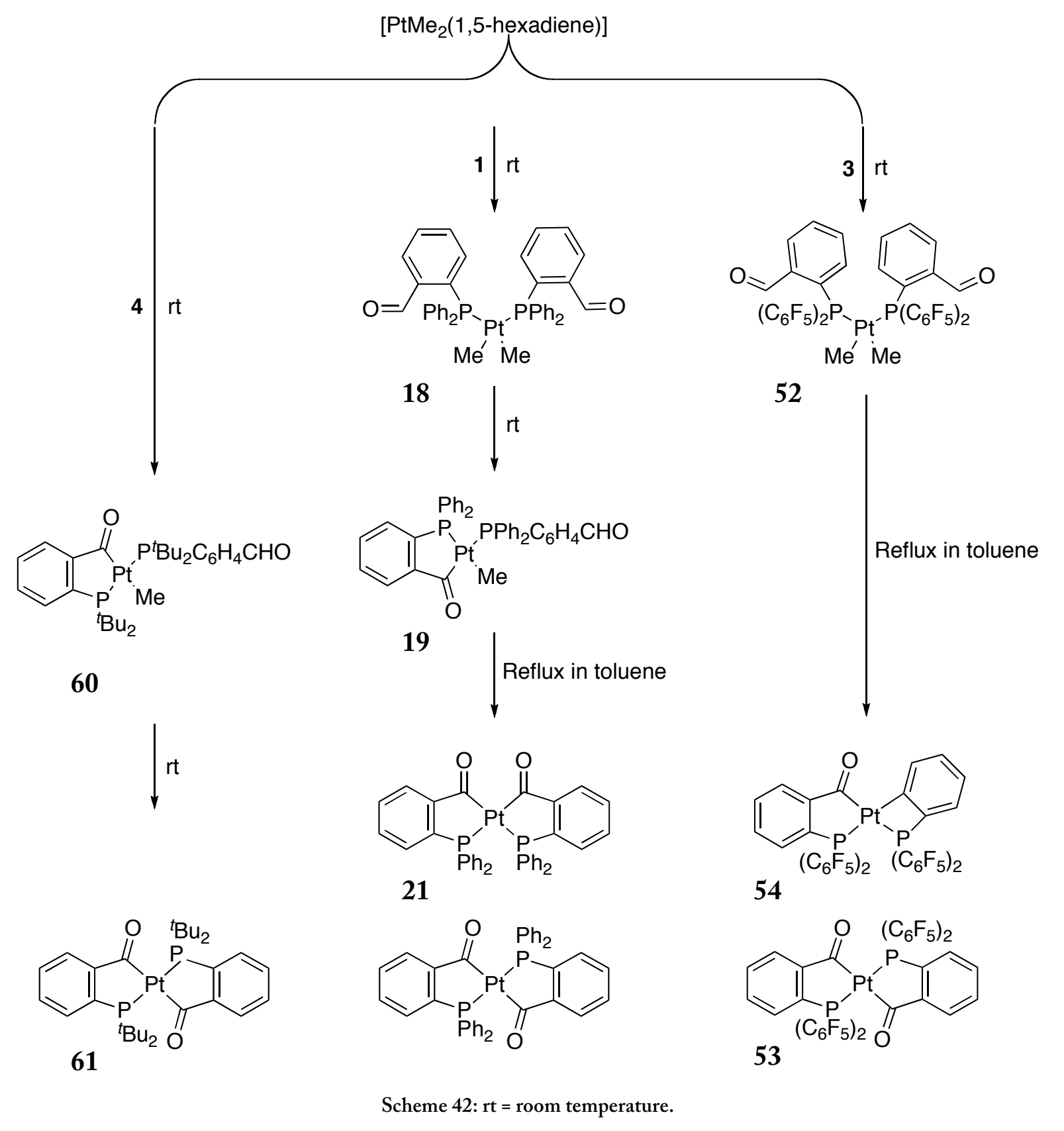

3.5.2 Comparison of the coordination chemistry of phosphinocarbonyl ligand 1 and ketophosphine ligand 2

The reactions of 1 and 2 with [ $\mathrm{PtMe}_{2}(1,5$-hexadiene)] appeared to follow very similar reaction pathways (Scheme 43). In both reactions, the coordination of the phosphine moieties was followed by $\mathrm{C}-\mathrm{H}$ activation of an aldehyde $\mathrm{CHO}$ for $\mathbf{1}$ or the methyl group of the ketone for 2. Formation of the bimetallated complexes 21 and 47 only occurred at 
elevated temperatures, although the preparation of complex 47 could be carried out at lower temperatures than for the preparation of 21.

The reaction pathways of 1 and 2 with $\left[\mathrm{Pt}(\mathrm{nb})_{3}\right]$ diverged after the $\mathrm{C}-\mathrm{H}$ activation of one ligand. Whereas the first $\mathrm{C}-\mathrm{H}$ activation of 1 produced an isolable 2-norbornyl intermediate, $\mathrm{C}-\mathrm{H}$ activation of 2 resulted in the formation of a platinum hydride intermediate containing a six-membered $P, C$ chelate ring (49), where the hydride then reacted with the pendant ketone group (which was probably platinum-mediated) converting it to a hydroxyl moiety (Scheme 43). It is interesting that the $\mathrm{C}-\mathrm{H}$ activation of 1 and 2 did not follow the same reaction pathway; late transition metal intermediates containing norbornyl ligands are relatively well known, as are complexes that result from the reduction of carbonyls to hydroxyls by interaction with metal hydrides. ${ }^{4}$

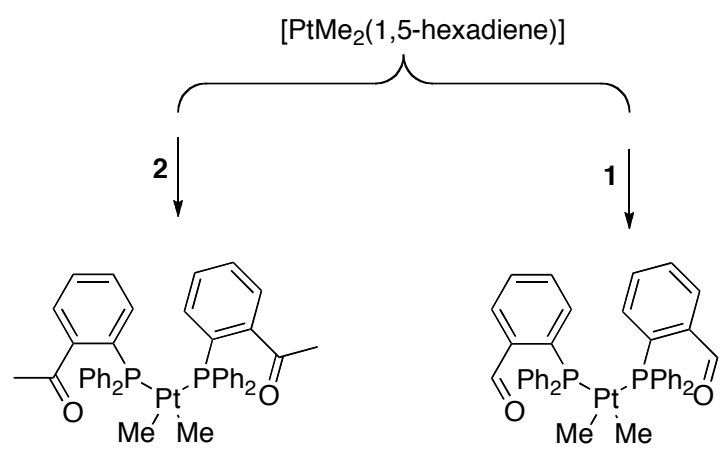

45

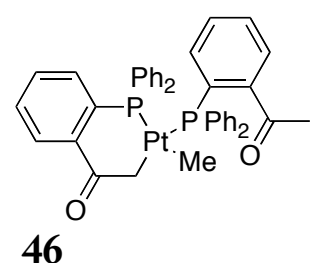

46

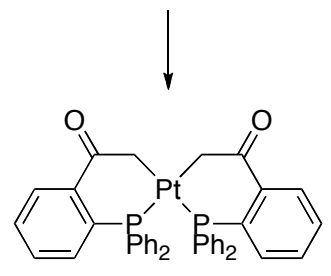

47
18
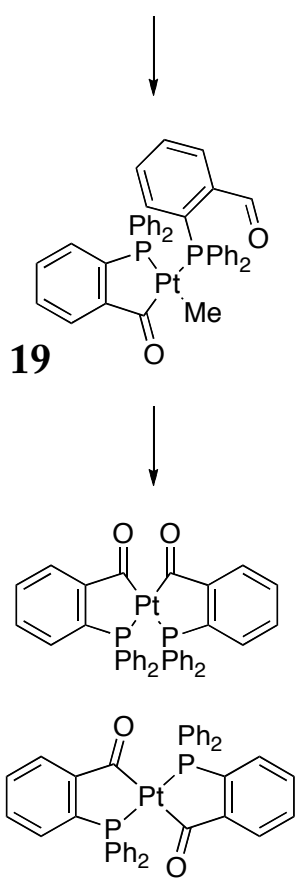

21
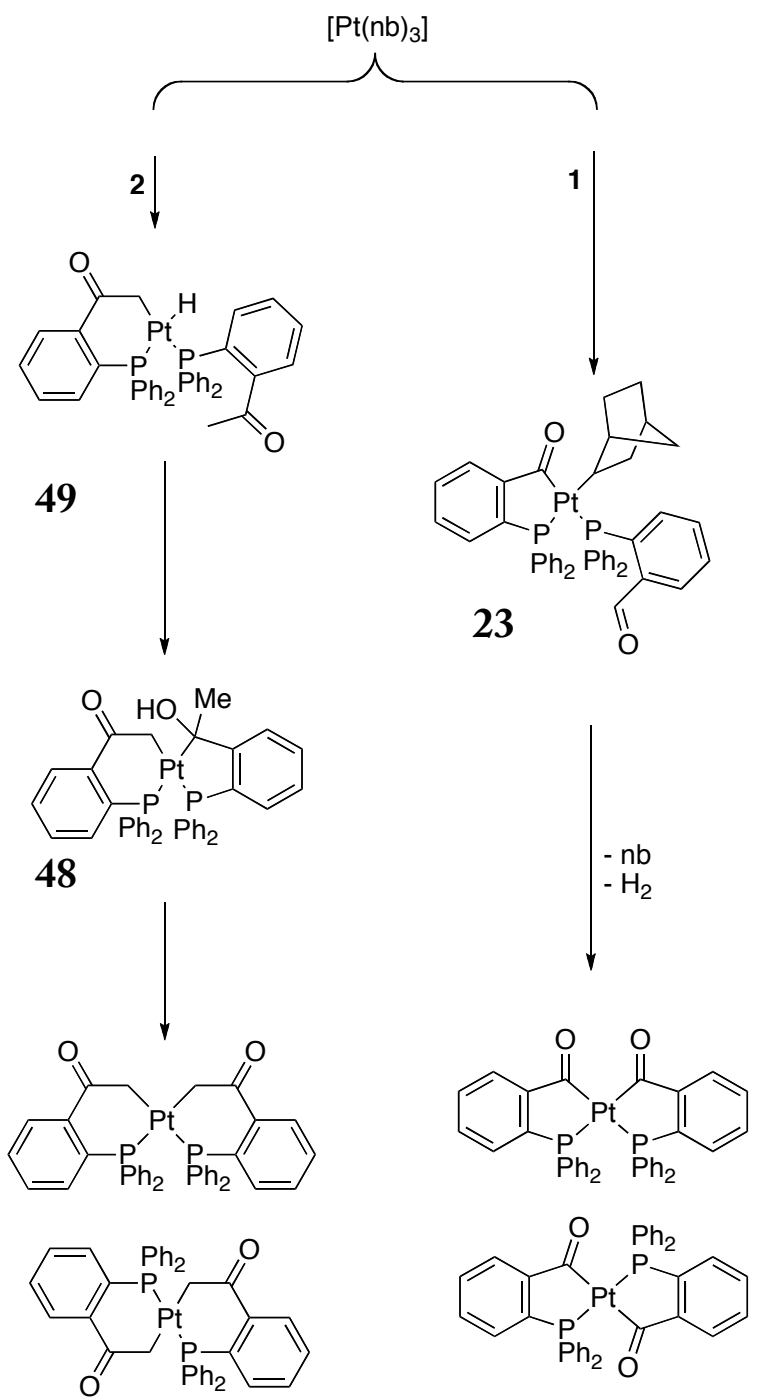

47<smiles>O=C1Pc2ccccc2C(=O)P(=P)(P)c2ccccc21</smiles>

21

Scheme 43 


\section{Conclusion}

The diversity of the coordination chemistry of phosphinocarbonyl ligands is due to the strong coordinating ability of phosphorus and the multiple modes through which the carbonyl group can to coordinate. The strong metal-phosphorus bond that forms in coordination reactions tethers the carbonyl moiety in close proximity to the metal, which increases its reactivity. This enables a wider range of reactivity than is commonly observed with carbonyl-containing compounds without a good ligating atom.

The primary aim of this research project was to investigate the role of the phosphine substituents in the coordination chemistry of phosphinocarbonyl compounds. To accomplish this, ligands $1-4$, were synthesised and reacted with platinum, and the resulting complexes that formed were characterised and compared. Compound 4 had not previously been reported, and a number of different synthetic strategies were attempted before a successful preparation method using organolithium reagents was established. Compounds 3 and 4 contained much bulkier phosphine substituents than the phenyl substituents of 1 . Of the bulky ligands, 3 and 4, compound 3 contained electron withdrawing pentafluorophenyl substituents and compound 4 contained electron donating tert-butyl substituents. This enabled the steric and electronic effects to be somewhat separated in the analysis of coordination reactions.

The coordination chemistry of ligands $\mathbf{1 - 4}$ with platinum showed that, in every case, $\mathrm{C}-\mathrm{H}$ activation was the mechanism by which the carbonyl moiety coordinated to the metal. The rate of chelation, however, appeared to be strongly influenced by the electronic character of the phosphine substituents: phosphines with more electron donating substituents chelated more rapidly and at lower temperatures than phosphines with electron withdrawing substituents. The similarity in cone angle between 3 and 4 more strongly suggests that electronic influences predominate. However, it cannot be rejected that large cone angles of the bulky phosphines in ligands 3 and 4 may have contributed towards some of the divergence in coordination chemistry, such as the decarbonylation of one ligand in complex 53 and for the exclusively trans configuration of the phosphines in complexes of ligand 4. 
The formation of the doubly metallated complexes 53 and 54 from compound 3 was also interesting as compound $\mathbf{5 4}$ was a product of decarbonylation, a process not observed for the same reaction with compound 1 . Single-crystal X-ray diffraction of compound 54 showed that it had a platinum-phosphorus bond longer than any other reported thus far.

The coordination chemistry of compound 1 with platinum has been reported previously, and it is well known that it can chelate to metals via $\mathrm{C}-\mathrm{H}$ activation. However, the doubly metallated complex, 21, has not previously been reported. The cis isomer of platina- $\beta$-diketone, 21 , is an interesting addition to the class of metalla- $\beta$-diketones previously reported by Lukehart, Steinborn, and Garralda. The diketone moiety of cis-21 was shown to have a relatively diverse chemistry in itself; it is capable of coordinating to a number of Lewis acids, such as $\mathrm{H}^{+}(31), \mathrm{Li}^{+}(32), \mathrm{BF}_{2}^{+}(44)$, and $[\mathrm{Rh}(\mathrm{COD})]^{+}$(38). Protonation of $\mathbf{2 1}$ followed by its reaction with a primary amine or ammonia results in the formation of platina- $\beta$-ketoimines.

Chelation of the ketophosphine ligand, 2, also proceeded through $\mathrm{C}-\mathrm{H}$ activation. Singly and doubly metallated complexes (46 and 47 , respectively) were isolated from the reaction with $\left[\mathrm{PtMe}_{2}(1,5\right.$-hexadiene) $]$. Reaction of 2 with $\left[\mathrm{Pt}(\mathrm{nb})_{3}\right]$, however, produced the partially reduced complex, 48 - a divergence from the reactivity of 1 with platinum(0).

The time limit of the research project meant that future work in the investigation of compounds 3 and 4 with platinum(0) is necessary to provide a more comprehensive analysis of the coordination chemistry. The coordination chemistry of these compounds has been virtually unexplored, and the interesting differences between their coordination chemistry and that of 1 raise the potential for their more detailed investigation with platinum and other transition metals. Furthermore, the successful preparation of 4 means that the synthesis of the related iminophosphine and the investigation of its coordination chemistry is now possible.

The comparison of the coordination chemistry of ligands 1-4 shows that the steric and electronic parameters of the phosphine substituents have a strong effect on the rate of chelation, the identity and stability of reaction intermediates, and the structure of the final product. The platinum complexes produced were markedly different for each ligand, however, the ultimate coordination mode of phosphinocarbonyls 1-4 was a $P, C$ chelate 
formed through $\mathrm{C}-\mathrm{H}$ activation. The propensity toward this coordination mode and the inert $\mathrm{Pt}-\mathrm{P}$ and $\mathrm{Pt}-\mathrm{C}$ bonds that are formed illustrates a major limitation on the use of these compounds as $P, O$ ligands with late transition metals.

Although it is difficult to separate steric and electronic influences in coordination chemistry, it is likely that reactivity is predominantly controlled by the electronic influence of the phosphine. The reactivity of phosphinocarbonyls with platinum reported in this thesis is not unprecedented with late transition metals; however, the role of the phosphine moiety in these reactions has become more evident, and this understanding may assist in the rational design of new phosphinocarbonyl ligands for organometallic synthesis in the future. 


\section{Experimental}

\subsection{General procedures}

Unless otherwise stated, all reactions and manipulations of products and reagents were carried out under an inert gas atmosphere of either nitrogen or argon using standard Schlenk techniques. Diethyl ether and tetrahydrofuran (THF) were dried by refluxing over sodium/benzophenone ketyl. Other high purity solvents and analytical grade reagents were degassed and purged with inert gas before use. Tris(norbornene)platinum ${ }^{113}$, dimethylplatinum(1,5-hexadiene $)^{113}$, bis(1,5-cyclooctadiene)platinum ${ }^{114}, \mathrm{CH}_{2}\left(\mathrm{SO}_{2} \mathrm{CF}_{3}\right)_{2}{ }^{115}$, $\mathrm{CHPh}\left(\mathrm{SO}_{2} \mathrm{CF}_{3}\right)_{2}{ }^{115}$, and $[\mathrm{Rh}(\mathrm{OMe})(1,5 \text {-cyclooctadiene })]_{2}{ }^{116}$ were prepared according to literature methods. Metal complex starting materials were stored at $-20{ }^{\circ} \mathrm{C}$. Deuterated solvents were degassed using the freeze-pump-thaw technique and stored over $3 \AA\left(\mathrm{CD}_{2} \mathrm{Cl}_{2}\right)$, $4 \AA\left(\mathrm{CDCl}_{3}\right)$, or $5 \AA\left(\mathrm{C}_{6} \mathrm{D}_{6}\right)$ molecular sieves. NMR spectra were recorded using a Varian Unity Inova 300 Spectrometer $\left(300 \mathrm{MHz}\right.$ for ${ }^{1} \mathrm{H}, 75 \mathrm{MHz}$ for ${ }^{13} \mathrm{C}, 121 \mathrm{MHz}$ for ${ }^{31} \mathrm{P}$, and $282 \mathrm{MHz}$ for ${ }^{19} \mathrm{~F}$ ), a Varian Unity Inova 500 Spectrometer $\left(500 \mathrm{MHz}\right.$ for ${ }^{1} \mathrm{H}$ and $125 \mathrm{MHz}$ for ${ }^{13} \mathrm{C}$ ), or a Varian DirectDrive 600 Spectrometer equipped with a triple-resonance $\mathrm{HCN}$ cryogenic probe $\left(600 \mathrm{MHz}\right.$ for ${ }^{1} \mathrm{H}, 150 \mathrm{MHz}$ for $\left.{ }^{13} \mathrm{C}\right) .{ }^{1} \mathrm{H}$ and ${ }^{13} \mathrm{C}$ NMR chemical shifts were referenced to the residual solvent peak. ${ }^{84}{ }^{31} \mathrm{P}$ NMR chemical shifts were referenced to external $85 \% \mathrm{H}_{3} \mathrm{PO}_{4}$; positive values indicate downfield shifts. Low temperature NMR was carried out using the Varian Unity Inova $300 \mathrm{MHz}$ NMR spectrometer. Infrared spectra were recorded with a PerkinElmer Spectrum One FT-IR spectrophotometer using pressed $\mathrm{KBr}$ discs. Elemental analyses were performed by the Campbell Microanalytical Laboratory at the University of Otago. High-resolution electrospray ionisation mass spectra (HR-ESIMS) were performed by the GlycoSyn QC laboratory at Industrial Research Limited using a Waters Q-TOF Premier Tandem mass spectrometer.

\subsection{Crystallography}

Single crystal X-ray diffraction data were recorded by the X-ray crystallography Laboratory at the University of Canterbury and The Chemical Crystallography Laboratory at Durham University, United Kingdom. Diffraction data were collected for 21 on a Bruker SMART CCD diffractometer using Mo K $\alpha$ radiation (0.71073 $\mathrm{A})$ from fine-focus sealed tubes with 
graphite monochromators, using phi and omega scans. Data were reduced using Bruker SAINT software. Absorption correction was performed using the SADABS program. The structure was solved using the Patterson method and full-matrix least squares refinement, with anisotropic thermal parameters for all non-H atoms. Hydrogen atoms were in calculated positions and refined using a riding model with SHELXL97 defaults. ${ }^{112}$

Diffraction data for 31 and 54 were collected using an Oxford Diffraction Gemini Ultra diffractometer, solved, and refined by Dr Horst Puschmann at Durham University, United Kingdom. The structure of $\mathbf{3 1}$ was solved using the charge flipping algorithm implemented in olex2.solve ${ }^{77}$ and refined using olex2.refine. ${ }^{76}$

Molecular drawings were produced with ORTEP-3 software.

\subsection{Ligand synthesis}

\subsubsection{2-Diphenylphosphinobenzaldehyde (1)}

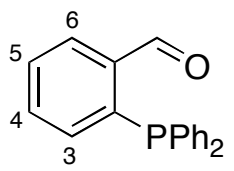

Magnesium turnings $(1.0 \mathrm{~g}, 41.1 \mathrm{mmol})$ were dry-stirred overnight in a flame-dried $500 \mathrm{~mL}$ three-necked round bottom flask equipped with a pressure equalising dropping funnel and a condenser connected to a nitrogen supply. THF $(90 \mathrm{~mL})$ was added to the flask and the dropping funnel was charged with 2-bromobenzaldehyde diethyl acetal. Without stirring, 1,2-dibromoethane $(0.1 \mathrm{~mL})$ was injected into the turnings and the base of the reaction flask was heated gently. After 30 minutes, 2-bromobenzaldehyde diethyl acetal was added dropwise with stirring. At the end of the addition, the dropping funnel was rinsed with a small quantity of THF. The reaction was heated throughout the addition to maintain a gentle reflux. The colour of the solution had changed to orange, and a few specks of magnesium remained in the reaction flask. The reaction flask was immersed in an ice-water bath and the dropping funnel was charged with chlorodiphenylphosphine $(7.1 \mathrm{~mL}$, $39.6 \mathrm{mmol}$, diluted with $20 \mathrm{~mL}$ of THF), which was added dropwise with stirring. After addition was complete, the reaction was heated at reflux overnight. The dark brown reaction mixture was cooled to room temperature and a saturated solution of ammonium chloride $(10 \mathrm{~mL})$ was added followed by distilled water $(20 \mathrm{~mL})$. The biphasic solution was 
transferred to a separating funnel, where the aqueous layer was separated and washed with diethyl ether $(2 \times 40 \mathrm{~mL})$ and the organic layer was washed with a saturated solution of sodium chloride $(2 \times 40 \mathrm{~mL})$. The organic fractions were combined, dried over magnesium sulfate, filtered into a round bottom flask, and the solvent was removed in vacuo to yield a transparent yellow oil, which was characterised as 2-diphenylphosphinobenzaldehyde diethyl acetal. The product was recrystallised from a solution of $13 \mathrm{~mL}$ of hot ethanol cooled to $-20{ }^{\circ} \mathrm{C}$. Recrystallised yield: $12.64 \mathrm{~g}, 88 \%$.

The recrystallised material was transferred to a round bottom flask fitted with a reflux condenser and dissolved in acetone $(150 \mathrm{~mL})$. para-Toluenesulfonic acid monohydrate (200 mg) was added and the mixture was heated to reflux for five hours. Once cooled the solvent was removed in vacuo to yield a crude sample of 1 . The crude solid was recrystallised from $27 \mathrm{~mL}$ of hot dichloromethane/methanol solution (1:1) cooled to $-20{ }^{\circ} \mathrm{C}$. Recrystallised yield: $6.60 \mathrm{~g}, 58 \%$.

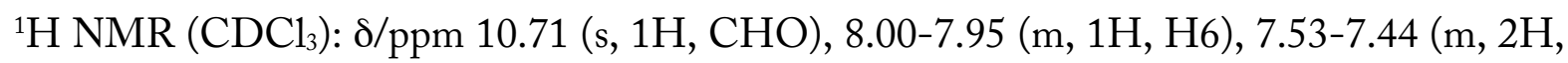
$\mathrm{H} 4$ and $\mathrm{H} 5), 7.38-7.26(\mathrm{~m}, 10 \mathrm{H}, \mathrm{Ar}-\mathrm{H}), 6.99-6.64(\mathrm{~m}, 1 \mathrm{H}, \mathrm{H} 3) .{ }^{13} \mathrm{C}\left\{{ }^{1} \mathrm{H}\right\}\left(\mathrm{CDCl}_{3}\right), \delta / \mathrm{ppm}$ 191.9 (d, JP-C $=19 \mathrm{~Hz}, \mathrm{CHO}), 141.4$ (s, Ar-C), 138.5 (d, JP-C $=7 \mathrm{~Hz}, \mathrm{Ar}-\mathrm{C}$ ), 136.2 (d, $J_{\mathrm{P}-\mathrm{C}}=10 \mathrm{~Hz}, \mathrm{Ar}-\mathrm{C}$ ), 134.3 (s, Ar-C), 134.1 (s), Ar-C, 134.0 (s, Ar-C), 133.8 (s, Ar-C), 130.9 (d, JP-C $=4$ Hz, Ar-C), 129.3 (s, Ar-C), 129.0 (s, Ar-C), 128.9 (d, JP-C $=7$ Hz, Ar-C). ${ }^{31} \mathrm{P}\left\{{ }^{1} \mathrm{H}\right\} \mathrm{NMR}\left(\mathrm{CDCl}_{3}\right): \delta / \mathrm{ppm}-10.9(\mathrm{~s})$.

\subsubsection{2-Diphenylphosphinoacetophenone (2)}<smiles>CC(=O)c1ccccc1-c1ccccc1</smiles>

To a flame-dried Schlenk tube with stir bar was added potassium metal (0.46 g, $12 \mathrm{mmol}$, washed with hexane) in small chips. THF $(20 \mathrm{~mL})$ was added, and the Schlenk tube was cooled to $-78{ }^{\circ} \mathrm{C}$. Diphenylphosphine $(2.1 \mathrm{~mL}, 12 \mathrm{mmol})$ was added and the reaction was stirred overnight allowing the mixture to gradually warm to room temperature. The reaction mixture turned red overnight, indicating the formation of $\mathrm{KPPh}_{2}$. 2-Fluoroacetophenone $(1.4 \mathrm{~mL}, 11 \mathrm{mmol})$ was added. A reflux condenser was attached to the Schlenk tube, and the reaction was heated to reflux for 30 minutes, whereupon the reaction mixture turned yellow. 
The reaction was cooled and water $(30 \mathrm{~mL})$ was added followed by dichloromethane $(30 \mathrm{~mL})$. The biphasic solution was transferred to a separating funnel, the organic layer was separated and the aqueous layer was washed with dichloromethane $(2 \times 15 \mathrm{~mL})$. The organic fractions were combined and dried over magnesium sulfate, filtered, and the solvent was removed in vacuo. The product was recrystallised from hot methanol (ca. $25 \mathrm{~mL}$ ) to yield yellow crystals of 2 . Recrystallised yield: $2.40 \mathrm{~g}, 66 \%$.

${ }^{1} \mathrm{H} \mathrm{NMR}\left(\mathrm{CDCl}_{3}\right)$ : $\delta / p p m ~ 7.95$ (m, 1H, H6), 7.47-7.26 (m, 12H, Ar-H), 7.04-7.01 (m, 1H, $\mathrm{H} 3), 2.59$ (s, 3H, $\left.\mathrm{CH}_{3}\right) \cdot{ }^{13} \mathrm{C}\left\{{ }^{1} \mathrm{H}\right\} \operatorname{NMR}\left(\mathrm{C}_{6} \mathrm{D}_{6}\right): \delta / \mathrm{ppm} 197.4$ (s, CO), 141.7 (d, $\left.J_{\mathrm{P}-\mathrm{C}}=17.3 \mathrm{~Hz}, \mathrm{C} 1\right), 140.9\left(\mathrm{~d}, J_{\mathrm{P}-\mathrm{C}}=29.3 \mathrm{~Hz}, \mathrm{C} 2\right), 139.7\left(\mathrm{~d}, J_{\mathrm{P}-\mathrm{C}}=12.0 \mathrm{~Hz}, \mathrm{Ar}-\mathrm{C}\right), 135.2(\mathrm{~s}$, Ar-C), 134.5 (s, Ar-C), 134.3 (s, Ar-C), 131.6 (s, Ar-C), 130.2 (d, JP-C = 2.9 Hz, Ar-C), 128.73 (s, Ar-C), 128.67 (s, Ar-C), 128.6 (s, Ar-C), 128.4 (s, Ar-C), 128.2 (s, Ar-C), 128.0 (s, Ar-C), $27.4\left(\mathrm{~s}, \mathrm{CH}_{3}\right) .{ }^{31} \mathrm{P}\left\{{ }^{1} \mathrm{H}\right\} \mathrm{NMR}\left(\mathrm{CDCl}_{3}\right): \delta / \mathrm{ppm}-2.3$ (s).

\subsubsection{2-Bis(pentafluorophenyl)phosphinobenzaldehyde (3)}

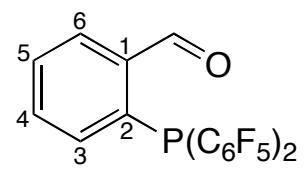

Magnesium turnings (229 mg, $9.4 \mathrm{mmol}$ ) were dry-stirred overnight in a two-necked round bottom flask equipped with a pressure equalising dropping funnel and a condenser attached to a nitrogen adaptor. THF $(20 \mathrm{~mL})$ was added to the flask and the dropping funnel was charged with 2-bromobenzaldehyde diethyl acetal (1.7 mL, $8.5 \mathrm{mmol}$, in $10 \mathrm{~mL}$ THF). Without stirring, about $0.1 \mathrm{~mL}$ of 1,2-dibromoethane was injected directly into the magnesium turnings and left for 15 minutes, followed by the addition of about ten drops of 2-bromobenzaldehyde diethyl acetal. The solution was warmed until a fairly vigorous bubbling was sustained and the rest of the 2-bromobenzaldehyde diethyl acetal was added at a rate keep the reaction flask warm. After addition was complete, the reaction was heated at reflux for 30 minutes, leaving an amber solution with a little magnesium remaining. The dropping funnel was charged with a solution of bromobis(pentafluorophenyl)phosphine $(1.94 \mathrm{~mL}, 8.5 \mathrm{mmol}$ in $10 \mathrm{~mL}$ THF). With stirring, the solution was added dropwise at a rate that warmed the solution but did not bring it to reflux. After addition, the solution was heated at reflux overnight. The reaction was cooled and $10 \%$ aqueous ammonium chloride solution $(10 \mathrm{~mL})$ was added to the mixture. The organic fraction was separated using a 
separating funnel and transferred to a round bottom flask and the aqueous layer was washed with diethyl ether $(2 \times 6 \mathrm{~mL})$. The solvent was removed in vacuo leaving a pale yellow oil of 2- $\mathrm{P}\left(\mathrm{C}_{6} \mathrm{~F}_{5}\right)_{2} \mathrm{C}_{6} \mathrm{H}_{4} \mathrm{CH}(\mathrm{OEt})_{2}$. The product was used without further purification.

In a round bottom flask fitted with a reflux condenser, 2- $\mathrm{P}\left(\mathrm{C}_{6} \mathrm{~F}_{5}\right)_{2} \mathrm{C}_{6} \mathrm{H}_{4} \mathrm{CH}(\mathrm{OEt})_{2}$ was dissolved in acetone $(20 \mathrm{~mL})$ and para-toluenesulfonic acid $(45 \mathrm{mg})$ was added. The solution was heated at reflux for five hours, at which point ${ }^{1} \mathrm{H}$ and ${ }^{31} \mathrm{P}$ NMR analysis of a sample indicated complete deprotection. The reaction was cooled and the solvent was removed in vacuo. The solid was redissolved in diethyl ether and transferred to a separating funnel. The organic layer was washed with $\mathrm{H}_{2} \mathrm{O}(20 \mathrm{~mL})$ and the aqueous layer was washed with diethyl ether $(20 \mathrm{~mL})$. The organic fractions were combined and dried over magnesium sulfate, filtered, and concentrated under vacuum to yield the product, 3 (3.56 g). The crude product was recrystallised from methanol/dichloromethane (1:1), yielding pale yellow crystals of 3 . Recrystallised yield: 2.18 g, 55\%.

IR $\left(\mathrm{KBr}, \mathrm{cm}^{-1}\right): 1643(\mathrm{~s}) v(\mathrm{C}=\mathrm{O}) .{ }^{1} \mathrm{H}$ NMR $\left(\mathrm{CDCl}_{3}\right): \delta / \mathrm{ppm} 10.07\left(\mathrm{~d}, \mathrm{~J}_{\mathrm{P}-\mathrm{H}}=2.5 \mathrm{~Hz}, 1 \mathrm{H}\right.$, $\mathrm{CHO}$ ), 8.03 (ddd, $\left.J_{\mathrm{H}-\mathrm{H}}=7.4,1.5 \mathrm{~Hz}, J_{\mathrm{P}-\mathrm{H}}=4.4 \mathrm{~Hz}, 1 \mathrm{H}, \mathrm{H} 6\right), 7.69\left(\mathrm{tt}, J_{\mathrm{H}-\mathrm{H}}=7.5,1.2 \mathrm{~Hz}\right.$, $1 \mathrm{H}, \mathrm{H} 4), 7.60\left(\mathrm{tt}, J_{\mathrm{H}-\mathrm{H}}=7.6,1.4 \mathrm{~Hz}, 1 \mathrm{H}, \mathrm{H} 5\right), 7.22\left(\mathrm{dd}, J_{\mathrm{H}-\mathrm{H}}=7.2 \mathrm{~Hz}, J_{\mathrm{P}-\mathrm{H}}=4.9 \mathrm{~Hz}, 1 \mathrm{H}\right.$, H3). ${ }^{13} \mathrm{C}\left\{{ }^{1} \mathrm{H}\right\} \mathrm{NMR}\left(\mathrm{CDCl}_{3}\right): \delta / \mathrm{ppm} 193.0$ (s, 1H, CHO), 147.9 (d, J J-C $=248 \mathrm{~Hz}$, ortho ArF-C), 142.7 (d, JF-C $=257 \mathrm{~Hz}$, para ArF-C), 138.4 (d, JP-C $=15.8 \mathrm{~Hz}, \mathrm{C} 1), 137.7$ (d, $J_{\mathrm{F}-\mathrm{C}}=254.8 \mathrm{~Hz}$, meta ArF-C), 136.1 (s, C6), 134.0 (s, C4), 133.0 (d, JP-C = 29.3 Hz, C2), 132.4 (s, C3), 130.0 (s, C5), 109.3 (m, ipso ArF-C). ${ }^{19} \mathrm{~F}\left\{{ }^{1} \mathrm{H}\right\} \mathrm{NMR}\left(\mathrm{CDCl}_{3}\right): \delta / \mathrm{ppm}-129.4$ (m, 4F, ortho Ar-F), -150.3 (tt, $J_{\mathrm{F}-\mathrm{F}}=20.5,3.9 \mathrm{~Hz}, 2 \mathrm{~F}$, para Ar-F), -160.7 (m, 4F, meta Ar-F). ${ }^{31} \mathrm{P}\left\{{ }^{1} \mathrm{H}\right\} \mathrm{NMR}\left(\mathrm{CDCl}_{3}\right): \delta / \mathrm{ppm}-47.8$ (quin, $J_{\mathrm{P}-\mathrm{F}}=37.5 \mathrm{~Hz}$ ).

\subsubsection{2-Di-tert-butylphosphinobenzaldehyde diethyl acetal (15)}<smiles>CC=Cc1ccccc1CCCCCCCC</smiles>

To a flame-dried Schlenk tube with stir bar was added diethyl ether $(50 \mathrm{~mL})$ and 2-bromobenzaldehyde diethyl acetal $(2.0 \mathrm{~mL}, 10 \mathrm{mmol})$. The solution was cooled to $-78{ }^{\circ} \mathrm{C}$ and tert-butyllithium (1.6 M in pentane, $12.5 \mathrm{~mL}, 20 \mathrm{mmol})$ was added dropwise. After the reaction had been stirred at $-78{ }^{\circ} \mathrm{C}$ for one hour, chlorodi-tert-butylphosphine $(2.1 \mathrm{~mL}$, 
$11 \mathrm{mmol}$ ) was added dropwise. The reaction was allowed to slowly return to room temperature over 18 hours, and was stirred for ten days. Degassed water $(20 \mathrm{~mL})$ was added slowly to the reaction mixture, and the organic fraction was transferred via syringe to a flame-dried round bottom flask containing a stir bar. The aqueous layer was then washed twice with diethyl ether $(2 \times 10 \mathrm{~mL})$, and the organic layers were combined. The solvent was removed in vacuo and the resulting oil was kept under vacuum and heated to $35^{\circ} \mathrm{C}$ until a ${ }^{31} \mathrm{P}$ NMR spectrum of a sample confirmed that there was no residual ${ }^{t} \mathrm{Bu}_{2} \mathrm{PCl}$ remaining. At this stage, the crude product, 15, contained roughly 15\% benzaldehyde diethyl acetal (by integration of the ${ }^{1} \mathrm{H}$ NMR signals of the acetal methyne $\mathrm{C}-\mathrm{H}$ ) and was used without further purification. Yield: $1.98 \mathrm{~g}$.

${ }^{1} \mathrm{H}$ NMR $\left(\mathrm{CDCl}_{3}\right): \delta / \mathrm{ppm} 8.07\left(\mathrm{ddd}, J_{\mathrm{H}-\mathrm{H}}=7.8,1.1 \mathrm{~Hz}, J_{\mathrm{P}-\mathrm{H}}=3.6 \mathrm{~Hz}, 1 \mathrm{H}, \mathrm{H} 6\right), 7.74(\mathrm{~d}$, $\left.J_{\mathrm{H}-\mathrm{H}}=7.6 \mathrm{~Hz}, 1 \mathrm{H}, \mathrm{H} 4\right), 7.61\left(\mathrm{~d}, J_{\mathrm{H}-\mathrm{H}}=7.6 \mathrm{~Hz}, 1 \mathrm{H}, \mathrm{H} 5\right), 7.09\left(\mathrm{td}, J_{\mathrm{H}-\mathrm{H}}=7.5,1.4 \mathrm{~Hz}, 1 \mathrm{H}\right.$, $\mathrm{H} 5), 6.79\left(\mathrm{~d}, J_{\mathrm{H}-\mathrm{H}}=8.1 \mathrm{~Hz}, 1 \mathrm{H}, \mathrm{CH}(\mathrm{OEt})_{2}\right), 3.60\left(\mathrm{~m}, 4 \mathrm{H}, \mathrm{CH}_{2}\right) 1.21\left(\mathrm{t}, J_{\mathrm{H}-\mathrm{H}}=7.1 \mathrm{~Hz}, 6 \mathrm{H}\right.$, $\left.\mathrm{CH}_{2} \mathrm{CH}_{3}\right), 1.19\left(\mathrm{~d}, J_{\mathrm{P}-\mathrm{H}}=11.9 \mathrm{~Hz}, 18 \mathrm{H}, \mathrm{C}\left(\mathrm{CH}_{3}\right)_{3}\right) .{ }^{13} \mathrm{C}\left\{{ }^{1} \mathrm{H}\right\} \mathrm{NMR}\left(\mathrm{CDCl}_{3}\right): \delta / \mathrm{ppm} 146.8$ $\left(\mathrm{d}, J_{\mathrm{P}-\mathrm{C}}=23.7 \mathrm{~Hz}, \mathrm{C} 1\right), 126.8\left(\mathrm{~d}, J_{\mathrm{P}-\mathrm{C}}=9.2 \mathrm{~Hz}, \mathrm{Ar}-\mathrm{C}\right), 100.3\left(\mathrm{~d}, J_{\mathrm{P}-\mathrm{C}}=34.6 \mathrm{~Hz}, \mathrm{C} 2\right), 62.3(\mathrm{~s}$, $\left.\mathrm{CH}(\mathrm{OEt})_{2}\right), 32.6$ (d, $\left.J_{\mathrm{P}-\mathrm{C}}=22.3 \mathrm{~Hz}, \mathrm{CH}_{2}\right), 30.8$ (d, $\left.J_{\mathrm{P}-\mathrm{C}}=15.1 \mathrm{~Hz}, \mathrm{C}\left(\mathrm{CH}_{3}\right)\right), 15.4$ (d, $\left.J_{\mathrm{P}-\mathrm{C}}=16.5 \mathrm{~Hz}, \mathrm{CH}_{3}\right) .{ }^{31} \mathrm{P}\left\{{ }^{1} \mathrm{H}\right\} \mathrm{NMR}\left(\mathrm{CDCl}_{3}\right): \delta / \mathrm{ppm} 11.7(\mathrm{~s})$.

\subsubsection{2-Di-tert-butylphosphinobenzaldehyde (4)}<smiles>CCCCc1ccccc1C=O</smiles>

To a pressure tube was added $25 \mathrm{~mL}$ of a $2: 1$ mixture of $\mathrm{THF} / \mathrm{H}_{2} \mathrm{O}$, para-toluenesulfonic acid $(100 \mathrm{mg})$, and the crude compound 15 (1.98 g). The mixture was sealed in the pressure tube, and stirred at $80{ }^{\circ} \mathrm{C}$ for two hours. The mixture was cooled to room temperature and diethyl ether $(10 \mathrm{~mL})$ was added which formed a biphasic solution. The organic layer was transferred via syringe to a Schlenk tube and the aqueous layer was washed with diethyl ether $(2 \times 5 \mathrm{~mL})$. The organic layers were combined and passed through a short plug of alumina, followed by more diethyl ether $(5 \mathrm{~mL})$. The solvent was removed in vacuo to yield a mixture of 4 and 5\% benzaldehyde. The benzaldehyde was removed under vacuum at $35{ }^{\circ} \mathrm{C}$ for four hours leaving the final product as an orange oil. Yield: $1.41 \mathrm{~g}, 56.4 \%$. 
${ }^{1} \mathrm{H}$ NMR $\left(\mathrm{CDCl}_{3}\right): \delta / p p m 11.19$ (dd, 9.2, $\left.0.9 \mathrm{~Hz}, \mathrm{CHO}\right), 7.96$ (ddd, $J_{\mathrm{H}-\mathrm{H}}=7.6,2.0 \mathrm{~Hz}$, $\left.J_{\mathrm{P}-\mathrm{H}}=3.7 \mathrm{~Hz}, 1 \mathrm{H}, \mathrm{H} 6\right), 7.89(\mathrm{~m}, 1 \mathrm{H}, \mathrm{H} 4) 7.56\left(\mathrm{td}, J_{\mathrm{H}-\mathrm{H}}=7.3,1.5 \mathrm{~Hz}, 1 \mathrm{H}, \mathrm{H} 3\right), 7.48(\mathrm{td}$, $\left.J_{\mathrm{H}-\mathrm{H}}=7.6,0.8 \mathrm{~Hz}, 1 \mathrm{H}, \mathrm{H} 5\right), 1.21\left(\mathrm{~d}, J_{\mathrm{P}-\mathrm{H}}=12.1 \mathrm{~Hz}, 18 \mathrm{H}, \mathrm{C}\left(\mathrm{CH}_{3}\right)_{3}\right) .{ }^{13} \mathrm{C}\left\{{ }^{1} \mathrm{H}\right\} \mathrm{NMR}$ $\left(\mathrm{CDCl}_{3}\right): \delta /$ ppm: $194.4\left(\mathrm{~d}, J_{\mathrm{P}-\mathrm{C}}=41.8 \mathrm{~Hz}, \mathrm{CHO}\right), 143.2\left(\mathrm{~d}, J_{\mathrm{P}-\mathrm{C}}=17.8 \mathrm{~Hz}, \mathrm{C} 1\right), 140.9$ (d, $\left.J_{\mathrm{P}-\mathrm{C}}=35.0 \mathrm{~Hz}, \mathrm{C} 2\right), 135.6\left(\mathrm{~d}, J_{\mathrm{P}-\mathrm{C}}=2.9 \mathrm{~Hz}, \mathrm{C} 3\right), 132.0(\mathrm{~s}, \mathrm{C} 5), 129.3\left(\mathrm{~d}, J_{\mathrm{P}-\mathrm{C}}=1.0 \mathrm{~Hz}, \mathrm{C} 6\right)$, $127.6\left(\mathrm{~d}, J_{\mathrm{P}-\mathrm{C}}=6.2 \mathrm{~Hz}, \mathrm{C} 4\right), 32.7\left(\mathrm{~d}, J_{\mathrm{P}-\mathrm{C}}=14.9 \mathrm{~Hz}, \mathrm{C}\left(\mathrm{CH}_{3}\right)_{3}\right), 25.9\left(\mathrm{~d}, J_{\mathrm{P}-\mathrm{C}=1.5 \mathrm{~Hz}}\right.$, $\left.\mathrm{C}\left(\mathrm{CH}_{3}\right)_{3}\right) .{ }^{31} \mathrm{P}\left\{{ }^{1} \mathrm{H}\right\} \mathrm{NMR}\left(\mathrm{CDCl}_{3}\right): \delta / \mathrm{ppm} 7.4$ (s).

\subsubsection{2-Butylbenzaldehyde (16)}

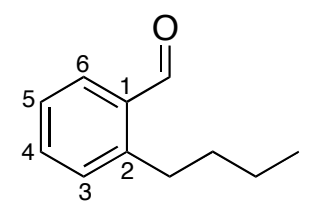

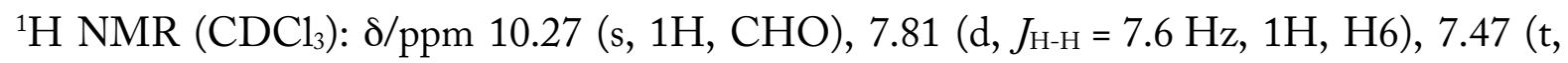
$\left.J_{\mathrm{H}-\mathrm{H}}=7.6 \mathrm{~Hz}, 1 \mathrm{H}, \mathrm{H} 4\right), 7.32\left(\mathrm{t}, J_{\mathrm{H}-\mathrm{H}}=7.6 \mathrm{~Hz}, 1 \mathrm{H}, \mathrm{H} 5\right), 7.20\left(\mathrm{~d}, J_{\mathrm{H}-\mathrm{H}}=7.6 \mathrm{~Hz}, 1 \mathrm{H}, \mathrm{H} 3\right)$, $3.00\left(\mathrm{dd}, J_{\mathrm{H}-\mathrm{H}}=9.0,7.0 \mathrm{~Hz}, 2 \mathrm{H}, \mathrm{CH}_{2}\right), 1.58\left(\mathrm{~m}, 2 \mathrm{H}, \mathrm{CH}_{2}\right), 1.39\left(\mathrm{sex}, J_{\mathrm{H}-\mathrm{H}}=7.5 \mathrm{~Hz}, 2 \mathrm{H}\right.$, $\left.\mathrm{CH}_{2}\right), 0.92\left(\mathrm{t}, J_{\mathrm{H}-\mathrm{H}}=7.3 \mathrm{~Hz}, 3 \mathrm{H}, \mathrm{CH}_{3}\right) .{ }^{13} \mathrm{C}\left\{{ }^{1} \mathrm{H}\right\} \mathrm{NMR}\left(\mathrm{CDCl}_{3}\right): \delta / \mathrm{ppm} 192.3,(\mathrm{~s}, \mathrm{CHO})$, 145.9 (s, C2), 133.8 (s, C1), 131.4 (s, C4), 131.0 (s, C3), 126.4 (s, C5), 34.6 (s, CH $\mathrm{CH}_{2}$ ), 32.3 (s, $\mathrm{CH}_{2}$ ), 22.7 (s, $\left.\mathrm{CH}_{2}\right), 14.0$ (s, $\mathrm{CH}_{3}$ ).

\subsection{Platinum complexes of 2-diphenylphosphinobenzaldehyde}

\subsection{1 $\left[\mathrm{PtMe}_{2}\left(2-\mathrm{PPh}_{2} \mathrm{C}_{6} \mathrm{H}_{4} \mathrm{CHO}\right)_{2}\right]$ (18) and} $\left[\mathrm{PtMe}\left(P, C-2-\mathrm{PPh}_{2} \mathrm{C}_{6} \mathrm{H}_{4} \mathrm{CO}\right)\left(2-\mathrm{PPh}_{2} \mathrm{C}_{6} \mathrm{H}_{4} \mathrm{CHO}\right)\right](19)$

Dimethylplatinum(1,5-hexadiene) $\quad(20 \mathrm{mg}, \quad 0.07 \mathrm{mmol})$ and compound 1 (39 $\mathrm{mg}$, $0.13 \mathrm{mmol}$ ) were combined in an NMR tube and dissolved in $\mathrm{CDCl}_{3}\left(0.5 \mathrm{~cm}^{3}\right)$. Complex 18 was rapidly produced followed by the chelation of one ligand to platinum over 24 hours to form complex 19. The solution was transferred to a round bottom flask and dried in vacuo. Complex 19 was recrystallised from the diffusion of diethyl ether into a dichloromethane solution, yielding orange crystals. Recrystallised yield: $40 \mathrm{mg}, 80 \%$. 
$\left[\mathrm{PtMe}_{2}\left(2-\mathrm{PPh}_{2} \mathrm{C}_{6} \mathrm{H}_{4} \mathrm{CHO}\right)_{2}\right](18)$

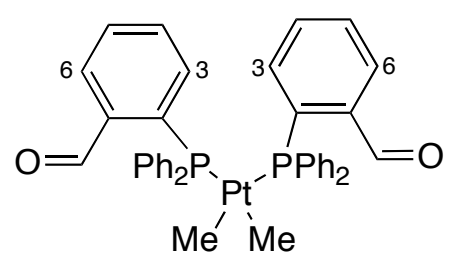

${ }^{1} \mathrm{H}$ NMR $\left(\mathrm{CDCl}_{3}\right): \delta / p p m 10.69$ (d, $\left.J_{\mathrm{P}-\mathrm{H}}=2.3 \mathrm{~Hz}, 2 \mathrm{H}, \mathrm{CHO}\right), 7.68\left(\mathrm{~d}, J_{\mathrm{H}-\mathrm{H}}=6.9 \mathrm{~Hz}, 2 \mathrm{H}\right.$, H6), 7.41 (t, $\left.J_{\mathrm{H}-\mathrm{H}}=8.8 \mathrm{~Hz}, 8 \mathrm{H}, \mathrm{Ar}-\mathrm{H}\right), 7.29$ (t, $\left.J_{\mathrm{H}-\mathrm{H}}=7.7 \mathrm{~Hz}, 6 \mathrm{H}, \mathrm{Ar}-\mathrm{H}\right), 7.19$ (t, $\left.J_{\mathrm{H}-\mathrm{H}}=7.1 \mathrm{~Hz}, 10 \mathrm{H}, \mathrm{Ar}-\mathrm{H}\right), 7.05\left(\mathrm{t}, J_{\mathrm{H}-\mathrm{H}}=8.8 \mathrm{~Hz}, 2 \mathrm{H}, \mathrm{H} 3\right), 0.46\left(\mathrm{~m}, J_{\mathrm{Pt}-\mathrm{H}}=69.9 \mathrm{~Hz}, 6 \mathrm{H}\right.$, $\left.\mathrm{Pt}-\mathrm{CH}_{3}\right) .{ }^{31} \mathrm{P}\left\{{ }^{1} \mathrm{H}\right\} \mathrm{NMR}\left(\mathrm{CDCl}_{3}\right): \delta / \mathrm{ppm} 23.7\left(\mathrm{~s}, J_{\mathrm{Pt}-\mathrm{P}}=1831.4 \mathrm{~Hz}\right)$.

$\left[\mathrm{PtMe}\left(P, C-2-\mathrm{PPh}_{2} \mathrm{C}_{6} \mathrm{H}_{4} \mathrm{CO}\right)\left(2-\mathrm{PPh}_{2} \mathrm{C}_{6} \mathrm{H}_{4} \mathrm{CHO}\right)\right](19)$

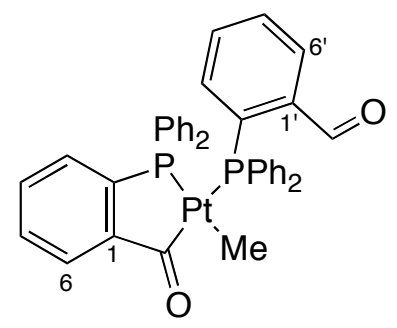

IR $\left(\mathrm{KBr}, \mathrm{cm}^{-1}\right)$ : $1694(\mathrm{~s}), v(\mathrm{C}=\mathrm{O})$ (pendant $\left.\mathrm{CHO}\right) ; 1618(\mathrm{~m}), v(\mathrm{C}=\mathrm{O})$ (coordinated $\left.\mathrm{CO}\right)$. ${ }^{1} \mathrm{H} \mathrm{NMR}\left(\mathrm{CDCl}_{3}\right): \delta / p p m 10.47\left(\mathrm{~d}, J_{\mathrm{P}-\mathrm{H}}=2.5 \mathrm{~Hz}, 1 \mathrm{H}, \mathrm{CHO}\right), 7.97$ (ddd, $J_{\mathrm{H}-\mathrm{H}}=7.8,1.5 \mathrm{~Hz}$, $\left.J_{\mathrm{P}-\mathrm{H}}=3.9,1 \mathrm{H}, \mathrm{H} 6\right), 7.82\left(\mathrm{~d}, J_{\mathrm{P}-\mathrm{H}}=7.0 \mathrm{~Hz}, 1 \mathrm{H}, \mathrm{H} 6{ }^{\prime}\right), 7.51-7.22(\mathrm{~m}, 14 \mathrm{H}, \mathrm{Ar}-\mathrm{H}), 7.22-7.12$ $(\mathrm{m}, 12 \mathrm{H}, \mathrm{Ar}-\mathrm{H}) 0.77\left(\mathrm{~d}, J_{\mathrm{P}-\mathrm{H}}=3.5 \mathrm{~Hz}, J_{\mathrm{Pt}-\mathrm{H}}=70 \mathrm{~Hz}, 3 \mathrm{H}, \mathrm{Pt}-\mathrm{CH}_{3}\right) .{ }^{13} \mathrm{C}\left\{{ }^{1} \mathrm{H}\right\} \mathrm{NMR}$ $\left(\mathrm{CDCl}_{3}\right): \delta / \mathrm{ppm} 232.5\left(\mathrm{~d}, J_{\mathrm{P}-\mathrm{C}}=133 \mathrm{~Hz}, J_{\mathrm{Pt}-\mathrm{C}}=1080 \mathrm{~Hz}, \mathrm{CO}\right), 190.2\left(\mathrm{~d}, J_{\mathrm{P}-\mathrm{C}}=13.2 \mathrm{~Hz}\right.$, $\mathrm{CHO}), 159.2\left(\mathrm{dd}, J_{\mathrm{P}-\mathrm{C}}=37.5,27.5 \mathrm{~Hz}, \mathrm{C} 1\right), 140.2\left(\mathrm{dd}, J_{\mathrm{P}-\mathrm{C}}=47.6,2.6 \mathrm{~Hz}, \mathrm{C} 1{ }^{\prime}\right), 137.7$ (d,

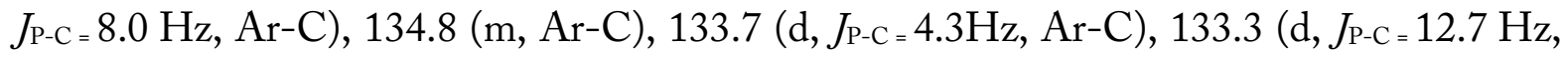
Ar-C), 133.3 (m, Ar-C), 132.3 (d, J $\left.J_{\mathrm{P}-\mathrm{C}}=5.8 \mathrm{~Hz}, \mathrm{Ar}-\mathrm{C}\right), 131.5$ (s, Ar-C), 130.5 (dd, JP-C = 13.2,

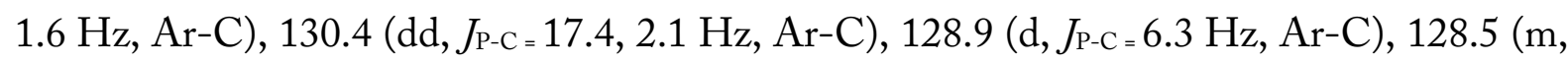

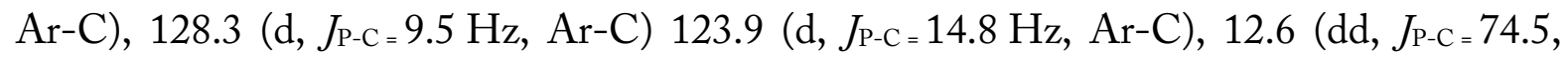
$\left.9.0 \mathrm{~Hz}, J_{\mathrm{Pt}-\mathrm{C}}=664 \mathrm{~Hz}, \mathrm{Pt}-\mathrm{CH}_{3}\right) .{ }^{31} \mathrm{P}\left\{{ }^{1} \mathrm{H}\right\} \mathrm{NMR}\left(\mathrm{CDCl}_{3}\right): \delta / \mathrm{ppm} 51.4\left(\mathrm{~d}, J_{\mathrm{P}-\mathrm{P}}=5.2 \mathrm{~Hz}\right.$, $\left.J_{\mathrm{Pt}-\mathrm{P}}=2088 \mathrm{~Hz}\right), 18.8\left(\mathrm{~d}, J_{\mathrm{P}-\mathrm{P}}=5.2 \mathrm{~Hz}, J_{\mathrm{Pt}-\mathrm{P}}=1558 \mathrm{~Hz}\right)$. Elemental Analysis (with a $\mathrm{CH}_{2} \mathrm{Cl}_{2}$ 
solvent of crystallisation): $\mathrm{C}, 54.38, \mathrm{H}, 3.87 \%\left(\mathrm{C}_{39} \mathrm{H}_{32} \mathrm{O}_{2} \mathrm{P}_{2} \mathrm{Pt} \cdot \mathrm{CH}_{2} \mathrm{Cl}_{2}\right.$ requires $\mathrm{C}, 54.93$; H, 3.92\%).

\subsection{2 cis- and trans- $\left[\mathrm{Pt}\left(P, C-2-\mathrm{PPh}_{2} \mathrm{C}_{6} \mathrm{H}_{4} \mathrm{CO}\right)_{2}\right]($ cis-21 and trans-21)}

Dimethylplatinum(1,5-hexadiene) (80 mg, $0.261 \mathrm{mmol})$ and 1 (165 mg, $0.569 \mathrm{mmol})$ were combined in a two-necked flask fitted with a nitrogen adaptor and reflux condenser. Toluene $(20 \mathrm{~mL})$ was added and the mixture was stirred at room temperature for 16 hours followed by reflux for eight hours. A microcrystalline solid containing cis-21 and some trans-21 isomer, precipitated from the solution. The mixture was cooled and the precipitate was filtered out using a sintered glass frit and washed with toluene and hexane. The product was used without further purification. Yield: $143 \mathrm{mg}, 71 \%$.

For the purposes of obtaining a pure sample of the cis and trans isomers of 21, the solid was dry loaded onto a silica column and eluted with toluene/hexane (1:1).

NB. The cis and trans isomers of 21 can also be isolated by reacting the crude material with $\mathrm{HBF}_{4}, \mathrm{CH}_{2}\left(\mathrm{SO}_{2} \mathrm{CF}_{3}\right)_{2}$, or $\mathrm{CHPh}\left(\mathrm{SO}_{2} \mathrm{CF}_{3}\right)_{2}$ in dichloromethane to protonate the cis isomer exclusively. The trans isomer can be filtered off leaving a solution containing the protonated cis isomer, 31. Complex 31 can be deprotonated with $\mathrm{DABCO}$ or $\mathrm{NaH}$ to yield a pure sample of cis-21 (DABCO = 1,4-diazabicyclo[2.2.2] octane).

cis- $\left[\mathrm{Pt}\left(P, C-2-\mathrm{PPh}_{2} \mathrm{C}_{6} \mathrm{H}_{4} \mathrm{CO}\right)_{2}\right]($ cis-21)<smiles>O=C1c2ccccc2P[PH]1(P)Pc1ccccc1</smiles>

$\mathrm{UV}\left(\mathrm{CH}_{2} \mathrm{Cl}_{2}\right) \lambda_{\max }, \mathrm{nm}(\varepsilon): 456$ (254). IR $\left(\mathrm{KBr}, \mathrm{cm}^{-1}\right): 1632$ (vs), $v(\mathrm{C}=\mathrm{O}) .{ }^{1} \mathrm{H}$ NMR $\left(\mathrm{C}_{6} \mathrm{D}_{6}\right)$ :

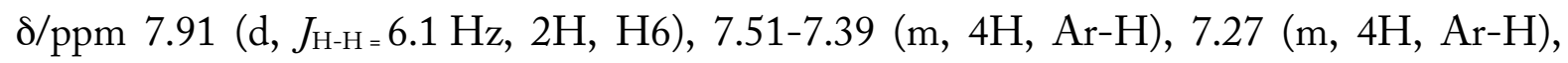
7.20-7.08 (m, 18H, Ar-H). ${ }^{31} \mathrm{P}\left\{{ }^{1} \mathrm{H}\right\} \operatorname{NMR}\left(\mathrm{C}_{6} \mathrm{D}_{6}\right): \delta / \mathrm{ppm} 47.8\left(\mathrm{~s}, J_{\mathrm{Pt}-\mathrm{P}}=1843 \mathrm{~Hz}\right)$. 
trans- $\left[\mathrm{Pt}\left(P, C-2-\mathrm{PPh}_{2} \mathrm{C}_{6} \mathrm{H}_{4} \mathrm{CO}\right)_{2}\right]($ trans -21$)$<smiles>O=C1c2ccccc2[PH](=O)C1Pc1ccccc1P</smiles>

UV $\left(\mathrm{CH}_{2} \mathrm{Cl}_{2}\right) \lambda_{\max }, \mathrm{nm}(\varepsilon): 456$ (199), 602 (122). IR $\left(\mathrm{KBr}, \mathrm{cm}^{-1}\right): 1598(\mathrm{~m}), v(\mathrm{C}=\mathrm{O}) .{ }^{1} \mathrm{H}$

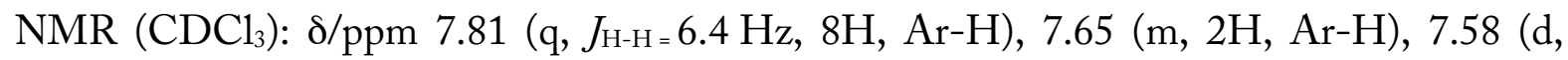
$\left.J_{\mathrm{H}-\mathrm{H}}=7.3 \mathrm{~Hz}, 2 \mathrm{H}, \mathrm{Ar}-\mathrm{H}\right), 7.49-7.39(\mathrm{~m}, 16 \mathrm{H}, \mathrm{Ar}-\mathrm{H}) .{ }^{31} \mathrm{P}\left\{{ }^{1} \mathrm{H}\right\} \mathrm{NMR}\left(\mathrm{C}_{6} \mathrm{D}_{6}\right): \delta / p p m 51.0$ (s, $\left.J_{\mathrm{Pt}-\mathrm{P}}=3362 \mathrm{~Hz}\right)$.

\subsection{3 $\left[\mathrm{Pt}\left(\mathrm{C}_{7} \mathrm{H}_{11}\right)\left(P, C-2-\mathrm{PPh}_{2} \mathrm{C}_{6} \mathrm{H}_{4} \mathrm{CO}\right)\left(2-\mathrm{PPh}_{2} \mathrm{C}_{6} \mathrm{H}_{4} \mathrm{CHO}\right)\right]($ cis-23)}

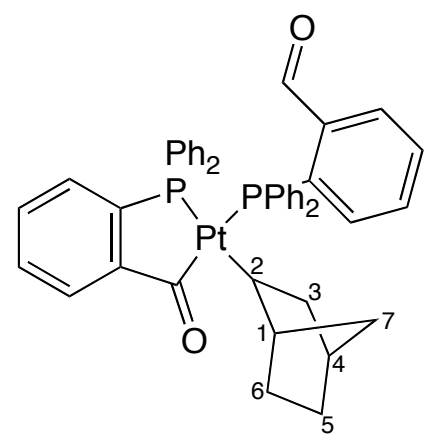

Tris(norbornene)platinum (100 mg, $0.21 \mathrm{mmol})$ and $1(128 \mathrm{mg}, 0.44 \mathrm{mmol})$ were combined in a Schlenk tube and dissolved in toluene $(7 \mathrm{~mL})$. The mixture was stirred for two hours and then left to stand for 20 hours, over which time yellow crystals formed. The solvent was removed under vacuum and the residue was dried in vacuo for two hours to remove free norbornene. This method produced a virtually pure sample of cis-23, although in solution the complex reacts to form the cis and trans isomers of complex 21. The complex is air-sensitive in solution but stable for days at room temperature as a solid. Yield: $125 \mathrm{mg}, 69 \%$.

${ }^{1} \mathrm{H}$ NMR $\left(\mathrm{CD}_{2} \mathrm{Cl}_{2}\right): \delta / p p m 10.59\left(\mathrm{~d}, J_{\mathrm{P}-\mathrm{H}}=2.7 \mathrm{~Hz}, 1 \mathrm{H}, \mathrm{CHO}\right), 7.93$ (ddd, $J_{\mathrm{H}-\mathrm{H}}=7.5$, $\left.1.5 \mathrm{~Hz}, J_{\mathrm{P}-\mathrm{H}}=3.6,1 \mathrm{H}, \mathrm{Ar}-\mathrm{H}\right), 7.6-7.0(\mathrm{~m}, 27 \mathrm{H}, \mathrm{Ar}-\mathrm{H}), 2.85$ (br, $\left.J_{\mathrm{Pt}-\mathrm{H}}=103 \mathrm{~Hz}, 1 \mathrm{H}, \mathrm{H} 1\right)$, 2.12 (s, 1H, H4), 2.08 (m, 1H, H7a), 1.87 (m, 1H, H2), 1.33, (s, 1H, H6a), 1.19 (m, 1H, H5a), 1.09 (m, 1H, H5b), 0.97 (m, 1H, H3a), 0.78 (m, 1H, H6b), 0.70 (m, 1H, H6b), -0.05 (t, $\left.J_{\mathrm{H}-\mathrm{H}}=9.8 \mathrm{~Hz}, \mathrm{H} 3 \mathrm{~b}\right) .{ }^{13} \mathrm{C} \quad\left\{{ }^{1} \mathrm{H}\right\} \quad \mathrm{NMR} \quad\left(\mathrm{CD}_{2} \mathrm{Cl}_{2}\right): \delta / \mathrm{ppm} 191.7$ (d, $\left.J_{\mathrm{P}-\mathrm{C}}=5.4 \mathrm{~Hz}, \mathrm{CHO}\right) 190.2\left(\mathrm{~d}, J_{\mathrm{P}-\mathrm{C}}=13.9 \mathrm{~Hz}, \mathrm{CO}\right) 164.2\left(\mathrm{dd}, J_{\mathrm{P}-\mathrm{C}}=39.8,29.6 \mathrm{~Hz}, \mathrm{Ar}-\mathrm{C}\right)$ $139.9\left(\mathrm{dd}, J_{\mathrm{P}-\mathrm{C}}=49.1,2.3 \mathrm{~Hz}, \mathrm{Ar}-\mathrm{C}\right), 138.2\left(\mathrm{~d}, J_{\mathrm{P}-\mathrm{C}}=7.5 \mathrm{~Hz}, \mathrm{Ar}-\mathrm{C}\right), 135.6-128.6(\mathrm{~m}$, 
Ar-C), $122.4\left(\mathrm{~d}, J_{\mathrm{P}-\mathrm{C}}=15.0 \mathrm{~Hz}, \mathrm{Ar}-\mathrm{C}\right), 42.5\left(\mathrm{~d}, J_{\mathrm{P}-\mathrm{C}}=1.9 \mathrm{~Hz}, \mathrm{C} 4\right), 39.5\left(\mathrm{dd}, J_{\mathrm{P}-\mathrm{C}}=75\right.$, $\left.5.6 \mathrm{~Hz}, J_{\mathrm{Pt}-\mathrm{C}}=751 \mathrm{~Hz}, \mathrm{C} 2\right), 38.1\left(\mathrm{~d}, J_{\mathrm{P}-\mathrm{C}}=2.2 \mathrm{~Hz}, \mathrm{C} 1\right), 35.6(\mathrm{~s}, \mathrm{C} 6), 35.0$ (br s, C7), 33.4 (d, $\left.J_{\mathrm{P}-\mathrm{C}}=8.2 \mathrm{~Hz}, \mathrm{C} 3\right), 28.4(\mathrm{~s}, \mathrm{C} 5) .{ }^{31} \mathrm{P}\left\{{ }^{1} \mathrm{H}\right\} \mathrm{NMR}\left(\mathrm{CDCl}_{3}\right): \delta / \mathrm{ppm} 45.0\left(\mathrm{~s}, J_{\mathrm{Pt}-\mathrm{P}}=1696 \mathrm{~Hz}\right)$, $18.5\left(\mathrm{~s}, J_{\mathrm{Pt}-\mathrm{P}}=1642 \mathrm{~Hz}\right)$. HR-ESIMS $(\mathrm{m} / \mathrm{z})$ calculated for $[\mathrm{M}+\mathrm{H}]^{+}, 869.2209$; observed, 869.2211. Elemental Analysis: C, 62.65, H, 4.78\% $\left(\mathrm{C}_{45} \mathrm{H}_{40} \mathrm{O}_{2} \mathrm{P}_{2} \mathrm{Pt}\right.$ requires $\mathrm{C}, 62.14$; $\mathrm{H}, 4.64 \%)$.

\subsection{Platina- $\beta$-diketones}

\subsection{1 $\left[\mathrm{Pt}\left\{\left(P, C-2-\mathrm{PPh}_{2} \mathrm{C}_{6} \mathrm{H}_{4} \mathrm{CO}\right)_{2} \mathrm{H}\right\}\right]^{+}(31)$}

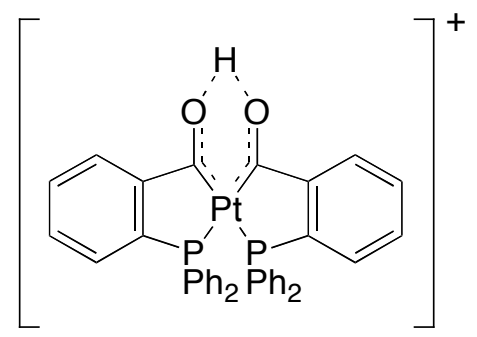

Complex cis-21 (27.7 mg, $0.0358 \mathrm{mmol})$ was suspended in dichloromethane $(10 \mathrm{~mL})$ and an acid, $\mathrm{CH}_{2}\left(\mathrm{CF}_{3} \mathrm{SO}_{2}\right)_{2}, \mathrm{CPhH}\left(\mathrm{CF}_{3} \mathrm{SO}_{2}\right)_{2}$, or $\mathrm{HBF}_{4}(0.0358 \mathrm{mmol})$, was added to the suspension. An immediate change from red suspension to yellow solution was observed. The solvent was removed under vacuum and the product, 31, was recrystallised from the diffusion of diethyl ether into a dichloromethane solution. Complex 31 was isolated as yellow, needleshaped crystals when either $\mathrm{CH}_{2}\left(\mathrm{SO}_{2} \mathrm{CF}_{3}\right)_{2}$ or $\mathrm{CHPh}\left(\mathrm{SO}_{2} \mathrm{CF}_{3}\right)_{2}$ were used, and as yellow block-like prismatic crystals when $\mathrm{HBF}_{4}$ was used. Recrystallised yield: $27 \mathrm{mg}, 72 \%$.

UV $\left(\mathrm{CH}_{2} \mathrm{Cl}_{2}\right) \lambda_{\max }, \mathrm{nm}(\varepsilon): 426(\mathrm{sh}, 356)$. IR $\left(\mathrm{KBr}, \mathrm{cm}^{-1}\right): 1524(\mathrm{~s}), v(\mathrm{C}=\mathrm{O}) .{ }^{1} \mathrm{H}$ NMR $\left(\mathrm{CDCl}_{3}\right): \delta / \mathrm{ppm} 22.05\left(\mathrm{~s}, J_{\mathrm{Pt}-\mathrm{H}}=104.2 \mathrm{~Hz}, 1 \mathrm{H}, \mathrm{OHO}\right), 8.45\left(\mathrm{~d}, J_{\mathrm{H}-\mathrm{H}}=8 \mathrm{~Hz}, 2 \mathrm{H}, \mathrm{H} 6\right), 7.93$ $\left(\mathrm{t}, J_{\mathrm{H}-\mathrm{H}}=8.0 \mathrm{~Hz}, 2 \mathrm{H}, \mathrm{H} 4\right), 7.83\left(\mathrm{t}, J_{\mathrm{H}-\mathrm{H}}=7.8 \mathrm{~Hz}, 2 \mathrm{H}, \mathrm{H} 3\right), 7.80\left(\mathrm{t}, J_{\mathrm{H}-\mathrm{H}}=7.5 \mathrm{~Hz}, 2 \mathrm{H}, \mathrm{H} 5\right)$, $7.44\left(\mathrm{td}, J_{\mathrm{H}-\mathrm{H}}=7.0 \mathrm{~Hz}, 1.5 \mathrm{~Hz}, 4 \mathrm{H}, \mathrm{Ar}-\mathrm{H}\right), 7.25-7.17(\mathrm{~m}, 16 \mathrm{H}, \mathrm{Ar}-\mathrm{H}), 3.93$ (s, 1H, $\left.\mathrm{CH}\left(\mathrm{SO}_{2} \mathrm{CF}_{3}\right)_{2}\right) .{ }^{13} \mathrm{C}\left\{{ }^{1} \mathrm{H}\right\} \mathrm{NMR}\left(\mathrm{CDCl}_{3}\right): \delta / \mathrm{ppm} 250.5\left(\mathrm{~d}, J_{\mathrm{P}-\mathrm{C}}=108.8 \mathrm{~Hz}, J_{\mathrm{Pt}-\mathrm{C}}=991.2 \mathrm{~Hz}\right.$, CO) 153.8 (m, Ar-C, C1), 143.5 (d, JP-C $=52$ Hz, C2), 138.5 (m, Ar-C), 133.7 (s), 133.0 (m, Ar-C), 132.5 (Jt-P $=10.9 \mathrm{~Hz}, \operatorname{Ar}-\mathrm{C}), 132.4$ (s, Ar-C), 129.5 (m, Ar-C), 127.1 (m, $\mathrm{Ar}-\mathrm{C}$ ), 120.8 (q, $\left.J_{\mathrm{F}-\mathrm{C}}=326 \mathrm{~Hz}, \mathrm{CH}\left(\mathrm{SO}_{2} \mathrm{CF}_{3}\right)_{2}\right), 54.2\left(\mathrm{~s}, \mathrm{CH}\left(\mathrm{SO}_{2} \mathrm{CF}_{3}\right)_{2}\right) .{ }^{31} \mathrm{P}\left\{{ }^{1} \mathrm{H}\right\} \mathrm{NMR}$ $\left(\mathrm{CDCl}_{3}\right): \delta / \mathrm{ppm} 45.2\left(\mathrm{~s}, J_{\mathrm{Pt}-\mathrm{P}}=2114 \mathrm{~Hz}\right)$. Elemental Analysis (of 30[CPh $\left.\left.\left(\mathrm{SO}_{2} \mathrm{CF}_{3}\right)_{2}\right]\right)$ : C, 49.41; H, 3.24\% $\left(\mathrm{C}_{47} \mathrm{H}_{34} \mathrm{~F}_{6} \mathrm{O}_{6} \mathrm{P}_{2} \mathrm{PtS}_{2}\right.$ requires $\left.\mathrm{C}, 49.96 ; \mathrm{H}: 3.03 \%\right)$. 


\subsection{2 $\left[\mathrm{Pt}\left\{\left(P, C-2-\mathrm{PPh}_{2} \mathrm{C}_{6} \mathrm{H}_{4} \mathrm{CO}\right)_{2} \mathrm{Li}\right\}\right] \mathrm{CH}\left(\mathrm{SO}_{2} \mathrm{CF}_{3}\right)_{2}(32)$}

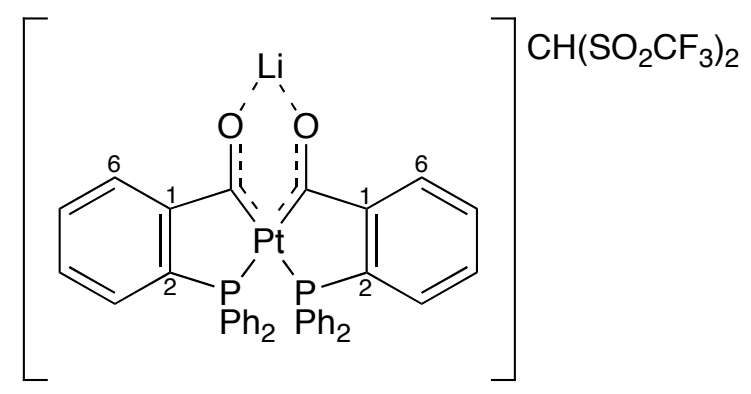

$\mathrm{LiCH}\left(\mathrm{SO}_{2} \mathrm{CF}_{3}\right)_{2}(6.2 \mathrm{mg}, 0.022 \mathrm{mmol})$, synthesised from the stoichiometric reaction of lithium carbonate or lithium hydroxide with $\mathrm{CH}_{2}\left(\mathrm{SO}_{2} \mathrm{CF}_{3}\right)_{2}$, was added to a round bottom flask containing a suspension of cis-21 (16.7 mg, $0.022 \mathrm{~mol})$ in $\mathrm{CDCl}_{3}(0.5 \mathrm{~mL})$. An immediate colour from red suspension to orange solution was observed. The product was recrystallised from the diffusion of pentane into a dichloromethane solution, and isolated as orange needle-like crystals. Recrystallised yield: $16.5 \mathrm{mg}, 71 \%$.

$\mathrm{UV}\left(\mathrm{CH}_{2} \mathrm{Cl}_{2}\right) \lambda_{\max }, \mathrm{nm}(\varepsilon): 421$ (251). IR $\left(\mathrm{KBr}, \mathrm{cm}^{-1}\right): 1625$ (s), $v(\mathrm{C}=\mathrm{O}) .{ }^{1} \mathrm{H}$ NMR $\left(\mathrm{CDCl}_{3}\right)$ :

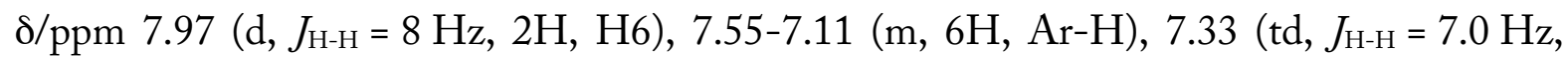
$1.3 \mathrm{~Hz}, 4 \mathrm{H}, \mathrm{Ar}-\mathrm{H}), 7.23-7.13$ (m, 16H, Ar-H), 4.07 (s, $\left.1 \mathrm{H}, \mathrm{CH}\left(\mathrm{SO}_{2} \mathrm{CF}_{3}\right)_{2}\right) .{ }^{13} \mathrm{C} \mathrm{NMR}$ $\left(\mathrm{CDCl}_{3}\right): \delta / \mathrm{ppm} 244.1$ (d, $J_{\mathrm{P}-\mathrm{C}}=113 \mathrm{~Hz}, J_{\mathrm{Pt}-\mathrm{C}}$ not observed, CO), $159.2(\mathrm{~m}, \mathrm{C} 1), 138.6$ (d, $\left.J_{\mathrm{P}-\mathrm{C}}=50 \mathrm{~Hz}, \mathrm{C} 2\right), 133.9$ (m, Ar-C), 133.2 (m, Ar-C), 132.7 (s, Ar-C), 131.1 (s, Ar-C), 130.6 (s, Ar-C), 129.8 (d, JP-C $=50 \mathrm{~Hz}, \mathrm{Ar}-\mathrm{C}), 128.9$ (m, Ar-C), 125.4 (m, Ar-C), 120.9 (q, $\left.J_{\mathrm{F}-\mathrm{C}}=324 \mathrm{~Hz}, \mathrm{CH}\left(\mathrm{SO}_{2} \mathrm{CF}_{3}\right)_{2}\right), 51.7\left(\mathrm{~s}, \mathrm{CH}\left(\mathrm{SO}_{2} \mathrm{CF}_{3}\right)_{2}\right) .{ }^{31} \mathrm{P}\left\{{ }^{1} \mathrm{H}\right\} \mathrm{NMR}\left(\mathrm{CDCl}_{3}\right): \delta / \mathrm{ppm}$ $46.6\left(\mathrm{~s}, J_{\mathrm{Pt}-\mathrm{P}}=1917 \mathrm{~Hz}\right)$.

\subsection{3 $\left[\mathrm{Pt}\left(P, C-2-\mathrm{PPh}_{2} \mathrm{C}_{6} \mathrm{H}_{4} \mathrm{CO}\right)\left(P, C-2-\mathrm{PPh}_{2} \mathrm{C}_{6} \mathrm{H}_{4} \mathrm{CNH}\right)\right] \mathrm{CH}\left(\mathrm{SO}_{2} \mathrm{CF}_{3}\right)_{2}(39)$}<smiles>O=C1C(=NCc2ccccc2P)P(c2ccccc2)c2ccccc21</smiles>

Complex 31 (22 mg, $0.02 \mathrm{mmol})$ was dissolved in dichloromethane $(5 \mathrm{~mL})$ with several $4 \AA$ molecular sieves. Benzylamine $(2.3 \mu \mathrm{L}, 0.02 \mathrm{mmol})$ was added and the reaction was stirred at room temperature overnight. The product, 39, was isolated as a yellow oil, and recrystallised from the diffusion of pentane into a dichloromethane solution. NMR data showed the 
product comprised 84\% syn isomer (pictured) and 16\% anti isomer. Recrystallised yield: $19 \mathrm{mg}, 85 \%$.

NMR data is for the syn isomer: ${ }^{1} \mathrm{H}$ NMR $\left(\mathrm{CDCl}_{3}\right)$ : $\delta / \mathrm{ppm} 13.11\left(\mathrm{~s}, J_{\mathrm{Pt}-\mathrm{H}}=84.1 \mathrm{~Hz}, 1 \mathrm{H}\right.$, $\mathrm{NH}), 8.04$ (m, 1H, H6), 7.91 (dd, JP-H $=7.5,2.9 \mathrm{~Hz}, 1 \mathrm{H}, \mathrm{H} 6$ '), 7.71 (m, 2H), 7.63 (m, 2H, Ar-H), 7.56 (m, 3H, Ar-H), 7.43 (m, 6H, Ar-H), 7.33 (m, 2H, Ar-H), 7.29-7.19 (m, 12H, Ar-H), 7.08 (d, $\left.J_{\mathrm{H}-\mathrm{H}}=8.1 \mathrm{~Hz}, 2 \mathrm{H}, \mathrm{Ar}-\mathrm{H}\right), 7.05\left(\mathrm{~d}, J_{\mathrm{H}-\mathrm{H}}=8.0 \mathrm{~Hz}, 2 \mathrm{H}, \mathrm{Ar}-\mathrm{H}\right), 5.24(\mathrm{~d}$, $\left.J_{\mathrm{H}-\mathrm{H}}=5.9 \mathrm{~Hz}, 2 \mathrm{H}, \mathrm{CH}_{2}\right), 3.93\left(\mathrm{~s}, 1 \mathrm{H}, \mathrm{CH}\left(\mathrm{SO}_{2} \mathrm{CF}_{3}\right)_{2}\right) .{ }^{31} \mathrm{P}\left\{{ }^{1} \mathrm{H}\right\} \mathrm{NMR}\left(\mathrm{CDCl}_{3}\right): \delta / \mathrm{ppm} 49.1$ $\left(\mathrm{d}, J_{\mathrm{P}-\mathrm{P}}=13.1 \mathrm{~Hz}, J_{\mathrm{Pt}-\mathrm{P}}=2532.0 \mathrm{~Hz}\right), 33.1\left(\mathrm{~d}, J_{\mathrm{P}-\mathrm{P}}=13.1 \mathrm{~Hz}, J_{\mathrm{Pt}-\mathrm{P}}=1736.2 \mathrm{~Hz}\right)$.

\subsection{4 $\left[\mathrm{Pt}\left(P, C-2-\mathrm{PPh}_{2} \mathrm{C}_{6} \mathrm{H}_{4} \mathrm{CO}\right)\left(P, C-2-\mathrm{PPh}_{2} \mathrm{C}_{6} \mathrm{H}_{4} \mathrm{CNBn}\right)\right](40)$}

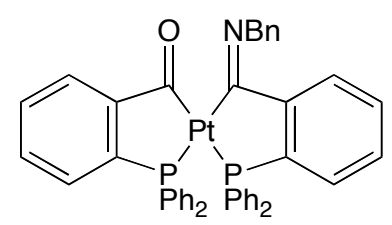

Complex 39 (70 mg, $0.06 \mathrm{mmol})$ was dissolved in diethyl ether $(15 \mathrm{~mL})$ and a slight excess of potassium hydride ( $3 \mathrm{mg}, 0.08 \mathrm{mmol}$ ) was added. The mixture was stirred for 45 minutes, by which time the product had precipitated, leaving a colourless solvent. The solvent was removed in vacuo and the solid was redissolved in dichloromethane $(4 \mathrm{~mL})$ and filtered through sintered glass to remove excess potassium hydride. The resulting product, 40, was recrystallised from the diffusion of pentane into the dichloromethane solution yielding red-orange crystals. Recrystallised yield: $41 \mathrm{mg}, 80 \%$.

IR (KBr, cm $\left.{ }^{-1}\right): 1613$ (vs), $v(\mathrm{C}=\mathrm{O}) .{ }^{1} \mathrm{H}$ NMR $\left(\mathrm{CDCl}_{3}\right):$ d/ppm 7.97-6.88 (m, 33H, Ar-H), $4.84\left(\mathrm{~s}, J_{\mathrm{Pt}-\mathrm{H}}=13 \mathrm{~Hz}, 2 \mathrm{H}, \mathrm{CH}_{2}\right) .{ }^{13} \mathrm{C} \mathrm{NMR}\left(\mathrm{CDCl}_{3}\right): \delta / \mathrm{ppm} 237.9$ (d, JP-C $=115 \mathrm{~Hz}$, $\left.J_{\mathrm{Pt}-\mathrm{C}}=1051 \mathrm{~Hz}, \mathrm{CO}\right), 201.1\left(\mathrm{~d}, J_{\mathrm{P}-\mathrm{C}}=92 \mathrm{~Hz}, J_{\mathrm{Pt}-\mathrm{C}}=972 \mathrm{~Hz}, \mathrm{CN}\right), 161.7\left(\mathrm{dd}, J_{\mathrm{P}-\mathrm{C}}=33.0\right.$, $12.6 \mathrm{~Hz}, \mathrm{Ar}-\mathrm{C}$ ), 161.0 (dd, $\left.J_{\mathrm{P}-\mathrm{C}}=37.3,26.1 \mathrm{~Hz}, \operatorname{Ar}-\mathrm{C}\right), 142.2$ (s, Ar-C), 138.0 (dd, $\left.J_{\mathrm{P}-\mathrm{C}}=47.7,2.8 \mathrm{~Hz}, \mathrm{Ar}-\mathrm{C}\right), 134.4,\left(\mathrm{dd}, J_{\mathrm{P}-\mathrm{C}}=52.1,3.9 \mathrm{~Hz}, \mathrm{Ar}-\mathrm{C}\right), 133.3\left(\mathrm{~d}, J_{\mathrm{P}-\mathrm{C}}=10.1 \mathrm{~Hz}\right.$, $\operatorname{Ar}-\mathrm{C}), 132.5$ (d, $\left.J_{\mathrm{P}-\mathrm{C}}=2.1 \mathrm{~Hz}, \mathrm{Ar}-\mathrm{C}\right), 132.5$ (d, $\left.J_{\mathrm{P}-\mathrm{C}}=6.8 \mathrm{~Hz}, \mathrm{Ar}-\mathrm{C}\right), 132.1$ (s, Ar-C), 131.6 (s, Ar-C), 131.5 (s, Ar-C), 131.3 (s, Ar-C), 130.5 (dd, JP-C = 34.0, 2.3 Hz, Ar-C), 130.1 (s, Ar-C), 129.7 (s, Ar-C), 129.0 (dd, $J_{\mathrm{P}-\mathrm{C}}=45.3,11.3 \mathrm{~Hz}, \mathrm{Ar}-\mathrm{C}$ ), 129.0 (d, J $J_{\mathrm{P}-\mathrm{C}}=6.7 \mathrm{~Hz}$, $\mathrm{Ar}-\mathrm{C}), 128.6\left(\mathrm{~d}, J_{\mathrm{P}-\mathrm{C}}=10.4 \mathrm{~Hz}, \mathrm{Ar}-\mathrm{C}\right), 128.3$ (d, JP-C $\left.=10.4 \mathrm{~Hz}, \mathrm{Ar}-\mathrm{C}\right), 128.2(\mathrm{~s}, \mathrm{Ar}-\mathrm{C})$, 127.8 (s, Ar-C), 125.8 (d, JP-C $=13.0 \mathrm{~Hz}, \mathrm{Ar}-\mathrm{C}$ ), 123.6 (d, JP-C = 16.6 Hz, Ar-C), 67.8 (d, $\left.J_{\mathrm{P}-\mathrm{C}}=9 \mathrm{~Hz}, J_{\mathrm{Pt}-\mathrm{C}}=132 \mathrm{~Hz}, \mathrm{CH}_{2}\right) .{ }^{31} \mathrm{P}\left\{{ }^{1} \mathrm{H}\right\} \mathrm{NMR}\left(\mathrm{CDCl}_{3}\right): \delta / \mathrm{ppm} 47.1\left(\mathrm{~d}, J_{\mathrm{P}-\mathrm{P}}=7 \mathrm{~Hz}\right.$ 
$\left.J_{\mathrm{Pt}-\mathrm{P}}=2117 \mathrm{~Hz}\right), 38.7\left(\mathrm{~d}, J_{\mathrm{P}-\mathrm{P}}=7 \mathrm{~Hz}, J_{\mathrm{Pt}-\mathrm{P}}=1687 \mathrm{~Hz}\right)$. Elemental Analysis: C, 62.73; $\mathrm{H}, 4.13 ; \mathrm{N}, 1.56 \%\left(\mathrm{C}_{45} \mathrm{H}_{35} \mathrm{NOP}_{2} \mathrm{Pt}\right.$ requires $\left.\mathrm{C}, 62.64 ; \mathrm{H}, 4.09 ; \mathrm{N}, 1.62 \%\right)$.

\subsection{5 $\left[\mathrm{Pt}\left(P, C-2-\mathrm{PPh}_{2} \mathrm{C}_{6} \mathrm{H}_{4} \mathrm{CO}\right)_{2}\{\mathrm{Rh}(\mathrm{COD})\}\right] \mathrm{CH}\left(\mathrm{SO}_{2} \mathrm{CF}_{3}\right)_{2}(38)$}

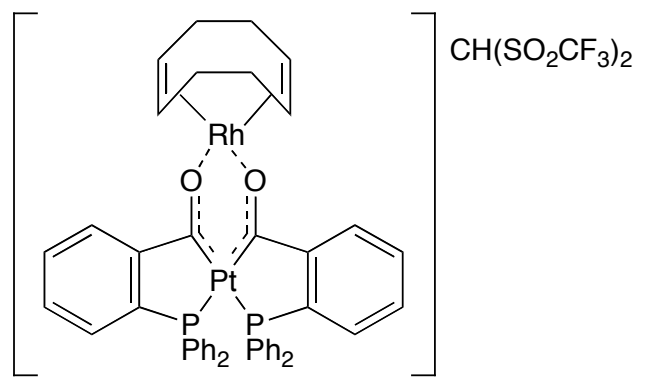

$[\mathrm{Rh}(\mathrm{OMe})(\mathrm{COD})]_{2} \quad(15 \mathrm{mg}, 0.03 \mathrm{mmol})$ and complex $31 \quad(65 \mathrm{mg}, 0.06 \mathrm{mmol})$ were combined in a round bottom flask and dissolved in dichloromethane $(5 \mathrm{~mL})$. A blood red colour was observed immediately upon addition of the solvent. The mixture was stirred for 30 minutes. The solvent was removed and the product was dried in vacuo at $30{ }^{\circ} \mathrm{C}$ to yield pure 38 as a dark red solid. Yield: $75 \mathrm{mg}, 100 \%$.

UV $\left(\mathrm{CH}_{2} \mathrm{Cl}_{2}\right) \lambda_{\max }, \mathrm{nm}(\varepsilon): 500$ (925). IR $\left(\mathrm{KBr}, \mathrm{cm}^{-1}\right) 1525.5(\mathrm{~s}), v(\mathrm{C}=\mathrm{O}) .{ }^{1} \mathrm{H}$ NMR $\left(\mathrm{CDCl}_{3}\right): \delta / \mathrm{ppm} 7.64\left(\mathrm{dd}, J_{\mathrm{RH}-\mathrm{H}}=12.6 \mathrm{~Hz}, J_{\mathrm{H}-\mathrm{H}}=7.2 \mathrm{~Hz}, 4 \mathrm{H}, \mathrm{Ar}-\mathrm{H}\right), 7.58\left(\mathrm{t}, J_{\mathrm{H}-\mathrm{H}}=7.4 \mathrm{~Hz}\right.$, 2H, Ar-H), 7.47 (t, $\left.J_{\mathrm{H}-\mathrm{H}}=7.4 \mathrm{~Hz}, 4 \mathrm{H}, \mathrm{Ar}-\mathrm{H}\right), 7.43\left(\mathrm{t}, J_{\mathrm{H}-\mathrm{H}}=8.1 \mathrm{~Hz}, 2 \mathrm{H}, \mathrm{Ar}-\mathrm{H}\right), 7.35-7.28$ (m, 16H, Ar-H), 3.99 (s, 4H, COD), 3.95 (s, 1H, CH( $\left.\left.\mathrm{SO}_{2} \mathrm{CF}_{3}\right)_{2}\right), 2.47$ (br d, $J_{\mathrm{H}-\mathrm{H}}=7.9 \mathrm{~Hz}$, 4H, COD), 1.86 (br d, $\left.J_{\mathrm{H}-\mathrm{H}}=7.9 \mathrm{~Hz}, 4 \mathrm{H}, \mathrm{COD}\right) .{ }^{13} \mathrm{C}\left\{{ }^{1} \mathrm{H}\right\} \mathrm{NMR}\left(\mathrm{CDCl}_{3}\right): \delta / \mathrm{ppm} 257.5$ (d, $\left.J_{\mathrm{P}-\mathrm{C}}=111.7 \mathrm{~Hz}, \mathrm{CO}\right), 157.4(\mathrm{~m}), 139.2\left(\mathrm{~d}, J_{\mathrm{P}-\mathrm{C}}=54.0 \mathrm{~Hz}, \mathrm{Ar}-\mathrm{C}\right), 135.0(\mathrm{~s}, \mathrm{Ar}-\mathrm{C}), 133.4$ (s, Ar-C), 133.1 (m, Ar-C), 132.2 (s, Ar-C), 131.4 (s, Ar-C), 129.5 (m, Ar-C), 127.3 (d, $\left.J_{\mathrm{P}-\mathrm{C}}=55.9 \mathrm{~Hz}, \mathrm{Ar}-\mathrm{C}\right), 124.7(\mathrm{~m}, \mathrm{Ar}-\mathrm{C}), 121.3$ (q, $\left.J_{\mathrm{F}-\mathrm{C}}=331.1 \mathrm{~Hz}, \mathrm{CH}\left(\mathrm{SO}_{2} \mathrm{CF}_{3}\right)_{2}\right), 79.9$ (d, $\left.J_{\mathrm{Rh}-\mathrm{C}}=14.4 \mathrm{~Hz}, \mathrm{COD}\right), 54.1\left(\mathrm{~s}, \mathrm{CH}\left(\mathrm{SO}_{2} \mathrm{CF}_{3}\right)_{2}\right), 30.7$ (s, COD). ${ }^{31} \mathrm{P}\left\{{ }^{1} \mathrm{H}\right\} \mathrm{NMR}\left(\mathrm{CDCl}_{3}\right)$ : $\delta / \mathrm{ppm} 38.6\left(\mathrm{~s}, \quad J_{\mathrm{Pt}-\mathrm{P}}=1970.5 \mathrm{~Hz}\right)$. Elemental Analysis: C, 46.59\%; H, 3.20\%. $\left(\mathrm{C}_{49} \mathrm{H}_{41} \mathrm{~F}_{6} \mathrm{O}_{6} \mathrm{P}_{2} \mathrm{PtRhS}_{2}\right.$ requires $\left.\mathrm{C}, 49.56 \% ; \mathrm{H}, 3.27 \%\right)$. HR-ESIMS $(\mathrm{m} / \mathrm{z})$ calculated for $[\mathrm{M}+\mathrm{H}]^{+}:$983.1185; observed, 983.1201. 


\subsection{6 $\left[\mathrm{Pt}\left(P, C-2-\mathrm{PPh}_{2} \mathrm{C}_{6} \mathrm{H}_{4} \mathrm{CO}\right)\left(P, C-2-\mathrm{PPh}_{2} \mathrm{C}_{6} \mathrm{H}_{4} \mathrm{CNBn}\right)\{\mathrm{Rh}(\mathrm{COD})\}\right]$ $\mathrm{CH}\left(\mathrm{SO}_{2} \mathrm{CF}_{3}\right)_{2}(42)$}

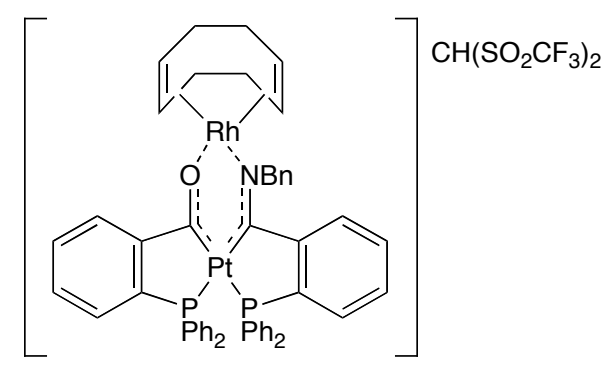

To a round bottom flask $[\mathrm{Rh}(\mathrm{OMe})(\mathrm{COD})]_{2}(22 \mathrm{mg}, 0.045 \mathrm{mmol})$ and $39(100 \mathrm{mg}$, $0.09 \mathrm{mmol})$ were combined and dissolved in dichloromethane $(5 \mathrm{~mL})$. A dark red colour was observed immediately upon addition of the solvent. The mixture was stirred for three hours. The solvent was removed and the product was dried in vacuo at $30^{\circ} \mathrm{C}$ to yield pure 42 as a dark red solid. Yield: $119 \mathrm{mg}$, 98\%.

${ }^{1} \mathrm{H}$ NMR $\left(\mathrm{CD}_{2} \mathrm{Cl}_{2}\right): \delta / p p m 7.85$ (br s, $\left.2 \mathrm{H}, \mathrm{Ar}-\mathrm{H}\right), 7.80\left(\mathrm{~d}, J_{\mathrm{H}-\mathrm{H}}=7.3 \mathrm{~Hz}, 2 \mathrm{H}, \mathrm{Ar}-\mathrm{H}\right), 7.65$ $(\mathrm{m}, 4 \mathrm{H}, \operatorname{Ar}-\mathrm{H}), 7.61-7.56(\mathrm{~m}, 6 \mathrm{H}, \mathrm{Ar}-\mathrm{H}), 7.53\left(\mathrm{t}, J_{\mathrm{H}-\mathrm{H}}=8.0 \mathrm{~Hz}, 1 \mathrm{H}, \operatorname{Ar}-\mathrm{H}\right), 7.46(\mathrm{t}$, $\left.J_{\mathrm{H}-\mathrm{H}}=7.4 \mathrm{~Hz}, 1 \mathrm{H}, \operatorname{Ar}-\mathrm{H}\right), 7.42(\mathrm{br} \mathrm{s}, 1 \mathrm{H}, \operatorname{Ar}-\mathrm{H}), 7.33(\mathrm{~m}, 2 \mathrm{H}, \mathrm{Ar}-\mathrm{H}), 7.26(\mathrm{br} \mathrm{m}, 2 \mathrm{H}$, Ar-H), $7.20\left(\mathrm{t}, J_{\mathrm{H}-\mathrm{H}}=8.5 \mathrm{~Hz}, 2 \mathrm{H}, \mathrm{Ar}-\mathrm{H}\right), 7.14(\mathrm{br} \mathrm{m}, 2 \mathrm{H}, \mathrm{Ar}-\mathrm{H}), 7.11(\mathrm{~m}, 1 \mathrm{H}, \mathrm{Ar}-\mathrm{H})$, $7.05(\mathrm{~m}, 2 \mathrm{H}, \mathrm{Ar}-\mathrm{H}), 6.98(\mathrm{br} \mathrm{s}, 2 \mathrm{H}, \mathrm{Ar}-\mathrm{H}), 6.82(\mathrm{~m}, 2 \mathrm{H}, \mathrm{Ar}-\mathrm{H}), 5.04\left(\mathrm{~d}, J_{\mathrm{RH}-\mathrm{H}}=14.6 \mathrm{~Hz}\right.$, 1H, COD), 4.31 (br s, 1H, COD), 3.97 (d, $15.9 \mathrm{~Hz}, 1 \mathrm{H}, \mathrm{COD}), 3.85$ (s, 1H, $\left.\mathrm{CH}\left(\mathrm{SO}_{2} \mathrm{CF}_{3}\right)_{2}\right), 2.61$ (br s, 1H, COD), 2.27 (br s, 1H, COD), 1.99 (br, 3H, COD), 1.42 (m, $4 \mathrm{H}, \mathrm{COD}) .{ }^{13} \mathrm{C}\left\{{ }^{1} \mathrm{H}\right\} \mathrm{NMR}\left(\mathrm{CD}_{2} \mathrm{Cl}_{2}\right): \delta / \mathrm{ppm} 249.3\left(\mathrm{~d}, J_{\mathrm{P}-\mathrm{C}}=104.9 \mathrm{~Hz}, J_{\mathrm{Pt}-\mathrm{C}}\right.$ not observed, $\mathrm{CO}), 214.0\left(\mathrm{dd}, J_{\mathrm{P}-\mathrm{C}}=104.3,5.5 \mathrm{~Hz}, J_{\mathrm{Pt}-\mathrm{C}}=950.8 \mathrm{~Hz}, \mathrm{C}=\mathrm{N}\right), 157.4\left(\mathrm{dd}, J_{\mathrm{P}-\mathrm{C}}=30.4\right.$, $16.3 \mathrm{~Hz}, \mathrm{Ar}-\mathrm{C}), 152.4\left(\mathrm{dd}, J_{\mathrm{P}-\mathrm{C}}=28.0 \mathrm{~Hz}, 6.9 \mathrm{~Hz}\right), 140.8\left(\mathrm{dd}, J_{\mathrm{P}-\mathrm{C}}=51.3,3.9 \mathrm{~Hz}, \mathrm{Ar}-\mathrm{C}\right)$, 138.7 (s, Ar-C), 135.5 (dd, $\left.J_{\mathrm{P}-\mathrm{C}}=53.0,4.1 \mathrm{~Hz}, \mathrm{Ar}-\mathrm{C}\right), 134.7\left(\mathrm{~d}, J_{\mathrm{P}-\mathrm{C}}=7.1 \mathrm{~Hz}, \mathrm{Ar}-\mathrm{C}\right)$, 134.2 (br m, Ar-C), 134.0 (br m, Ar-C), 133.6 (s, Ar-C), 132.8 (br m, Ar-C), 132.7 (s, Ar-C), 132.6 (br m), 132.3 (s, Ar-C), 132.2 (br m, Ar-C), 132.8 (br s, Ar-C), 131.6 (d, $J_{\mathrm{P}-\mathrm{C}}=2.0 \mathrm{~Hz}, \mathrm{Ar}-\mathrm{C}$ ), $131.3(\mathrm{br} \mathrm{s}, \mathrm{Ar}-\mathrm{C}), 130.8\left(\mathrm{~d}, J_{\mathrm{P}-\mathrm{C}}=7.2 \mathrm{~Hz}, \mathrm{Ar}-\mathrm{C}\right), 130.0-129.2(\mathrm{br} \mathrm{m}$, Ar-C), 129.5 (s, Ar-C), 127.8 (s, Ar-C), 127.0 (s, Ar-C), 127.6 (m, Ar-C), 121.5 (q, $\left.J_{\mathrm{F}-\mathrm{C}}=326.1 \mathrm{~Hz}, \mathrm{CH}\left(\mathrm{SO}_{2} \mathrm{CF}_{3}\right)_{2}\right), 89.6$ (br s, $\mathrm{COD}$ ), 81.6 (br s, COD), 78.5 (br s, COD), 72.8 (br s, $\mathrm{COD}$ ), $57.8\left(\mathrm{~d}, J_{\mathrm{Rh}-\mathrm{C}}=8.2 \mathrm{~Hz}, J_{\mathrm{Pt}-\mathrm{C}}=72.6 \mathrm{~Hz}, \mathrm{CH}\left(\mathrm{SO}_{2} \mathrm{CF}_{3}\right)_{2}\right), 33.8(\mathrm{br} \mathrm{s}, \mathrm{COD})$, 31.3 (br s, COD), 29.7 (br s, COD), 28.0 (br s, COD). ${ }^{31} \mathrm{P}\left\{{ }^{1} \mathrm{H}\right\} \mathrm{NMR}\left(\mathrm{CD}_{2} \mathrm{Cl}_{2}\right): \delta / \mathrm{ppm}$ $39.7\left(\mathrm{~d}, J_{\mathrm{P}-\mathrm{P}}=13.5 \mathrm{~Hz}, J_{\mathrm{Pt}-\mathrm{P}}=2173 \mathrm{~Hz}\right), 29.3\left(\mathrm{~d}, J_{\mathrm{P}-\mathrm{P}}=13.5 \mathrm{~Hz}, J_{\mathrm{Pt}-\mathrm{P}}=1857 \mathrm{~Hz}\right)$. Elemental 
Analysis: C, 49.19\%; H, 3.61\%; N, 1.00\%. $\left(\mathrm{C}_{56} \mathrm{H}_{48} \mathrm{~F}_{6} \mathrm{NO}_{5} \mathrm{P}_{2} \mathrm{PtRhS}_{2}\right.$ requires $\mathrm{C}, 49.71 \%$; $\mathrm{H}, 3.58 \%$; N, 1.04\%). HR-ESIMS $(\mathrm{m} / \mathrm{z})$ calculated for $[\mathrm{M}+\mathrm{H}]^{+}:$1072.1815; observed, 1072.1813.

\subsection{7 $\left[\mathrm{Pt}\left(P, C-2-\mathrm{PPh}_{2} \mathrm{C}_{6} \mathrm{H}_{4} \mathrm{CO}\right)\left(P, C-2-\mathrm{PPh}_{2} \mathrm{C}_{6} \mathrm{H}_{4} \mathrm{CNH}_{2}\right)\right] \mathrm{CH}\left(\mathrm{SO}_{2} \mathrm{CF}_{3}\right)_{2}(43)$}<smiles>O=C1C(=NN=c2c3ccccc3p(OC(F)(F)F)c3ccccc23)P(c2ccccc2)c2ccccc21</smiles>

Complex 31 (20 mg, $0.019 \mathrm{mmol})$ was dissolved in dichloromethane $(10 \mathrm{~mL})$ with several $4 \AA$ molecular sieves. Dry ammonia was bubbled through the solution for five seconds resulting a colour change to pink indicating the deprotonation of 31. Extra $\mathrm{CH}_{2}\left(\mathrm{SO}_{2} \mathrm{CF}_{3}\right)_{2}$ was added, and the mixture was stirred for three hours at room temperature. The solution was filtered through alumina and then dried in vacuo, resulting in a yellow solid product, 43. The product was recrystallised from the diffusion of pentane into a dichloromethane solution. Recrystallised yield: $10 \mathrm{mg}, 50 \%$.

${ }^{1} \mathrm{H} \mathrm{NMR}\left(\mathrm{CDCl}_{3}\right)$ : $\delta / p p m 13.40$ (br s, 1H, NH), 10.21 (br, s, 1H, NH), 8.35 (m, 1H, H6), $8.10\left(\mathrm{~m},{ }^{\prime} .{ }^{31} \mathrm{P}\left\{{ }^{1} \mathrm{H}\right\} \mathrm{NMR}\left(\mathrm{CDCl}_{3}\right): \delta / \mathrm{ppm} 49.7\left(\mathrm{~d}, J_{\mathrm{P}-\mathrm{P}}=12.9 \mathrm{~Hz}, J_{\mathrm{Pt}-\mathrm{P}}=2504.3 \mathrm{~Hz}\right), 38.2\right.$ $\left(\mathrm{d}, J_{\mathrm{P}-\mathrm{P}}=12.9 \mathrm{~Hz}, J_{\mathrm{Pt}-\mathrm{P}}=1724.9 \mathrm{~Hz}\right)$.

\subsection{Platinum complexes of 2-diphenylphosphinoacetophenone}

\subsection{1 $\left[\mathrm{PtMe}_{2}\left(2-\mathrm{PPh}_{2} \mathrm{C}_{6} \mathrm{H}_{4} \mathrm{COCH}_{3}\right)_{2}\right](45)$ and} $\left[\mathrm{PtMe}\left(P, C-2-\mathrm{PPh}_{2} \mathrm{C}_{6} \mathrm{H}_{4} \mathrm{COCH}_{2}\right)\left(2-\mathrm{PPh}_{2} \mathrm{C}_{6} \mathrm{H}_{4} \mathrm{COCH}_{3}\right)\right](46)$

Dimethylplatinum(1,5-hexadiene) $(80 \mathrm{mg}, 0.26 \mathrm{mmol})$ and $2(170 \mathrm{mg}, 0.56 \mathrm{mmol})$ were combined in a Schlenk tube and dissolved in dichloromethane $(5 \mathrm{~mL})$. There was immediate conversion to complex 45, as observed by ${ }^{1} \mathrm{H}$ and ${ }^{31} \mathrm{P}$ NMR. The reaction was stirred for one day at which point the solvent was removed in vacuo. Complexes of cis- and trans-46 were produced in a cis/trans ratio of approximately 2:1 and recrystallised from the diffusion of diethyl ether into a dichloromethane solution. 


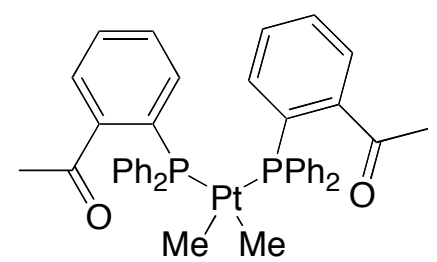

${ }^{1} \mathrm{H} \mathrm{NMR}\left(\mathrm{C}_{6} \mathrm{D}_{6}\right): \delta / p p m 7.87$ (br s, 8H, Ar-H), 7.41 (t, $\left.7.9 \mathrm{~Hz}, 2 \mathrm{H}, \mathrm{Ar}-\mathrm{H}\right), 7.13$ (br s, 2H, Ar-H) 6.99-6.73 (m, 16H, Ar-H), 2.15 (br s, 6H, $\left.\mathrm{COCH}_{3}\right), 0.86\left(\mathrm{~m}, J_{\mathrm{Pt}-\mathrm{H}}=69.9 \mathrm{~Hz}, 6 \mathrm{H}\right.$, $\left.\mathrm{Pt}-\mathrm{CH}_{3}\right) .{ }^{31} \mathrm{P}\left\{{ }^{1} \mathrm{H}\right\} \mathrm{NMR}\left(\mathrm{C}_{6} \mathrm{D}_{6}\right): \delta / \mathrm{ppm} 33.1\left(\mathrm{~s}, J_{\mathrm{Pt}-\mathrm{P}}=2066.6 \mathrm{~Hz}\right)$.

$\left[\mathrm{PtMe}\left(P, C-2-\mathrm{PPh}_{2} \mathrm{C}_{6} \mathrm{H}_{4} \mathrm{COCH}_{2}\right)\left(2-\mathrm{PPh}_{2} \mathrm{C}_{6} \mathrm{H}_{4} \mathrm{COCH}_{3}\right)\right](46)$

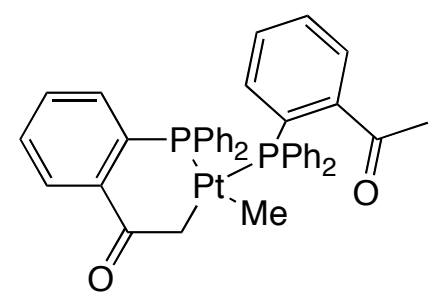

${ }^{1} \mathrm{H} \mathrm{NMR}\left(\mathrm{CDCl}_{3}\right): \delta / p p m 7.87\left(\mathrm{ddd}, J_{\mathrm{H}-\mathrm{H}}=7.8 \mathrm{~Hz}, 1.2 \mathrm{~Hz}, J_{\mathrm{P}-\mathrm{H}}=4.3 \mathrm{~Hz}, 1 \mathrm{H}, \mathrm{Ar}-\mathrm{H}\right), 7.70$ $\left(\mathrm{ddd}, J_{\mathrm{H}-\mathrm{H}}=7.6,1.3 \mathrm{~Hz}, J_{\mathrm{P}-\mathrm{H}}=4.0 \mathrm{~Hz}, 1 \mathrm{H}, \mathrm{Ar}-\mathrm{H}\right), 7.44-7.05(\mathrm{~m}, 25 \mathrm{H}, \mathrm{Ar}-\mathrm{H}), 6.63$ (t, $\left.J_{\mathrm{H}-\mathrm{H}}=8.3 \mathrm{~Hz}, 1 \mathrm{H}, \mathrm{Ar}-\mathrm{H}\right), 3.12\left(\mathrm{t}, J_{\mathrm{P}-\mathrm{H}}=10.0 \mathrm{~Hz}, J_{\mathrm{Pt}-\mathrm{H}}=94.5 \mathrm{~Hz}, 2 \mathrm{H}, \mathrm{Pt}_{-} \mathrm{CH}_{2}\right), 2.39(\mathrm{~s}, 3 \mathrm{H}$, $\left.\mathrm{COCH}_{3}\right), 0.38\left(\mathrm{t}, J_{\mathrm{H}-\mathrm{H}}=7.1 \mathrm{~Hz}, J_{\mathrm{Pt}-\mathrm{H}}=63.6 \mathrm{~Hz}, 3 \mathrm{H}, \mathrm{Pt}-\mathrm{CH}_{3}\right) .{ }^{31} \mathrm{P}\left\{{ }^{1} \mathrm{H}\right\} \mathrm{NMR}\left(\mathrm{CDCl}_{3}\right)$ : ठ/ppm $33.4\left(\mathrm{~d}, J_{\mathrm{P}-\mathrm{P}}=10.8 \mathrm{~Hz}, J_{\mathrm{Pt}-\mathrm{P}}=2827.5 \mathrm{~Hz}\right), 22.1\left(\mathrm{~d}, J_{\mathrm{P}-\mathrm{P}}=11.0 \mathrm{~Hz}, J_{\mathrm{Pt}-\mathrm{P}}=1887.5 \mathrm{~Hz}\right)$.

\subsection{2 $\left[\mathrm{Pt}\left(P, C-2-\mathrm{PPh}_{2} \mathrm{C}_{6} \mathrm{H}_{4} \mathrm{COCH}_{2}\right)_{2}\right](47)$}

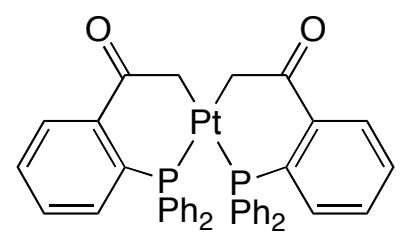

Tris(norbornene)platinum (50 mg, $0.10 \mathrm{mmol})$ and $2(64 \mathrm{mg}, 0.20 \mathrm{mmol})$ were combined in a round bottom flask and dissolved in toluene $(10 \mathrm{~mL})$. The flask was opened to air and stirred for one day. Stirring was stopped and over five days block-like crystals formed. The crystals were separated from the supernatant and washed with hexane. Both cis and trans isomers of 47 were formed. Recrystallised yield: $47 \mathrm{mg}, 58 \%$. 
An alternative synthesis used dimethylplatinum(1,5-hexadiene) $(80 \mathrm{mg}, 0.261 \mathrm{mmol})$ and 2 (165 mg, $0.543 \mathrm{mmol}$ ). The reactants were dissolved in chloroform and heated at reflux for 72 hours. The solvent was removed in vacuo and the solid was washed with toluene. The white microcrystalline solid was recrystallised from the diffusion of diethyl ether into a dichloromethane solution. Recrystallised yield: $140 \mathrm{mg}, 67 \%$.

IR $\left(\mathrm{KBr}, \mathrm{cm}^{-1}\right): 1629(\mathrm{~s}), v(\mathrm{C}=\mathrm{O})$. HR-ESIMS: $(\mathrm{m} / \mathrm{z})$ calculated for $[\mathrm{M}+\mathrm{H}]^{+}, 801.1583$; observed, 801.1580. Elemental Analysis: C, 60.15; H, 4.05\% $\left(\mathrm{C}_{40} \mathrm{H}_{32} \mathrm{O}_{2} \mathrm{P}_{2} \mathrm{Pt}\right.$ requires C, 59.93; H, 4.02\%). NMR data for trans-46: ${ }^{1} \mathrm{H} \mathrm{NMR}\left(\mathrm{CDCl}_{3}\right)$ : $\delta / \mathrm{ppm} 7.81$ (m, 2H, H6), 7.29-6.78 (m, 26H, Ar-H), $3.38\left(\mathrm{dd}, J_{\mathrm{H}-\mathrm{H}}=7.3 \mathrm{~Hz}, J_{\mathrm{P}-\mathrm{H}}=2.2, J_{\mathrm{Pt}-\mathrm{H}}=93 \mathrm{~Hz}, 4 \mathrm{H}, \mathrm{Pt}-\mathrm{CH}_{2}\right)$, ${ }^{31} \mathrm{P}\left\{{ }^{1} \mathrm{H}\right\} \mathrm{NMR}\left(\mathrm{CDCl}_{3}\right): \delta / \mathrm{ppm} 17.5\left(\mathrm{~s}, J_{\mathrm{Pt}-\mathrm{P}}=2823 \mathrm{~Hz}\right)$. NMR data for cis-46: ${ }^{1} \mathrm{H} \mathrm{NMR}$ $\left(\mathrm{CDCl}_{3}\right): \delta /$ ppm $7.63(\mathrm{~m}, 2 \mathrm{H}, \mathrm{H} 6), 7.64-6.71(\mathrm{~m}, 26 \mathrm{H}, \mathrm{Ar}-\mathrm{H}), 2.60$ (t, $J_{\mathrm{H}-\mathrm{H}}=6.3 \mathrm{~Hz}$, $\left.J_{\mathrm{Pt}-\mathrm{H}}=82 \mathrm{~Hz}, 4 \mathrm{H}, \mathrm{Pt}-\mathrm{CH}_{2}\right) \cdot{ }^{13} \mathrm{C}\left\{{ }^{1} \mathrm{H}\right\} \mathrm{NMR}\left(\mathrm{CDCl}_{3}\right): \delta / \mathrm{ppm} 201.4\left(\mathrm{~s}, J_{\mathrm{Pt}-\mathrm{C}}=52 \mathrm{~Hz}, \mathrm{CO}\right)$, 147.5 (s, Ar-C), 134.8-128.2 (m, Ar-C), 40.7 (dd, $J_{\mathrm{P}-\mathrm{C}}=60.7,7.2 \mathrm{~Hz}, J_{\mathrm{Pt}-\mathrm{C}}=354 \mathrm{~Hz}$, $\left.\mathrm{Pt}-\mathrm{CH}_{2}\right) .{ }^{31} \mathrm{P}\left\{{ }^{1} \mathrm{H}\right\} \mathrm{NMR}\left(\mathrm{CDCl}_{3}\right): \delta / \mathrm{ppm} 18.0\left(\mathrm{~s}, J_{\mathrm{Pt}-\mathrm{P}}=2459 \mathrm{~Hz}\right)$.

\subsection{3 $\left[\mathrm{Pt}\left(P, C-2-\mathrm{PPh}_{2} \mathrm{C}_{6} \mathrm{H}_{4} \mathrm{C}(\mathrm{OH})\left(\mathrm{CH}_{3}\right)\right)\left(P, C-2-\mathrm{PPh}_{2} \mathrm{C}_{6} \mathrm{H}_{4} \mathrm{COCH}_{2}\right)\right](48)$}

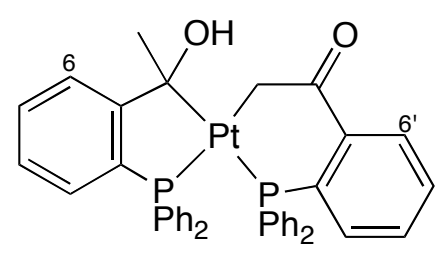

Tris(norbornene)platinum (59 $\mathrm{mg}, 0.124 \mathrm{mmol})$ and $2(75 \mathrm{mg}, 0.248 \mathrm{mmol})$ were added to a Schlenk tube and dissolved in dichloromethane $(3 \mathrm{~mL})$. The mixture was stirred overnight at room temperature. The solvent and residual norbornene were removed in vacuo, leaving a yellow solid identified as complex 48. The product was sensitive to oxygen in solution, and converted to complex 47 over time. Yield $60 \mathrm{mg}, 60 \%$.

${ }^{1} \mathrm{H}$ NMR $\left(\mathrm{C}_{6} \mathrm{D}_{6}\right): \delta / p p m 8.39\left(\mathrm{dd}, J_{\mathrm{H}-\mathrm{H}}=8.3 \mathrm{~Hz}, J_{\mathrm{P}-\mathrm{H}}=3.1 \mathrm{~Hz}, 1 \mathrm{H}, \mathrm{H} 6\right), 8.15$ (dd, $\left.J_{\mathrm{H}-\mathrm{H}}=7.6 \mathrm{~Hz}, J_{\mathrm{P}-\mathrm{H}}=4.6 \mathrm{~Hz}, 1 \mathrm{H}, \mathrm{H} 6{ }^{\prime}\right), 7.59(\mathrm{~m}, 2 \mathrm{H}, \mathrm{Ar}-\mathrm{H}), 7.18(\mathrm{~m}, 6 \mathrm{H}, \mathrm{Ar}-\mathrm{H}), 7.02-6.66$ $(\mathrm{m}, 14 \mathrm{H}, \mathrm{Ar}-\mathrm{H}), 6.50(\mathrm{~m}, 4 \mathrm{H}, \mathrm{Ar}-\mathrm{H}), 6.06\left(\mathrm{br} \mathrm{s}, J_{\mathrm{Pt}-\mathrm{H}}=30 \mathrm{~Hz}, 1 \mathrm{H}, \mathrm{OH}\right), 4.16$ (td, $\left.J_{\mathrm{H}-\mathrm{H}}=4.1 \mathrm{~Hz}, \quad J_{\mathrm{P}-\mathrm{H}}=8.0 \mathrm{~Hz}, \quad J_{\mathrm{Pt}-\mathrm{H}}=97.8 \mathrm{~Hz}, 1 \mathrm{H}, \quad \mathrm{CH}_{2}-\mathrm{Pt}\right), 3.68 \quad\left(\mathrm{td}, J_{\mathrm{H}-\mathrm{H}}=4.1 \mathrm{~Hz}\right.$, $\left.J_{\mathrm{P}-\mathrm{H}}=9.4 \mathrm{~Hz}, J_{\mathrm{Pt}-\mathrm{H}}=88.4 \mathrm{~Hz}, 1 \mathrm{H}, \mathrm{Pt}_{-} \mathrm{CH}_{2}\right), 2.19\left(\mathrm{~d}, J_{\mathrm{H}-\mathrm{H}}=6.4 \mathrm{~Hz}, J_{\mathrm{Pt}-\mathrm{H}}=38.5 \mathrm{~Hz}, 3 \mathrm{H}\right.$, $\left.\mathrm{CH}_{3}\right) .{ }^{13} \mathrm{C} \quad\left\{{ }^{1} \mathrm{H}\right\} \quad \mathrm{NMR} \quad\left(\mathrm{C}_{6} \mathrm{D}_{6}\right): \quad \delta / \mathrm{ppm} 170.9 \quad\left(\mathrm{~d}, \quad J_{\mathrm{P}-\mathrm{C}}=34.9 \mathrm{~Hz}, \mathrm{CO}\right), 150.5 \quad(\mathrm{~d}$, 
$\left.J_{\mathrm{P}-\mathrm{C}}=19.8 \mathrm{~Hz}, \mathrm{Ar}-\mathrm{C}\right), 146.6(\mathrm{~m}, \mathrm{Ar}-\mathrm{C}), 141.6\left(\mathrm{~d}, J_{\mathrm{P}-\mathrm{C}}=16.8 \mathrm{~Hz}, \mathrm{Ar}-\mathrm{C}\right), 140.8$ (d, $\left.J_{\mathrm{P}-\mathrm{C}}=29.0 \mathrm{~Hz}, \mathrm{Ar}-\mathrm{C}\right), 139.6\left(\mathrm{~d}, J_{\mathrm{P}-\mathrm{C}}=11.9 \mathrm{~Hz}, \mathrm{Ar}-\mathrm{C}\right), 135.1$ (s, Ar-C), 135.0 (s, Ar-C), 134.9 (s, Ar-C), 134.8 (s, Ar-C), 134.1 (d, JP-C = 19.7 Hz, Ar-C), 133.8-127.5 (m, Ar-C), $87.0\left(\mathrm{~d}, J_{\mathrm{P}-\mathrm{C}}=107.5 \mathrm{~Hz}, J_{\mathrm{Pt}-\mathrm{C}}=728 \mathrm{~Hz}, \mathrm{C}(\mathrm{OH})\left(\mathrm{CH}_{3}\right)\right), 42.2\left(\mathrm{~d}, J_{\mathrm{P}-\mathrm{C}}=5.3 \mathrm{~Hz}, J_{\mathrm{Pt}-\mathrm{C}}=377 \mathrm{~Hz}\right.$, Pt- $\left.\mathrm{CH}_{2}\right), \quad 37.2 \quad\left(\mathrm{~s}, \quad \mathrm{CH}_{3}\right) . \quad{ }^{31} \mathrm{P} \quad\left\{{ }^{1} \mathrm{H}\right\} \quad \mathrm{NMR} \quad\left(\mathrm{C}_{6} \mathrm{D}_{6}\right): \quad \delta / \mathrm{ppm} 41.0 \quad\left(\mathrm{~d}, \quad J_{\mathrm{P}-\mathrm{P}}=8.1 \mathrm{~Hz}\right.$, $\left.J_{\mathrm{Pt}-\mathrm{P}}=2972 \mathrm{~Hz}\right), 19.2\left(\mathrm{~d}, J_{\mathrm{P}-\mathrm{P}}=8.1 \mathrm{~Hz}, J_{\mathrm{Pt}-\mathrm{P}}=1525 \mathrm{~Hz}\right)$.

\subsection{Platinum complexes of}

\section{2-bis(pentafluorophenyl)phosphinobenzaldehyde}

\subsection{1 $\left[\mathrm{PtMe}_{2}\left\{2-\mathrm{P}\left(\mathrm{C}_{6} \mathrm{~F}_{5}\right)_{2} \mathrm{C}_{6} \mathrm{H}_{4} \mathrm{CHO}\right\}_{2}\right](52)$, trans- $\left[\mathrm{Pt}\left\{P, C-2-\mathrm{P}\left(\mathrm{C}_{6} \mathrm{~F}_{5}\right)_{2} \mathrm{C}_{6} \mathrm{H}_{4} \mathrm{CO}\right\}_{2}\right](53)$, and $\left[\mathrm{Pt}\left\{P, C-2-\mathrm{P}\left(\mathrm{C}_{6} \mathrm{~F}_{5}\right)_{2} \mathrm{C}_{6} \mathrm{H}_{4} \mathrm{CO}\right\}\left\{P, C-2-\mathrm{P}\left(\mathrm{C}_{6} \mathrm{~F}_{5}\right)_{2} \mathrm{C}_{6} \mathrm{H}_{4}\right\}\right](54)$}

Compound 3 (244 mg, $0.52 \mathrm{mmol})$ and [PtMe 2 (1,5-hexadiene)] (80 mg, $0.26 \mathrm{mmol})$ were combined in a two-necked flask fitted with a nitrogen adaptor and reflux condenser. Toluene $(10 \mathrm{~mL})$ was added and the mixture was stirred at room temperature for two days, resulting in the complete conversion of starting materials to complex 52. The mixture was then heated at reflux for four hours. The reaction was cooled and the solvent removed in vacuo yielding a brown solid comprising the air stable complexes, 53 and 54. The crude product was dryloaded onto a silica column and eluted with hexane/ethyl acetate (9:1) to separate complexes 53 and 54.

$\left[\mathrm{PtMe}_{2}\left\{2-\mathrm{P}\left(\mathrm{C}_{6} \mathrm{~F}_{5}\right)_{2} \mathrm{C}_{6} \mathrm{H}_{4} \mathrm{CHO}_{2}\right](52)\right.$

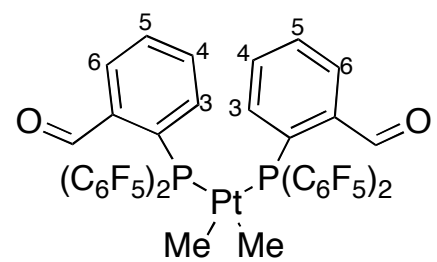

${ }^{1} \mathrm{H}$ NMR $\left(\mathrm{CDCl}_{3}\right): \delta / \mathrm{ppm} 10.06\left(\mathrm{~d}, J_{\mathrm{P}-\mathrm{H}}=2.7 \mathrm{~Hz}, 2 \mathrm{H}, \mathrm{CHO}\right), 8.02\left(\mathrm{dd}, J_{\mathrm{H}-\mathrm{H}}=7.0 \mathrm{~Hz}\right.$, $\left.J_{\mathrm{P}-\mathrm{H}}=3.6 \mathrm{~Hz}, 2 \mathrm{H}, \mathrm{H} 6\right), 7.95(\mathrm{~m}, 4 \mathrm{H}, \mathrm{H} 4$ and $\mathrm{H} 5), 7.81-7.67(\mathrm{~m}, 2 \mathrm{H}, \mathrm{H} 3), 0.65$ (br s, $\left.J_{\mathrm{Pt}-\mathrm{H}}=73.4 \mathrm{~Hz}, 6 \mathrm{H}, \mathrm{Pt}-\mathrm{CH}_{3}\right) .{ }^{31} \mathrm{P}\left\{{ }^{1} \mathrm{H}\right\} \mathrm{NMR}\left(\mathrm{CDCl}_{3}\right): \delta / \mathrm{ppm} 17.5\left(\mathrm{~s}, J_{\mathrm{Pt}-\mathrm{P}}=2091.4 \mathrm{~Hz}\right)$. 
trans ${ }^{-}\left[\mathrm{Pt}\left\{P, C-2-\mathrm{P}\left(\mathrm{C}_{6} \mathrm{~F}_{5}\right)_{2} \mathrm{C}_{6} \mathrm{H}_{4} \mathrm{CO}\right\}_{2}\right](53)$

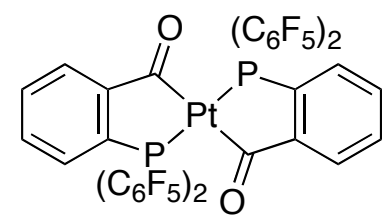

IR $\left(\mathrm{KBr}, \mathrm{cm}^{-1}\right): 1643(\mathrm{~s}) v(\mathrm{C}=\mathrm{O}) .{ }^{1} \mathrm{H}$ NMR $\left(\mathrm{C}_{6} \mathrm{D}_{6}\right): \delta / p p m 7.92(\mathrm{~m}, 4 \mathrm{H}, \mathrm{Ar}-\mathrm{H}), 6.98(\mathrm{~m}$, $4 \mathrm{H}, \mathrm{Ar}-\mathrm{H}) .{ }^{19} \mathrm{~F}\left\{{ }^{1} \mathrm{H}\right\} \mathrm{NMR}\left(\mathrm{C}_{6} \mathrm{D}_{6}\right): \delta / \mathrm{ppm}-126.8\left(\mathrm{~d}, J_{\mathrm{F}-\mathrm{F}}=20.0 \mathrm{~Hz}, 8 \mathrm{~F}\right.$, ortho Ar-F), -145.0 $\left(\mathrm{tt}, J_{\mathrm{F}-\mathrm{F}}=21.2,4.8 \mathrm{~Hz}, 4 \mathrm{~F}\right.$, para Ar-F), $-159.0\left(\mathrm{t}, J_{\mathrm{F}-\mathrm{F}}=20.4 \mathrm{~Hz}, 8 \mathrm{~F}\right.$, meta $\left.A r-\mathrm{F}\right) .{ }^{31} \mathrm{P}\left\{{ }^{1} \mathrm{H}\right\}$ $\operatorname{NMR}\left(\mathrm{C}_{6} \mathrm{D}_{6}\right): \delta / \mathrm{ppm} 19.9\left(\mathrm{~s}, J_{\mathrm{Pt}-\mathrm{P}}=3916.7 \mathrm{~Hz}\right)$. HR-ESIMS $(\mathrm{m} / \mathrm{z})$ calculated for $[\mathrm{M}+\mathrm{H}]^{+}$, 1132.9385; observed, 1132.9382.

$\left[\mathrm{Pt}\left\{P, C-2-\mathrm{P}\left(\mathrm{C}_{6} \mathrm{~F}_{5}\right)_{2} \mathrm{C}_{6} \mathrm{H}_{4} \mathrm{CO}\right\}\left\{P, C-2-\mathrm{P}\left(\mathrm{C}_{6} \mathrm{~F}_{5}\right)_{2} \mathrm{C}_{6} \mathrm{H}_{4}\right\}\right](54)$

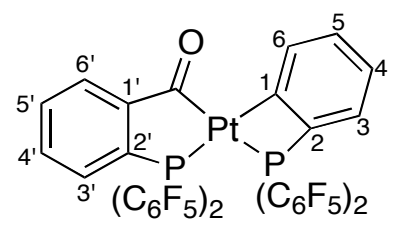

IR $\left(\mathrm{KBr}, \mathrm{cm}^{-1}\right): 1644$ (s) $v(\mathrm{C}=\mathrm{O}) .{ }^{1} \mathrm{H}$ NMR $\left(\mathrm{C}_{6} \mathrm{D}_{6}\right): \delta / \mathrm{ppm} 9.37$ (q, $J_{\mathrm{H}-\mathrm{H}}=7.4 \mathrm{~Hz}$, $\left.J_{\mathrm{Pt}-\mathrm{H}}=52.7 \mathrm{~Hz}, 1 \mathrm{H}, \mathrm{H} 6\right), 8.13\left(\mathrm{ddd}, J_{\mathrm{H}-\mathrm{H}}=7.5,1.2 \mathrm{~Hz}, J_{\mathrm{P}-\mathrm{H}}=3.6 \mathrm{~Hz}, 1 \mathrm{H}, \mathrm{H} 6{ }^{\prime}\right), 7.74(\mathrm{t}$, $\left.J_{\mathrm{H}-\mathrm{H}}=8.8 \mathrm{~Hz}, 1 \mathrm{H}, \mathrm{H} 3^{\prime}\right), 7.45\left(\mathrm{~m}, 2 \mathrm{H}, \mathrm{H}^{\prime}\right.$ and $\left.\mathrm{H} 5^{\prime}\right), 7.17$ (m, 2H, H3 and H4), 7.02 (m, 1H, H5). ${ }^{13} \mathrm{C}\left\{{ }^{1} \mathrm{H}\right\} \mathrm{NMR}\left(\mathrm{C}_{6} \mathrm{D}_{6}\right): \delta / \mathrm{ppm} 209.2$ (d, JP-C $=148.6 \mathrm{~Hz},{ }^{1} J_{\mathrm{Pt}-\mathrm{P}}$ not observed, CO), $158.5\left(\mathrm{~d}, J_{\mathrm{F}-\mathrm{C}}=188.5 \mathrm{~Hz}\right.$, ipso ArF-C), 147.2 (br d, $J_{\mathrm{F}-\mathrm{C}}=257.6 \mathrm{~Hz}$, ortho ArF-C), 145.0 (d, $\left.J_{\mathrm{P}-\mathrm{C}}=39.5 \mathrm{~Hz}, \mathrm{C} 2\right), 143.6\left(\mathrm{br} \mathrm{d}, J_{\mathrm{F}-\mathrm{C}}=260.5 \mathrm{~Hz}\right.$, para ArF-C), 137.8 (br d, $J_{\mathrm{F}-\mathrm{C}}=250.6 \mathrm{~Hz}$, meta $\mathrm{ArF}-\mathrm{C}), 133.8$ (s, C4'), 133.5 (d, J $\mathrm{P}_{\mathrm{C}}=6.6 \mathrm{~Hz}, \mathrm{C} 5$ '), 132.7 (br d, J $\left.\mathrm{P}_{\mathrm{C}}=51.7 \mathrm{~Hz}, \mathrm{C} 5\right)$, 131.5 (d, JP-C $=22.5 \mathrm{~Hz}, \mathrm{C} 6), 130.0$ (br s, C3'), 125.9 (d, JP-C $=18.4$ Hz, C6'), 123.0 (s, C3), 118.5 (s, C4), 104.8 (d, JP-C $=142.2 \mathrm{~Hz},{ }^{1} J_{\mathrm{Pt}-\mathrm{P}}$ not observed, C1). ${ }^{19} \mathrm{~F}\left\{{ }^{1} \mathrm{H}\right\} \mathrm{NMR}\left(\mathrm{C}_{6} \mathrm{D}_{6}\right)$ : d/ppm -128.7 (br s, 4F, ortho Ar-F), -130.8 (br s, 4F, ortho Ar-F), -146.3 (m, 4F, para Ar-F), -159.5 (m, 8F, meta Ar-F). ${ }^{31} \mathrm{P}\left\{{ }^{1} \mathrm{H}\right\} \mathrm{NMR}\left(\mathrm{C}_{6} \mathrm{D}_{6}\right): \delta / \mathrm{ppm} 16.1$ (s, JPt-P$\left.=2298.5 \mathrm{~Hz}\right)$, $-96.8\left(\mathrm{~s}, J_{\mathrm{Pt}-\mathrm{P}}=522.2 \mathrm{~Hz}\right)$. HR-ESIMS $(\mathrm{m} / \mathrm{z})$ calculated for $[\mathrm{M}+\mathrm{H}]^{+}, 1105.9436$; observed, 1105.9427. 


\subsection{2 $\left[\mathrm{Pt}\left\{P, C-2-\mathrm{P}\left(\mathrm{C}_{6} \mathrm{~F}_{5}\right)_{2} \mathrm{C}_{6} \mathrm{H}_{4} \mathrm{CO}\right\}\left\{P, C-2-\mathrm{P}\left(\mathrm{C}_{6} \mathrm{~F}_{5}\right)_{2} \mathrm{C}_{6} \mathrm{H}_{4}\right\} \mathrm{PPh}_{3}\right](58)$}

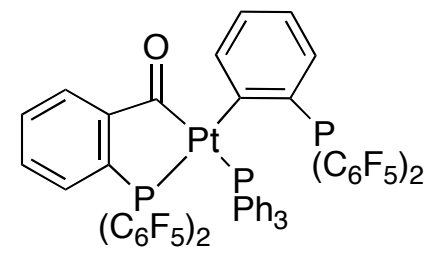

Complex $54(10 \mathrm{mg}, 0.009 \mathrm{mmol})$ was placed in an NMR tube and dissolved in $\mathrm{CD}_{2} \mathrm{Cl}_{2}$ $(0.4 \mathrm{~mL})$. Triphenylphosphine $(2.4 \mathrm{mg}, 0.009 \mathrm{mmol})$ was added to the solution. The solution was transferred to a Schlenk tube and the solvent was removed in vacuo, yielding 58 as a yellow solid. The product was formed quantitatively from 53 according to NMR.

${ }^{1} \mathrm{H}$ NMR $\left(\mathrm{CD}_{2} \mathrm{Cl}_{2}\right): \delta / p p m 7.75\left(\mathrm{t}, 6.8 \mathrm{~Hz}, J_{\mathrm{Pt}-\mathrm{H}}=61.8 \mathrm{~Hz}, 1 \mathrm{H}\right), 7.63(\mathrm{~m}, 1 \mathrm{H}, \mathrm{Ar}-\mathrm{H}), 7.45$ (m, 2H, Ar-H), 7.27-7.29 (m, 10H, Ar-H), 7.13 (t, 6.6 Hz, 7H, Ar-H), 6.82 (t, 6.6 Hz, 1H, Ar-H), 6.59 (m, 1H, Ar-H). ${ }^{19} \mathrm{~F}\left\{{ }^{1} \mathrm{H}\right\}$ NMR $\left(\mathrm{CD}_{2} \mathrm{Cl}_{2}\right)$ : $\delta / p p m-123.8$ (d, $20.2 \mathrm{~Hz}, 2 \mathrm{~F}$, ortho Ar-F), -124.6 (br s, 4F, ortho Ar-F), -127.9 (br s, 2F, ortho Ar-F), -145.4 (t, 1F, para Ar-F), -146.1 (t, 1F, para Ar-F), -148.8 (t, 20.2 Hz, 1F, para Ar-F), -151.6 (t, 20.6 Hz, 1F, para Ar-F), -157.1 (t, $16.8 \mathrm{~Hz}, 2 \mathrm{~F}$, meta Ar-F), -157.3 (t, $16.9 \mathrm{~Hz}, 2 \mathrm{~F}$ meta Ar-F), -159.5 (m, 2F meta Ar-F), -161.0 (m, 2F meta Ar-F). ${ }^{31} \mathrm{P}\left\{{ }^{1} \mathrm{H}\right\}$ NMR $\left(\mathrm{CD}_{2} \mathrm{Cl}_{2}\right): \delta / \mathrm{ppm} 16.3$ (s, $\left.J_{\mathrm{Pt}-\mathrm{P}}=1605 \mathrm{~Hz}\right), 16.0\left(\mathrm{br} \mathrm{s}, J_{\mathrm{Pt}-\mathrm{P}}=1988.7 \mathrm{~Hz}\right),-61.4$ (br s).

\subsection{Platinum complexes of 2-di-tert-butylphosphinobenzaldehyde}

\subsection{1 $\left[\mathrm{PtMe}\left(P, C-2-\mathrm{P}^{t} \mathrm{Bu}_{2} \mathrm{C}_{6} \mathrm{H}_{4} \mathrm{CO}\right)\left(2-\mathrm{P}^{t} \mathrm{Bu}_{2} \mathrm{C}_{6} \mathrm{H}_{4} \mathrm{CHO}\right)\right](59)$, $\left[\mathrm{Pt}\left(P, C-2-\mathrm{P}^{t} \mathrm{Bu}_{2} \mathrm{C}_{6} \mathrm{H}_{4} \mathrm{CO}\right)_{2}\right](60)$, and $\left[\mathrm{Pt}\left(P, O-2-\mathrm{P}^{t} \mathrm{Bu}_{2} \mathrm{C}_{6} \mathrm{H}_{4} \mathrm{COO}\right)\left(P, C-2-\mathrm{P}^{t} \mathrm{Bu}_{2} \mathrm{C}_{6} \mathrm{H}_{4} \mathrm{CO}\right)\right](62)$}

Dimethylplatinum(1,5-hexadiene) $(17 \mathrm{mg}, 0.05 \mathrm{mmol})$ was dissolved in $\mathrm{C}_{6} \mathrm{D}_{6}(0.4 \mathrm{~mL})$ and transferred to an NMR tube containing compound $4(27 \mathrm{mg}, 0.11 \mathrm{mmol})$. Complexes 59 and 60 were characterised in solution. Complex 60 was isolated from the reaction solution as yellow prismatic crystals, which had formed after three days. Both 59 and 60 are air-sensitive and decompose in chlorinated solvents. Complex 62 is formed when the reaction mixture is brought into contact with air, and crystallised as purple prisms. 


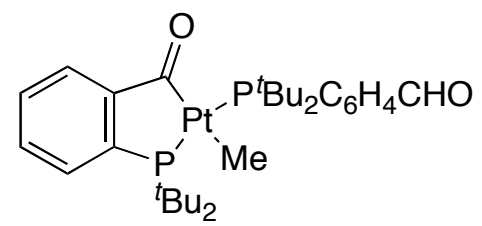

${ }^{1} \mathrm{H}$ NMR $\left(\mathrm{C}_{6} \mathrm{D}_{6}\right): \delta / p p m 12.35$ (d, JP-H $\left.=3.6 \mathrm{~Hz}, 1 \mathrm{H}, \mathrm{CHO}\right), 8.33(\mathrm{~m}, 1 \mathrm{H}, \mathrm{Ar}-\mathrm{H}), 7.91(\mathrm{~m}$, 1H, Ar-H), 7.89 (t, J $\left.J_{\mathrm{H}-\mathrm{H}}=7.3 \mathrm{~Hz}, 1 \mathrm{H}, \operatorname{Ar}-\mathrm{H}\right), 7.67$ (m, 2H, Ar-H), 7.15-7.02 (m, 3H, $\mathrm{Ar}-\mathrm{H}), 1.57\left(\mathrm{~d}, J_{\mathrm{P}-\mathrm{H}}=13.2 \mathrm{~Hz}, 9 \mathrm{H}, \mathrm{C}\left(\mathrm{CH}_{3}\right)_{3}\right), 1.48\left(\mathrm{br} \mathrm{d}, J_{\mathrm{P}-\mathrm{H}}=14.2 \mathrm{~Hz}, 9 \mathrm{H}, \mathrm{C}\left(\mathrm{CH}_{3}\right)_{3}\right)$, $1.35\left(\mathrm{~d}, J_{\mathrm{P}-\mathrm{H}}=14.2 \mathrm{~Hz}, 9 \mathrm{H}, \mathrm{C}\left(\mathrm{CH}_{3}\right)_{3}\right), 1.20\left(\mathrm{~d}, J_{\mathrm{P}-\mathrm{H}}=13.6 . \mathrm{Hz}, 9 \mathrm{H}, \mathrm{C}\left(\mathrm{CH}_{3}\right)_{3}\right), 0.75(\mathrm{br} \mathrm{m}$, 3H, Pt- $\left.\mathrm{CH}_{3}\right) .{ }^{31} \mathrm{P}\left\{{ }^{1} \mathrm{H}\right\} \mathrm{NMR}\left(\mathrm{C}_{6} \mathrm{D}_{6}\right): \delta / \mathrm{ppm} 78.7\left(\mathrm{~d}, J_{\mathrm{P}-\mathrm{P}}=369.1 \mathrm{~Hz}, J_{\mathrm{Pt}-\mathrm{P}}=3457.5 \mathrm{~Hz}\right)$, $43.0\left(\right.$ br d, $\left.J_{\mathrm{P}-\mathrm{P}}=369.1 \mathrm{~Hz}, J_{\mathrm{Pt}-\mathrm{P}}=2913.2 \mathrm{~Hz}\right)$.

$\left[\mathrm{Pt}\left(P, C-2-\mathrm{P}^{t} \mathrm{Bu}_{2} \mathrm{C}_{6} \mathrm{H}_{4} \mathrm{CO}\right)_{2}\right](60)$<smiles>CCCCp1c(=O)c2ccccc2c(=O)p1C(=O)c1ccccc1P</smiles>

${ }^{1} \mathrm{H} \mathrm{NMR}\left(\mathrm{CDCl}_{3}\right): \delta / p p m 7.96\left(\mathrm{~d}, J_{\mathrm{H}-\mathrm{H}}=7.4 \mathrm{~Hz}, 2 \mathrm{H}, \mathrm{H} 6\right), 7.86\left(\mathrm{t}, J_{\mathrm{H}-\mathrm{H}}=7.4 \mathrm{~Hz}, 2 \mathrm{H}, \mathrm{H} 5\right)$, $7.80\left(\mathrm{t}, J_{\mathrm{H}-\mathrm{H}}=7.1 \mathrm{~Hz}, 2 \mathrm{H}, \mathrm{H} 4\right), 7.55\left(\mathrm{~d}, J_{\mathrm{H}-\mathrm{H}}=7.2 \mathrm{~Hz}, 2 \mathrm{H}, \mathrm{H} 3\right), 1.42$ (t, $J_{\mathrm{P}-\mathrm{H}}=7.3 \mathrm{~Hz}, 18 \mathrm{H}$, $\left.\mathrm{C}\left(\mathrm{CH}_{3}\right)_{3}\right) .{ }^{31} \mathrm{P}\left\{{ }^{1} \mathrm{H}\right\}\left(\mathrm{CDCl}_{3}\right): \delta / \mathrm{ppm} 82.0\left(\mathrm{~s}, J_{\mathrm{Pt}-\mathrm{P}}=3307.0 \mathrm{~Hz}\right)$.

$\left[\mathrm{Pt}\left(P, O-2-\mathrm{P}^{t} \mathrm{Bu}_{2} \mathrm{C}_{6} \mathrm{H}_{4} \mathrm{COO}\right)\left(P, C-2-\mathrm{P}^{t} \mathrm{Bu}_{2} \mathrm{C}_{6} \mathrm{H}_{4} \mathrm{CO}\right)\right](62)$

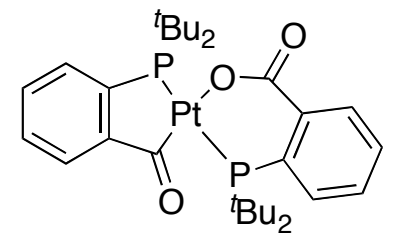

IR $\left(\mathrm{KBr}, \mathrm{cm}^{-1}\right) 1638.2(\mathrm{~s}) v(\mathrm{C}=\mathrm{O}), 1612.1(\mathrm{~s}) v(\mathrm{C}=\mathrm{O}) .{ }^{1} \mathrm{H}$ NMR $\left(\mathrm{CDCl}_{3}\right): \delta / \mathrm{ppm} 8.04(\mathrm{dd}$, $\left.J_{\mathrm{H}-\mathrm{H}}=7.6 \mathrm{~Hz}, J_{\mathrm{P}-\mathrm{H}}=3.4 \mathrm{~Hz}, 1 \mathrm{H}, \mathrm{CO}\right), 7.87(\mathrm{~m}, 1 \mathrm{H}, \mathrm{Ar}-\mathrm{H}), 7.80\left(\mathrm{t}, J_{\mathrm{H}-\mathrm{H}}=7.3 \mathrm{~Hz}, 1 \mathrm{H}\right.$, $\mathrm{Ar}-\mathrm{H}), 7.64\left(\mathrm{~d}, J_{\mathrm{H}-\mathrm{H}}=7.8 \mathrm{~Hz}, 1 \mathrm{H}, \mathrm{Ar}-\mathrm{H}\right), 7.53$ (t, $\left.J_{\mathrm{H}-\mathrm{H}}=7.3 \mathrm{~Hz}, 1 \mathrm{H}, \mathrm{Ar}-\mathrm{H}\right), 7.44(\mathrm{~m}, 2 \mathrm{H}$, Ar-H), 7.39 (m, 1H, Ar-H), 1.54 (d, J $\left.\mathrm{P}_{\mathrm{H}}=15.2 \mathrm{~Hz}, 18 \mathrm{H}, \mathrm{C}\left(\mathrm{CH}_{3}\right)_{3}\right), 1.49$ (d, $\left.J_{\mathrm{P}-\mathrm{H}}=14.6 \mathrm{~Hz}, \mathrm{C}\left(\mathrm{CH}_{3}\right)_{3}\right) .{ }^{13} \mathrm{C}\left\{{ }^{1} \mathrm{H}\right\} \mathrm{NMR}\left(\mathrm{CDCl}_{3}\right): \delta / \mathrm{ppm} 200.6$ (s, $J_{\mathrm{Pt}-\mathrm{C}}$ not observed, $\left.\mathrm{CO}\right)$, 
174.3 (s, COO), 164.0 (s, Ar-C), 162.2 (d, JP-C $=36.5 \mathrm{~Hz}, \mathrm{Ar}-\mathrm{C}), 145.4$ (d, $J_{\mathrm{P}-\mathrm{C}}=10.5 \mathrm{~Hz}$, Ar-C), 135.9 (d, JP-C $=3.9 \mathrm{~Hz}, A r-C), 131.8-128.4$ (m, Ar-C), 127.7 (d, $J_{\mathrm{P}-\mathrm{C}}=5.3 \mathrm{~Hz}$, Ar-C), $124.6\left(\mathrm{~d}, J_{\mathrm{P}-\mathrm{C}}=13.9 \mathrm{~Hz}, \mathrm{Ar}-\mathrm{C}\right), 122.2\left(\mathrm{t}, J_{\mathrm{P}-\mathrm{C}}=6.7 \mathrm{~Hz}, \mathrm{Ar}-\mathrm{C}\right), 37.5\left(\mathrm{dd}, J_{\mathrm{P}-\mathrm{C}}=19.7\right.$, $\left.2.4 \mathrm{~Hz}, \mathrm{C}\left(\mathrm{CH}_{3}\right)_{3}\right), 37.4\left(\mathrm{dd}, J_{\mathrm{P}-\mathrm{C}}=16.3,2.4 \mathrm{~Hz}, \mathrm{C}\left(\mathrm{CH}_{3}\right)_{3}\right), 31.6\left(\mathrm{~d}, J_{\mathrm{P}-\mathrm{C}}=5.3 \mathrm{~Hz}, \mathrm{C}\left(\mathrm{CH}_{3}\right)_{3}\right)$, $30.1\left(\mathrm{~d}, \quad J_{\mathrm{P}-\mathrm{C}}=2.8 \mathrm{~Hz}, \mathrm{C}\left(\mathrm{CH}_{3}\right)_{3}\right) .{ }^{31} \mathrm{P} \quad\left\{{ }^{1} \mathrm{H}\right\} \quad\left(\mathrm{CDCl}_{3}\right): \quad \delta / \mathrm{ppm} 78.8 \quad\left(\mathrm{~d}, J_{\mathrm{P}-\mathrm{P}}=324.5\right.$, $\left.J_{\mathrm{Pt}-\mathrm{P}}=3673.9 \mathrm{~Hz}\right), 42.2\left(\mathrm{~d}, J_{\mathrm{P}-\mathrm{P}}=324.5 \mathrm{~Hz}, J_{\mathrm{Pt}-\mathrm{P}}=3134 \mathrm{~Hz}\right)$. HR-ESIMS $(m / z)$ calculated for $[\mathrm{M}+\mathrm{H}]^{+}:$709.2471; observed, 709.2471.

\subsection{2 $\left[\mathrm{PtCl}\left(P, C-2-\mathrm{P}^{t} \mathrm{Bu}_{2} \mathrm{C}_{6} \mathrm{H}_{4} \mathrm{CO}\right)\left(2-\mathrm{P}^{t} \mathrm{Bu}_{2} \mathrm{C}_{6} \mathrm{H}_{4} \mathrm{CHO}\right)\right](61)$}

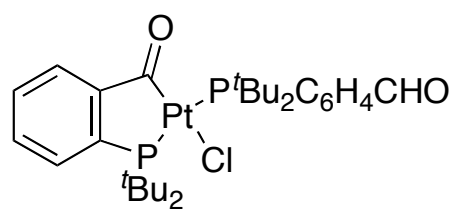

Chloromethylplatinum(1,5-hexadiene $) \quad(23 \mathrm{mg}, \quad 0.070 \mathrm{mmol})$ was dissolved in $\mathrm{C}_{6} \mathrm{D}_{6}$ $(0.4 \mathrm{~mL})$ and transferred to an NMR tube containing $4(36 \mathrm{mg}, 0.142 \mathrm{mmol})$. After two days, the reaction mixture was withdrawn from the NMR tube and passed through a short plug of alumina. The solvent was removed in vacuo yielding the product, 61, as a yellow solid. Yield: $18 \mathrm{mg}, 38 \%$.

${ }^{1} \mathrm{H}$ NMR $\left(\mathrm{C}_{6} \mathrm{D}_{6}\right): \delta / p p m 12.78\left(\mathrm{~d}, J_{\mathrm{P}-\mathrm{H}}=3.0 \mathrm{~Hz}, 1 \mathrm{H}, \mathrm{CHO}\right), 8.31(\mathrm{~m}, 1 \mathrm{H}, \mathrm{Ar}-\mathrm{H}), 7.88$ (t, $\left.J_{\mathrm{H}-\mathrm{H}}=7.6 \mathrm{~Hz}, \mathrm{Ar}-\mathrm{H}\right), 7.64\left(\mathrm{br} \mathrm{d}, J_{\mathrm{H}-\mathrm{H}}=7.6 \mathrm{~Hz}, 1 \mathrm{H}, \mathrm{Ar}-\mathrm{H}\right), 7.48$ (dd, $J_{\mathrm{H}-\mathrm{H}}=7.6 \mathrm{~Hz}$, $\left.J_{\mathrm{P}-\mathrm{H}}=5.0 \mathrm{~Hz}, 1 \mathrm{H}, \mathrm{Ar}-\mathrm{H}\right), 7.12\left(\mathrm{t}, J_{\mathrm{H}-\mathrm{H}}=7.4 \mathrm{~Hz}, 1 \mathrm{H}, \mathrm{Ar}-\mathrm{H}\right), 7.08\left(\mathrm{t}, J_{\mathrm{H}-\mathrm{H}}=7.4 \mathrm{~Hz}, 1 \mathrm{H}\right.$, $\mathrm{Ar}-\mathrm{H}), 6.94\left(\mathrm{t}, J_{\mathrm{H}-\mathrm{H}}=7.6 \mathrm{~Hz}, 1 \mathrm{H}, \mathrm{Ar}-\mathrm{H}\right), 6.84\left(\mathrm{t}, J_{\mathrm{H}-\mathrm{H}}=7.6 \mathrm{~Hz}, 1 \mathrm{H}, \mathrm{Ar}-\mathrm{H}\right), 1.74$ (d, $\left.J_{\mathrm{P}-\mathrm{H}}=13.7 \mathrm{~Hz}, 9 \mathrm{H}, \mathrm{C}\left(\mathrm{CH}_{3}\right)_{3}\right), 1.52\left(\mathrm{~d}, J_{\mathrm{P}-\mathrm{H}}=14.6 \mathrm{~Hz}, 9 \mathrm{H}, \mathrm{C}\left(\mathrm{CH}_{3}\right)_{3}\right), 1.52$ (br d, $\left.J_{\mathrm{P}-\mathrm{H}}=13.7 \mathrm{~Hz}, 9 \mathrm{H}, \mathrm{C}\left(\mathrm{CH}_{3}\right)_{3}\right), 1.39\left(\mathrm{~d}, J_{\mathrm{P}-\mathrm{H}}=14.3 \mathrm{~Hz}, 9 \mathrm{H}, \mathrm{C}\left(\mathrm{CH}_{3}\right)_{3}\right) .{ }^{13} \mathrm{C}\left\{{ }^{1} \mathrm{H}\right\} \mathrm{NMR}$ $\left(\mathrm{C}_{6} \mathrm{D}_{6}\right): \delta / \mathrm{ppm} 200.4\left(\mathrm{~s}, J_{\mathrm{Pt}-\mathrm{C}}=1121.5 \mathrm{~Hz}, \mathrm{CO}\right), 190.7$ (s, CHO), $160.0\left(\mathrm{~d}, J_{\mathrm{P}-\mathrm{C}}=36.9 \mathrm{~Hz}\right.$, $\mathrm{CCO}), 139.7$ (d, J $\left.J_{\mathrm{P}-\mathrm{C}}=6.8 \mathrm{~Hz}, \mathrm{CCHO}\right), 134.1$ (d, J $\left.\mathrm{P}_{\mathrm{C}}=2.0 \mathrm{~Hz}, \mathrm{Ar}-\mathrm{C}\right), 131.9$ (d, $\left.J_{\mathrm{P}-\mathrm{C}}=4.4 \mathrm{~Hz}, \mathrm{Ar}-\mathrm{C}\right), 131.5\left(\mathrm{~d}, J_{\mathrm{P}-\mathrm{C}}=1.9 \mathrm{~Hz}, \mathrm{Ar}-\mathrm{C}\right), 131.3\left(\mathrm{~d}, J_{\mathrm{P}-\mathrm{C}}=5.8 \mathrm{~Hz}, \mathrm{Ar}-\mathrm{C}\right), 130.8(\mathrm{~d}$, $\left.J_{\mathrm{P}-\mathrm{C}}=5.3 \mathrm{~Hz}, \mathrm{Ar}-\mathrm{C}\right), 129.0\left(\mathrm{~d}, J_{\mathrm{P}-\mathrm{C}}=1.9 \mathrm{~Hz}, \mathrm{Ar}-\mathrm{C}\right), 129.0\left(\mathrm{~d}, J_{\mathrm{P}-\mathrm{C}}=7.2 \mathrm{~Hz}, \mathrm{Ar}-\mathrm{C}\right), 125.7$ (d, $\left.J_{\mathrm{P}-\mathrm{C}}=13.9 \mathrm{~Hz}, \mathrm{Ar}-\mathrm{C}\right), 39.3\left(\mathrm{dd}, J_{\mathrm{P}-\mathrm{C}}=16.8,2.9 \mathrm{~Hz}, \mathrm{C}\left(\mathrm{CH}_{3}\right)_{3}\right), 38.1\left(\mathrm{~m}, \mathrm{C}\left(\mathrm{CH}_{3}\right)_{3}\right) 37.8(\mathrm{~d}$, $\left.J_{\mathrm{P}-\mathrm{C}}=2.9 \mathrm{~Hz}, \mathrm{C}\left(\mathrm{CH}_{3}\right)_{3}\right), 37.6\left(\mathrm{~d}, J_{\mathrm{P}-\mathrm{C}}=2.9 \mathrm{~Hz}, \mathrm{C}\left(\mathrm{CH}_{3}\right)_{3}\right), 33.5\left(\mathrm{br} \mathrm{s}, \mathrm{C}\left(\mathrm{CH}_{3}\right)_{3}\right), 31.2$ (br s, $\left.\mathrm{C}\left(\mathrm{CH}_{3}\right)_{3}\right), 30.6\left(\mathrm{dd}, J_{\mathrm{P}-\mathrm{C}}=3.8,1.4 \mathrm{~Hz}, \mathrm{C}\left(\mathrm{CH}_{3}\right)_{3}\right), 30.5\left(\mathrm{dd}, J_{\mathrm{P}-\mathrm{C}}=4.4,1.5 \mathrm{~Hz}, \mathrm{C}\left(\mathrm{CH}_{3}\right)_{3}\right)$. 
${ }^{31} \mathrm{P}\left\{{ }^{1} \mathrm{H}\right\}$ NMR $\left(\mathrm{C}_{6} \mathrm{D}_{6}\right): \delta / p p m 78.3\left(\mathrm{~d}, J_{\mathrm{P}-\mathrm{P}}=341.0 \mathrm{~Hz}, J_{\mathrm{Pt}-\mathrm{P}}=3617.1 \mathrm{~Hz}\right), 44.7(\mathrm{br} \mathrm{d}$, $\left.J_{\mathrm{P}-\mathrm{P}}=341.0 \mathrm{~Hz}, J_{\mathrm{Pt}-\mathrm{P}}=3472.5 \mathrm{~Hz}\right)$. 


\section{References}

(1) Ghilardi, C. A.; Midollini, S.; Moneti, S.; Orlandini, A. J. Chem. Soc., Dalton Trans. 1988, 1833.

(2) Garralda, M. A. C. R. Chim. 2005, 8, 1413.

(3) van Leeuwen, P. W. N. M. Homogeneous Catalysis: Understanding the Art; 1 ed.; Kluwer Academic Publishers: Dordrecht, 2004.

(4) Garralda, M. A. Dalton Trans. 2009, 3635.

(5) Landvatter, E. F.; Rauchfuss, T. B. Organometallics 1982, 1, 506.

(6) El Mail, R.; Garralda, M. A.; Hernández, R.; Ibarlucea, L.; Pinilla, E.; Torres, M. R. Organometallics 2000, 19, 5310.

(7) Garralda, M. A.; Hernandez, R.; Ibarlucea, L.; Pinilla, E.; Torres, M. R. Organometallics 2003, 22, 3600.

(8) Acha, F.; Garralda, M. A.; Ibarlucea, L.; Pinilla, E.; Torres, M. R. Inorg. Chem. 2005, 44, 9084.

(9) Garralda, M. A.; Hernández, R.; Ibarlucea, L.; Pinilla, E.; Torres, M. R.; Zarandona, M. Organometallics 2007, 26, 1031.

(10) Acha, F.; Ciganda, R.; Garralda, M. A.; Hernández, R.; Ibarlucea, L.; Pinilla, E.; Torres, M. R. Dalton Trans. 2008, 4602.

(11) Ciganda, R.; Garralda, M. A.; Ibarlucea, L.; Pinilla, E.; Torres, M. R. Dalton Trans. 2009, 4227.

(12) Ciganda, R.; Garralda, M. A.; Ibarlucea, L.; Pinilla, E.; Torres, M. R. Dalton Trans. 2010, 39, 7226.

(13) Barquín, M.; Garralda, M. A.; Ibarlucea, L.; Mendicute-Fierro, C.; Pinilla, E.; San Nacianceno, V.; Torres, M. R. Organometallics 2011, 30, 1577.

(14) Lorenzini, F.; Moiseev, D.; Patrick, B. O.; James, B. R. Inorg. Chem.

(15) Tolman, C. A. Chem. Rev. 1977, 77, 313.

(16) Fernandez, A. L.; Wilson, M. R.; Prock, A.; Giering, W. P. Organometallics 2001, 20, 3429.

(17) Wilson, M. R.; Prock, A.; Giering, W. P.; Fernandez, A. L.; Haar, C. M.; Nolan, S. P.; Foxman, B. M. Organometallics 2002, 21, 2758.

(18) Haar, C. M.; Nolan, S. P.; Marshall, W. J.; Moloy, K. G.; Prock, A.; Giering, W. P. Organometallics 1999, 18, 474.

(19) Tolman, C. A. J. Am. Chem. Soc. 1970, 92, 2953.

(20) Matsumoto, M.; Yoshioka, H.; Nakatsu, K.; Yoshida, T.; Otsuka, S. J. Am. Chem. Soc. 1974, 96, 3322.

(21) Musco, A.; Kuran, W.; Silvani, A.; Anker, M. W. J. Chem. Soc., Chem. Commun. 1973, 938.

(22) Ferguson, G.; Roberts, P. J.; Alyea, E. C.; Khan, M. Inorg. Chem. 1978, 17, 2965.

(23) Immirzi, A.; Musco, A. Inorg. Chim. Acta 1977, 25, L41.

(24) Orpen, A. G.; Connelly, N. G. Organometallics 1990, 9, 1206.

(25) Van Leeuwen, P. W. N. M.; Roobeek, C. F.; Orpen, A. G. Organometallics 1990, 9, 2179.

(26) Golovin, M. N.; Rahman, M. M.; Belmonte, J. E.; Giering, W. P. Organometallics 1985, 4, 1981.

(27) Bader, A.; Lindner, E. Coord. Chem. Rev. 1991, 108, 27. 
(28) Kuhl, O. Phosphorus-31 NMR Spectroscopy: A Concise Introduction for the Synthetic Organic and Organometallic Chemist, Springer-Verlag: Berlin Heidelberg, 2008.

(29) Bennett, M. A.; Bhargava, S. K.; Privér, S. H.; Willis, A. C. Eur. J. Inorg. Chem. 2008, 2008, 3467.

(30) Blau, R. J.; Espenson, J. H. Inorg. Chem. 1986, 25, 878.

(31) Mather, G. G.; Pidcock, A.; Rapsey, G. J. N. J. Chem. Soc., Dalton Trans. 1973, 2095.

(32) Bao, Q. B.; Geib, S. J.; Rheingold, A. L.; Brill, T. B. Inorg. Chem. 1987, 26, 3453.

(33) Waddell, P. G.; Slawin, A. M. Z.; Woollins, J. D. Dalton Trans. 2010, 39, 8620.

(34) Rauchfuss, T. B. J. Am. Chem. Soc. 1979, 101, 1045.

(35) Maria Casas, J.; Fornies, J.; Martin, A. J. Chem. Soc., Dalton Trans. 1997, 1559.

(36) Thorn, D. L. J. Am. Chem. Soc. 1980, 102, 7109.

(37) Koh, J. J.; Lee, W.-H.; Williard, P. G.; Risen, W. M. J. Organomet. Chem. 1985, 284, 409.

(38) Klein, H.-F.; Lemke, U.; Lemke, M.; Brand, A. Organometallics 1998, 17, 4196.

(39) Beck, R.; Flörke, U.; Klein, H.-F. Inorg. Chem. 2009, 48, 1416.

(40) Couillens, X.; Gressier, M.; Dartiguenave, M.; Fortin, S.; Beauchamp, A. L. J. Chem. Soc., Dalton Trans. 2002, 3032.

(41) Yeh, W.-Y.; Lin, C.-S.; Peng, S.-M.; Lee, G.-H. Organometallics 2004, 23, 917.

(42) Slone, C. S.; Weinberger, D. A.; Mirkin, C. A. Progress in Inorganic Chemistry, Vol 48 1999, 48, 233.

(43) Lenges, C. P.; Brookhart, M.; White, P. S. Angew. Chem. Int. Ed. 1999, 38, 552.

(44) J.E. Hoots; T.B. Rauchfuss; D.A. Wrobleski Inorg. Synth. 1982, 21, 175.

(45) Coote, S. J.; Dawson, G. J.; Frost, C. G.; Williams, J. M. J. Synlett 1993, 509.

(46) Ashby, E. C.; Gurumurthy, R.; Ridlehuber, R. W.J. Org. Chem. 1993, 58, 5832.

(47) Toth, I.; Hanson, B. E.; Davis, M. E. Organometallics 1990, 9, 675.

(48) Barber, J.; Victoria University of Wellington: Wellington, 2008.

(49) J. Atherton, M.; Fawcett, J.; H. Holloway, J.; G. Hope, E.; R. Russell, D.; C. Saunders, G. J. Chem. Soc., Dalton Trans. 1997, 2217.

(50) Clarke, M. L.; Ellis, D.; Mason, K. L.; Orpen, A. G.; Pringle, P. G.; Wingad, R. L.; Zaher, D. A.; Baker, R. T. Dalton Trans. 2005, 1294.

(51) Vaughan, T. F.; Victoria University of Wellington: Wellington, 2009.

(52) Haenel, M. W.; Oevers, S.; Angermund, K.; Kaska, W. C.; Fan, H.-J.; Hall, M. B. Angew. Chem. Int. Ed. 2001, 40, 3596.

(53) Schultz, T.; Pfaltz, A. Synthesis 2005, 1005.

(54) Savoia, D.; Trombini, C.; Umani-Ronchi, A. Pure Appl. Chem. 1985, 57, 1887.

(55) Lalancette, J.-M.; Rollin, G.; Dumas, P. Can.J. Chem. 1972, 50, 3058.

(56) Herrmann, W. A.; Salzer, A. In Synthetic Methods of Organometallic and Inorganic Chemistry; Herrmann, W. A., Salzer, A., Eds.; Georg Thieme Verlag Stuttgart: New York City, 1996; Vol. 1.

(57) Goryunov, L. I.; Grobe, J.; Le Van, D.; Shteingarts, V. D.; Mews, R.; Lork, E.; Würthwein, E.-U. Eur.J. Org. Chem. 2010, 2010, 1111.

(58) Bei, X.; Uno, T.; Norris, J.; Turner, H. W.; Weinberg, W. H.; Guram, A. S.; Petersen, J. L. Organometallics 1999, 18, 1840.

(59) Bei, X.; Turner, H. W.; Weinberg, W. H.; Guram, A. S.; Petersen, J. L. J. Org. Chem. 1999, 64, 6797.

(60) Goodfellow, R. J.; Hardy, M. J.; Taylor, B. F. J. Chem. Soc., Dalton Trans. 1973, 2450.

(61) Chatt, J.; Shaw, B. L. J. Chem. Soc. 1959, 705. 
(62) Greaves, E. O.; Bruce, R.; Maitlis, P. M. Chem. Commun. (London) 1967, 860.

(63) Garrou, P. E. Chem. Rev. 1981, 81, 229.

(64) Garrou, P. E. Inorg. Chem. 1975, 14, 1435.

(65) Parella, T.; Sánchez-Ferrando, F.; Virgili, A. Magn. Reson. Chem. 1995, 33, 196.

(66) Mata, J. A.; Peris, E.; Incarvito, C.; Crabtree, R. H. Chem. Commun. 2003, 184.

(67) El Mail, R. Eur. J. Inorg. Chem. 2005, 1671.

(68) Stemmler, R. T.; Bolm, C. Adv. Synth. Catal. 2007, 349, 1185.

(69) Lukehart, C. M. Acc. Chem. Res. 1981, 14, 109.

(70) Lukehart, C. M.; Torrence, G. P.; Zeile, J. V.J. Am. Chem. Soc. 1975, 97, 6903.

(71) Gramstad, T.; Haszeldine, R. N. J. Chem. Soc. 1957, 4069.

(72) Steinborn, D.; Schwieger, S. Chem. Eur. J. 2007, 13, 9668.

(73) Burdett, J. L.; Rogers, M. T. J. Am. Chem. Soc. 1964, 86, 2105.

(74) Casey, C. P. J. Am. Chem. Soc. 1997, 119, 3971.

(75) Chisholm, M. H.; Clark, H. C.; Ward, J. E. H.; Yasufuku, K. Inorg. Chem. 1975, 14, 893.

(76) Dolomanov, O. V.; Bourhis, L. J.; Gildea, R. J.; Howard, J. A. K.; Puschmann, H. J. Appl. Crystallogr. 2009, 42, 339.

(77) Bourhis, L. J.; Dolomanov, O. V.; Gildea, R. J.; Howard, J. A. K.; Puschmann, H.; Durham University: 2011.

(78) Dolomanov, O. V.; Bourhis, L. J.; Gildea, R. J.; Howard, J. A. K.; Puschmann, H. 2011.

(79) Lukehart, C. M.; Torrence, G. P.; Zeile, J. V. Inorg. Chem. 1976, 15, 2393.

(80) Lukehart, C. M.; Torrence, G. P. Inorg. Chem. 1979, $18,3150$.

(81) Lenhert, P. G.; Lukehart, C. M.; Srinivasan, K. J. Am. Chem. Soc. 1984, 106, 124.

(82) Steinborn, D.; Gerisch, M.; Merzweiler, K.; Schenzel, K.; Pelz, K.; Boegel, H.; Magull, J. Organometallics 1996, 15, 2454.

(83) Albrecht, C.; Wagner, C.; Steinborn, D. Z. Anorg. Allg. Chem. 2008, 634, 2858.

(84) Fulmer, G. R.; Miller, A. J. M.; Sherden, N. H.; Gottlieb, H. E.; Nudelman, A.; Stoltz, B. M.; Bercaw, J. E.; Goldberg, K. I. Organometallics 2010, 29, 2176.

(85) Lukehart, C. M.; Zeile, J. V. Inorg. Chem. 1978, 17, 2369.

(86) Jones, M. Organic Chemistry; W W Norton \& Co Inc, 1998.

(87) Zumdahl, S. S.; Drago, R. S. J. Am. Chem. Soc. 1968, 90, 6669.

(88) Siedle, A. R.; Newmark, R. A.; Gleason, W. B. J. Am. Chem. Soc. 1986, $108,767$.

(89) Siedle, A. R.; Newmark, R. A.; Howells, R. D. Inorg. Chem. 1988, 27, 2473.

(90) O'Neil, M. J. The Merck index : an encyclopedia of chemicals, drugs, and biologicals; Merck: Whitehouse Station, N.J., 2001.

(91) Darst, K. P.; Lukehart, C. M. J. Organomet. Chem. 1978, 161, 1.

(92) Lukehart, C. M.; Warfield, L. T. Inorg. Chem. 1978, 17, 201.

(93) Monkowius, U.; Zabel, M. Acta Crystallogr., Sect. E: Struct. Rep. Online 2007, E64, 196.

(94) Matano, Y.; Northcutt, T. O.; Brugman, J.; Bennett, B. K.; Lovell, S.; Mayer, J. M. Organometallics 2000, 19, 2781.

(95) Cobley, C. J.; Pringle, P. G. Inorg. Chim. Acta 1997, 265, 107.

(96) Vaughn, G. D.; Strouse, C. E.; Gladysz, J. A. J. Am. Chem. Soc. 1986, 108, 1462.

(97) Vaughn, G. D.; Gladysz, J. A. J. Am. Chem. Soc. 1986, 108, 1473.

(98) Cross, R. J.; Phillips, I. G. J. Chem. Soc., Dalton Trans. 1982, 2261.

(99) Kemmitt, R. D. W.; Nichols, D. I.; Peacock, R. D. Chem. Commun. (London) 1967, 599b. 
(100) Kemmitt, R. D. W.; Nichols, D. I.; Peacock, R. D. J. Chem. Soc. A. 1968, 2149.

(101) Docherty, J. B.; Rycroft, D. S.; Sharp, D. W. A.; Webb, G. A. J. Chem. Soc., Chem. Commun. 1979, 336.

(102) Bernès, S.; Villanueva, L.; Torrens, H. J. Chem. Crystallogr. 2008, 38, 123.

(103) Bennett, M. A.; Bhargava, S. K.; Ke, M.; Willis, A. C. J. Chem. Soc., Dalton Trans. 2000, 3537.

(104) Mohr, F.; Privér, S. H.; Bhargava, S. K.; Bennett, M. A. Coord. Chem. Rev. 2006, 250, 1851.

(105) Bennett, M. A.; Bhargava, S. K.; Messelhauser, J.; Priver, S. H.; Welling, L. L.; Willis, A. C. Dalton Trans. 2007, 3158.

(106) Bennett, M. A.; Bhargava, S. K.; Keniry, M. A.; Privér, S. H.; Simmonds, P. M.; Wagler, J.; Willis, A. C. Organometallics 2008, 27, 5361.

(107) Schaefer, W. P.; Lyon, D. K.; Labinger, J. A.; Bercaw, J. E. Acta Crystallogr., Sect. C: Cryst. Struct. Commun. 1992, C48, 1582.

(108) Bruno, I. J.; Cole, J. C.; Kessler, M.; Luo, J.; Motherwell, W. D. S.; Purkis, L. H.; Smith, B. R.; Taylor, R.; Cooper, R. I.; Harris, S. E.; Orpen, A. G. J. Chem. Inf. Comput. Sci. 2004, 44, 2133. <last accessed 10 ${ }^{\text {th }}$ September 2011>

(109) Hitchcock, P. B.; Jacobson, B.; Pidcock, A. J. Chem. Soc., Dalton Trans. 1977, 2038.

(110) Appleton, T. G.; Clark, H. C.; Manzer, L. E. Coord. Chem. Rev. 1973, 10, 335.

(111) Porzio, W.; Musco, A.; Immirzi, A. Inorg. Chem. 1980, 19, 2537.

(112) Sheldrick, G. Acta Crystallogr., Sect. A: Found. Crystallogr. 2008, 64, 112.

(113) Vaughan, T. F, Koedyk, D. J., Spencer, J. L. Organometallics 2011, 30, 5170.

(114) Crascall, L. E.; Spencer, J. L. Inorg. Synth. 1990, 28, 126

(115) Koshar, R. J.; Mitsch, R. A. J. Org. Chem. 1973, 38, 335

(116) R. Usón, L. A. Oro and J. A. Cabeza, Inorg. Synth. 1985, 23, 126. 